\title{
Efeitos de áudio baseados em decomposição AM/FM
}

\author{
Antonio José Homsi Goulart
}

TESE APRESENTADA

$\mathrm{AO}$

Instituto de Matemática e Estatística

DA

Universidade DE SÃo PaUlo

PARA

OBTENÇÃO DO TÍTULO

$\mathrm{DE}$

DOUTOR EM CIÊNCIAS

Programa: Doutorado em Ciência da Computação

Orientador: Prof. Dr. Marcelo Gomes de Queiroz

Durante o desenvolvimento deste trabalho o autor recebeu auxílio financeiro da CAPES 


\section{Efeitos de áudio baseados em decomposição AM/FM}

Esta versão da tese contém as correções e alterações sugeridas pela Comissão Julgadora durante a defesa da versão original do trabalho, realizada em 16/12/2016. Uma cópia da versão original está disponível no

Instituto de Matemática e Estatística da Universidade de São Paulo.

Comissão Julgadora:

- Prof. Dr. Marcelo Gomes de Queiroz (orientador) - IME-USP

- Prof. Dr. Victor Emmanuel Pullin Lazzarini - Maynooth University

- Prof. Dr. Rodrigo Capobianco Guido - IBILCE-UNESP

- Prof. Dr. Regis Rossi Alves Faria - FFCLRP-USP

- Prof. Dr. Roberto Hirata Júnior - IME-USP 
Aos que me ensinam/inspiram 
All sincere aspiration has its effect. ${ }^{1}$

The intensity of the aspiration brings the intensity of the experience and by repeated intensity of the experience, the change. ${ }^{2}$

Sri Aurobindo

\footnotetext{
${ }^{1}$ Tradução do autor: Toda aspiração sincera tem seu efeito.

${ }^{2}$ Tradução do autor: A intensidade da aspiração resulta na intensidade da experiência e repetidas intensidades de experiência resultam em mudança.
} 


\section{Agradecimentos}

O interesse e as explorações na área de Computação Musical começaram ainda cedo, configurando parâmetros de efeitos em pedaleiras de guitarra na primeira banda em que participei. Agradeço aos membros desta banda, Matheus Fortes Bonelli, Rodrigo Narcizo Gaudio e Lucas Carareto Macieirinha, não apenas por fazerem parte daquela etapa maravilhosa da vida.

Ainda terminando o mestrado conheci meu querido amigo Flávio Luiz Schiavoni, na disciplina de Computação Musical do IME. Sou imensamente agradecido por vários motivos: pela fundamental parceria no trabalho final da disciplina; pela paciência em me ensinar a prática, programando os primeiros efeitos; e pelo carinho paterno nas várias conversas.

Se é uma pena que tanto tenha demorado para o Linux chegar à minha vida, o jeito como aconteceu não poderia ter sido melhor. Ninguém como André Jucovski Bianchi para te inspirar, e Beraldo Leal para te ensinar. Agradeço por tantas coisas e por esta importante mudança de sistema e conceitos na minha vida.

Fundamentais para uma melhor compreensão desta etapa, e do todo, foram os aprendizados de yoga. Agradeço ao querido amigo Deva Bandhu pelo incessante carinho e vontade de compartilhar. Sem estes ensinamentos teria sido tão mais difícil e com um propósito tão menor.

A oportunidade de ser orientado por Marcelo Gomes de Queiroz foi um tesouro. Agradeço pelo estímulo para começar a jornada, por me deixar caminhar por conta própria, e por todas as sugestões. Agradeço também aos meus supervisores no estágio internacional, Victor Lazzarini e Joseph Timoney, por me receberem tão carinhosamente e ajudarem tão decisivamente nas explorações.

Uma das grandes alegrias desta etapa foi o ambiente no qual trabalhei. Agradeço a todos os amigos do Grupo de Pesquisa em Computação Musical do IME, que dividiram comigo espaço, tempo, críticas, código e música. Agradeço também aos colegas das disciplinas realizadas no primeiro ano, parceiros de inúmeras maratonas de estudos e trabalhos em grupo. Sozinho teria sido infinitamente mais complicado. Obrigado pela lição de humildade.

Outra maravilha destes anos foi a chance de estudar música e conviver na ECA em ótima companhia. Agradeço aos amigos do Núcleo de Pesquisa em Sonologia por toda a paciência em me mostrar e discutir conceitos desde os simples até os mais complexos, desde os mais até os menos

musicais. Agradeço pela oportunidade de ter participado em diversos projetos e cursado diversas disciplinas.

Se existe algo que pode motivar imensamente a realização de uma pesquisa é a possibilidade de aplicar os resultados. Sou imensamente grato aos amigos da Orquestra Errante, da qual orgulhosamente fiz parte ao longo do doutorado. Obrigado pela oportunidade de me juntar ao grupo, explorar a guitarra e o computador não-convencionalmente (e em alguns momentos não-musicalmente), explorar sonoridades, por compartilhar opiniões, pelas calorosas discussões, e por improvisar em qualquer, ou sem, circunstância. 
Também agradeço aqueles com os quais não converso muito sobre computação musical, muito embora conversemos bastante sobre música. Tenho a sorte de ter amigos e amigas especiais, aos quais agradeço imensamente por tantas coisas, principalmente por cuidarem de mim às suas maneiras.

Agradeço finalmente à minha família, por todo o apoio, amor e zelo, especialmente de meu irmão, João Maurício, minha mãe, Cíntia, e minha avó, Hebi. A inspiração necessária para a conclusão da jornada e combustível para a próxima etapa veio com Lais, que me faz pensar no que fazer com as descobertas. 


\section{Resumo}

\section{GOULART, A. J. H. Efeitos de áudio baseados em decomposição AM/FM}

Tese (Doutorado) - Instituto de Matemática e Estatística, Universidade de São Paulo, 2017

Esta pesquisa aborda o projeto de efeitos de áudio baseados em decomposições que levam um sinal proveniente de um instrumento musical para a representação AM/FM. A decomposição AM/FM produz um par de sinais também no domínio do tempo, que representam o envelope (porção AM) e a frequência instantânea (porção FM) do sinal analisado. Estes dois sinais atuam em conjunto e podem recriar o sinal original caso utilizados para modular um oscilador senoidal em amplitude e em frequência. Por outro lado, a manipulação individual das porções AM e FM oferece novas possibilidades para processamento de sinais e implementação de efeitos musicais. Neste trabalho discutimos aspectos sobre diferentes técnicas para a decomposição, baseadas na Transformada de Hilbert em conjunto com o Sinal Analítico ou no Operador de Energia de Teager-Kaiser em conjunto com o Algoritmo de Separação de Energia. Apresentamos novos efeitos de áudio baseados em filtragem simples (passa-baixa, passa-banda, passa-alta), processamento dinâmico (distorção, compressor, expander) e manipulações das porções AM e FM inspiradas em efeitos clássicos (tremolo, flanger, octaver, chorus), entre outros efeitos. Implementações para operação em tempo-real são apresentadas e discutidas. Também foi realizada uma avaliação experimental da aplicação dos

efeitos propostos, baseada na análise do comportamento de descritores de áudio relacionados com amplitude (variação dinâmica) e frequência (variação espectral) de sinais.

Palavras-chave: efeitos de áudio, modulação de sinais, decomposição AM/FM 


\section{Abstract}

\section{GOULART, A. J. H. Audio effects based on AM/FM decomposition}

PhD Thesis - Institute of Mathematics and Statistics, University of São Paulo, 2017

This research explores the design of audio effects based on decompositions that take a music instrument signal and unravel it to the AM/FM representation. The AM/FM decomposition produces a pair of signals, also in the time domain, that represent the analyzed signal's envelope (AM portion) and instantaneous frequency (FM portion). This pair of signals act jointly, and when used to modulate an oscillator's amplitude and frequency are able to reconstruct the original signal. However, by manipulating the AM and FM portions new possibilities arise for signal processing and implementation of musical effects. In this work we discuss aspects of different techniques for the decomposition, either based on the Hilbert Transform, which results in an Analytic Signal, or on the Teager-Kaiser Energy Operator which is applied in the Energy Separation Algorithm. We present novel audio effects based on regular filtering (low-pass, band-pass, high-pass), dynamics processing (distortion, compressor, expander) and classic effects (tremolo, flanger, octaver, chorus) inspired manipulations of the AM and FM portions. Implementations for real-time operation are presented and discussed. An experimental evaluation of the proposed effects was also realized, which compares audio descriptors related to amplitude (dynamics variation) and frequency (spectral variation) from the original and processed signals.

Keywords: audio effects, signal modulation, AM/FM analysis 


\section{Sumário}

Lista de Códigos $\quad$ Xv

Lista de Figuras $\quad$ xvii

1 Introdução $\quad 1$

1.1 Instrumentos musicais e efeitos de áudio . . . . . . . . . . . . . . . 1

1.2 O paradigma Decomposição/Processamento/Ressíntese . . . . . . . . . . . . 6

1.3 Modulações e o domínio AM/FM . . . . . . . . . . . . . . 7

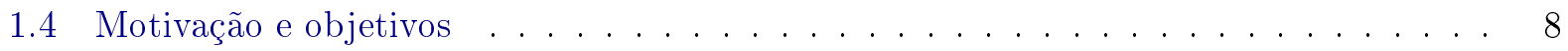

1.5 Organização do trabalho . . . . . . . . . . . . . . . . . . 11

2 Conceitos $\quad 13$

2.1 Técnicas de modulação para síntese e efeitos de áudio $\ldots \ldots \ldots \ldots$

2.1.1 AM - Modulação em amplitude . . . . . . . . . . . . . . . . . . 14

2.1 .2 Variações da AM . . . . . . . . . . . . . . . . . . 16

2.1.3 FM - Modulação em frequência . . . . . . . . . . . . . . . 20

2.1 .4 Variações da FM . . . . . . . . . . . . . . . 25

2.2 Representação AM/FM de sinais . . . . . . . . . . . . . . . . 35

2.2.1 Envelope, frequência instantânea, fase . . . . . . . . . . . . 35

2.2 .2 Decomposição AM/FM via Sinal Analítico . . . . . . . . . . . . . 38

2.2 .3 Decomposição AM/FM via Separação de Energia . . . . . . . . . . . . . 46

2.2.4 Decomposição multicomponente . . . . . . . . . . . . . . . 56

2.3 Processamento de áudio no domínio $\mathrm{AM} / \mathrm{FM} \ldots \ldots \ldots$. . . . . . . . . 64

2.3 .1 Modulation Vocoder . . . . . . . . . . . . . . . 64

2.3 .2 Modulation Filtering . . . . . . . . . . . . . . . . . 66

2.3 .3 Análise e classificação de sinais . . . . . . . . . . . . . . 67 
3 AM/FM DAFx: Efeitos de áudio no domínio AM/FM

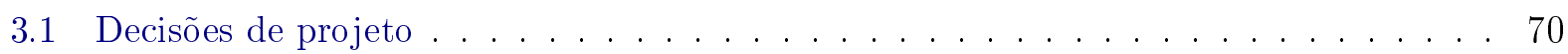

3.1 .1 Método de decomposição . . . . . . . . . . . . . . . . . 70

3.1 .2 Separação prévia em bandas . . . . . . . . . . . . . . . . . . 73

3.2 Efeitos baseados em filtragem . . . . . . . . . . . . . . . . . 76

3.2.1 Passa-baixa da AM/FM: env-lowpf, lowp-if . . . . . . . . . . . . 77

3.2.2 Passa-alta da AM/FM: hip-env, hip-if . . . . . . . . . . . 78

3.2.3 Passa-banda da AM: env-wah-lope . . . . . . . . . . . . . . . 78

3.3 Efeitos baseados em mapeamento não-linear . . . . . . . . . . . . . . . . . . 79

3.3.1 Distorção da AM/FM: env-ortion, if-ortion . . . . . . . . . . . . 79

3.3.2 Compressão da AM/FM: compr-env, compr-if . . . . . . . . . . . . 80

3.3.3 Expansão da AM/FM: exp-env, exp-if, gat-if . . . . . . . . . . . . 83

3.4 Miscelânea de efeitos . . . . . . . . . . . . . . . . . . . . . 85

3.4.1 Modulação da FM: gliss-if, wheel-if, d-if-tune, v-if-brato . . . . . . . . 85

3.4.2 FM fixada em nota específica: fix-if . . . . . . . . . . . . . 86

3.4.3 Hibridização de instrumentos: hybr-if . . . . . . . . . . . . . . 87

3.5 Implementações alternativas de efeitos clássicos $\ldots \ldots \ldots \ldots$

3.5.1 Chorus alternativo: chor-if .................... 88

3.5.2 Octaver alternativo: oct-if . . . . . . . . . . . . . . 89

3.5.3 Reverb alternativo: sq-env . . . . . . . . . . . . . . . 90

3.6 Efeitos multi-bandas . . . . . . . . . . . . . . . . . . 91

3.6 .1 Aplicação dos efeitos . . . . . . . . . . . . . . . . . . 91

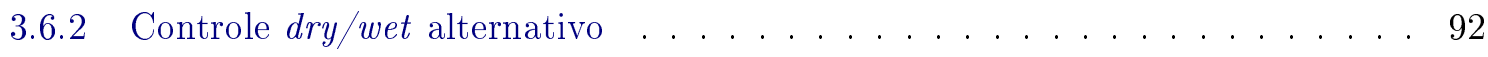

3.6.3 Alargamento stereo alternativo . . . . . . . . . . . . . . . . 93

4 Avaliação experimental dos efeitos AM/FM $\quad 95$

4.1 Metodologia experimental . . . . . . . . . . . . . . . . . . 95

4.2 Avaliação baseada em descritores perceptuais . . . . . . . . . . . . . 96

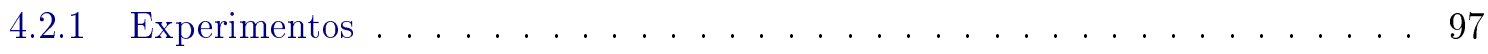

4.2 .2 Resultados e discussão . . . . . . . . . . . . . . . . . . . . 98

4.3 Avaliação de desempenho computacional . . . . . . . . . . . . . . . . 110

4.3 .1 Experimentos . . . . . . . . . . . . . . . . . 111

4.3 .2 Resultados e discussão . . . . . . . . . . . . . . . . . . . . . 112 
5 Conclusão

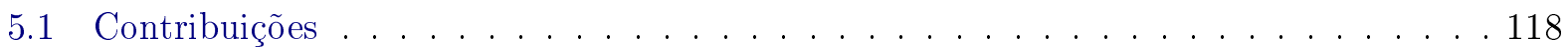

5.2 Trabalhos futuros . . . . . . . . . . . . . . . . . . . . . 119

A Csound, linguagem para programação de processamento de áudio

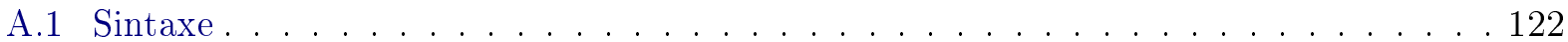

A.2 Definição de opcodes pelo usuário . . . . . . . . . . . . . . . . . . . . . 125

A.3 Resumo dos opcodes utilizados no trabalho . . . . . . . . . . . . . . . 125

A.4 Csound, Linux, controladores, interface de áudio, tempo-real

(ou, Configurando seu computador como pedaleira de efeitos) . . . . . . . . . 128 


\section{Lista de Códigos}

2.1 Modulação em amplitude com sinais senoidais. . . . . . . . . . . . . . . . 15

2.2 Modulação de amplitude com retroalimentação. . . . . . . . . . . . . . . . . . 19

2.3 Modulação em frequência. . . . . . . . . . . . . . . . . . . 20

2.4 FM com índice de modulação variando. . . . . . . . . . . . . . . 23

2.5 Implementação da FM assimétrica. . . . . . . . . . . . . . . . . . . 26

2.6 Uma das possibilidades com a síntese SpSB . . . . . . . . . . . . . . . 28

2.7 Modulação de frequência com retroalimentação. . . . . . . . . . . . . . . . . 30

2.8 Implementação da FM modificada (ModFM) . . . . . . . . . . . . . . . . . . 34

2.9 UDOs para decomposição AM/FM utilizando Transformada de Hilbert. . . . . . . . 42

2.10 UDO para decomposição AM/FM baseada em Operador de Energia de Teager-Kaiser e Algoritmo de Separação de Energia. . . . . . . . . . . . . . . . . . 53

2.11 Efeito de áudio baseado na deteç̧ão de fundamental e transformação do sinal de instrumento acústico para senoide mantendo o pitch original. . . . . . . . . . . . 62

2.12 Separação do sinal em bandas centradas na fundamental e dois primeiros múltiplos

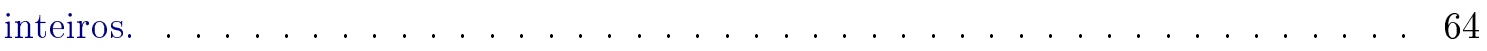

3.1 Esqueleto para implementação dos efeitos AM/FM. . . . . . . . . . . . . . . . 74

3.2 lowpif: filtragem passa baixa da frequência instantânea. . . . . . . . . . . . . 77

3.3 env-lowpf: filtragem passa-baixa do envelope. . . . . . . . . . . . . 77

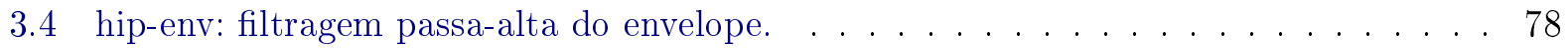

3.5 hip-if: filtragem passa-alta da frequência instantânea. . . . . . . . . . . . . 78

3.6 env-wah-lope: filtragem passa-banda variante do envelope. . . . . . . . . . . . . . 79

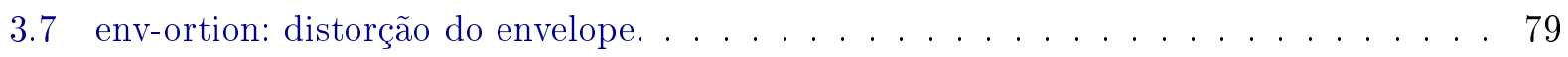

3.8 if-ortion: ceifamento da frequência instantânea. . . . . . . . . . . . . . . 80

3.9 compr-env: compressão (descendente neste exemplo) do envelope. . . . . . . . . . . 81

3.10 compr-if: compressão (descendente neste exemplo) da frequência instantânea. . . . . 83

3.11 exp-if: expansão (ascendente neste exemplo) da frequência instantânea. . . . . . . . . 84

3.12 gat-if: gate (expansão descendente extrema) da frequência instantânea. . . . . . . . . 84

3.13 gliss-if: modulação em anel "lenta" da frequência instantânea. . . . . . . . . . . . . 85

3.14 wheel-if: modulação em anel da frequência instantânea. . . . . . . . . . . . . . . . 85

3.15 d-if-tune: modulação em amplitude "lenta" da frequência instantânea. . . . . . . . . . 86

3.16 v-if-brato: modulação em amplitude da frequência instantânea. . . . . . . . . . . 86

3.17 fix-if: fixação da frequência instantânea em nota específica. . . . . . . . . . . . . . . 86

3.18 Hibridização de instrumentos com o efeito hybr-if. . . . . . . . . . . . . . . 87

3.19 chor-if: releitura do efeito chorus. . . . . . . . . . . . . . . . . . . 88

3.20 oct-if up: dobro da frequência instantânea. . . . . . . . . . . . . . . . 89 
3.21 oct-if down: metade da frequência instantânea. . . . . . . . . . . . . . . . . . 89

3.22 sq-env: raiz quadrada do envelope. . . . . . . . . . . . . . . . . . . . 90

3.23 Obtenção de acordes com o efeito pedal-if. . . . . . . . . . . . . . . . . . . . . . 92

3.24 Geração de acordes baseado no efeito multi-oct-if. . . . . . . . . . . . . . . . . 93 


\section{Lista de Figuras}

1.1 Protótipo do Moog de 1964. Fonte: Wikimedia Commons. . . . . . . . . . . . . . . 2

1.2 Teclado digital DX7, da Yamaha. Fonte: Wikimedia Commons. . . . . . . . . . . . . 2

1.3 Controlador MIDI conectado ao PC. . . . . . . . . . . . . . . . . . . . . . . . 2

1.4 Exemplos de efeitos acústicos. Fonte: Wikimedia Commons / Flickr / Flickr. . . . . . 4

1.5 Ligação em série de vários pedais de efeitos. Porção superior, da esquerda pra direita: equalizador paramétrico, distorção fuzz, wah-wah, compressor e afinador (digital). Porção inferior, da esquerda pra direita: tremolo, distorção standard, distorção overdrive e oitavador. Fonte: Wikimedia Commons. . . . . . . . . . . . . . . . . . . . 4

1.6 Exemplos de pedaleiras digitais multiefeitos. Fonte: http://boss.info / http://zoom.

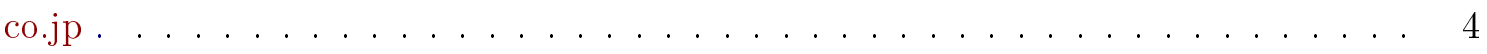

1.7 Equipamento utilizado pelo autor: guitarra, baixo, amplificador, e RaspberryPi (em conjunto com interface de áudio e controlador MIDI) programado como pedaleira de efeitos de áudio personalizados. . . . . . . . . . . . . . . . . . .

2.1 Circuito analógico para implementação de modulação em anel. Note o anel de diodos. A e K referem-se a ânodo e cátodo. Fonte: Wikimedia Commons (figura adaptada pelo autor). . . . . . . . . . . . . . . . . . . . . . . . 14

2.2 Descrição do instrumento FBAM utilizado por Risset. Fonte: [Ris69] (adaptada). . . 16

2.3 Evolução do espectro da FBAM em função do fator de retroalimentação $\beta$. Fonte: [KLVT11] (adaptada). . . . . . . . . . . . . . . . . . . . . . . . . . 17

2.4 Limites de $\beta$ para garantir estabilidade (curva tracejada) e para evitar aliasing (curva sólida referente à $f_{S}=44100 H z$ e curva pontilhada referente à $\left.f_{S}=88200 H z\right)$. Fonte: [KLVT11] (adaptada). . . . . . . . . . . . . . . . . . . . . . 18

2.5 Funções de Bessel do primeiro tipo. Fonte: [Cho73] (adaptada). . . . . . . . . . . . . 22

2.6 Esquema da modulação em frequência por retroalimentação. Fonte: [Tom81] (adaptada). . . . . . . . . . . . . . . . . . . . . . . . . . . 29

2.7 Região das funções de Bessel onde se concentra a FBFM. Fonte: [Tom81] (adaptada). 30

2.8 Modulação em frequência com retroalimentação cruzada. Fonte: [Tom81] (adaptada). 32

2.9 Valores das funções de Bessel modificadas normalizada. Fonte: [LT10b] (adaptada). . 33

2.10 Exemplos de envelope de sinais. Fonte: Wikimedia Commons. . . . . . . . . . . . . . 35

2.11 Representação de um fasor. A projeção no eixo real gera um sinal senoidal. Fonte: Wikimedia Commons. . . . . . . . . . . . . . . . . . . . . . 39

2.12 Interpretação do sinal analítico como sobreposição de fasores com frequências positivas. 40 
2.13 Paradoxo do envelope retangular: levando em consideração um sinal senoidal como entrada, a amplitude instantânea estimada (curva tracejada) a partir da Transformada de Hilbert apresenta valores não-nulos mesmo antes do início da senoide (curva

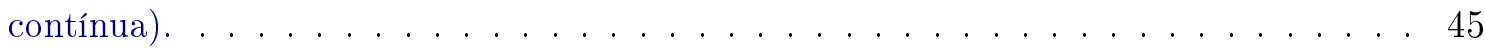

2.14 Cenários para aproximação da derivada de um sinal. . . . . . . . . . . . . . 50

2.15 Valor constante do TEO discreto aplicado a uma entrada senoidal. . . . . . . . . . . 51

2.16 Estimativa via DESA de envelope (alto) e frequência instantânea (baixo) de senoide com frequência $2 \mathrm{~Hz}$ e amplitude de pico unitária. Exemplo criado com amostragem em $20 \mathrm{~Hz}\left(\frac{2 \pi}{20} \approx 0.32 \frac{\mathrm{rad}}{\mathrm{s}}\right) . \ldots \ldots \ldots \ldots \ldots \ldots$

2.17 Envelope (à esquerda) e frequência instantânea (à direita) de oscilador modulado em amplitude e frequência. Neste exemplo a AM foi gerada com um oscilador senoidal e a FM com uma rampa linear. . . . . . . . . . . . . . . . . . . 56 56

2.18 Diagrama de blocos do PLL. Na parte superior da figura temos os 3 elementos principais: detector de fase, filtro, e oscilador local. Na parte inferior da figura temos um esquema para obtenção de um indicativo de sincronia. Fonte: [Gar05] (adaptada). . . 58

2.19 PLL adaptado para estimava de frequência fundamental. Fonte: [ZSM12] (adaptada). 59

2.20 Esquema de análise do modulation vocoder. Fonte: adaptado de [DE08] (adaptada). . 65

3.1 Sinal de guitarra utilizado nos experimentos; forma de onda à esquerda e espectrograma à direita. . . . . . . . . . . . . . . . . . . . . . . 70

3.2 Sinais estimados para envelope (esquerda) e frequência instantânea (direita) de sinal de guitarra, utilizando decomposição baseada em Transformada de Hilbert em conjunto com o sinal analítico.

3.3 Sinais estimados para envelope (esquerda) e frequência instantânea (direita) de sinal de guitarra, utilizando decomposição baseada em operador de energia e algoritmo de separação de energia. . . . . . . . . . . . . . . . . . . . . 71

3.4 Comparação das estimativas de FI utilizando TH (esquerda) e DESA (direita). . . 71

3.5 Espectrograma do sinais estimados para envelope (esquerda) e frequência instantânea (direita) utilizando Transformada de Hilbert.

3.6 Espectrograma do sinais estimados para envelope (esquerda) e frequência instantânea (direita) utilizando TH. Ampliação da faixa de 0 até $2500 \mathrm{~Hz}$. Notar a presença de harmônicos regularmente espaçados. . . . . . . . . . . . . . . 73

3.7 Espectro do sinal de guitarra. Versões ampliadas em regiões específicas. . . . . . . . 74

3.8 Deteç̧ão de frequência fundamental utilizando o Audio PLL. . . . . . . . . . . . . . 75

3.9 Exemplos de projetos de filtros passa-baixa. O filtro de Butterworth não apresenta ripples na banda de passagem e banda de rejeição, mas sua banda de transição é maior que a dos filtros de Chebyshev. . . . . . . . . . . . . . . . . . 76

3.10 Tangente hiperbólica. . . . . . . . . . . . . . . . . . . . 80

3.11 Tipos de compressão de dinâmica. Fonte: Wikimedia Commons (adaptada). . . . . . 81

3.12 Comportamento do compressor de acordo com diferentes taxas de compressão. Fonte: Wikimedia Commons (adaptada) . . . . . . . . . . . . . . 81

3.13 Influência dos parâmetros de attack e release no comportamento do compressor descendente. Fonte: Wikimedia Commons (adaptada). . . . . . . . . . . . . . . . . . . . . . 82

3.14 Raiz quadrada de valores no intervalo $[0,1] \ldots \ldots \ldots \ldots$. . . . . . . . . 90 
4.1 Influência de filtragem passa-baixa no centroide espectral. Frequência de corte em 1000 Hz. Sinal limpo em azul e processado em verde. . . . . . . . . . . . . . . . 98

4.2 Influência de filtragem passa-baixa no centroide espectral. Frequência de corte em $1000 \mathrm{~Hz}$ (azul) e $10 \mathrm{~Hz}$ (verde) . . . . . . . . . . . . . . . . 98

4.3 Influência de filtragem passa-baixa no centroide espectral. Frequência de corte em 1 Hz. Sinal limpo em azul e processado em verde. . . . . . . . . . . . . . . . . 99

4.4 Influência de filtragem passa-baixa no fluxo espectral. Frequência de corte em 1000 $\mathrm{Hz}$ (azul) e $10 \mathrm{~Hz}$ (verde). . . . . . . . . . . . . . . . . . . . . . 99

4.5 Influência de filtragem passa-baixa no RMS. Frequência de corte em $1 \mathrm{~Hz}$. Sinal limpo em azul e processado em verde. . . . . . . . . . . . . . . . . . . 100

4.6 Influência de compressão de FI no centroide. Limiar em $100 \mathrm{~Hz}$ e taxa 2:1. Sinal limpo em azul e processado em verde. . . . . . . . . . . . . . . . . 100

4.7 Influência de compressão de FI no centroide. Em azul, taxa de compressão 2:1. Em verde, taxa 4:1. Limiares em $100 \mathrm{~Hz}$. . . . . . . . . . . . . . . . . . . . . 101

4.8 Influência de expansão de FI no centroide. Limiar em $100 \mathrm{~Hz}$ e taxa de expansão 1.2:1. Sinal limpo em azul e processado em verde. . . . . . . . . . . . . . . . . 101

4.9 Influência de expansão de FI no centroide. Em azul, taxa 1.2:1. Em verde, taxa 2:1. Ambos os limiares em $100 \mathrm{~Hz}$. . . . . . . . . . . . . . . . . . . . . . . 102

4.10 Influência de expansão de FI no centroide. Em azul, limiar em $100 \mathrm{~Hz}$. Em verde, limiar em 10 Hz. Ambas as taxas em 2:1. . . . . . . . . . . . . . . . . . 102

4.11 Influência de fixação de FI no centroide. FI $=2000 \mathrm{~Hz}$. Sinal limpo em azul e processado em verde. . . . . . . . . . . . . . . . . . . . . 103

4.12 Influência de fixação de FI no centroide. FI $=200 \mathrm{~Hz}$. Sinal limpo em azul e processado em verde. . . . . . . . . . . . . . . . . . . . . . 103

4.13 Influência no RMS de fixação de FI em $2 \mathrm{kHz}$. Sinal limpo em azul e processado em verde. . . . . . . . . . . . . . . . . . . . . . . . . 104

4.14 Influência de modulação em amplitude da FI no centroide. Sinal limpo em azul e processado em verde. Efeito AM/FM v-if-brato. . . . . . . . . . . . . . . . . . . 104

4.15 Influência de modulação em anel da FI no centroide. Sinal limpo em azul e processado em verde. Efeito AM/FM whee-if. . . . . . . . . . . . . . . . . . 105

4.16 Influência de modulação em anel da FI no fluxo espectral. Sinal limpo em azul e processado em verde. . . . . . . . . . . . . . . . . . . . 105

4.17 Influência de modulação em anel da FI na proeminência de pitch. Sinal limpo em azul e processado em verde. . . . . . . . . . . . . . . . 106

4.18 Influência de modulação em anel da FI no centroide. Sinal limpo em azul e processado em verde. Efeito AM/FM gliss-if. . . . . . . . . . . . . . . . . . 106

4.19 Influência de ganho (multiplicação por 0.25) na FI no centroide. Sinal limpo em azul e processado em verde. . . . . . . . . . . . . . . . . . 107

4.20 Influência de ganho (multiplicação por 0.25 ) na FI no fluxo espectral. Sinal limpo em azul e processado em verde. . . . . . . . . . . . . . . . . 107

4.21 Influência de ganho (multiplicação por 0.25 ) na FI na proeminência de pitch. Sinal limpo em azul e processado em verde. 
4.22 Influência de ganho (multiplicação por 2) na FI no centroide. Sinal limpo em azul e processado em verde. . . . . . . . . . . . . . . . . . . . . . . . 108

4.23 Influência de aplicação de raiz quadrada do envelope no centroide. Sinal limpo em azul e processado em verde. . . . . . . . . . . . . . . . . . . . . . 109

4.24 Influência de aplicação de raiz quadrada do envelope no RMS. Sinal limpo em azul e processado em verde. . . . . . . . . . . . . . . . . . . . . . . 109

4.25 Influência de aplicação de raiz quadrada do envelope na dissonância. Sinal limpo em azul e processado em verde. . . . . . . . . . . . . . . . . . . . . 110 


\section{Capítulo 1}

\section{Introdução}

A violin may be beautiful but it always will sound like a violin. The computer can sound like anything. ${ }^{1}$

Max Mathews

\subsection{Instrumentos musicais e efeitos de áudio}

Qualquer som, juntamente com o silêncio, apresenta o potencial para ser utilizado para fazer música. Sendo assim, qualquer dispositivo capaz de gerar qualquer tipo de áudio pode ser considerado um instrumento musical. Do mesmo modo, dispositivos que apresentam o potencial para alterar sonoridades também podem ser considerados como instrumentos musicais, ou, mais poeticamente, efeitos de áudio, ou ainda, extensões de um instrumento.

Exemplos conhecidos de instrumentos musicais são a voz, violão, guitarra, contrabaixo e bateria, considerando os mais comuns em bandas de pop/rock. Já num conjunto de jazz é comum aparecerem saxofone, trompete, piano, entre outros. Em orquestras sinfônicas temos violinos, violas, violoncelos, flauta, clarinete, fagote, percussão e muito mais. Estes são apenas alguns exemplos de instrumentos musicais, mais especificamente, instrumentos acústicos. Quando tocamos estes instrumentos são produzidas diretamente ondas acústicas ${ }^{2}$, caracterizadas por variações de pressão na atmosfera que serão percebidas como sons.

Outra classe de instrumentos musicais é a dos instrumentos eletrônicos, que podem ser analógicos ou digitais. Quando tocamos instrumentos analógicos sinais elétricos são produzidos a partir de um circuito eletrônico analógico, passam na sequência por um amplificador eletrônico e finalmente são conectados a um alto-falante, causando um movimento ${ }^{3}$ na membrana deste e gerando assim as ondas acústicas que chegarão aos nossos ouvidos. Exemplos de instrumentos musicais eletrônicos analógicos são os clássicos sintetizadores Moog. A Figura 1.1 mostra um dos vários modelos desta lendária série criada por Robert Moog.

\footnotetext{
${ }^{1}$ Tradução do autor: Um violino pode ser lindo mas sempre vai soar como um violino. O computador pode soar como qualquer coisa.

${ }^{2}$ No caso da guitarra e contrabaixo elétrico as ondas são produzidas por alto-falantes, mas consideramos estes instrumentos como acústicos pois é justamente a vibração de suas cordas que é captada magneticamente.

${ }^{3} \mathrm{O}$ nome analógico é uma referência ao fato de que este movimento é análogo ao sinal elétrico que o alimenta.
} 


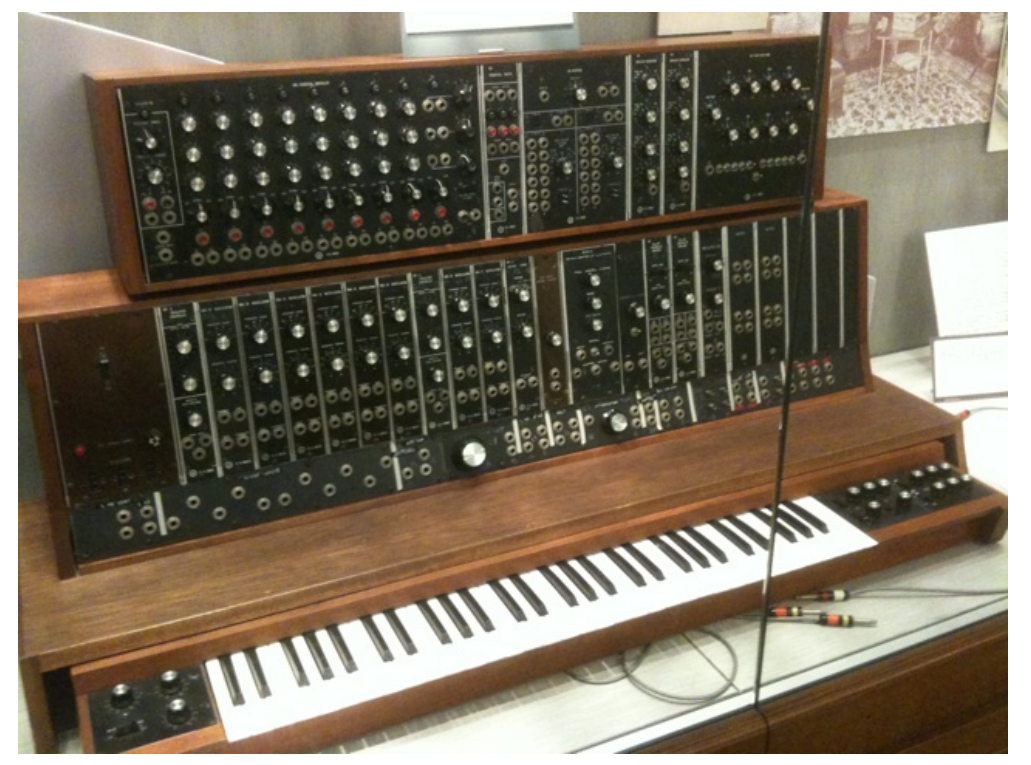

Figura 1.1: Protótipo do Moog de 1964. Fonte: Wikimedia Commons.

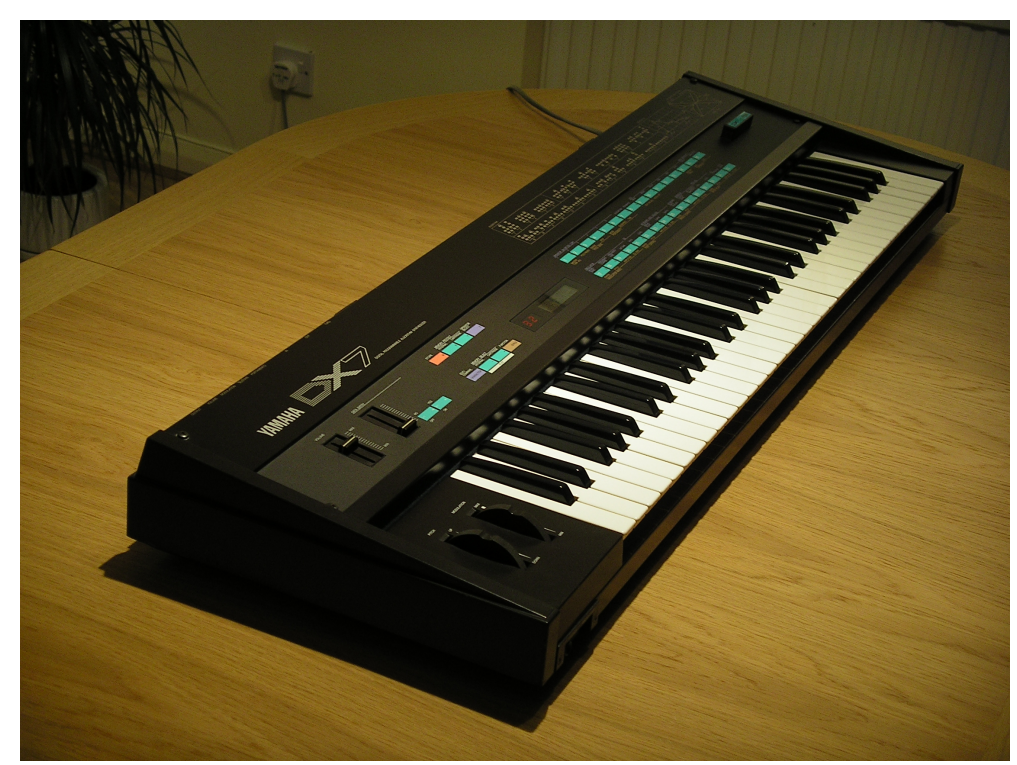

Figura 1.2: Teclado digital DX7, da Yamaha. Fonte: Wikimedia Commons.

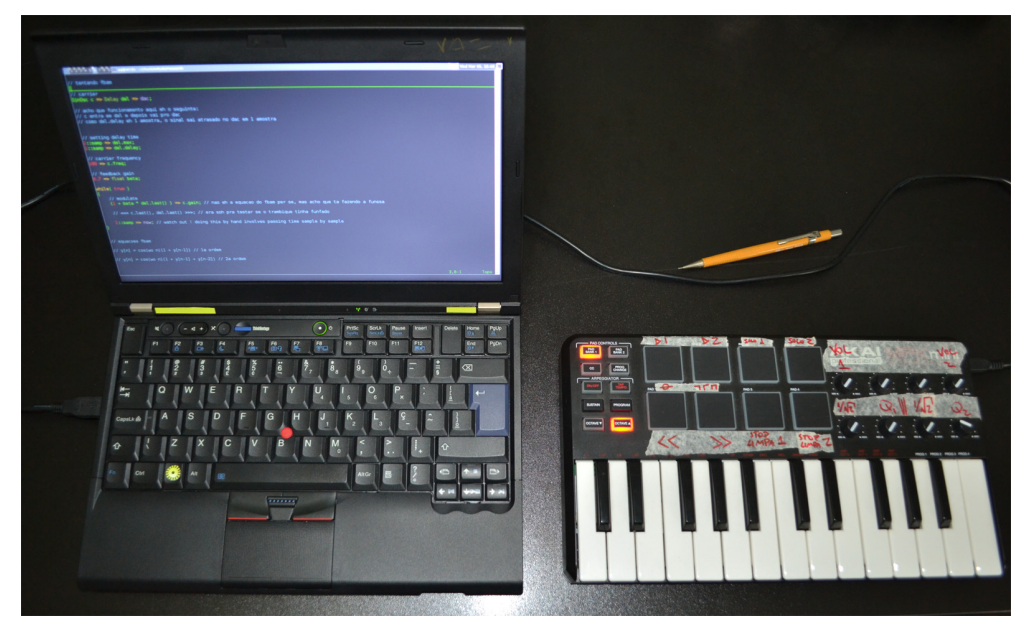

Figura 1.3: Controlador MIDI conectado ao PC. 
No caso de um instrumento eletrônico digital o som é produzido a partir de um sistema digital, cuja saída é um sinal digital, ou seja, uma sequência de números. Ao sair do sistema essa sequência passa por um conversor digital-analógico, transformando o sinal digital num sinal analógico equivalente, que é então amplificado e reproduzido a partir do alto-falante. Um exemplo de instrumento musical eletrônico digital muito popular é o teclado Yamaha DX7 (Figura 1.2), cujo sistema digital é um conjunto de software que roda em uma unidade dedicada de processamento localizado dentro da carcaça do instrumento.

Outro exemplo de instrumento musical digital é o computador, atualmente representado na maioria dos casos por um laptop. O sistema digital responsável pela geração do sinal consiste num conjunto de software que roda no computador. Assim como as interfaces dos instrumentos analógicos e do teclado digital são baseadas num teclado que imita as teclas de um piano, existem controladores $\mathrm{MIDI}^{4}$ que podem ser conectados ao computador (Figura 1.3) para controlar o instrumento digital programado. No entanto, o controle do instrumento musical pode ser feito também a partir de outras interfaces como joysticks, mouse, o próprio teclado do PC, um software sequenciador, ou até um programa escrito ao vivo ${ }^{5}$ (de preferência com a tela projetada para o público) pelo músico.

Neste contexto do computador como instrumento musical, o sistema digital mencionado nos últimos parágrafos consiste num algoritmo para a síntese do sinal musical (daí o nome sintetizador, dado para estes instrumentos). Diferentemente de instrumentos acústicos, cujos sons são gerados fisicamente ao tocar os instrumentos, e de instrumentos analógicos, cujos sons são produzidos por meio da manipulação de eletricidade com circuitos eletrônicos, os sons dos instrumentos eletrônicos digitais são gerados por meio de software, a partir de diversas técnicas de síntese, que são fórmulas matemáticas para produzir as amostras de um sinal digital [Moo85].

\section{Efeitos de áudio}

Uma vez escolhidos os instrumentos com os quais trabalhar, existe ainda a possibilidade de aplicação de efeitos de áudio para alterar as sonoridades originais dos mesmos, seja a intenção artística ou corretiva. Da mesma maneira que os instrumentos musicais, os efeitos podem ser acústicos (mecânicos), eletrônicos analógicos ou digitais. Diversas famílias de efeitos de áudio foram desenvolvidas e categorizadas [Zöl11].

Como exemplo de efeito acústico podemos citar os ressonadores de Helmholtz [Hel85] (Fig. 1.4(a)), que exploram o fenômeno de ressonância do ar em uma cavidade, como ocorre ao batermos com uma colher numa garrafa de vidro: dependendo do volume de líquido na garrafa, uma nota diferente será produzida, permitindo assim a construção de xilofones de garrafa (Fig. 1.4(b)). Reverberadores de mola também podem ser considerados como um efeito acústico/mecânico; um transdutor acopla um sinal de áudio à ponta de uma mola, enquanto na outra ponta um captador (similar ao de uma guitarra) converte o movimento da mola em áudio novamente (Fig. 1.4(c)).

A mesma explicação relativa ao princípio de funcionamento de instrumentos eletrônicos vale para os efeitos, analógicos e digitais. A Figura 1.5 mostra uma coleção de pedais analógicos de efeitos; a Figura 1.6(a) mostra uma pedaleira digital multi-efeitos com vários possibilidades de programação e controle, popular entre guitarristas profissionais, enquanto a Figura 1.6(b) mostra também uma pedaleira digital, mais acessível, muito popular em meados de 2000 entre guitarristas amadores.

\footnotetext{
${ }^{4}$ Musical Instrument Digital Interface: https://www.midi.org/

${ }^{5}$ Acesse http://toplap.org/ para conferir mais sobre performances musicais de live coding.
} 


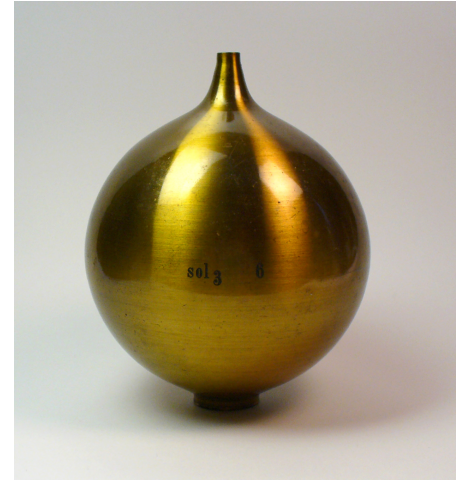

(a) Ressonador

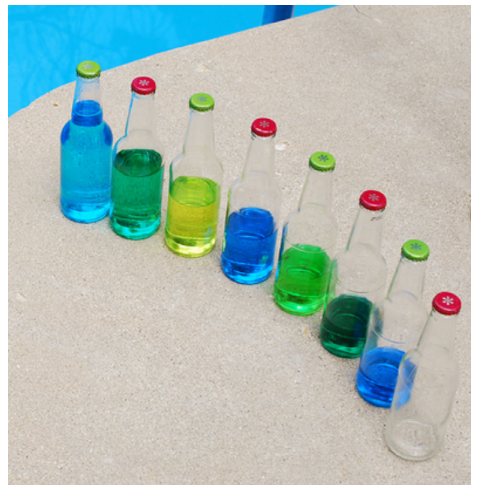

(b) Xilofone de garrafas

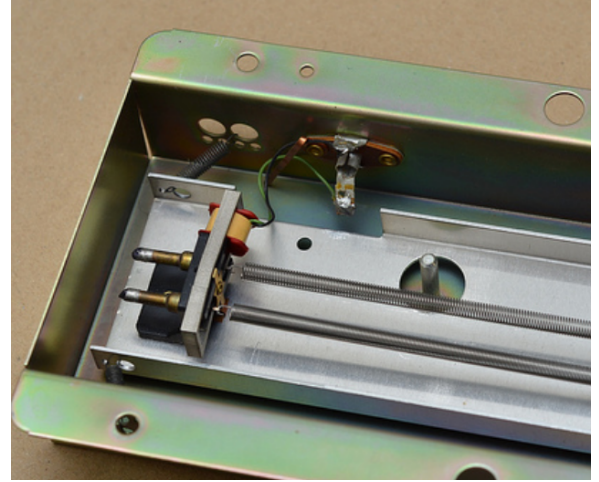

(c) Reverb de mola

Figura 1.4: Exemplos de efeitos acústicos. Fonte: Wikimedia Commons / Flickr / Flickr.

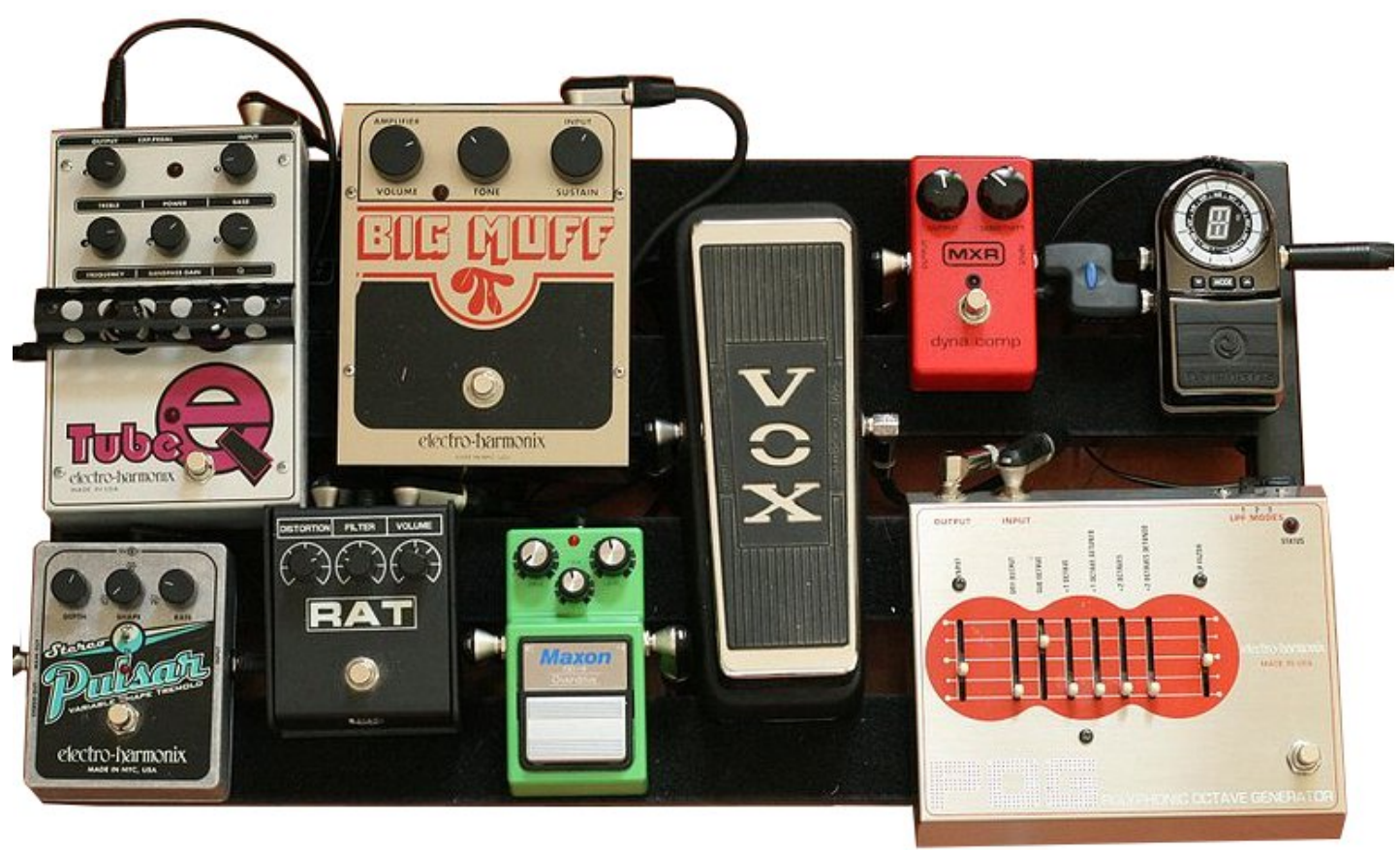

Figura 1.5: Ligação em série de vários pedais de efeitos. Porção superior, da esquerda pra direita: equalizador paramétrico, distorção fuzz, wah-wah, compressor e afinador (digital). Porção inferior, da esquerda pra direita: tremolo, distorção standard, distorção overdrive e oitavador. Fonte: Wikimedia Commons.

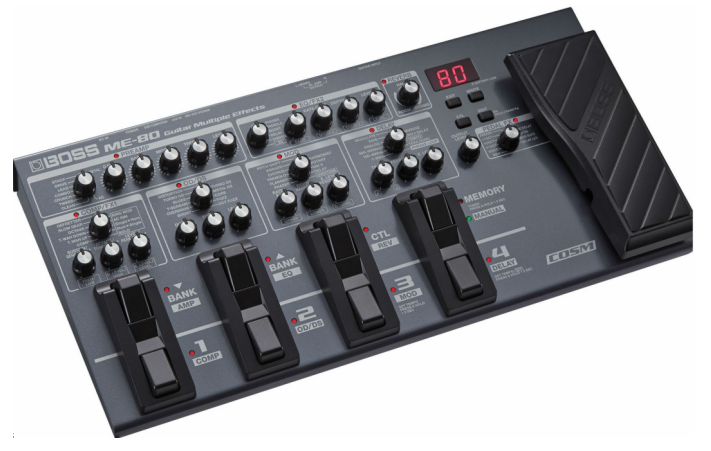

(a) Boss ME 80

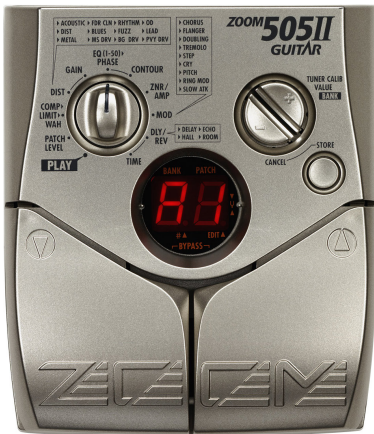

(b) Zoom 505 II

Figura 1.6: Exemplos de pedaleiras digitais multiefeitos. Fonte: http://boss.info/http://zoom.co.jp . 
Diversos são os exemplos de efeitos de áudio eletrônicos. Ferramentas como equalizadores permitem o ajuste de diferentes níveis de ganho em diferentes porções do espectro de um sinal. Como exemplo simples desta categoria temos os controles de graves (bass) e agudos (treble) em amplificadores de áudio. Diferentes tipos de equalizadores, com circuitos e possibilidades de controles muito mais complexas também podem ser encontrados. A Figura 1.5 mostra um equalizador paramétrico valvulado. Outro efeito, o de distorção, é obtido a partir da alteração da forma de onda do sinal original (fazendo jus ao nome). O efeito pode ser implementado, por exemplo, a partir do ceifamento de valores do sinal acima de um limiar escolhido pelo usuário. O sinal processado apresenta um acréscimo de harmônicos nas altas frequências e um aspecto que pode ser descrito como áspero e brilhante. Normalmente diferentes tipos de distorção (Figura 1.5) são exploradas em diferentes estilos musicais.

Não discutiremos aqui as minúcias de cada família de efeitos de áudio. Os exemplos anteriores servem apenas para ilustrar a ideia de um sistema genérico que recebe o sinal original de áudio já existente (este sinal de entrada não é necessariamente limitado a apenas um canal), aplica algum tipo de processamento ao mesmo, e produz em sua saída um novo sinal de áudio (também não há restrição para o número de canais produzidos com o efeito). Assim obtemos um novo sinal de áudio relacionado com o original de acordo com o processo implementado.

De uma maneira geral vários efeitos podem ser implementados tanto no contexto analógico quanto no digital. Inclusive, muitos efeitos digitais são baseados em modelagens "analógicas virtuais ${ }^{6 "}$ de circuitos eletrônicos de efeitos clássicos [YAS07] [GW15] (em algumas instâncias chamados de vintage [SS96]), ou então em algoritmos que tentam emular o comportamento destes [Zav12]. No âmbito de ferramentas para produção musical existem efeitos que emulam aspectos da sonoridade de equipamentos antigos a partir de suas curvas de saturação [Zöl11] ou da modelagem dos componentes [Huo04] [DV13], entre outros fatores. É possível dizer que tais implementações digitais de efeitos clássicos são amplamente aceitas $^{7}$ e utilizadas, vide a imensa oferta de pedaleiras digitais ou a importância de pacotes de plugins como GuitaRix ${ }^{8}$.

Se por um lado sistemas digitais permitem emular efeitos consagrados, outra possibilidade que surge é a de explorar novas possibilidades [Mar15], como criar efeitos que seriam impossíveis ou inviáveis (por questões de preço, dificuldade de encontrar ou produzir componentes, entre outros pontos) de implementar senão computacionalmente. Desta maneira, releituras inspiradas nos clássicos [GTL15] representam opções interessantes, assim como o projeto de novos efeitos que exploram conceitos que vão além da concretude de circuitos analógicos. Abstrações matemáticas, como por exemplo dimensões elevadas, transformadas, mudanças de domínio, entre outras operações, são facilmente implementáveis digitalmente, e se casadas com uma boa intuição sobre o significado de tais técnicas e aplicações em determinado contexto, podem representar um fértil terreno para novas explorações.

\footnotetext{
${ }^{6}$ https://signalprocessingsociety.org/get-involved/audio-and-acoustic-signal-processing/newsletter/ virtual-analog-audio-signal-processing

${ }^{7}$ Não entraremos em discussões sobre comparação/preferência entre equipamentos analógicos versus digitais.

${ }^{8}$ Amplificador virtual que emula diversos gabinetes e efeitos. Veja mais em: http://guitarix.org/
} 


\subsection{O paradigma Decomposição/Processamento/Ressíntese}

Geralmente existem diferentes maneiras de encarar um mesmo problema, sendo que as particularidades de cada abordagem costumam ser vantajosas em relação às demais em pelo menos um aspecto. Para a implementação de efeitos de áudio devemos considerar o cenário em que o processamento se dará. Operações no domínio do tempo são aplicadas diretamente ao sinal, podendo ser encaradas como operações de superfície [Zöl11], uma vez que alteram diretamente os dados brutos do sinal de áudio. Por exemplo, um simples efeito de ganho recebe as amostras do sinal original, as multiplica pela amplificação desejada e retorna como um novo sinal as amostras modificadas. O próprio efeito de distorção já mencionado aplica uma função não-linear ao sinal de entrada, alterando o valor de cada amostra do mesmo de acordo com o projeto de uma curva de distorção [Roa79].

Por outro lado, sistemas baseados em decomposição/processamento/ressíntese apresentam um processamento de mais alto nível [Zöl11], uma vez que o sinal de áudio passa por uma transformação matemática e é desdobrado para um novo domínio de representação no qual será esculpido. Em outras palavras, o sinal original pode ser refinado neste novo domínio e na sequência uma transformada inversa devolve o mesmo para o domínio do tempo. Também amplamente explorado para o processamento de sinais, o domínio da frequência se mostra como uma alternativa bastante informativa do ponto de vista da percepção sobre como se dará o processamento, uma vez que sabemos relacionar informação na frequência com notas musicais ou altura de um som. Por exemplo, pode ser mais natural pensar o já mencionado efeito de equalização neste domínio, pois uma vez que temos o sinal original transformado para seu espectro, podemos amplificar ou atenuar frequências específicas e depois aplicar a transformada inversa neste espectro modificado, obtendo o sinal no domínio do tempo, já com o efeito desejado [DJ97].

Neste contexto de análise espectral, a informação sobre o sinal de entrada é obtida por meio de uma análise de Fourier. O espectro é visto como uma sobreposição de osciladores senoidais com amplitudes, frequências e fases individuais, sendo que o sinal original também pode ser reconstruído utilizando um esquema de síntese aditiva [Col10] [DJ97], somando osciladores com parâmetros de acordo com a informação que aparece na etapa de análise. Como uma maneira de impor mudanças ao sinal, pode-se alterar amplitude, frequência e fase de um subconjunto de osciladores, ou até eliminar alguns. Este é o princípio de funcionamento do Vocoder, amplamente utilizado em aplicações musicais.

A decomposição AM/FM, seguida de processamento dos sinais AM e FM e ressíntese representa uma alternativa interessante para o processamento de sinais musicais. Diferentemente do paradigma de síntese aditiva (comportamento do sinal dado de acordo com soma de componentes), no paradigma $\mathrm{AM} / \mathrm{FM}$ interpretamos o sinal em termos do modelo de um único oscilador senoidal, mas com amplitude e frequência variantes no tempo, ou seja, o comportamento do sinal é dado por um par de sinais que representam modulações em amplitude e frequência. Como analogia, podemos pensar num sistema massa-mola em que poderíamos controlar a massa do corpo suspenso (este seria um recipiente com controle de entrada e saída de líquido) [GTLQ15]. Neste novo domínio em que conhecemos as modulações em amplitude e frequência deste oscilador, somos então capazes de aplicar mudanças ao sinal original alterando os padrões dessas modulações. 


\subsection{Modulações e o domínio AM/FM}

No contexto de processamento de sinais, modulação se refere à alteração de algum parâmetro de um sinal a partir de outro sinal ou por meio de retroalimentação. Por exemplo, para um oscilador senoidal temos como parâmetros principais a sua amplitude, frequência e fase. A modulação consiste na alteração sistemática do valor de qualquer um desses parâmetros. A modulação da amplitude (AM) ou da frequência (FM) de uma onda são utilizadas há muitos anos em comunicações de rádio para transmitir informação eficientemente, e músicos também exploram essas técnicas para criar timbres para suas composições [DJ97]. O sinal que codifica a informação é chamado de modulador, e a portadora é a onda que carrega a informação.

A decomposição AM/FM traduz a informação do sinal sob análise em dois outros sinais que atuam em conjunto. A porção AM da decomposição é conhecida como amplitude instantânea, ou envelope do sinal, enquanto que a porção FM da decomposição é chamada de frequência instantânea do sinal. Uma boa intuição sobre a natureza da representação na qual o processamento ocorrerá pode revelar possibilidades que não seriam óbvias, ou até possíveis, no domínio do tempo ou da frequência, ou outros.

Para melhor compreender a representação AM/FM de sinais podemos considerar brevemente algumas teorias para o sistema de produção da nossa fala, e como seria a geração de um sinal cuja amplitude e frequência variam. De acordo com a revisão apresentada por Potamianos [Pot95], sabemos que no sistema vocal humano o som é produzido quando ar é empurrado dos pulmões para o trato vocal, passando pela glote. Numa tentativa de modelar esse sistema, representações lineares amplamente utilizadas em processamento de voz supõem que o fluxo de ar preenche toda a área do trato vocal, e que a velocidade deste fluxo é uniforme ao longo de uma seção do trato. A viscosidade do fluido em questão é considerada desprezível, cancelando-se assim a contribuição da tensão de cisalhamento, com características não-lineares. No entanto, os experimentos de Teager [Tea80] [TT90] mostraram que:

- o fluxo de ar no trato vocal forma jatos instáveis que geralmente se separam das paredes da cavidade;

- a velocidade ao longo de um perfil de seção não é uniforme;

- vórtices também podem se formar;

- ocorrem excitações secundárias durante a abertura da glote, que tendem a alterar o amortecimento do fluxo.

Jatos instáveis e vórtices tendem a modular a intensidade do fluxo de ar. Velocidade não-uniforme e alterações no amortecimento tendem a modular a frequência do fluxo. Tais resultados motivaram a elaboração de um modelo não-linear para a produção de voz, que leva em conta tais instabilidades no fluxo. No modelo, cada formante $r(t)$ da voz é descrita por uma modulação AM combinada com uma modulação FM, de acordo com a expressão

$$
r(t)=a(t) \cos (\underbrace{f_{c} t+\int_{0}^{t} f_{m}(\tau) d \tau+\phi_{0}}_{\phi(t)}),
$$


onde $f_{c}$ é a frequência central do formante, $a(t)$ sua amplitude instantânea e $f_{m}(t)$ o sinal modulador, responsável pela excursão da frequência. $\mathrm{O}$ argumento do cosseno, $\phi(t)$, corresponde à fase do sinal. A frequência instantânea deste formante é definida como a derivada de $\phi(t)$. Tal discussão será aprofundada no capítulo seguinte.

Como podemos perceber, a Equação 1.1 gera um sinal levando em conta uma contribuição devido a uma modulação em amplitude e também a um processo de modulação em frequência, sendo as razões para esta dupla modulação decorrentes das não-linearidades no modelo mencionado para a produção de fala. Neste trabalho, fazemos primeiro o caminho oposto, ou seja, dado um sinal de áudio $x(t)$ qualquer, aplicamos uma técnica de decomposição que nos fornece um par $(a(t), f(t))$ de sinais, que podem recuperar $x(t)$ se combinados de acordo com a expressão

$$
x(t)=a(t) \cos \left(\int_{0}^{t} f(\tau) d \tau\right) .
$$

No entanto, estamos interessados em interpretar estes sinais de AM e FM como descritores de processos internos de modulação do sinal original, e manipular estas quantias com o intuito de imprimir variações interessantes musicalmente, as quais chamaremos de efeitos AM/FM de áudio.

\subsection{Motivação e objetivos}

Como já comentado, vários são os efeitos musicais consagrados, utilizados há tempos [Bod84] no domínio analógico e mais recentemente também em sistemas digitais. Pedaleiras programáveis sempre serão uma divertida fonte de experimentação com parâmetros para criar versões personalizadas dos efeitos disponíveis, tendo de fato despertado (Figura 1.6(b)) o interesse do autor por engenharia e computação musical.

No entanto, além da emulação de efeitos, o processamento digital traz a possibilidade de criar timbres jamais solfejados [Let85]. Em especial, a família de métodos não-lineares (ou modelagem abstrata [Smi91] [Col10], categoria onde se incluem os métodos de modulação AM e FM) utiliza funções matemáticas compactas e com poucos parâmetros, que no entanto são capazes de gerar inúmeras possibilidades de material musical. Como colocado por Risset, o computador ajuda no processo de desenvolver os sons propriamente ditos, livrando o compositor de apenas compor com os sons:

"Muitos compositores estão interessados em estender suas atividades de composição para o nível da micro-estrutura - para a elaboração do som" [Ris96].

O baixo custo computacional e consumo de memória das técnicas de modulação fazem dos efeitos AM/FM fortes candidatos para serem integrados ao arsenal de artistas, uma vez que podem ser implementados mesmo em hardware com recursos limitados, como:

- netbooks e laptops antigos com processadores $\operatorname{lentos}^{9}$;

- as atuais plataformas de programação como RaspberryPi ${ }^{10}$, BeagleBone ${ }^{11}$, Galileo ${ }^{12}$, entre

\footnotetext{
${ }^{9}$ Veja no Apêndice A como configurar o computador como pedaleira para uso em tempo-real utilizando Csound (ou outras linguagens de programação).

${ }^{10}$ http://www.raspberrypi.org/

${ }^{11} \mathrm{http}: / /$ beagleboard.org/Products/BeagleBone

${ }^{12}$ http://arduino.cc/en/ArduinoCertified/IntelGalileo\#.Uy3wEJB5u00
} 
outras (são baratas e extremamente portáteis mas possuem memória e poder computacional limitados);

- os ubíquos [KLP14] smartphones ${ }^{13}$ (embora possuam processadores cada vez mais potentes são alimentados por baterias, inviabilizando um alto poder computacional que acabaria rapidamente com a carga).

Dado o interesse deste autor e de tantos músicos em levarem seus efeitos para o palco, dispositivos de alta disponibilidade e/ou baixo custo [Bia14], como os supracitados, se apresentam como interessante opção do ponto de vista financeiro, social, ambiental, e da cultura faça-você-mesmo. A ideia de baixo custo está relacionada com a opção por adquirir equipamentos genéricos e cada vez mais baratos (como o RaspberryPi) e configurar os mesmos para a realização de tarefas de interesse (a Figura 1.7 mostra os equipamentos utilizados pelo autor; o RaspberryPi é utilizado como pedaleira de efeitos), ao invés de comprar um equipamento profissional altamente especializado (como pedais/pedaleiras de marcas renomadas). A ideia de alta disponibilidade está relacionada com a existência de dispositivos considerados obsoletos, que podem ser imediatamente reutilizados, como é o caso de laptops/netbooks que descartamos seja por parecerem lentos demais ou por já não mais funcionarem apenas com a bateria (fora da tomada). Da mesma maneira, smartphones imediatamente disponíveis no bolso de muitos músicos podem ser aproveitados como plataforma para implementação de sintetizadores e efeitos de áudio.
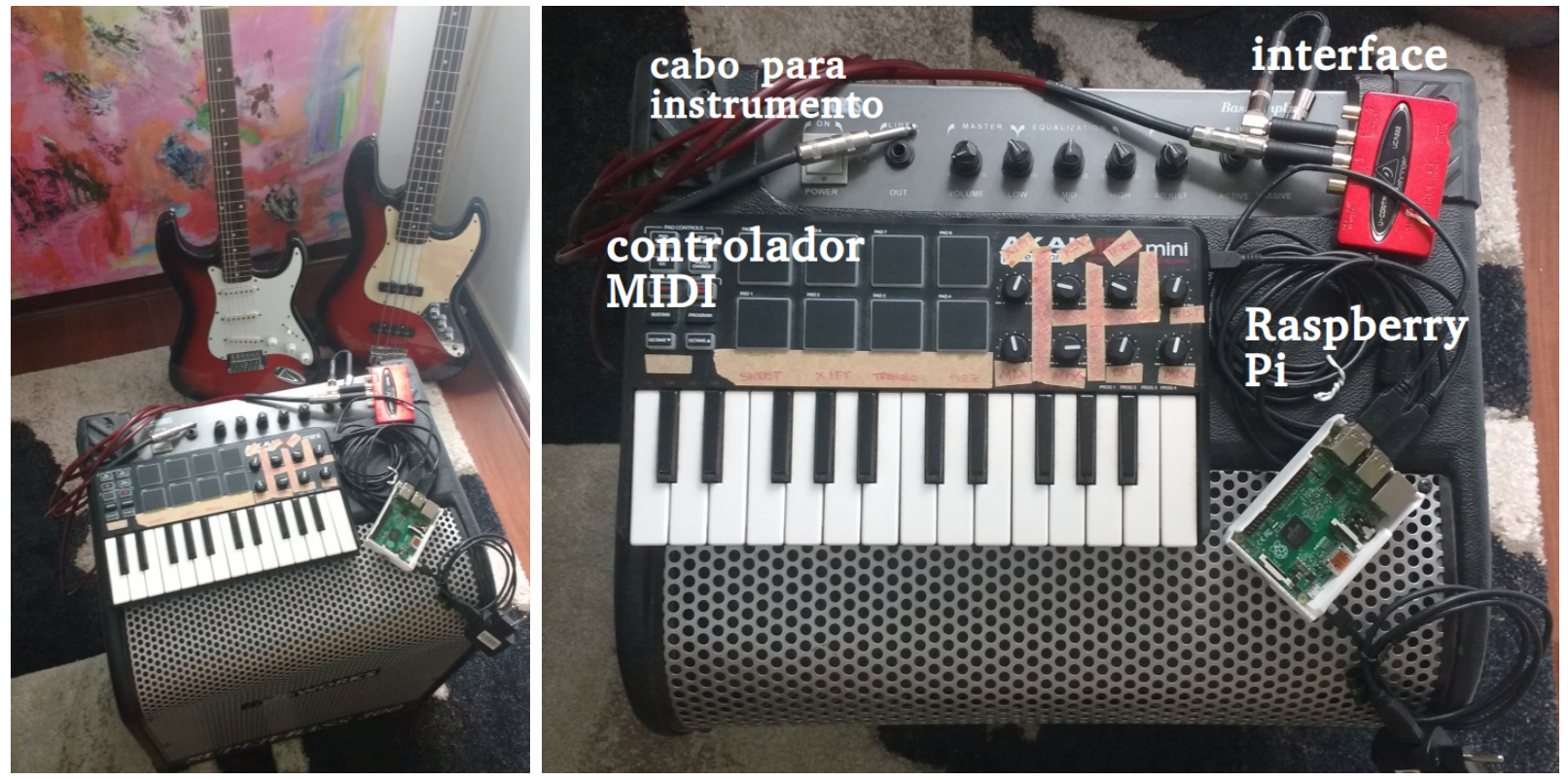

Figura 1.7: Equipamento utilizado pelo autor: guitarra, baixo, amplificador, e RaspberryPi (em conjunto com interface de áudio e controlador MIDI) programado como pedaleira de efeitos de áudio personalizados.

As técnicas de modulação remetem à velha guarda da computação musical, e é emocionante imaginar toda a rotina que os pioneiros da área se sujeitavam para conseguir sintetizar alguns segundos de música, além da alegria com cada nova descoberta. As técnicas não-lineares, mesmo que não dominadas totalmente na época, foram utilizadas experimentalmente em vários exemplos do catálogo introdutório de sons feito por Risset [Ris69]. Ainda sobre a busca, nas palavras ${ }^{14}$ de Max Mathews, pai da computação musical:

\footnotetext{
${ }^{13}$ É possível executar códigos Csound em aparelhos Android utilizando o CsoundApp.

${ }^{14} \mathrm{http}: / /$ www.youtube.com/watch? $\mathrm{v}=$ Mi9ZikB_BUA\&feature=player_embedded
} 
"When I first got some - I won't call it music - sounds out of a computer in 1957, they were pretty horrible. (...) Almost all the sequence of samples - the sounds that you produce with a digital process - are either uninteresting, or disagreeable, or downright painful and dangerous. It's very hard to find beautiful timbres" 15 .

\section{Objetivos}

Vários são os objetivos da realização deste trabalho. Os objetivos técnicos, e que justificam o programa no qual este doutorado é realizado são:

1. Estudar técnicas disponíveis para a decomposição AM/FM de sinais e selecionar métodos propícios para a implementação dos efeitos;

2. compreender o tipo de informação presente nos sinais originados com a decomposição, para propor e implementar novos efeitos de áudio baseados no novo domínio;

3. realizar avaliações objetivas das técnicas implementadas, analisando a excursão de um conjunto de descritores, em decorrência da aplicação de efeitos AM/FM;

4. disponibilizar como software livre implementações em Csound, juntamente com um tutorial, para estimular o uso (em tempo-real) das novas técnicas;

5. difundir o conhecimento explorado no trabalho a partir da escrita de artigos científicos e oferecimento de cursos, seminários e palestras.

Como já mencionado o autor possui também um lado musical, com interesse em tocar contrabaixo, guitarra, efeitos, live coding, e engenharia de mixagem. Durante o doutorado o autor foi membro da Orquestra Errante ${ }^{16}$, tocando e atuando em aspectos de engenharia. Sendo assim, os objetivos artísticos do presente trabalho são:

1. Desenvolver e aperfeiçoar novos efeitos de áudio para utilização em processamento de instrumentos acústicos, cenário este que pode interessar a diversos músicos;

2. Desenvolver e aperfeiçoar novos efeitos de áudio para utilização em mixagens de produções musicais, cenário este que pode interessar a diversos engenheiros e produtores;

3. participar de projetos musicais diversos;

4. convidar músicos a experimentarem as novas técnicas.

Os últimos objetivos citados são de especial interesse, uma vez que vários músicos e compositores talentosos dividem o ambiente de trabalho com o autor, tanto no Grupo de Pesquisa em Computação Musical $^{17}$ (IME/USP) quanto no NuSom ${ }^{18}$ - Núcleo de Sonologia (ECA+IME/USP).

\footnotetext{
${ }^{15}$ Tradução do autor: Quando eu obtive pela primeira vez - não vou chamar de música - sons de um computador eles eram horríveis. (...) Quase todas as sequências de amostras - os sons que você pode produzir com um processo digital - são desinteressantes, desagradáveis ou completamente dolorosas e perigosas. É muito difícil encontrar timbres bonitos.

${ }^{16}$ Orquestra de improviso livre sediada na Escola de Comunicações e Artes da ECA-USP. Para conhecer mais sobre o trabalho da Orquestra Errante acesse http://www2.eca.usp.br/nusom/arte e também https://soundcloud. com/orquestraerrante

${ }^{17} \mathrm{http}: / /$ compmus.ime.usp.br/

${ }^{18}$ http://www2.eca.usp.br/nusom/
} 


\subsection{Organização do trabalho}

O capítulo seguinte se inicia com uma extensa revisão acerca das técnicas de modulação utilizadas para fins de aplicação de efeitos de áudio e síntese de sinais musicais. As técnicas de modulação de amplitude e modulação de frequência, assim como suas extensões e variações, serão detalhadas matematicamente, juntamente com trechos de código ${ }^{19}$ com implementações das técnicas.

Também no Capítulo 2 será apresentada uma discussão de conceitos importantes para a compreensão da decomposição AM/FM, e serão detalhados dois métodos para a decomposição, a saber, o método baseado no sinal analítico e o algoritmo de separação de energia. O caso da decomposição multicomponente em seus diferentes cenários também será considerado, juntamente com a descrição de um algoritmo para estimativa de frequência fundamental de sinais de áudio baseado na estrutura de um Phase-Lock Loop. Finalizando o capítulo apresentamos uma revisão dos trabalhos referentes às aplicações da decomposição AM/FM, como análise e classificação de sinais de áudio, Modulation Filtering e Modulation Vocoder, principais referências do presente trabalho.

No Capítulo 3 estão detalhados matematicamente, juntamente com implementações computacionais, novos efeitos baseados no domínio AM/FM. Começamos o capítulo discutindo decisões de projeto de efeitos, como por exemplo a separação do sinal de entrada em bandas antes da decomposição, e qual método de decomposição utilizar de acordo com o efeito a ser projetado. Na sequência apresentamos efeitos baseados em filtragem das estimativas AM/FM, processamento dinâmico das estimativas, manipulações inspiradas em efeitos clássicos, implementações alternativas de efeitos consagrados, entre outros. Discutimos também uma possibilidade para controle da profundidade do efeito (ou controle da mistura dry/wet), além de implementação de efeitos stereo.

No Capítulo 4 apresentamos a metodologia e os descritores de áudio selecionados para avaliação objetiva dos efeitos AM/FM. Apresentamos os resultados juntamente com uma discussão relacionando os conceitos, os resultados esperados e os resultados observados nos experimentos. O capítulo se encerra com uma comparação entre custos computacionais e latências de efeitos AM/FM e de outras técnicas.

O Capítulo 5 apresenta conclusões sobre o trabalho e os resultados obtidos, e aponta possíveis trabalhos futuros e cenários de utilização das técnicas propostas.

O texto apresenta também o Apêndice A com um breve tutorial sobre a linguagem de programação Csound ${ }^{20}$, projetada principalmente para implementação de rotinas para processamento de áudio. Mostramos apenas o necessário para que aqueles que porventura não estão familiarizados com a linguagem possam acompanhar as implementações sem precisar buscar por outras fontes. No entanto, apresentamos a literatura apropriada caso haja interesse em se aprofundar. Discutimos também questões práticas sobre preparação e configuração de um computador rodando Linux como sistema operacional para utilizá-lo como uma pedaleira de áudio programável para funcionamento em tempo-real.

A linguagem de programação Octave ${ }^{21}$, linguagem de alto-nível projetada para trabalhos de computação numérica, também foi utilizada em alguns pontos do trabalho, especialmente para confecção de gráficos apresentados ao longo do texto e para inspeção de detalhes relativos ao fun-

\footnotetext{
${ }^{19}$ Neste trabalho utilizamos Csound para as implementações em tempo-real. No Apêndice A apresentamos um breve tutorial sobre a linguagem, suficiente para a compreensão dos códigos apresentados ao longo do texto.

${ }^{20}$ http://csound.github.io/

${ }^{21}$ http://wiki.octave.org/GNU_Octave_Wiki
} 
cionamento dos algoritmos de decomposição.

A biblioteca Essentia ${ }^{22}\left[\mathrm{BWG}^{+} 13\right]$, composta de diversas funcionalidades para análise de áudio e recuperação de informação musical, foi utilizada para a avaliação experimental baseada em descritores perceptuais. Utilizamos a interface de Essentia na linguagem de programação Python ${ }^{23}$ para o preparo das análises.

O software time ${ }^{24}$ foi utilizado para aferimento da intensidade computacional necessária para a execução dos efeitos.

Todos os códigos em Csound, Octave e Python utilizados, juntamente com arquivos de áudio, estão disponíveis na homepage ${ }^{25}$ do autor, e serão referenciados ao longo do texto. Arquivos de áudio serão referenciados com o símbolo [ nomearquivo.wav].

\footnotetext{
${ }^{22}$ http: //essentia.upf.edu/

${ }^{23}$ https://www.python.org/

${ }^{24}$ http://manpages.ubuntu.com/manpages/xenial/man1/time.1.html

${ }^{25}$ https://www.ime.usp.br/ $\sim$ ag/balde/code-audio.zip
} 


\section{Capítulo 2}

\section{Conceitos}

(...) sinusoidal oscillation with

slowly varying amplitude is

self-contradictory like a slightly

bent straight line. ${ }^{1}$

G. S. Goerelik

As técnicas baseadas em modulação são classificadas como métodos por distorção [Laz09]. Como colocado por Lazzarini, a questão principal para a qual esta família se dirige é sobre como gerar um espectro complexo, com vários componentes discretos, evoluindo no tempo. A abordagem por força bruta, domínio da síntese aditiva, consiste em utilizar um oscilador senoidal com um par de envelopes (para amplitude e frequência) para cada componente presente no sinal, e então mixar todas as componentes. As técnicas de distorção representam uma abordagem mais elegante, que consiste em encontrar maneiras de combinar poucos osciladores para gerar um espectro rico.

\subsection{Técnicas de modulação para síntese e efeitos de áudio}

Nesta seção apresentamos uma revisão detalhada sobre técnicas de síntese e efeitos de áudio baseadas nos conceitos de modulação em amplitude e modulação em frequência, além de suas extensões e variações. Tais técnicas representam os pilares da ressíntese AM/FM, que é nada mais que uma combinação de modulações em amplitude e em frequência.

Como já comentado no Capítulo 1, no contexto de processamento de sinais modulação refere-se à alteração de algum parâmetro de um sinal a partir de outro sinal ou por meio de retroalimentação. O sinal que codifica a informação é chamado de modulador, enquanto que o sinal cujo parâmetro é alterado é chamado de portador.

De uma maneira geral vamos apresentar as técnicas considerando osciladores senoidais, que apresentam um espectro simétrico com uma componente com frequência positiva e outra com frequência negativa, tornando assim a apresentação mais clara.

\footnotetext{
${ }^{1}$ Tradução do autor: (...) oscilação senoidal com amplitude variando lentamente é tão contraditório quanto uma linha reta ligeiramente curva.
} 


\subsubsection{AM - Modulação em amplitude}

\section{Modulação em anel}

Se o sinal modulador for diretamente conectado à entrada de amplitude da portadora estaremos diante da técnica denominada modulação em anel (ring modulation, RM). Esse nome é decorrente do fato de que o circuito utilizado para implementar esta técnica no contexto analógico é formado por um anel de diodos (Figura 2.1).

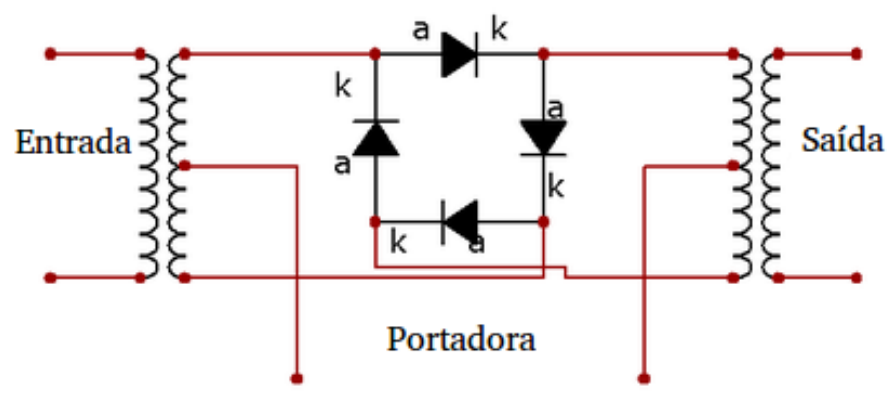

Figura 2.1: Circuito analógico para implementação de modulação em anel. Note o anel de diodos. A e K referem-se a ânodo e cátodo. Fonte: Wikimedia Commons (figura adaptada pelo autor).

Sendo $x_{c}$ uma portadora e $x_{m}$ um sinal modulador, a saída da modulação em anel é dada por:

$$
y_{R M}(n)=x_{c}(n) x_{m}(n)
$$

Se $x_{c}$ e $x_{m}$ forem senoidais, dois parciais estarão presentes em $y_{R M}$, localizados nas frequências $f_{c}+f_{m}$ e $f_{c}-f_{m}$, sendo $f_{c}$ a frequência da portadora e $f_{m}$ a frequência da moduladora. Este fato é ilustrado com a soma das relações trigonométricas

$$
\begin{aligned}
& \cos \left(2 \pi f_{c} n+2 \pi f_{m} n\right)=\cos \left(2 \pi f_{c} n\right) \cos \left(2 \pi f_{m} n\right)-\sin \left(2 \pi f_{c} n\right) \sin \left(2 \pi f_{m} n\right) \\
& \cos \left(2 \pi f_{c} n-2 \pi f_{m} n\right)=\cos \left(2 \pi f_{c} n\right) \cos \left(2 \pi f_{m} n\right)+\sin \left(2 \pi f_{c} n\right) \sin \left(2 \pi f_{m} n\right)
\end{aligned}
$$

chegando na relação

$$
\cos \left(2 \pi f_{c} n\right) \cos \left(2 \pi f_{m} n\right)=\frac{1}{2} \cos \left(2 \pi f_{c} n+2 \pi f_{m} n\right)+\frac{1}{2} \cos \left(2 \pi f_{c} n-2 \pi f_{m} n\right) .
$$

Percebemos então que embora a RM atue na amplitude da portadora, ela é utilizada para alterações nas frequências do sinal [DJ97].

Se os sinais de entrada não forem senoidais, para cada parcial de cada sinal um par de componentes no sinal de saída será produzido. Se a portadora e a moduladora possuem respectivamente $p$ e $q$ parciais, até $2 p q$ parciais podem aparecer na saída. Para evitar aliasing a soma das frequências da parcial mais alta de cada sinal deve ser menor que a frequência de Nyquist [DJ97]. O Código 2.1 [ rm.wav] apresenta a implementação da modulação em anel utilizando Csound.

A amplitude de cada um desses parciais produzidos equivale à metade do produto entre as amplitudes de $x_{c}$ e $x_{m}$. Além disso, como pode-se notar na equação 2.1, se não houver modulação $\left(x_{m}(n)=0, \forall n\right)$ o sinal de saída é nulo. Outra maneira para prever o espectro resultante parte do teorema da convolução, que diz que a multiplicação de dois sinais no domínio do tempo é equivalente 
à convolução de seus espectros [Moo90].

É importante notar que na saída da RM não estão presentes parciais nem com as frequências da portadora nem da moduladora, mas apenas $f_{m} \pm f_{c}$, então o sinal de saída pode ser bem diferente dos sinais de entrada (e por isso a RM é também muito utilizada como efeito de áudio [DJ97]). No Código 2.1, teremos parciais em $440-100=340 \mathrm{~Hz}$ e em $440+100=540 \mathrm{~Hz}$.

Código 2.1: Modulação em amplitude com sinais senoidais.

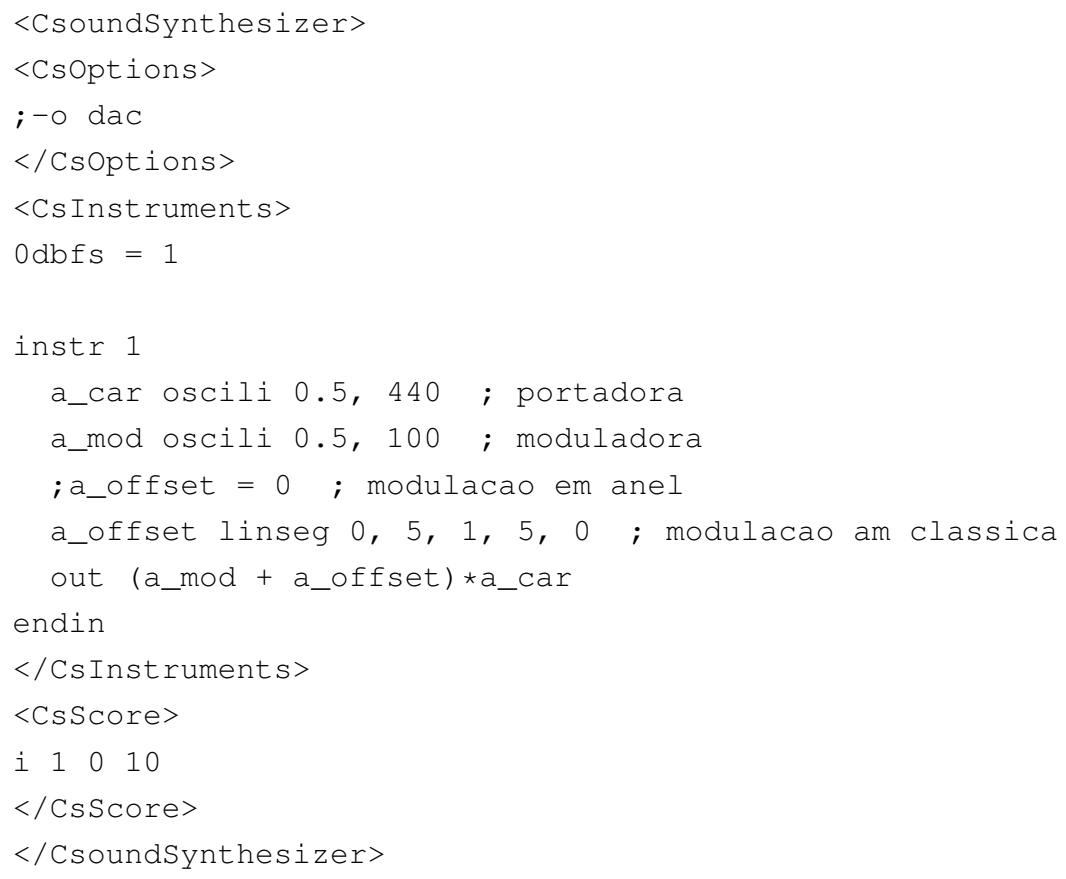

\section{Modulação em amplitude clássica}

A técnica de modulação em amplitude (AM) caracteriza-se quando o sinal modulador é somado a um offset antes de ser multiplicado à amplitude do sinal portador. Sendo $x_{c}$ a portadora e $x_{m}$ um sinal modulador, a saída da modulação em amplitude é dada por:

$$
y_{A M}(n)=\left(d x_{m}(n)+\alpha\right) x_{c}(n), \quad \alpha \neq 0,
$$

sendo $d$ a profundidade de modulação e $\alpha$ um offset. Podemos perceber na equação 2.2 que, diferentemente da técnica de RM, quando não há modulação o sinal resultante não é nulo, pois contém a portadora com a alteração de escala $\alpha$. Abrindo a equação $2.2 \mathrm{em}$

$$
y_{A M}(n)=d x_{m}(n) x_{c}(n)+\alpha x_{c}(n), \quad \alpha \neq 0,
$$

podemos perceber que o sinal resultante dessa modulação será equivalente a uma modulação em anel entre $x_{m}(n)$ e $x_{c}(n)$ somado com $\alpha x_{c}(n)$. Conclui-se assim que no caso de $x_{m}(n)$ e $x_{c}(n)$ senoidais o espectro resultante será formado por 3 componentes: $f_{c}, f_{c}+f_{m}$ e $f_{c}-f_{m}$. No caso de $x_{m}(n)$ e $x_{c}(n)$ com mais de uma componente, para cada componente de cada uma as 3 parciais mencionadas serão produzidas. Removendo a vírgula no começo da linha 12 no Código 2.1 [ $\boldsymbol{\sim}$ am . wav] teremos a inclusão de um valor não nulo como offset, caracterizando então a implementação da AM clássica. Rodando o código podemos conferir o efeito causado por uma variação temporal do valor do offset. 


\subsubsection{Variações da AM}

\section{FBAM - Feedback Amplitude Modulation (AM com retroalimentação)}

Já vimos que em seu catálogo [Ris69] Risset apresentou muitas novidades em relação aos processos de síntese de áudio, inclusive a primeira aparição da técnica de síntese por modulação de amplitude com retroalimentação. Ele atribui a autoria da técnica a Layzer, que publicou em 1971 um artigo [Lay71] apresentando a possibilidade de aproveitar sinais já computados para modular algum parâmetro do sistema. A Figura 2.2 mostra o diagrama de blocos de um dos instrumentos utilizados por Risset no exemplo \#510 do catálogo. Note que a saída do processo é realimentada após passar por um somador - para a entrada esquerda do oscilador F1, que controla sua amplitude.

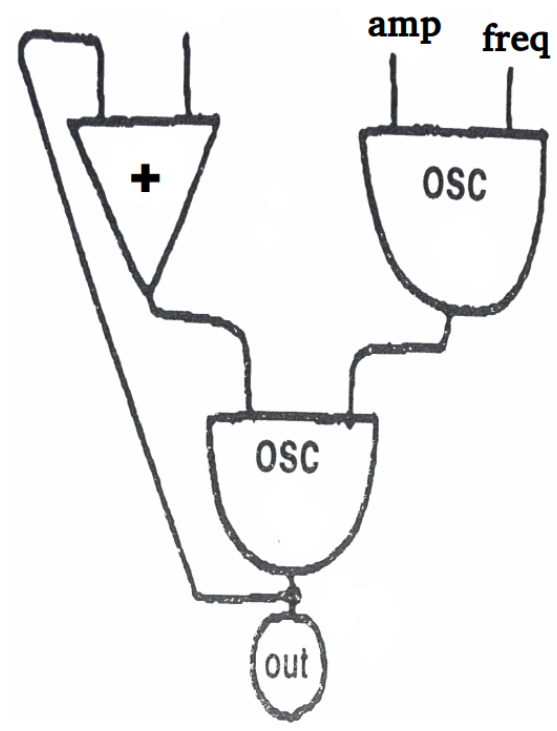

Figura 2.2: Descrição do instrumento FBAM utilizado por Risset. Fonte: [Ris69] (adaptada).

Valsamakis e Miranda [VM05] fizeram experimentos com a técnica de FBAM cruzada dupla, ou seja, utilizando dois osciladores, com a saída de um sendo realimentada para a entrada de amplitude do outro. Os autores comentam sobre processos composicionais e propõem conjuntos de parâmetros para a obtenção de sons musicalmente interessantes, mas sem apresentar uma análise matemática dos sinais de saída dessa técnica.

No entanto, a partir de 2009 aparece uma série de trabalhos sobre análise, variações e aplicações da FBAM [LTKV09] [KLVT11] [LKTV11]. A ideia básica da técnica é modular a amplitude de um oscilador a partir de sua saída, de acordo com a equação

$$
y(n)=\cos \left(\omega_{0} n\right)[1+y(n-1)]
$$

com $\omega_{0}=2 \pi f_{0}$ e a condição inicial $y(n)=0$ para $n \leq 0$.

Uma primeira análise [KLVT11] pode ser feita a partir da expansão da equação 2.4,

$$
\begin{gathered}
y(n)=\cos \left(\omega_{0} n\right)+\cos \left(\omega_{0} n\right) \cos \left(\omega_{0}[n-1]\right)+\cos \left(\omega_{0} n\right) \cos \left(\omega_{0}[n-1]\right) \cos \left(\omega_{0}[n-2]\right)+\ldots \\
y(n)=\sum_{k=0}^{\infty} \prod_{m=0}^{k} \cos \left(\omega_{0}[n-m]\right),
\end{gathered}
$$

mostrando que o sinal resultante é composto por vários harmônicos da fundamental $f_{0}$. 
A partir da introdução de um novo parâmetro $\beta$, é possível controlar a quantidade de retroalimentação [LTKV09], de acordo com a equação

$$
y(n)=\cos \left(\omega_{0} n\right)[1+\beta y(n-1)]
$$

e nesse caso a equação 2.5 passa a ser

$$
y(n)=\sum_{k=0}^{\infty} \beta^{k} \prod_{m=0}^{k} \cos \left(\omega_{0}[n-m]\right) .
$$

mostrando que valores baixos de $\beta$ resultam em poucos componentes produzidos.

Uma análise mais profunda [LTKV09] [KLVT11] é feita a partir da interpretação do sistema pela teoria de filtros periodicamente variantes (PLTV). Para isso reescrevemos 2.4 como

$$
y(n)=x(n)+a(n) y(n-1)
$$

com

$$
x(n)=a(n)=\cos \left(\omega_{0} n\right),
$$

ou seja, temos um filtro IIR de um polo com coeficiente modulado.

Estudos [Pek08] [TLPV09] sobre a síntese de áudio por modulação de coeficientes de filtros passa-tudo mostraram que o surgimento de novas componentes ao filtrar uma senoide de entrada são resultado da distorção de fase causada pela variação dos coeficientes. No caso da FBAM, como o filtro não é passa-tudo, além da distorção de fase causada pela resposta em fase do filtro, a resposta em frequência ainda altera o peso das componentes criadas.

O fator de retroalimentação $\beta$ pode ser interpretado como o índice de modulação convencional da FM, e a evolução do espectro de acordo com seu valor pode ser observada na Figura 2.3.

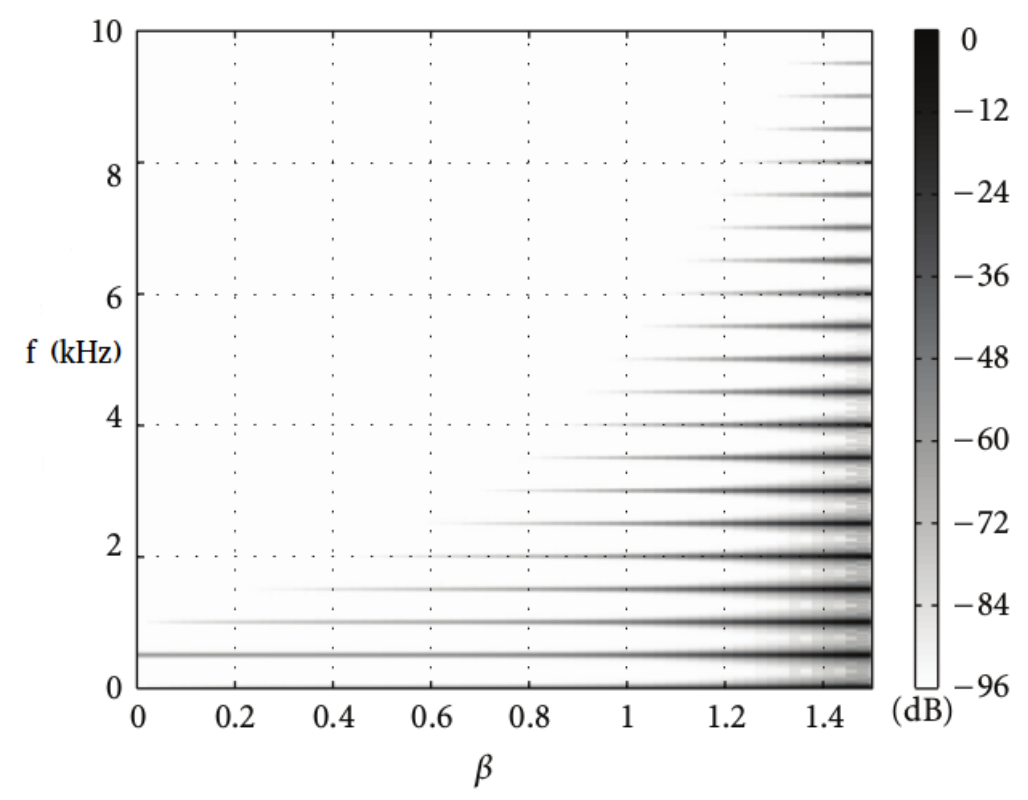

Figura 2.3: Evolução do espectro da FBAM em função do fator de retroalimentação $\beta$. Fonte: [KLVT11] (adaptada). 
Quanto à estabilidade da FBAM foi mostrado que a condição

$$
\left|\beta \prod_{m=1}^{N} \cos \left(\omega_{0} m\right)\right|<1
$$

garante a convergência da resposta ao impulso [Che03], e a expressão

$$
\beta_{\max } \approx 1.9986-0.00003532\left(f_{0}-27.5\right)
$$

foi proposta [KLVT11].

No entanto, aumentando o valor de $\beta$, problemas com aliasing aparecem antes de instabilidade. Na Figura 2.4 [KLVT11] temos plotados valores de $\beta$ dados pela expressão 2.11, juntamente com limites para valores toleráveis de aliasing para frequências de amostragem de 44100 e $88200 \mathrm{~Hz}$, comumente utilizadas em aplicações de processamento de áudio. Podemos notar que, para estas taxas de amostragem (ou mais altas), escolher $\beta$ que evite a ocorrência de aliasing automaticamente implica em estabilidade garantida.

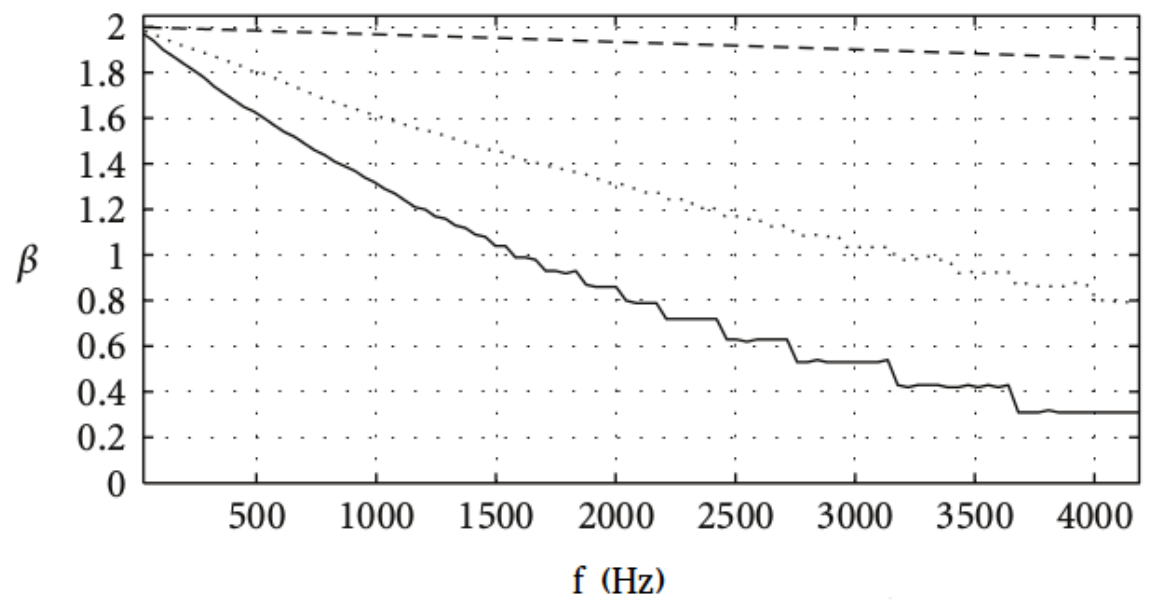

Figura 2.4: Limites de $\beta$ para garantir estabilidade (curva tracejada) e para evitar aliasing (curva sólida referente à $f_{S}=44100 \mathrm{~Hz}$ e curva pontilhada referente à $f_{S}=88200 \mathrm{~Hz}$ ). Fonte: [KLVT11] (adaptada).

Explorações na FBAM de segunda ordem [LKTV11] mostraram que o sinal gerado é um pulso mais estreito que o caso de primeira ordem, ou seja, o espectro gerado possui mais harmônicos. O algoritmo consiste em utilizar dois laços de retroalimentação com atrasos de 1 amostra e 2 amostras, controlando as quantidades com $\beta_{1}$ e $\beta_{2}$, de acordo com a equação

$$
y(n)=\cos \left(\omega_{0} n\right)\left[1+\beta_{1} y(n-1)+\beta_{2} y(n-2)\right] .
$$

Também foram exploradas [LKTV11] [KLVT11] variações dos modelos básicos de primeira e segunda ordem, como por exemplo variar o tamanho do atraso na retroalimentação, inserir um moldador dentro do laço de retroalimentação, aplicar modulação em anel ou moldagem na saída do sistema, entre outras técnicas. Uma implementação da FBAM de primeira ordem $\operatorname{com} \beta$ variando dinamicamente é apresentada no Código 2.2 [ fbam.wav]. Note o opcode definido pelo usuário (UDO) implementado para o filtro de primeira ordem com coeficientes modulados, e o UDO da FBAM propriamente dito; a variação de $\beta$ é realizada a partir do envelope linseg na linha 30. 
Código 2.2: Modulação de amplitude com retroalimentação.

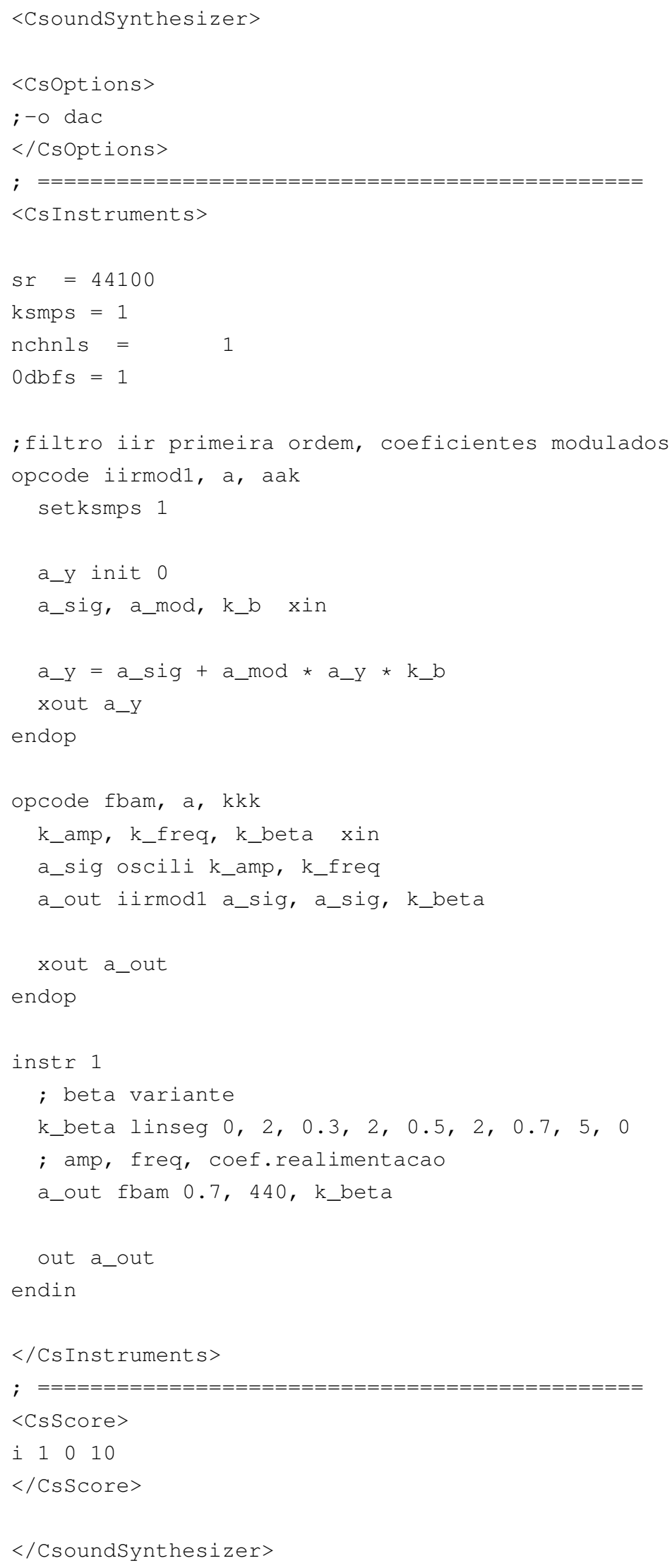




\subsubsection{FM - Modulação em frequência}

Modulação em frequência (FM) é a alteração ou distorção da frequência de um oscilador de acordo com a amplitude de um sinal modulador [DJ97]. A técnica de vibrato, frequentemente utilizada em instrumentos de corda, é um exemplo de FM: vibrar o dedo que pressiona a corda altera a frequência produzida pelo instrumento em uma pequena quantidade. A frequência dessa alteração é baixa, tipicamente abaixo de 5 vezes por segundo.

No entanto, com altos valores para a frequência e/ou a profundidade da modulação uma vasta gama de timbres pode ser criada [DJ97]. Devido a essa flexibilidade e ao seu baixo custo computacional, o surgimento da síntese por FM possibilitou o sucesso comercial de sintetizadores digitais (por exemplo o teclado Yamaha-DX7, mostrado na Figura 1.2 e baseado em síntese FM, era até 1990 o instrumento eletrônico mais vendido da história [Moo90]).

A teoria de FM já era dominada e utilizada em comunicações de rádio, mas John Chowning foi o responsável por trazer a técnica para o domínio da síntese de sinais de áudio em seu artigo de 1973, The synthesis of complex audio spectra by means of frequency modulation [Cho73]. Antes disso ele havia realizado demonstrações da técnica quando visitou o Bell Labs, deixando lá gravações e receitas para o uso da FM. Risset comenta que adaptou as receitas e utilizou os sons na sua peça Mutations, de 1969, provavelmente a primeira peça com FM [Ris96]. Chowning também utilizou a FM em sua composição Turenas, cujo nome é uma homenagem a Alan Turing.

A implementação básica da FM se dá a partir de dois osciladores. A senoide moduladora possui frequência $f_{m}$ e amplitude $d$ (de modulation depth). O sinal de saída da moduladora é adicionado ao valor da frequência da portadora $\left(f_{c}\right)$. Temos assim a equação da FM [Cho73] [Moo90]:

$$
y_{F M}(n)=\sin \left(2 \pi f_{c} n+d \sin \left(2 \pi f_{m} n\right)\right) .
$$

Esta implementação da técnica de FM simples pode ser realizada em Csound com o Código 2.3

[ fm-vib.wav]. Experimente também alternando as linhas 9 e 10 [ fm-deep.wav].

Código 2.3: Modulação em frequência.

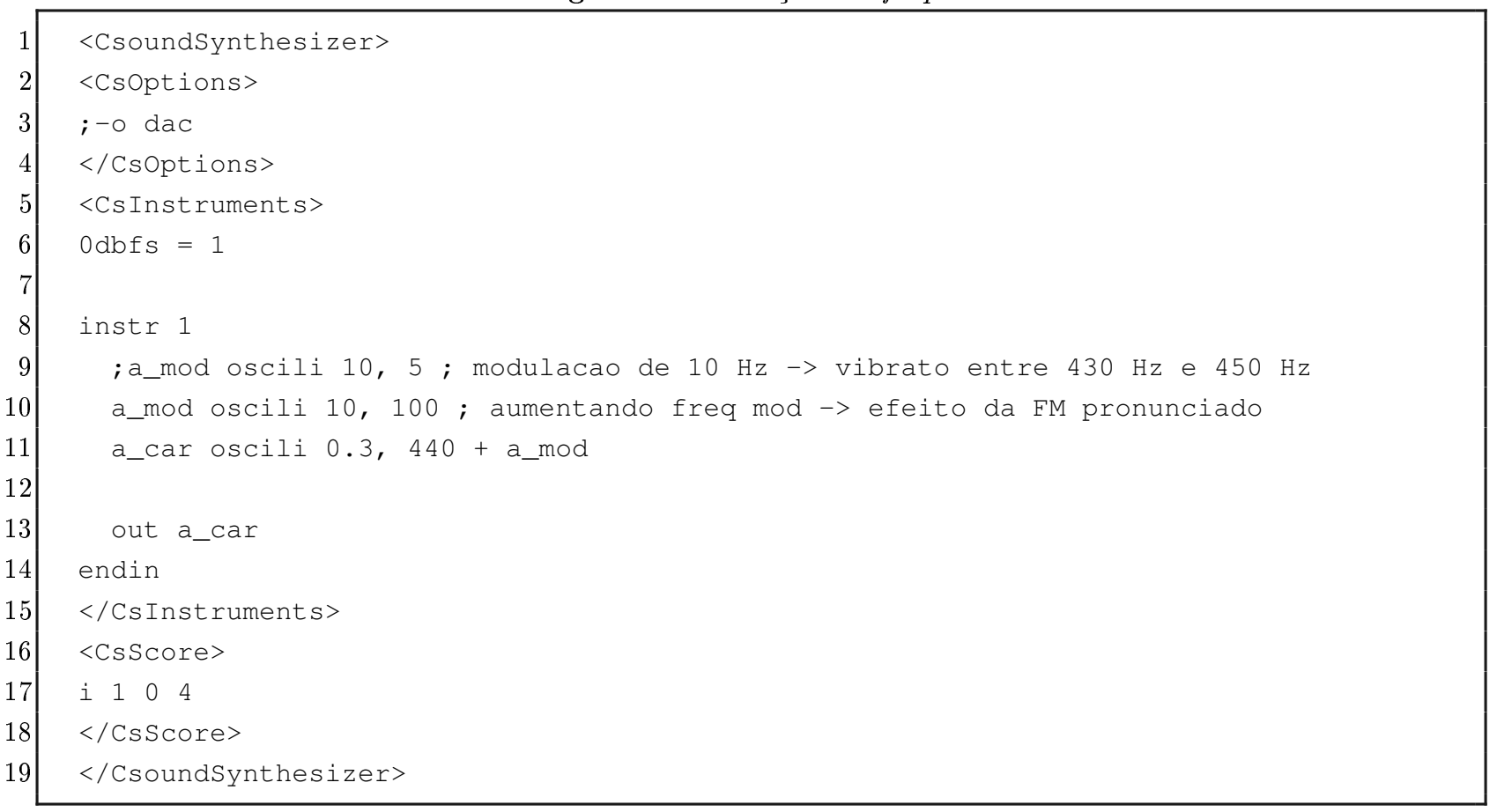


Para entender como é o espectro do sinal gerado por uma modulação em frequência podemos expandir a Equação 2.13 de acordo com [Cho73, Moo90]

$$
\begin{aligned}
y_{F M}(n)= & \sin \left(2 \pi f_{c} n+d \sin \left(2 \pi f_{m} n\right)\right) \\
=J_{0} & (I) \sin \left(2 \pi f_{c} n\right) \\
& +\sum_{k=1}^{\infty} J_{k}(I)\left[\sin \left(2 \pi\left(f_{c}+k f_{m}\right) n\right)+(-1)^{k} \sin \left(2 \pi\left(f_{c}-k f_{m}\right) n\right)\right] \\
= & J_{0}(I) \sin \left(2 \pi f_{c} n\right) \\
& +J_{1}(I)\left[\sin \left(2 \pi\left(f_{c}+f_{m}\right) n\right)-\sin \left(2 \pi\left(f_{c}-f_{m}\right) n\right)\right] \\
& +J_{2}(I)\left[\sin \left(2 \pi\left(f_{c}+2 f_{m}\right) n\right)-\sin \left(2 \pi\left(f_{c}-2 f_{m}\right) n\right)\right] \\
& +J_{3}(I)\left[\sin \left(2 \pi\left(f_{c}+3 f_{m}\right) n\right)-\sin \left(2 \pi\left(f_{c}-3 f_{m}\right) n\right)\right] \\
& +J_{4}(I)\left[\sin \left(2 \pi\left(f_{c}+4 f_{m}\right) n\right)-\sin \left(2 \pi\left(f_{c}-4 f_{m}\right) n\right)\right] \\
& +\ldots,
\end{aligned}
$$

sendo $J_{k}(I)$ a função de Bessel do primeiro tipo de ordem $k$, avaliada no valor do índice de modulação dado por

$$
I=\frac{d}{f_{m}}
$$

Podemos observar pela equação 2.14 que um sinal produzido por FM simples contém uma componente localizada na frequência da portadora $\left(f_{c}\right)$ com a amplitude dada por $J_{0}(I)$, além de um número infinito de pares de componentes localizadas nas frequências

$$
f_{c} \pm f_{m}, \quad f_{c} \pm 2 f_{m}, \quad f_{c} \pm 3 f_{m}, \quad f_{c} \pm 4 f_{m}, \quad \ldots
$$

sendo a amplitude do k-ésimo par dada por $J_{k}(I)$ [Moo90].

As funções de Bessel do primeiro tipo são soluções para a equação diferencial de Bessel e são dadas por [Moo90]

$$
J_{k}(x)=\sum_{p=0}^{\infty} \frac{(-1)^{p}\left(\frac{x}{2}\right)^{k+2 p}}{p !(k+p) !}, \quad k>0 .
$$

Moore ainda observa que as funções de Bessel podem ser calculadas iterativamente a partir da relação

$$
J_{k+1}(x)=\frac{2 k}{x} J_{k}(x)-J_{k-1}(x) .
$$

Logo, partindo de

$$
J_{0}(x)=1-\frac{x^{2}}{2^{2}}+\frac{x^{4}}{2^{2} 4^{2}}-\frac{x^{6}}{2^{2} 4^{2} 6^{2}}+\ldots
$$

$\mathrm{e}$

$$
J_{1}(x)=\frac{x}{2}-\frac{x^{3}}{2^{2} 4}+\frac{x^{5}}{2^{2} 4^{2} 6}-\frac{x^{7}}{2^{2} 4^{2} 6^{2} 8}+\ldots
$$

podemos ter acesso aos valores para ordens mais altas das funções de Bessel, bastando apenas utilizar a recursão. 
A Figura 2.5 mostra as funções de Bessel do primeiro tipo. Analisando as curvas podemos aprender fatos importantes [Moo90] acerca da técnica de FM:

- As funções lembram senoides amortecidas, indicando que a medida que $I$ aumenta as amplitudes das parciais vão diminuindo (mais parciais vão aparecendo e a energia do sinal é dividida entre elas);

- quando $d=0$ (portanto sem modulação) apenas $J_{0}(0) \neq 0$, ou seja, a única componente presente é a da portadora;

- funções de Bessel de ordem mais alta demoram mais para sair do zero, mostrando que as parciais mais altas aparecem apenas quando $I$ é grande;

- quando a função de Bessel de determinada ordem atinge seu pico, seu valor é maior do que o de todas as outras ordens;

- conforme I aumenta algumas parciais desaparecem (quando suas curvas de Bessel cruzam o zero) e depois voltam a aparecer;

- para sistemas com $I$ variante, as amplitudes das parciais passeiam por suas respectivas funções de Bessel, e as oscilações dessas curvas dão ao som uma qualidade muito característica. O Código 2.4 [ fm-var.wav] mostra uma implementação da FM com índice de modulação variante (linhas 12 e 13).

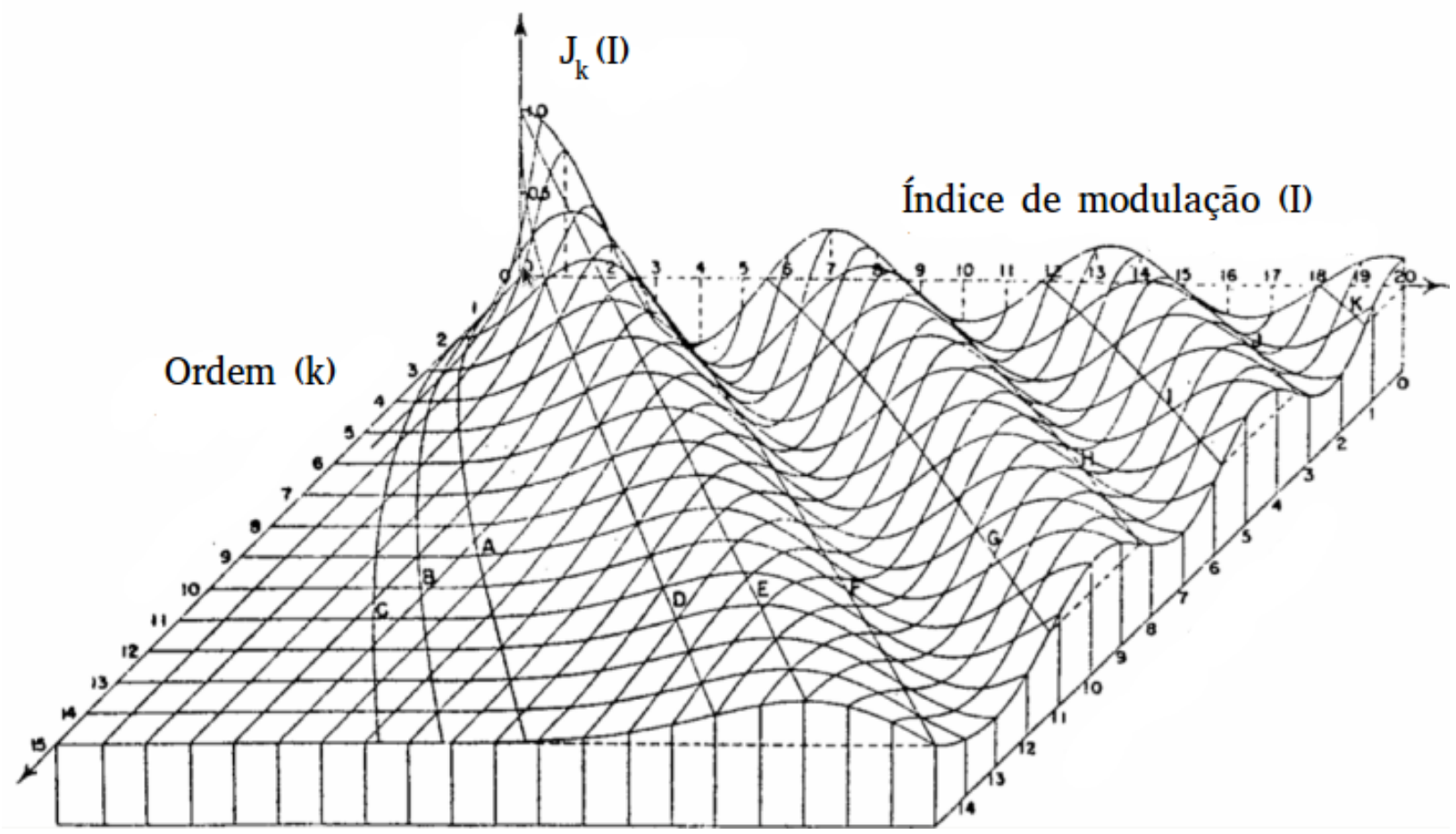

Figura 2.5: Funções de Bessel do primeiro tipo. Fonte: [Cho73] (adaptada). 
Código 2.4: FM com indice de modulação variando.

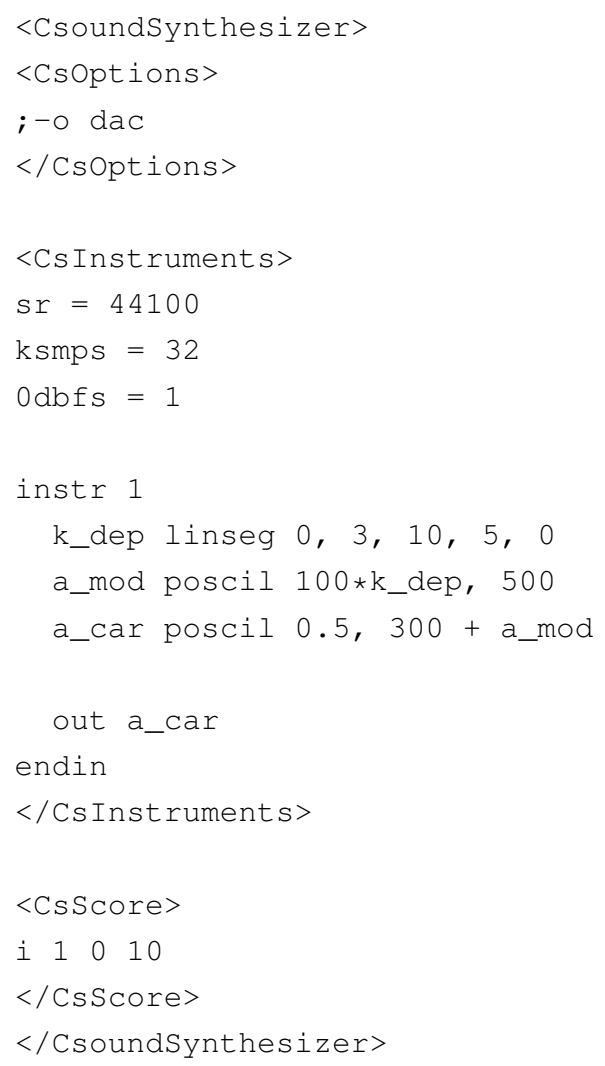

Sabendo que as parciais de um sinal modulado em frequência aparecem em $f_{c} \pm k f_{m}, k \geq 0$, podemos concluir que o espaçamento das componentes é proporcional à frequência de modulação. Além disso, se $f_{c}=f_{m}$, os componentes aparecem em múltiplos inteiros de $f_{c}$, caracterizando uma série harmônica. Nesse cenário temos:

$$
\begin{gathered}
f_{c}-f_{m}=f_{c}-f_{c}=0 \\
f_{c}+f_{m}=f_{c}+f_{c}=2 f_{c} \\
f_{c}-2 f_{m}=f_{c}-2 f_{c}=-f_{c} \\
f_{c}+2 f_{m}=f_{c}+2 f_{c}=3 f_{c}
\end{gathered}
$$

Como neste caso todas as parciais estão em fase de seno, as componentes em frequências negativas podem ser rebatidas para frequências positivas com troca de fase [DJ97], correspondendo a uma troca no sinal da amplitude da parcial. No caso de parciais se sobrepondo na mesma frequência, a resultante é o valor da soma das amplitudes.

A definição do índice de harmonicidade

$$
H=\frac{f_{m}}{f_{c}}
$$

simplifica a compreensão do efeito dos parâmetros da FM. Para $H=\frac{1}{N}$, sendo N inteiro maior ou igual a 1, o espectro resultante é harmônico e a portadora está localizada no harmônico $N$. Similarmente, quando $H=N$, sendo N inteiro maior ou igual a 1, o espectro resultante é harmônico, 
mas sem algumas componentes: a fundamental é a portadora, e apenas os harmônicos $k N+1$ (para $k=0,1,2, \ldots)$ estão presentes. De uma maneira geral, se $H$ é racional $\left(H=\frac{N_{1}}{N_{2}}, \operatorname{com} N_{1}\right.$ e $N_{2}$ inteiros) o espectro resultante é harmônico, caso contrário (por exemplo quando $H=\sqrt{2}$ ou $H=\pi$ ) a relação entre as frequências é irracional e o espectro resultante não possui uma fundamental e é inarmônico [Moo90, DJ97].

Fixadas as frequências $f_{c}$ e $f_{m}$ de interesse do compositor, o índice de modulação $I$ pode ser independentemente variado a partir da amplitude $d$ da moduladora. O índice de modulação controla diretamente a largura da banda do sinal resultante, ou seja, quanto maior seu valor mais componentes aparecem no sinal produzido [Col10]. Sendo assim, variando $I$ em função do tempo facilmente podemos obter um espectro dinâmico, porém, como já observado a evolução das amplitudes de cada parcial obedecem às funções de Bessel. Sendo assim, conforme $I$ aumenta as amplitudes dos harmônicos oscilam, passando inclusive pelo valor 0 e desaparecendo em alguns momentos [DJ97]. Dodge e Jerse observam ainda que, diferentemente da síntese aditiva, a síntese por FM possibilita apenas alguns tipos de evolução espectral, o que explica o timbre característico da FM.

\section{Extensões da FM}

\section{FM com múltiplas portadoras}

Quando temos um mesmo sinal modulando duas portadoras distintas temos como espectro do sinal resultante a soma dos espectros produzidos pela modulação de cada portadora separadamente [Moo90]. Uma aplicação interessante para isso é a síntese de um espectro com formantes, uma característica marcante em muitos sons naturais [DJ97]. A intensidade e a largura de banda de cada formante podem ser controlados independentemente, a primeira pela amplitude de sua portadora, e a segunda pelo índice de modulação. Qualquer número de portadoras (e assim formantes) pode ser utilizado. Dexter Morril utilizou algoritmos baseados em FM com duas portadoras para simular sons de trompete [Mor77].

\section{FM com múltiplas moduladoras}

Quando a moduladora possui mais de uma componente a descrição do espectro é mais complexa, mas consiste em encontrar o efeito que cada uma das parciais da moduladora gera. Bill Schottstaedt utilizou esta extensão da FM para simular tons de piano e cordas em geral [Sch77].

Quando duas moduladoras são utilizadas o processo pode ser descrito pela equação [Moo90]

$$
y(t)=A \sin \left(\omega_{c} t+I_{1} \sin \omega_{m 1} t+I_{2} \sin \omega_{m 2} t\right),
$$

sendo $I_{1}$ e $I_{2}$ os índices de modulação para cada portadora. O espectro do sinal resultante será composto pelas frequências $f_{c} \pm i f_{m 1} \pm k f_{m 2}$, com amplitudes dadas por [Bru77] $J_{i}\left(I_{1}\right) J_{k}\left(I_{2}\right)$, sendo $i$ e $k$ inteiros e $f_{m 1}$ e $f_{m 2}$ as frequências das moduladoras, revelando a descrição do sinal gerado

$$
y(t)=\sum_{i=-\infty}^{\infty} \sum_{k=-\infty}^{\infty} J_{i}\left(I_{1}\right) J_{k}\left(I_{2}\right) \sin \left(\omega_{c} t+i \omega_{m 1} t+k \omega_{m 2} t\right) .
$$

Ao invés de apenas duas moduladoras, qualquer número de moduladoras pode ser utilizado, e o sinal resultante se comporta de maneira análoga. 


\section{FMs em série}

Outra possibilidade de estender a FM simples é modular a frequência de uma portadora com a saída de um sinal sintetizado por modulação em frequência. A equação deste processo é dada por [Moo90]

$$
y(t)=A \sin \left[\omega_{c} t+I_{1} \sin \left(\omega_{m 1} t+I_{2} \sin \omega_{m 2} t\right)\right],
$$

em que $I_{2}$ determina a largura de banda da moduladora e $I_{1}$ determina a largura de banda do sinal de saída. As componentes do sinal resultante estarão nas frequências

$$
f_{c} \pm i\left(f_{m 1} \pm k f_{m 2}\right), \quad k, i \geq 0 .
$$

\subsubsection{Variações da FM}

\section{AFM - Asymmetric FM (FM assimétrica)}

Foi visto que as componentes produzidas com a técnica de FM se localizam simetricamente acima e abaixo da frequência da portadora, com cada par apresentando o mesmo valor de amplitude, o que pode limitar a síntese de alguns tipos de timbres. Palamin, Palamin e Ronveaux [PPR88] propuseram então um algoritmo de FM para gerar um envelope espectral assimétrico, de acordo com um índice de assimetria $r$ e o índice de modulação $I$. O sinal é descrito por:

$$
y_{A F M}(t)=\sum_{k=-\infty}^{\infty} r^{k} J_{k}(I) \sin \left[2 \pi\left(f_{c}+k f_{m}\right) t\right] .
$$

A implementação da técnica, por meio de uma fórmula fechada é dada por

$$
y_{A F M}(t)=e^{\frac{I}{2}\left(r-\frac{1}{r}\right) \cos \left(2 \pi f_{m} t\right)} \sin \left(2 \pi f_{c} t+\frac{I}{2}\left(r+\frac{1}{r}\right) \sin \left[2 \pi f_{m} t\right]\right),
$$

ou seja, temos a expressão da FM modulada em anel com uma exponencial, sendo que os trechos $\left(r-\frac{1}{r}\right)$ e $\left(r+\frac{1}{r}\right)$ são referentes à assimetria. No sinal resultante, a amplitude da componente localizada em $f_{c}+k f_{m}$ é dada por

$$
r^{k} J_{k}(I), \quad-\infty<k<\infty, \quad r \neq 0 .
$$

Quando $r=1$ a técnica reduz para a FM simples. Quando $r>1$, a ênfase é dada para as componentes mais altas, enquanto que para $0<r<1$ ocorre o contrário. Quanto maior for o valor de $k$ mais pronunciada fica a diferença de amplitude entre as componentes altas e baixas da modulação, e as componentes enfatizadas não explodem com valores altos de $k$ pois $r^{k}$ cresce mais lentamente do que $J_{k}(I)$ decresce, para qualquer valor finito de $r$ [DJ97].

Um cuidado que deve ser tomado ao sintetizar áudio com AFM é referente ao fato de que o valor de pico dos sinais produzidos com esta técnica excedem em várias vezes a amplitude dos sinais de entrada. Os autores da técnica chegam a propor uma normalização, que no entanto não funciona para todos os valores de $r$ e $I$; então Lazzarini [Laz09] sugere a divisão do sinal por

$$
e^{\frac{I}{2}\left(r-\frac{1}{r}\right)} .
$$


O Código 2.5 [ afm.wav] apresenta esta implementação da AFM em Csound.

Código 2.5: Implementação da FM assimétrica.

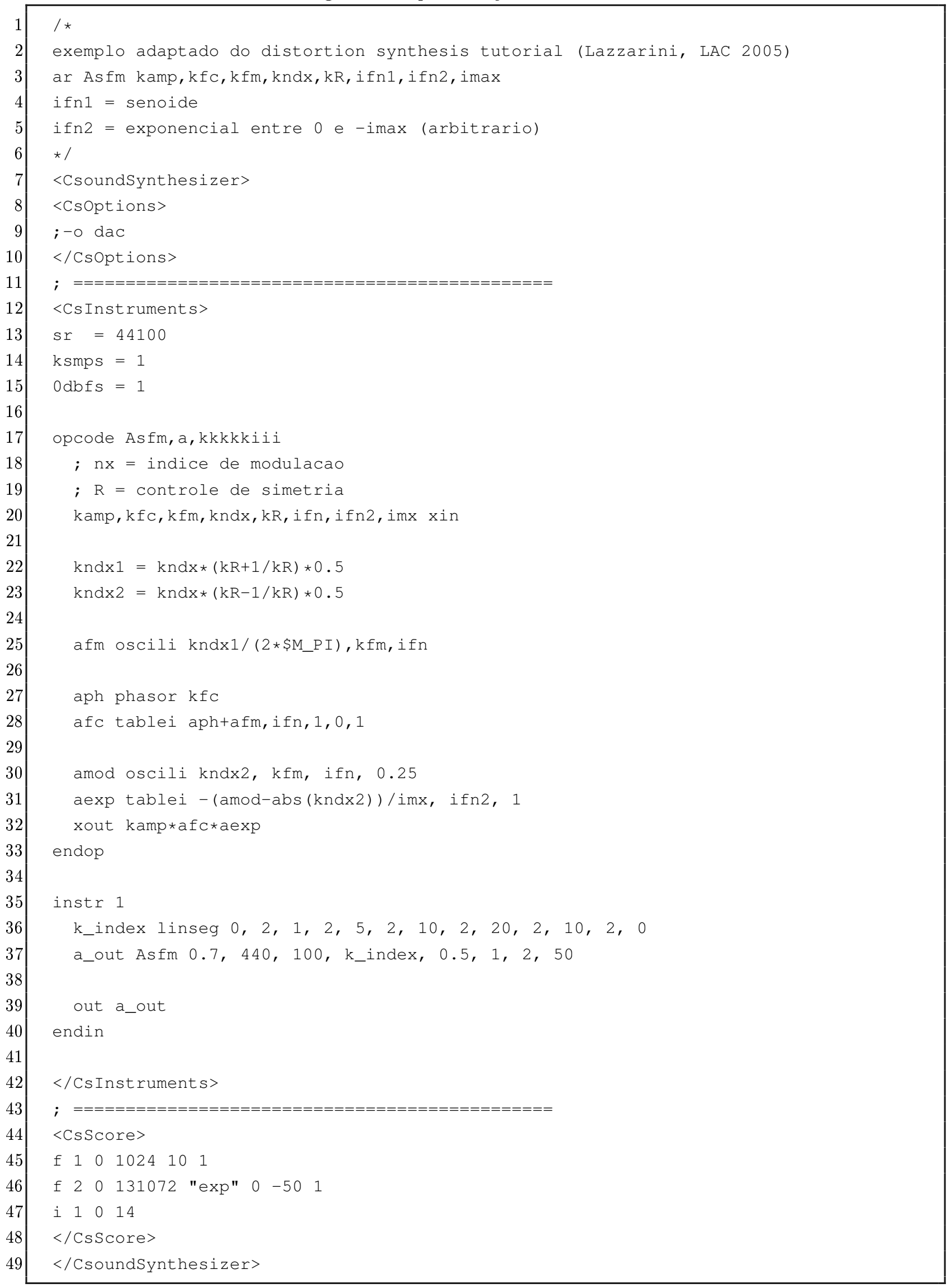




\section{SpSB - Split Side Band (Separação de bandas laterais)}

A síntese por separação de bandas laterais foi introduzida por Lazzarini, Timoney e Lisaght em 2008 [LTL08b] [LTL08a]. O intuito desta técnica é, como o próprio nome diz, possibilitar um acesso separado aos 4 grupos de componentes criadas: as componentes altas ímpares (AI), altas pares (AP), baixas ímpares (BI) e baixas pares (BP). Combinando estes 4 grupos com o mesmo peso um sinal idêntico àquele gerado pela síntese FM é produzido [LTL08b], mas escolhendo pesos diferentes ou cortando alguns grupos espectros diferentes são obtidos.

A síntese SpSB está relacionada com outras técnicas de síntese por distorção e é baseada nos princípios de modulação de amplitude com banda lateral suprimida (AM-SSB), que por sua vez é baseada na transmissão do sinal analítico referente ao sinal real que se quer transmitir.

Sendo $x(t)$ um sinal real sabemos que seu espectro é conjugado simétrico [Jus79], sendo assim redundante. $\mathrm{O}$ espectro do sinal analítico referente a $x(t)$, no entanto, não possui as componentes com frequências negativas. O sinal analítico $s(t)$ é dado por [Jus79]

$$
s(t)=x(t)+i \hat{x}(t)
$$

sendo $i=\sqrt{-1}$ e $\hat{x}$ a Transformada de Hilbert de $x(t)$ [Mar97] [War99]. Os detalhes sobre o sinal analítico, Transformada de Hilbert e possibilidades para sua implementação, assim como assuntos relacionados serão apresentados na Seção 2.2.

Representando por $H\{$.$\} a Transformada de Hilbert, os sinais produzidos utilizando SpSB são$ dados por:

$$
\begin{aligned}
& s_{A P}(t)=\cos \left(I \sin \left(\omega_{m} t\right)\right) \sin \left(\omega_{c} t\right)+H\left\{\cos \left(I \sin \left(\omega_{m} t\right)\right)\right\} \cos \left(\omega_{c} t\right)= \\
& J_{0}(I) \sin \left(\omega_{c} t\right)+2 \sum_{k=1}^{\infty} J_{2 k}(I) \sin \left(\omega_{c}+2 k \omega_{m} t\right) ;
\end{aligned}
$$

$$
\begin{aligned}
& s_{A I}(t)=\sin \left(I \sin \left(\omega_{m} t\right)\right) \sin \left(\omega_{c} t\right)+H\left\{\sin \left(I \sin \left(\omega_{m} t\right)\right)\right\} \cos \left(\omega_{c} t\right)= \\
& \quad 2 \sum_{k=1}^{\infty} J_{2 k-1}(I) \cos \left(\omega_{c}+[2 k-1] \omega_{m} t\right) ;
\end{aligned}
$$

$$
\begin{aligned}
& s_{B P}(t)=\cos \left(I \sin \left(\omega_{m} t\right)\right) \sin \left(\omega_{c} t\right)-H\left\{\cos \left(I \sin \left(\omega_{m} t\right)\right)\right\} \cos \left(\omega_{c} t\right)= \\
& J_{0}(I) \sin \left(\omega_{c} t\right)+2 \sum_{k=1}^{\infty} J_{2 k}(I) \sin \left(\omega_{c}-2 k \omega_{m} t\right) ;
\end{aligned}
$$

$$
\begin{aligned}
s_{B I}(t)=\sin \left(I \sin \left(\omega_{m} t\right)\right) \sin \left(\omega_{c} t\right)-H\left\{\sin \left(I \sin \left(\omega_{m} t\right)\right)\right\} \cos \left(\omega_{c} t\right) & = \\
& -2 \sum_{k=1}^{\infty} J_{2 k-1}(I) \cos \left(\omega_{c}-[2 k-1] \omega_{m} t\right) .
\end{aligned}
$$

Como podemos perceber, as amplitudes das parciais são dadas pelas funções de Bessel do primeiro 
tipo, assim como na síntese por FM. O atrativo nesta técnica é a possibilidade de controle independente dos grupos de parciais. O Código 2.6 [spsb.wav] a seguir mostra como implementar a SpSB e acessar apenas as parciais baixas ímpares do espectro. Neste exemplo, um interessante efeito estéreo foi obtido jogando as parciais baixas ímpares para um canal e as baixas pares para o outro canal do sinal de áudio.

Código 2.6: Uma das possibilidades com a síntese SpSB.

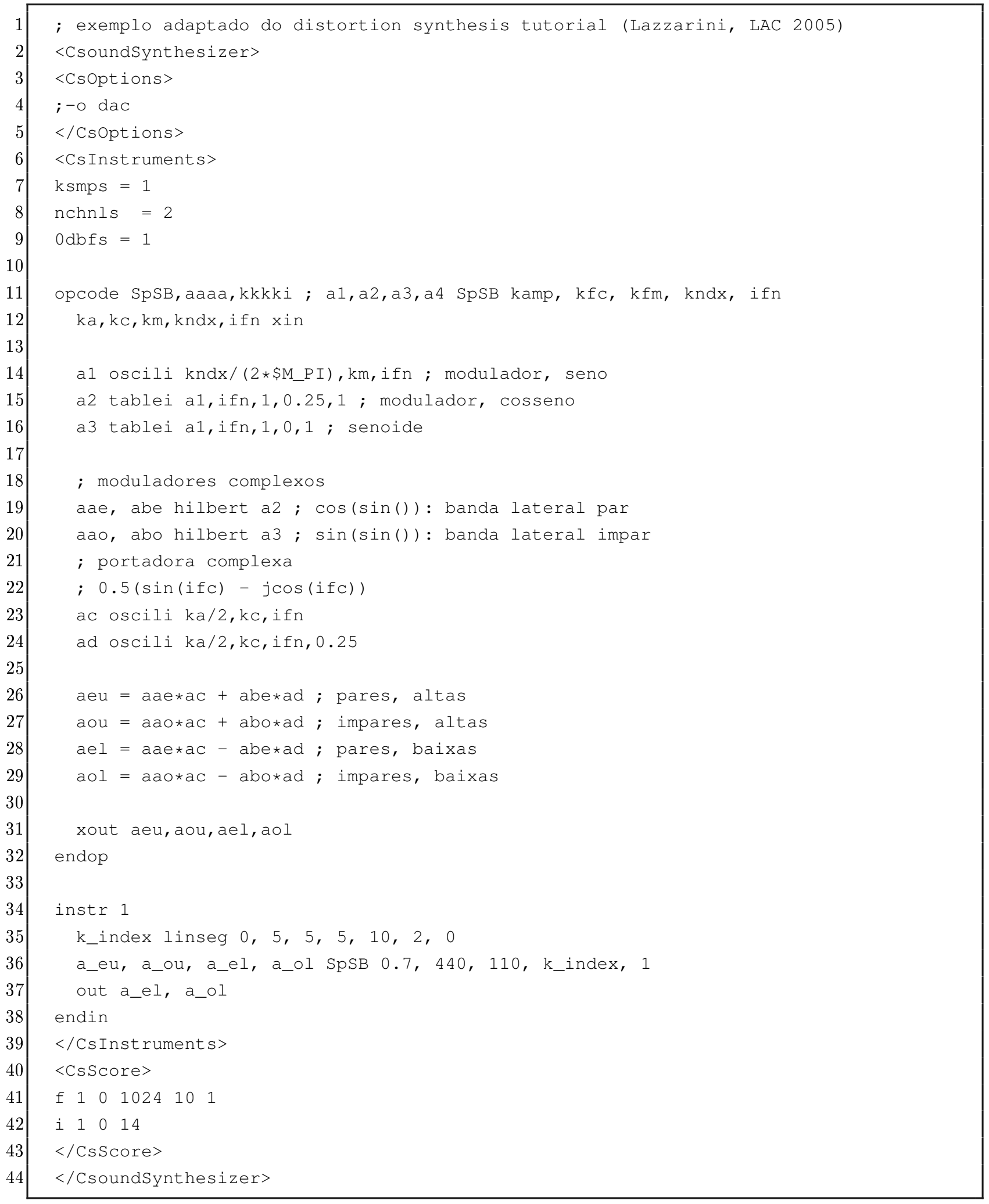




\section{FBFM - Feedback Frequency Modulation (FM com retroalimentação)}

Como já mencionado, embora a FM seja uma técnica muito eficiente e capaz de gerar uma infinidade de timbres para exploração musical, o fato de que as amplitudes das componentes obedecem a funções de Bessel pode ser uma limitação para a geração de espectros que evoluem no tempo. Tomisawa [Tom81] lembra que uma possibilidade para produzir espectros dinâmicos mais naturais seria utilizar um esquema de síntese aditiva (ele cita a patente de um instrumento denominado Computor Organ, pat. US 3809786), mas com a ressalva de que a alta quantidade de componentes e a complexidade do hardware necessário para implementação da alternativa seriam desvantagens.

A solução que ele propõe e patenteia (Tone production method for an electronic musical instrument [Tom81]) é um instrumento baseado na técnica de FM não com um oscilador extra fazendo o papel de moduladora, mas utilizando a retroalimentação da saída da própria portadora. Nesta técnica, a saída do oscilador é multiplicada por um coeficiente de retroalimentação $\beta$ e somada com a informação de fase de um gerador de fase comum; este valor é então utilizado como índice para a leitura de uma tabela ou argumento para uma função seno. A Figura 2.6 mostra o esquema do instrumento de Tomisawa.

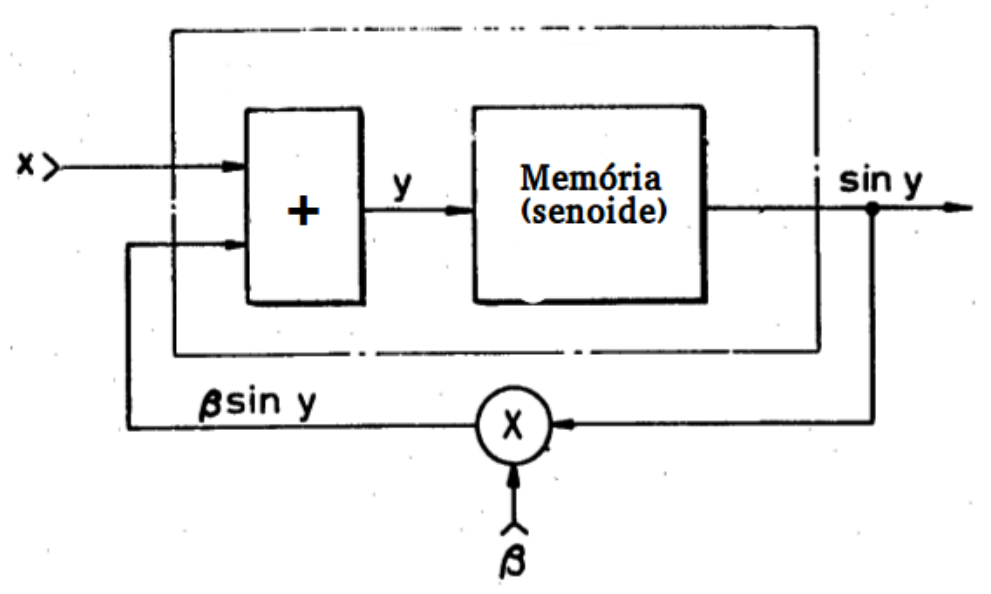

Figura 2.6: Esquema da modulação em frequência por retroalimentação. Fonte: [Tom81] (adaptada).

A equação que Tomisawa apresenta para o sistema é dada por

$$
y[n]=x[n]+\sin (y[n-1])
$$

sendo $x[n]$ um gerador de fase (rampa para leitura sequencial de uma tabela) com frequência $f_{x}$. Nesta equação, $y[n]$ representa o índice para leitura da tabela na memória (senoide), de forma que o sinal de saída seja dado por $y_{F B F M}[n]=\sin (y[n])$. Tomisawa expressa então a equação

$$
y_{F B F M}[n]=\sin (y[n])=\sum_{k=1}^{\infty} \frac{2}{k \beta} J_{k}(k \beta) \sin \left(k f_{x} n\right),
$$

revelando assim que a partir de um único oscilador o instrumento produz (infinitas) componentes da série harmônica da fundamental escolhida pelo compositor. $\beta$ controla a largura de banda do sinal, e no extremo $\beta=0$ não há retroalimentação, e o sinal produzido possui apenas a componente referente à fundamental do gerador de fase. 
Embora a equação 2.32 ainda mostre as funções de Bessel multiplicando as senoides, neste sistema o índice $k$ aparece como argumento multiplicando $\beta$ em $J_{k}(k \beta)$, além da multiplicação de cada componente por $\frac{2}{k \beta}$. Na FM convencional o argumento para as funções de Bessel de todas as componentes é o mesmo, o índice de modulação $I$. No caso da FBFM o índice de modulação $k \beta$ é proporcional à ordem da componente.

Como pode-se observar pela Figura 2.7, na região onde $0<\beta \leq 1$ a evolução espectral tende a variar de uma maneira aproximadamente monotônica. Além disso $J_{k}(k \beta)$ decai gradualmente tanto com o aumento de $n$ quanto com a diminuição de $\beta$. A multiplicação extra por $\frac{2}{k \beta}$ contribui com a tendência da amplitude diminuir com o aumento da ordem [Tom81]. Tomisawa apresenta algumas formulações e observa ainda que para valores de $\beta$ na vizinhança de 1 vale a relação

$$
\frac{2}{k \beta} J_{k}(k \beta)=\frac{2}{k} J_{k}(k) \approx \frac{1}{k}
$$

ou seja, o sinal produzido apresenta espectro semelhante ao de uma onda dente-de-serra [DJ97]. A partir do Código 2.7 é possível conferir a sonoridade da técnica. Alterar o valor de $\beta$ na linha 13 influencia a quantidade de harmônicos produzidos.

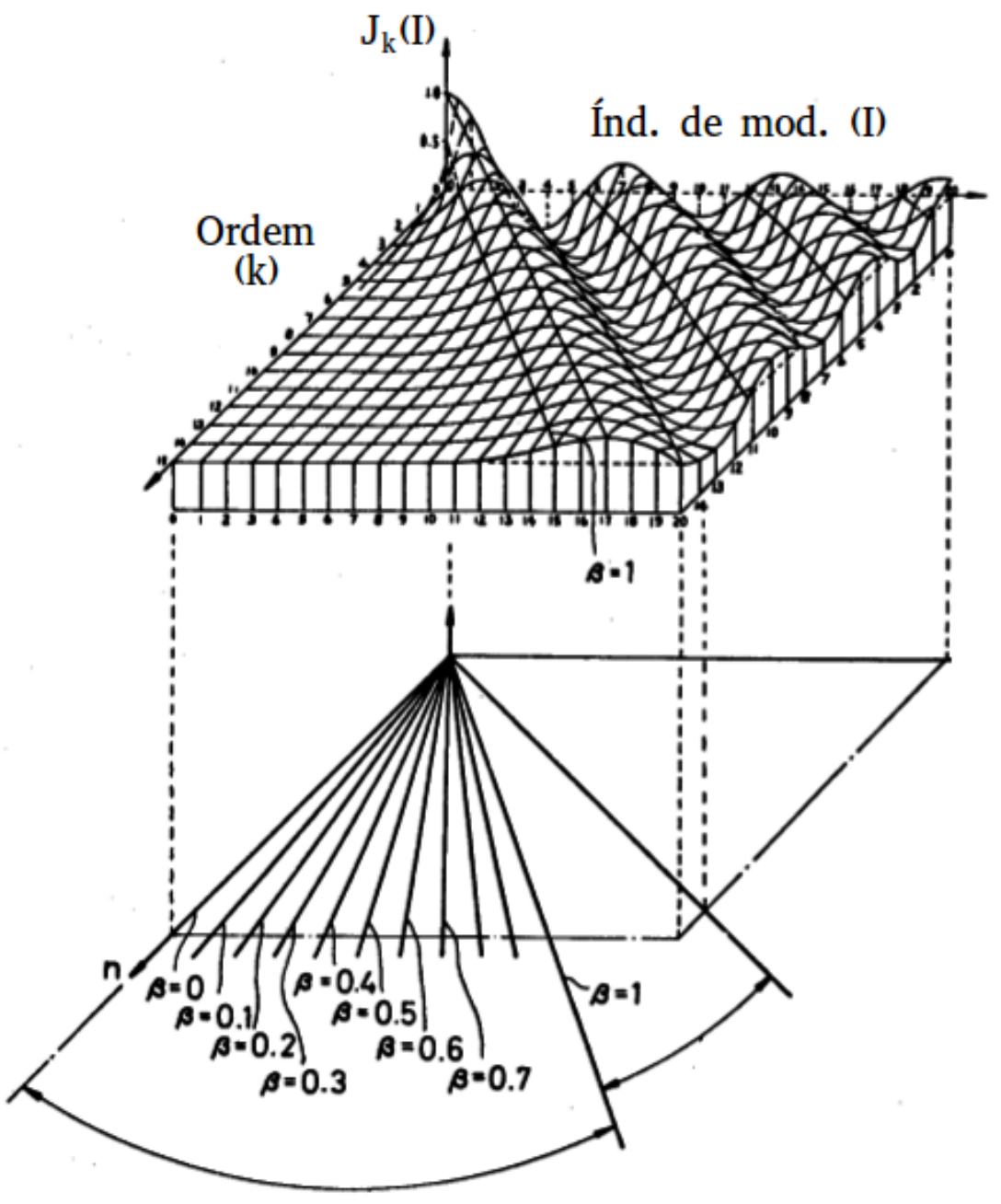

Figura 2.7: Região das funções de Bessel onde se concentra a FBFM. Fonte: [Tom81] (adaptada). 
Código 2.7: Modulação de frequência com retroalimentação.

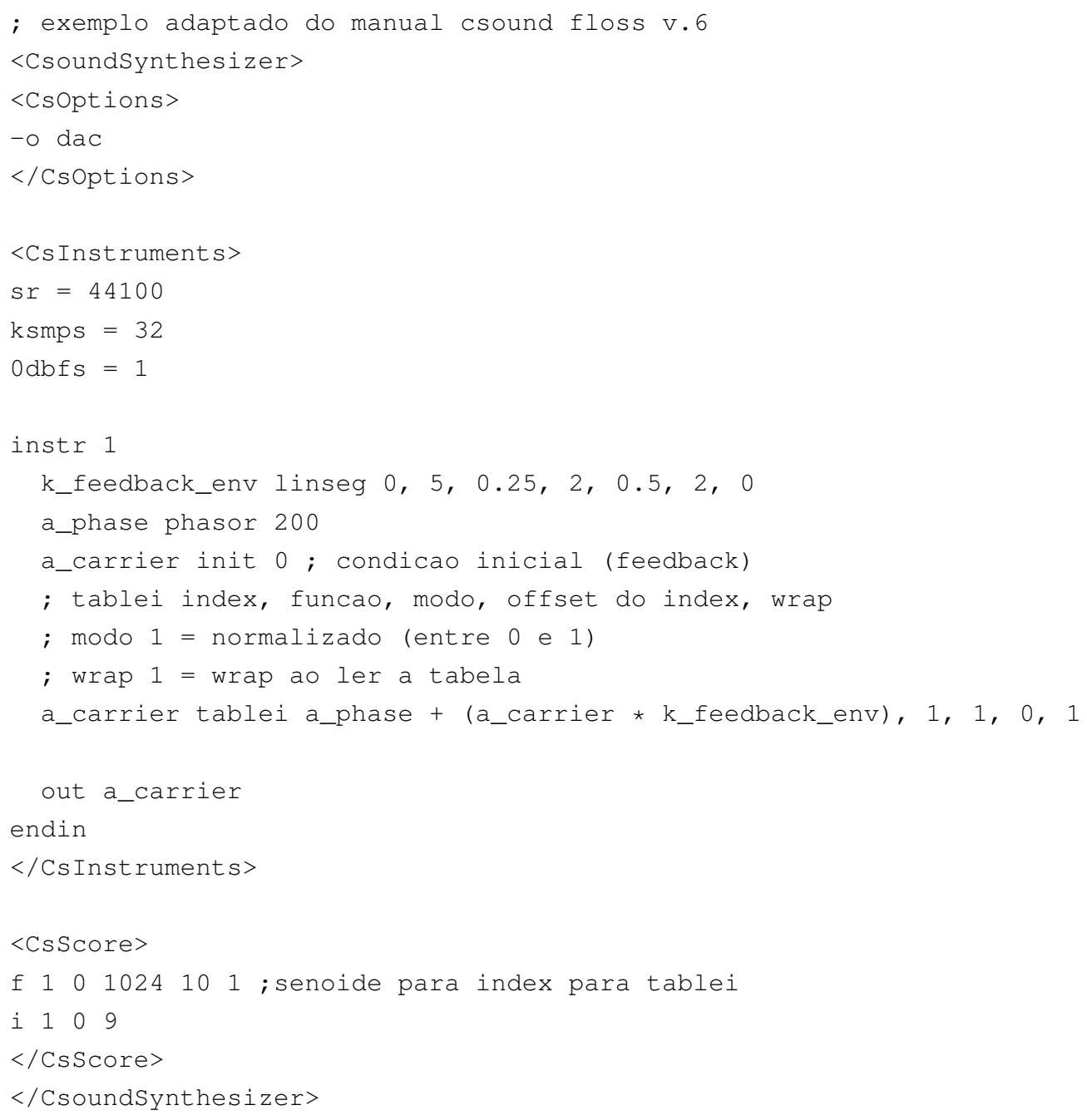

No texto da patente Tomisawa apresenta ainda algumas variações da FBFM, como utilizar dois osciladores, sendo que a saída do primeiro modula a entrada de frequência do outro oscilador. Assim é possível escolher frequências fundamentais $f_{1}$ e $f_{2}$ diferentes para cada oscilador e obter um conjunto de componentes $f_{1} \pm f_{2}$, diferentemente do caso do oscilador único em que as componentes se localizam nos múltiplos inteiros da fundamental.

Outra proposta de Tomisawa é fazer uma modulação em frequência com retroalimentação cruzada. A técnica consiste em utilizar dois osciladores, sendo que a saída de um modula a frequência do outro, como ilustrado na Figura 2.8. Valsamakis e Miranda [VM05] comentam sobre a utilização da técnica de FBFM cruzada em processos composicionais e propõem conjuntos de parâmetros para a obtenção de sons de interesse composicional, mas assim como Tomisawa não apresentam uma análise matemática dos sinais de saída dessa técnica.

\section{ModFM - Modified FM}

A aclamada técnica de síntese FM, ao mesmo tempo que permitia a geração de um grande número de parciais de maneira concisa e computacionalmente barata, atribuía às amplitudes das parciais o valor das funções de Bessel no índice de modulação sendo utilizado. Sendo assim, ao sintetizar áudio com a amplitude ou a frequência da moduladora variando dinamicamente, a amplitude das componentes geradas oscilavam bruscamente ao longo das curvas de Bessel (Figura 2.5). 


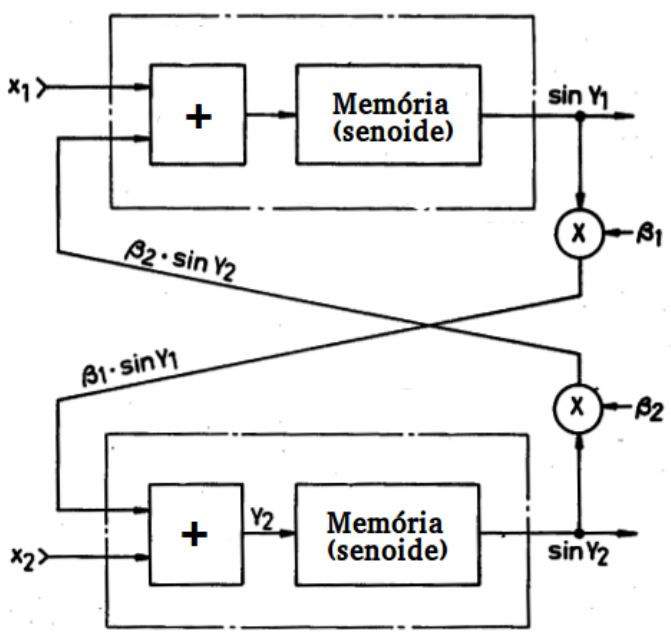

Figura 2.8: Modulação em frequência com retroalimentação cruzada. Fonte: [Tom81] (adaptada).

A característica sonora assim obtida era no início interessante, mas passou a ser questionada. Além disso estas oscilações trazem dificuldades para sintetizar sons que tentam emular instrumentos naturais. Quando a intenção é criar timbres que soem sintéticos as dificuldades podem ser menores, mas é difícil evitar o som clichê da FM [LT10b].

A síntese por FM modificada, ModFM, é uma alternativa quase tão eficiente computacionalmente quanto a FM, e que ataca o problema da oscilação na evolução espectral dos componentes criados com a FM tradicional. A técnica é construída [LT10a, LT10b] a partir da expressão da FM (equação 2.13) ligeiramente alterada

$$
y(t)=\cos \left(\omega_{c} t+z \cos \left(\omega_{m} t\right)\right)
$$

Como $e^{i x}=\cos x+i \sin x$, temos que $y(t)=\Re\left\{e^{i \omega_{c} t+i z \cos \left(\omega_{m} t\right)}\right\}$. Fazendo a mudança de variável $z=-i u$, ou seja, utilizando um índice de modulação puramente imaginário, ficamos com

$$
\begin{gathered}
y(t)=\Re\left\{e^{i \omega_{c} t+u \cos \left(\omega_{m} t\right)}\right\}=\Re\left\{e^{i \omega_{c} t} e^{u \cos \left(\omega_{m} t\right)}\right\} \\
y(t)=e^{u \cos \left(\omega_{m} t\right)} \cos \left(\omega_{c} t\right) .
\end{gathered}
$$

A expansão da equação 2.36 nos dá

$$
y(t)=Q_{0}(u) \cos \left(\omega_{c} t\right)+\sum_{k=1}^{\infty} Q_{k}(u)\left[\cos \left(\omega_{c} t-k \omega_{m} t\right)+\cos \left(\omega_{c} t+k \omega_{m} t\right)\right],
$$

sendo $Q_{k}(u)=i^{-k} J_{k}(i u)$ funções de Bessel modificadas, caso especial das funções de Bessel para argumentos puramente imaginários [LT10a, Wat44].

Lazzarini e Timoney fazem algumas observações referentes a $Q_{k}(u)$ e $J_{k}(u)$. Tendo em vista que

$$
Q_{k}(u)=\sum_{p=0}^{\infty} \frac{\left(\frac{u}{2}\right)^{k+2 p}}{p !(p+k) !}
$$




$$
J_{k}(u)=\sum_{p=0}^{\infty}(-1)^{p} \frac{\left(\frac{u}{2}\right)^{k+2 p}}{p !(p+k) !},
$$

podemos perceber que $Q_{k}(u)$ não apresentam o fator oscilante $(-1)^{p}$, e têm sempre um valor não-negativo. Além disso, diferentemente das funções de Bessel tradicionais, que apresentam a propriedade $J_{-k}(u)=(-1)^{k} J_{k}(u)$, no caso das funções modificadas temos que $Q_{-k}(u)=Q_{k}(u)$, então as parciais ímpares abaixo da portadora não apresentam inversão de fase.

Eles observam ainda que enquanto $J_{k}(u)$ decai em função de $u$, o mesmo não ocorre para $Q_{k}(u)$. Como aproximações para estas últimas podem ser dadas por

$$
Q_{k}(u) \approx \frac{e^{u}}{\sqrt{2 \pi u}}, \quad u \gg k
$$

uma possível normalização para as funções de Bessel modificadas podem ser dadas por

$$
g(u)=e^{-u} .
$$

A Figura 2.9 mostra valores normalizados de $Q_{k}(u)$. Note o decaimento monotônico e a ausência de componentes com fase invertida. O fato de que parciais mais altas possuem amplitude menor que as parciais mais baixas $\left(Q_{k}(u+1)<Q_{k}(u)\right)$ facilita o projeto de instrumentos com envelope espectral semelhante a um filtro passa baixa [LT10b]. Além disso as variações mais suaves e previsíveis facilitam a síntese de sinais com espectro dinâmico.

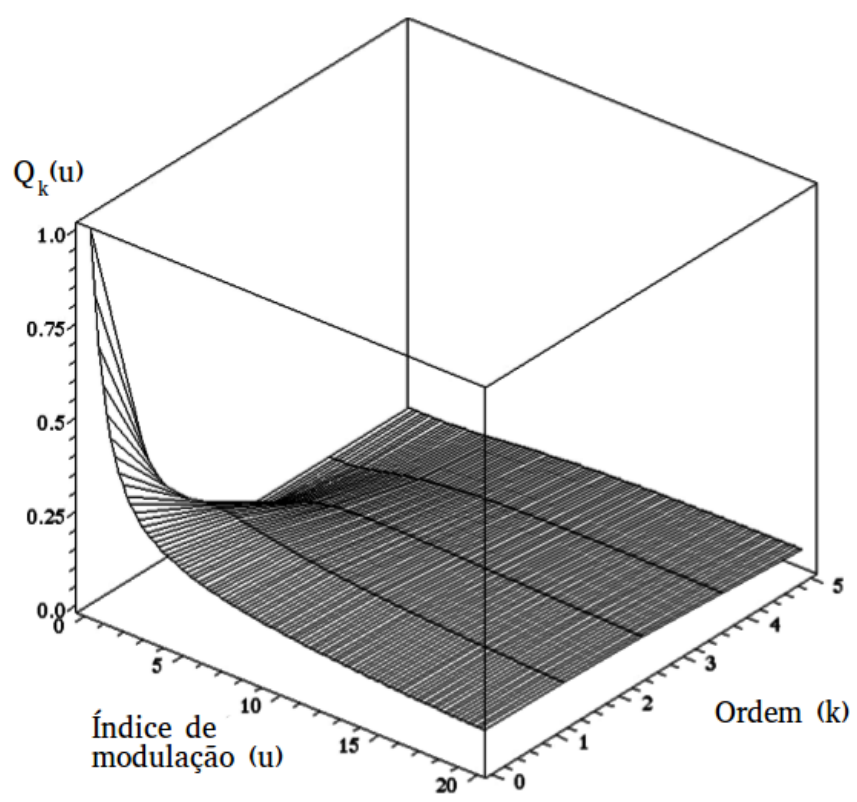

Figura 2.9: Valores das funções de Bessel modificadas normalizada. Fonte: [LT10b] (adaptada).

Finalmente, temos então a síntese FM modificada dada por

$$
y(t)=A g(u) e^{u \cos \left(\omega_{m} t\right)} \cos \left(\omega_{c} t\right)=\frac{A}{e^{u}} \sum_{k=-\infty}^{\infty} Q_{k}(u) \cos \left(\omega_{c} t+k \omega_{m} t\right),
$$

sendo $A$ a amplitude de pico do sinal, $u$ o índice de modulação, $\omega_{c}=2 \pi f_{c}$ e $\omega_{m}=2 \pi f_{m}$.

Utilizando $\frac{c}{m}=1$ e $A=1$ um trem de pulsos $y_{P}$ com largura dada pelo índice de modulação $u$ 
será produzido de acordo com [LT10a]

$$
y_{P}=\frac{1}{e^{u}} \sum_{k=1}^{\infty} \cos (k \omega)\left[Q_{k+1}(u)+Q_{k-1}(u)\right] .
$$

O Código 2.8 [ mod-fm.wav] a seguir mostra a implementação da FM Modificada. Neste exemplo está configurada a síntese do trem de pulsos, mas alterando os valores, diferentes tipos de timbres podem ser experimentados.

Lazzarini e Timoney comentam que a partir da integração de $y_{P}$ e posterior filtragem de nível DC (remoção de offset) pode-se obter a onda dente-de-serra. Para produzir a onda quadrada pode-se escolher $\frac{c}{m}=\frac{1}{2}$, começando com a geração de um pulso bipolar, e depois integrar esse sinal. Neste caso não é necessária a etapa de filtragem do nível DC, uma vez que o pulso bipolar não apresenta a componente em $0 \mathrm{~Hz}$.

Código 2.8: Implementação da FM modificada (ModFM).

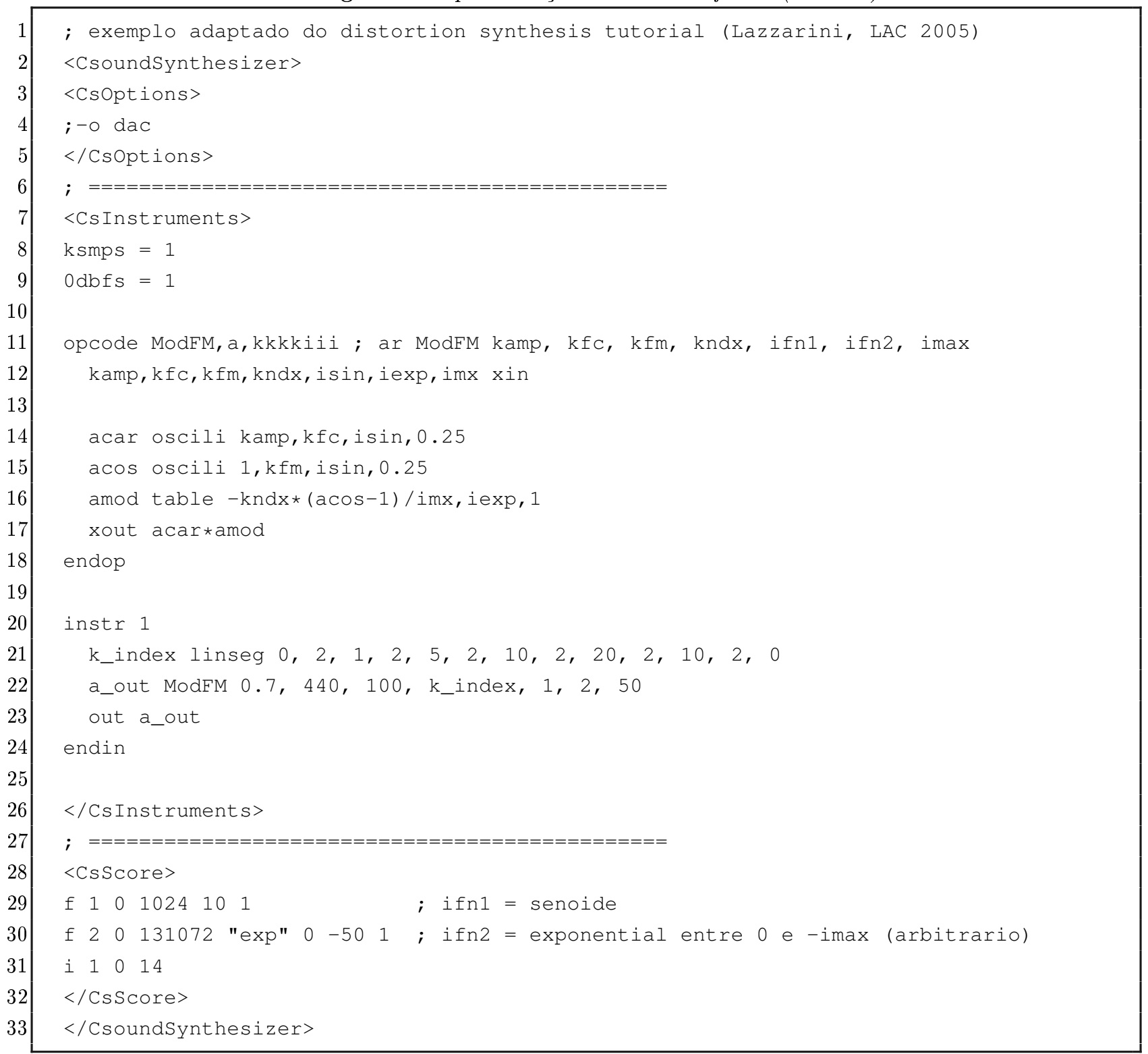




\subsection{Representação AM/FM de sinais}

Nesta seção vamos apresentar os métodos de decomposição AM/FM utilizados na pesquisa, as adaptações necessárias para o caso de considerar sinais de entrada com mais de uma componente, e revisar as principais séries de trabalhos relacionados, a saber, Modulation Vocoder, Modulation Filtering e análise de sinais. Para desenvolver intuição sobre o método, começaremos com uma discussão sobre os conceitos de envelope e frequência instantânea de um sinal.

\subsubsection{Envelope, frequência instantânea, fase}

O intuito da decomposição AM/FM é descrever um sinal a partir de um novo par de sinais, que consistem de uma estimativa para o envelope (porção AM do sinal) e outra para a frequência instantânea (porção FM) do sinal. Idealmente o processo de decomposição-ressíntese é transparente, ou seja, se utilizarmos um par AM/FM sem modificação podemos recuperar o sinal original [GTL15]. Sendo $a(t)$ a estimativa para o envelope e $f(t)$ a estimativa para a frequência instantânea, o sinal original pode ser ressintetizado a partir da expressão

$$
y(t)=a(t) \cos \left(\int_{0}^{t} f(\tau) d \tau\right) .
$$

Podemos perceber que tal ressíntese é caracterizada por uma combinação de modulações AM e FM, se relacionando assim com as técnicas apresentadas na Seção 2.1. Notamos também na Equação 2.44 que o argumento para o cosseno, a integral da frequência instantânea, corresponde à fase do sinal. Tal relação é explorada na decomposição AM/FM a partir do sinal analítico.

\section{Envelope}

O conceito de envelope de um sinal pode ser compreendido como uma curva que suavemente envolve o sinal analisado [JSK11], ou então como uma faixa de amplitude dentro da qual o sinal está contido. A Figura 2.10 mostra dois exemplos; podemos notar que de uma maneira geral o envelope é uma curva que passa pelos picos da forma de onda analisada [CR].
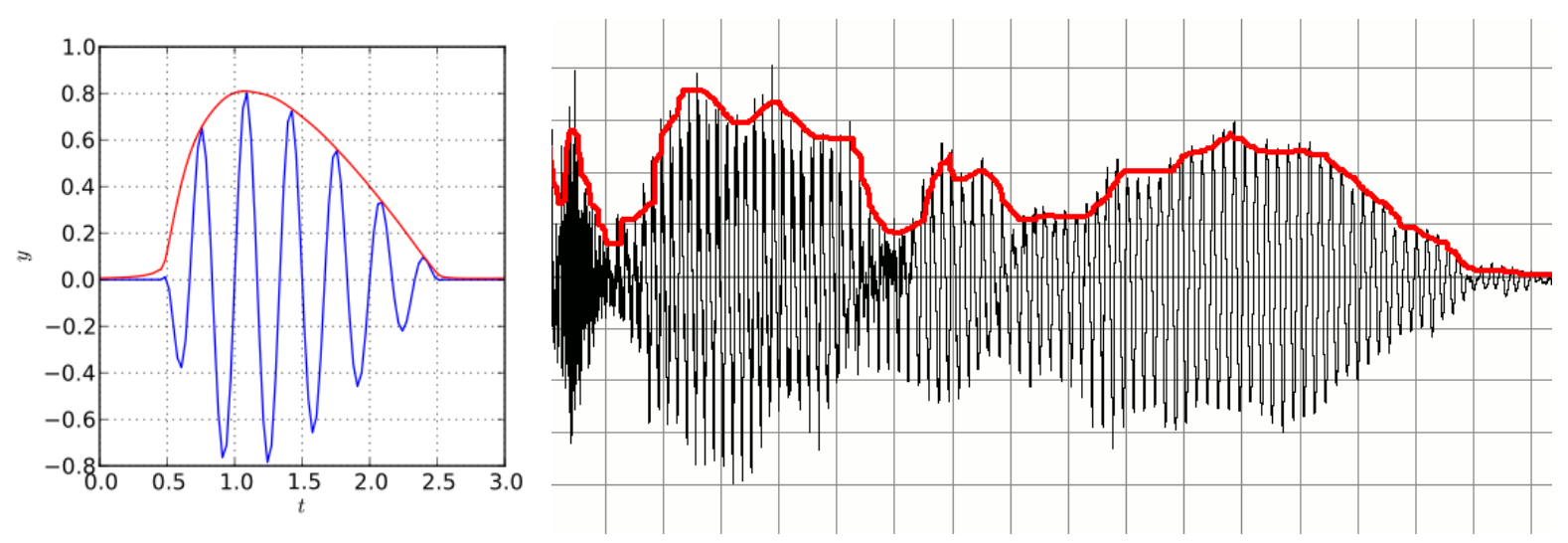

Figura 2.10: Exemplos de envelope de sinais. Fonte: Wikimedia Commons.

Um exemplo da utilização de envelopes é na transmissão e recepção de sinais de rádio por amplitude modulada. Neste contexto, a amplitude de uma onda portadora de alta frequência é modulada pelo sinal que contêm a informação que se quer transmitir. Neste processo as variações dinâmicas 
da moduladora atribuem um envelope à portadora. Pelo lado do receptor, a demodulação de sinais AM é baseada na detecção do envelope da portadora, recuperando assim a moduladora [JS03].

Outro exemplo da utilização de envelopes ocorre em práticas de mixagem em produções musicais. Para aumentar a coesão entre diferentes instrumentos numa produção, pode-se utilizar uma técnica que consiste em controlar algum parâmetro de um sinal de acordo com o envelope de outro sinal [Cas11].

\section{Frequência instantânea}

O conceito de frequência instantânea (FI) de um sinal é debatido há décadas, sendo possível dizer que não estamos perto de um consenso quanto à sua interpretação e generalização [Lou97] [Lou98]. Se pensamos num único oscilador cuja frequência varia (dentro dos limites da nossa audição), ou numa fonte de luz com a cor variando (dentro dos limites da nossa visão) talvez o conceito de FI seja intuitivo, podendo ser relacionado com a nota musical que estamos ouvindo ou cor que enxergamos. No entanto, o simples caso de um sinal resultante da sobreposição de dois osciladores com frequências distintas já complica a compreensão do significado deste parâmetro - se somos capazes de ouvir as duas frequências, como poderíamos, alternativamente, estar ouvindo uma única frequência cujo valor é, por exemplo, a média das duas?

Qualitativamente, a FI pode ser entendida como a frequência da senoide que melhor se ajusta localmente a cada instante ou amostra do sinal [WB98] [Boa92]. Alguns trabalhos consideram a frequência instantânea como a média entre as frequências presentes no sinal ${ }^{2}$. No entanto, geralmente não vale tal hipótese; no caso supracitado, dos dois osciladores com frequências distintas, foi demonstrado [Man97] [LT97b] que o único caso em que vale tal propriedade é quando a amplitude dos dois osciladores é igual. Para um número maior de componentes, nem esta condição garante que a FI seja a média das frequências presentes [WB98] [OB98].

O trabalho de Ville [Vil48], porém, mostrou que a média da FI equivale à média das frequências presentes no espectro do sinal. Na verdade, existem várias distribuições no domínio tempo-frequência que geram a derivada da fase do sinal para o primeiro momento condicional na frequência, de acordo com [LT97a] [Coh95]

$$
<\omega>_{t}=\int \omega P(\omega \mid t) d \omega=\frac{\int \omega P(t, \omega) d \omega}{\int P(t, \omega) d \omega}=\dot{\phi}(t),
$$

sendo $P(t, \omega)$ uma destas distribuições tempo-frequência. No entanto, Mandel [Man97] mostrou que momentos mais altos - por exemplo, a variância - da FI e frequências espectrais não coincidem [Lou97], e Fink mostrou [Fin66] que a variância da FI é menor que a variância da frequência espectral média.

A expressão em 2.45 mostra que a partir de distribuições conjuntas podemos definir momentos condicionais que geram valores "instantâneos" de uma quantia para um valor específico da outra (neste caso, valor de frequência num determinado instante de tempo) [Coh93].

Podemos também calcular o espalhamento ao redor destes momentos condicionais [Lou97]. Um conceito relacionado é o de largura de banda instantânea do sinal, proposto por Cohen [Coh92].

\footnotetext{
${ }^{2}$ Tais frequências, que aparecem ao analisar o sinal com a Transformada de Fourier, são chamadas por Mandel [Man97] de componentes de Fourier, e por Vakman [Vak98] de frequências espectrais.
} 
Para um sinal $A(t) e^{i \phi(t)}$, a largura de banda instantânea é dada por

$$
\sigma_{\omega}(t)=\left|\frac{\dot{A}(t)}{A(t)}\right| .
$$

Note que $\sigma_{\omega}(t)$ depende apenas da amplitude instantânea, ou seja, o espalhamento ao redor de uma média não depende do valor da média (neste caso, a média é a frequência instantânea) [Lou97]. Além disso, sinais com envelope constante apresentam $\dot{A}(t)=0$, e consequentemente $\sigma_{\omega}=0$. Nesse caso temos um sinal de modulação FM pura, em que a frequência instantânea é inteiramente responsável pela banda do sinal.

\section{Paradoxos da frequência instantânea}

A interpretação da FI pode apresentar paradoxos que dificultam ainda mais a intuição sobre tal valor. Primeiramente é importante discernir os tipos de frequência aos quais nos referimos. De um lado temos as frequências espectrais, cuja sobreposição resulta no sinal sob análise, de acordo com a teoria de Fourier. Do outro lado temos a frequência instantânea, valor atribuído à frequência local de um oscilador que gera uma aproximação do sinal. É evidente que tais frequências se tratam de quantias fundamentalmente diferentes, uma vez que as frequências espectrais, ou componentes senoidais, são definidas num intervalo infinito de tempo, enquanto que a frequência instantânea é definida num instante específico do tempo [Man97].

É interessante notar que temos familiaridade com estes dois tipos de frequência, ou em outras palavras, valores globais versus valores locais. Sabemos que com um processo de síntese aditiva podemos gerar qualquer sinal analisado via decomposição de Fourier, e neste caso estaremos sobrepondo componentes senoidais, cada uma com sua amplitude, frequência (sendo que a frequência de cada componente é fixa), e fase [DJ97]. Mas sabemos também que transmissões de rádio são baseadas em sinais que serão demodulados de acordo com o valor instantâneo das ondas captadas pela antenas receptoras [Vak98]; diversos instrumentos como servo-mecanismos, controladores automáticos de ganho, detectores de amplitude, limitadores, entre outros, operam com o mesmo princípio, baseados no fato de que podemos medir e alterar valores a cada instante, sem ter conhecimento de todo o curso do processo [VV77].

O cálculo da FI muitas vezes resulta num valor que não está necessariamente presente no espectro do sinal (como é o caso, por exemplo, da interpretação como a média do espectro, como em 2.45). Em alguns casos a FI pode ser inclusive maior que a frequência da componente mais alta de um sinal, ou até infinita [Lou98] [VV77]. Comentamos também sobre o único caso em que a FI é a média das frequências espectrais, então de uma maneira geral não vamos supor que vale tal propriedade ao trabalharmos com sinais de áudio. Sabemos, no entanto, que a média da FI equivale à média ponderada das componentes do sinal [Vil48] e que a variância daquela é menor que a desta [Fin66]. Tais fatos podem ser utilizados para projetarmos novos efeitos AM/FM.

\section{Ambiguidade da decomposição}

Além dos paradoxos e da dificuldade de interpretação ou compreensão do significado físico dos valores da AM e principalmente da FM, há uma ambiguidade na decomposição. O problema decorre do fato de que temos um único sinal $x(t)$ que (após o processo de análise) fica desmembrado na 
expressão

$$
x(t)=a(t) \cos (\phi(t)),
$$

que como podemos notar apresenta duas variáveis, $a(t)$ e $\phi(t)$ [Vak98]. Como consequência temos infinitas possibilidades para a decomposição do sinal, ou em outras palavras, podemos encontrar $b(t) \neq a(t)$ e $\theta(t) \neq \phi(t)$ de tal maneira que

$$
x(t)=b(t) \cos (\theta(t)),
$$

ou seja, um sinal idêntico aquele gerado pelo par $(a(t), f(t))$ [Lou98]. Dependendo da técnica utilizada diferentes sinais serão estimados para as porções AM e FM do sinal. Podemos inclusive pensar em dois casos extremos de decomposição:

- $a(t)=x(t)$

$\phi(t)=0 \rightarrow \cos (\phi(t))=1, \quad \forall t$

neste caso toda a informação do sinal é colocada na porção AM da decomposição. Sendo assim, a ressíntese do sinal seria realizada a partir de um processo de modulação AM pura, já que o valor do cosseno seria sempre constante;

- $a(t)=1, \quad \forall t$

$\phi(t)=\cos ^{-1}(x(t)) ;$

neste caso a informação seria codificada na porção FM da decomposição. A ressíntese seria realizada a partir de um processo de modulação FM pura, uma vez que o envelope $a(t)$ apresentaria valor constante.

No contexto de aplicação de efeitos de áudio, em geral não temos interesse em explorar estes casos extremos, uma vez que poderíamos atuar diretamente no sinal original, inclusive evitando os erros decorrentes do processo de decomposição. Nosso interesse se encontra nos contextos em que a decomposição atribui informação não trivial tanto à porção AM quanto à porção FM do sinal, de tal modo que a combinação destas porções produza o próprio sinal analisado, porém codificado num domínio diferente de representação.

Com uma boa intuição sobre a semântica desta decomposição podemos tirar proveito desta maneira não usual de representar um sinal, e assim construir versões processadas do mesmo. Nas seções seguintes vamos detalhar dois dos métodos mais utilizados para obter uma decomposição AM/FM e desenvolver intuição sobre os sinais obtidos. As estimativas que resultam ao utilizarmos cada uma destas técnicas (e suas variações) são de naturezas diferentes, apresentando assim diferentes possibilidades para o processamento e aplicação de efeitos de áudio.

\subsubsection{Decomposição AM/FM via Sinal Analítico}

Um sinal analítico é um sinal complexo que não apresenta frequências negativas [Smi07]. Dado um sinal real, seu sinal analítico correspondente apresenta um espectro idêntico na porção positiva, porém nulo na porção negativa.

Por exemplo, seja um oscilador senoidal $x(t)=\cos \left(\omega_{0} t\right)$. Sabemos que seu espectro apresenta duas componentes, localizadas em $+\omega_{0}$ e $-\omega_{0}$ [OS75]. Podemos observar esta propriedade a partir 
de uma das fórmulas derivadas da relação de Euler (Equação 2.59):

$$
\cos \left(\omega_{0} t\right)=\frac{1}{2}\left(e^{i \omega_{0} t}+e^{-i \omega_{0} t}\right)
$$

Sabemos que o fasor $e^{i \omega_{0} t}$ apresenta uma única componente em $+\omega_{0}$, e o fasor $e^{-i \omega_{0} t}$ apresenta uma única componente em $-\omega_{0}$.

Se considerarmos apenas a porção positiva do espectro, chegamos no sinal analítico referente a $x(t)$, que é justamente o fasor com frequência positiva. A Figura 2.11 mostra este fasor, que gira no plano complexo, no sentido anti-horário. Note que a projeção do fasor no eixo real gera o sinal senoidal $x(t)$.

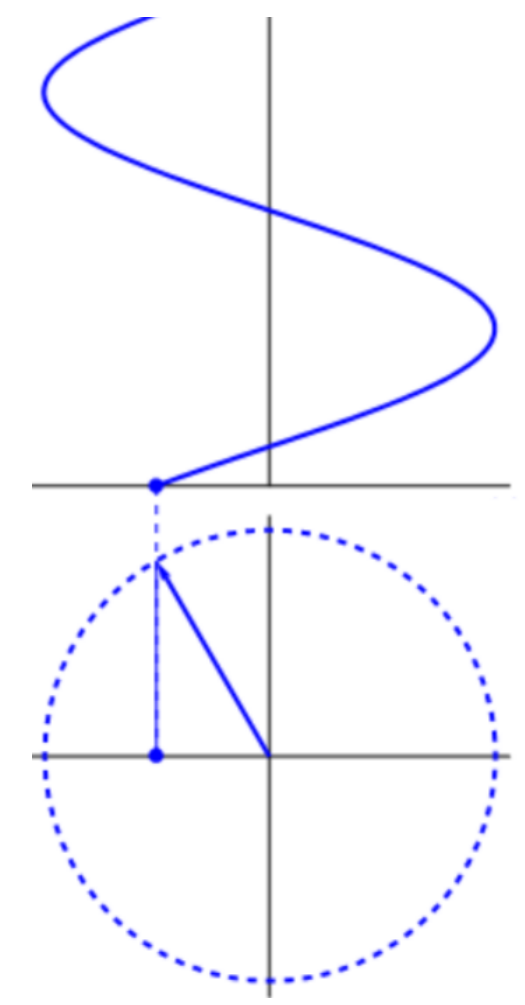

Figura 2.11: Representação de um fasor. A projeção no eixo real gera um sinal senoidal. Fonte: Wikimedia Commons.

Continuando no desenvolvimento da intuição sobre o sinal analítico, ao invés de pensar $x(t)$ como o caso senoidal puro, agora podemos pensar $x(t)$ como um sinal real qualquer. Pela Transformada de Fourier (ou, Equação de Análise) podemos obter seu espectro $X(\omega)$ de acordo com [OS75]

$$
X(\omega)=\int_{-\infty}^{+\infty} x(t) e^{-i \omega t} d t
$$

A partir do espectro $X(\omega)$ podemos, por meio da Transformada Inversa de Fourier (ou, Equação de Síntese), recuperar o sinal original $x(t)$, de acordo com [OS75]

$$
x(t)=\frac{1}{2 \pi} \int_{-\infty}^{+\infty} X(\omega) e^{i \omega t} d \omega
$$


Manipulando esta equação obtemos

$$
\begin{aligned}
x(t) & =\frac{1}{2 \pi} \int_{-\infty}^{+\infty} X(\omega) e^{i \omega t} d \omega \\
& =\frac{1}{2 \pi}\left(\int_{-\infty}^{0} X(\omega) e^{i \omega t} d \omega+\int_{0}^{+\infty} X(\omega) e^{i \omega t} d \omega\right) \\
& =\frac{1}{2 \pi}\left(\int_{0}^{+\infty} X(-\omega) e^{i(-\omega) t} d(-\omega)+\int_{0}^{+\infty} X(\omega) e^{i \omega t} d \omega\right) \\
& =\frac{1}{2 \pi}(-\underbrace{\int_{0}^{+\infty} X^{*}(\omega) e^{-i \omega t} d \omega}_{\text {frequências negativas }}+\underbrace{\int_{0}^{+\infty} X(\omega) e^{i \omega t} d \omega}_{\text {frequências positivas }}),
\end{aligned}
$$

sendo $X^{*}(\omega)$ a conjugação complexa de $X(\omega)$; como a Transformada de Fourier (TF) apresenta simetria hermitiana [OS75], temos que $X^{*}(\omega)=X(-\omega)$.

Da mesma maneira que chegamos no fasor simples como representação analítica do cosseno eliminando a componente negativa em 2.49, se eliminarmos a porção referente às frequências negativas neste exemplo obtemos o sinal analítico

$$
z(t)=\frac{1}{2 \pi} \int_{0}^{+\infty} X(\omega) e^{i \omega t} d \omega
$$

Como esta fórmula considera todos os valores possíveis para frequências positivas, podemos pensar em $z(t)$ no plano complexo como uma sobreposição (soma vetorial) de infinitos fasores, ou movimentos circulares, girando no sentido anti-horário com frequência $\omega$ e raio $X(\omega)$. A Figura 2.12 apresenta esta interpretação, mostrando a sobreposição de 3 fasores. A projeção no eixo real desta sobreposição resulta no sinal original $x(t)$.

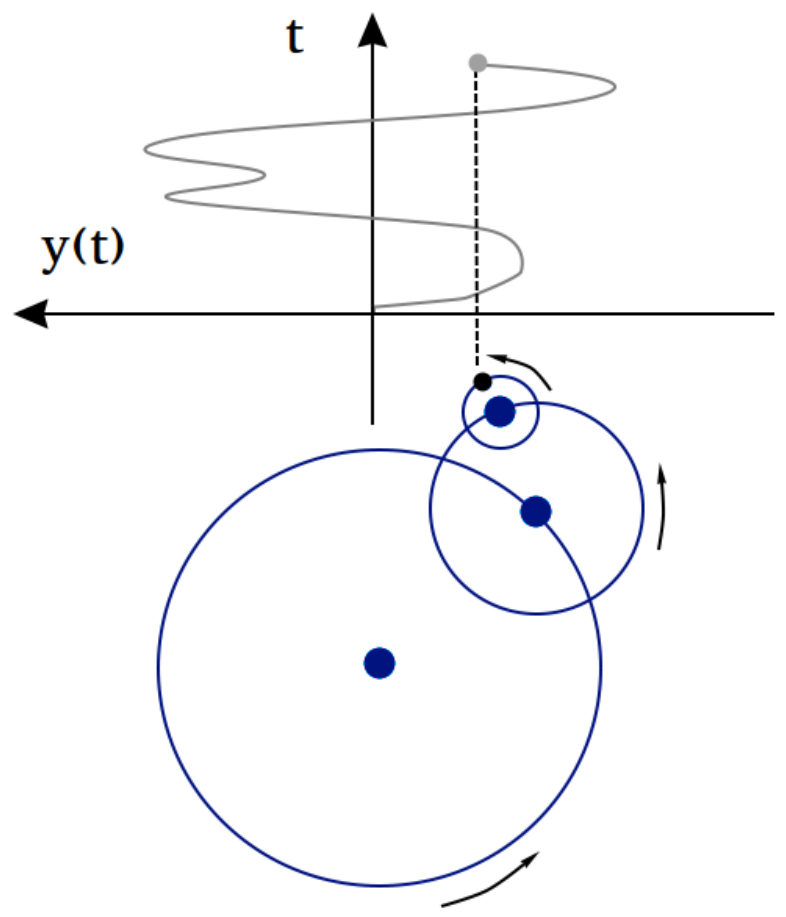

Figura 2.12: Interpretação do sinal analítico como sobreposição de fasores com frequências positivas. 
O sinal analítico é um sinal complexo, apresentando portanto uma parte real e outra imaginária. Vamos representá-lo por

$$
z(t)=x(t)+i \hat{x}(t)
$$

sendo $i=\sqrt{-1}$. A partir do sinal analítico $z(t)$ podemos proceder para a decomposição AM/FM de fato. O envelope, ou porção AM da decomposição, é calculado como

$$
a(t)=\sqrt{x^{2}(t)+\hat{x}^{2}(t)}=|z(t)| .
$$

A fase do sinal analítico é dada por

$$
\phi(t)=\arctan \left(\frac{\hat{x}(t)}{x(t)}\right)
$$

A frequência instantânea é obtida a partir da derivada da fase,

$$
f(t)=\dot{\phi}(t) .
$$

Podemos também reescrever o sinal analítico de acordo com a expressão

$$
z(t)=x(t)+i \hat{x}(t)=a(t) e^{i \phi(t)}
$$

Esta última fórmula nos ajuda a compreender ainda melhor o sinal analítico e os conceitos de envelope, fase e frequência instantânea. No caso de $x(t)$ senoidal com amplitude e frequência constantes, a representação analítica corresponde a um fasor, que gira no plano complexo. A amplitude deste fasor é constante, e equivale ao raio do círculo percorrido pelo fasor (vide Figura 2.11). A frequência do movimento giratório também é constante; ao invés de pensar a frequência como derivada da fase, como foi definido em 2.57, podemos pensar a fase como integral da frequência. Neste raciocínio a fase (posição do fasor no círculo) é dada por incrementos ao longo do tempo, de tal modo que o tamanho de cada passo está relacionado com a frequência, que neste caso é constante, ou seja, os incrementos ao longo do círculo apresentam sempre o mesmo ângulo.

Se ao invés de limitarmos $x(t)$ ao caso supracitado admitirmos o mesmo como um sinal AM/FM, com amplitude e frequência variando, podemos adaptar a interpretação no parágrafo anterior e pensar num fasor cuja amplitude e frequência não são fixas. Neste caso, os incrementos na fase (ou posição no círculo) não são constantes - e justamente por essa causa a oscilação não mais corresponde a uma senoide sem modulação; e a amplitude não mais será constante, ou seja, o ponto que representa o fasor não vai mais girar sempre sobre o mesmo círculo, mas vai apresentar espirais que hora se contraem e hora se expandem. É importante lembrar que a projeção desta oscilação no eixo real gera o sinal $x(t)$ sob análise.

\section{Implementação da Transformada de Hilbert / Sinal analítico}

Outra fórmula conhecida que nos ajuda a melhor compreender o sinal analítico é a relação de Euler, dada por

$$
e^{i \omega_{0}}=\cos \left(\omega_{0}\right)+i \sin \left(\omega_{0}\right) .
$$


A partir desta relação podemos observar que para obter a representação analítica do cosseno adicionamos um seno com a mesma frequência para representar a parte imaginária do sinal analítico. Este seno é nada mais que o próprio cosseno defasado em $90^{\circ}$, ou utilizando o jargão de telecomunicações, seno e cosseno são sinais em quadratura.

De uma maneira geral, a receita para obter a representação analítica $z(t)$ de um sinal real qualquer $x(t)$ é dada por

$$
z(t)=x(t)+i \hat{x}(t)
$$

sendo $\hat{x}(t)$ a transformada de Hilbert de $x(t)$.

A Transformada de Hilbert (TH) é um operador linear que a partir de uma função $x(t)$ produz outra função $\hat{x}(t)$ (portanto no mesmo domínio), com componentes defasadas em $90^{\circ}$ ou $\frac{\pi}{2}$ radianos em relação às componentes da função original [Hah96]. Desse modo, $x(t)$ e $\hat{x}(t)$ são sinais em quadratura, e seus espectros apresentam a mesma relação que aquela observada entre os espectros do seno e cosseno supracitados. Sendo assim, uma possibilidade para a obtenção do sinal analítico é utilizar uma rede de filtros passa-tudo que produza dois sinais com respostas em fase diferindo em aproximadamente $\frac{\pi}{2}$ em alguma porção de interesse do espectro. Atribuindo um destes sinais da saída da rede à parte real e a outra saída à porção imaginária de um sinal complexo, obter-se-á um sinal complexo cujas componentes com frequências negativas no sinal são desprezíveis [RD12], caracterizando assim o sinal analítico. Na literatura da TH tais redes de filtros são chamadas de Transformadores de Hilbert [RD12].

No código 2.9 mostramos nossa implementação de UDOs para a decomposição AM/FM utilizando Transformada de Hilbert. Em Csound, o opcode hilbert utiliza uma rede de filtros passatudo para gerar sinais em quadratura. A partir destes, podemos prosseguir para a decomposição como mostrado em 2.55, 2.56 e 2.57 (linhas 16 a 18 do código). Note que após a diferenciação uma operação de unwrapping é necessária para corrigir descontinuidades da fase (linhas 6 a 10).

Código 2.9: UDOs para decomposição AM/FM utilizando Transformada de Hilbert.

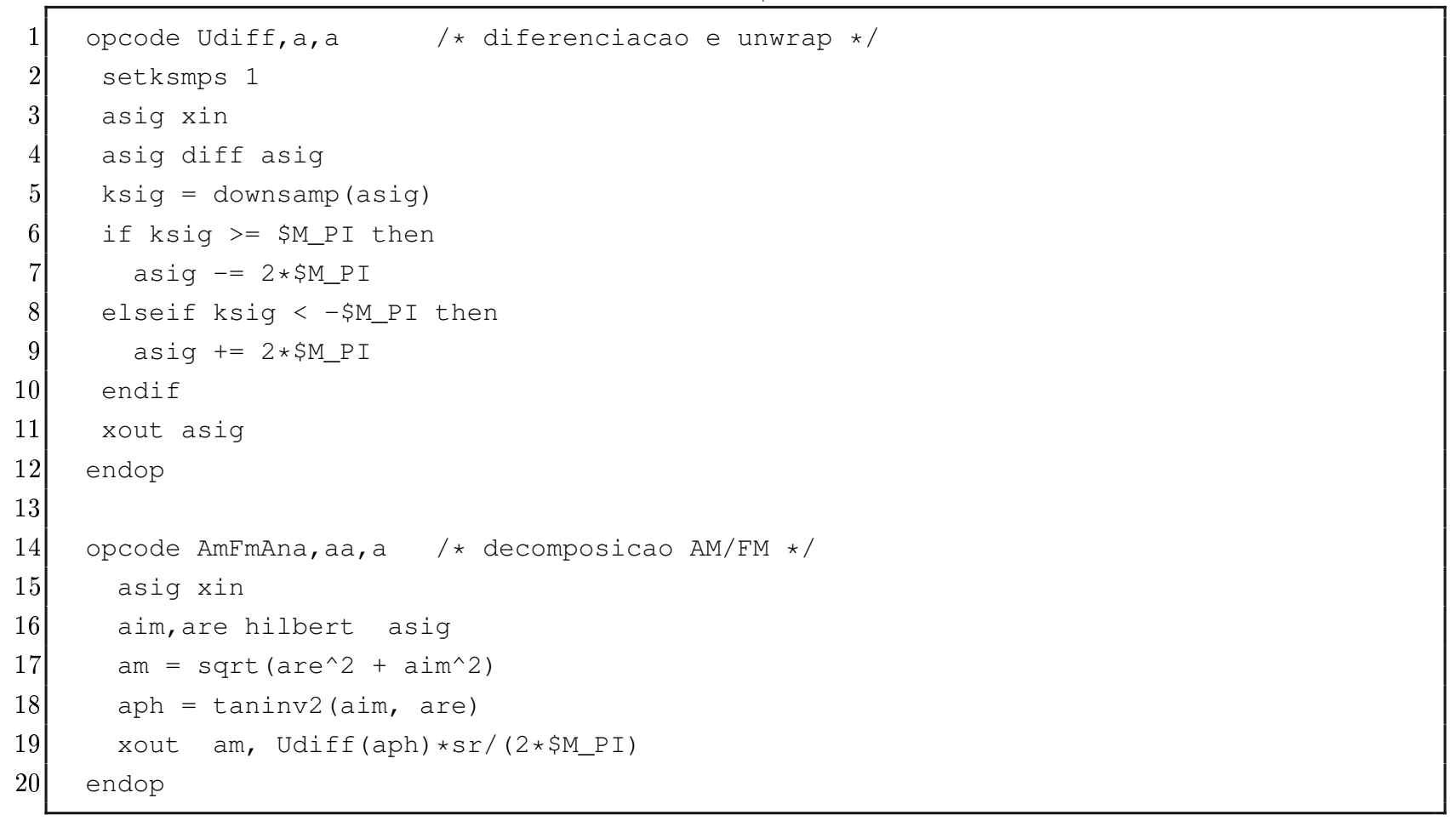


Outra possibilidade para implementação computacional que nos forneça o sinal analítico referente a um sinal real se dá a partir da Transforma de Fourier. Sabendo que o sinal analítico possui apenas as frequências positivas do sinal real sob transformação, podemos obtê-lo utilizando a Transformada de Fourier e preservando apenas a porção de componentes positivas do espectro, aplicando finalmente a Transformada Inversa de Fourier [Pic97] [OS75]. Separando na sequência as partes real e imaginária do sinal podemos então aplicar 2.55, 2.56 e 2.57.

Podemos deduzir a expressão para a TH no tempo a partir desta abordagem utilizando a TF. Seja $x(t)$ o sinal real de entrada e $X(\omega)$ seu espectro, e seja $\operatorname{sgn}(\omega)$ a função sinal, dada por [Vak98]

$$
\operatorname{sgn}(\omega)=\left\{\begin{array}{l}
1, \quad \omega>0, \\
0, \quad \omega=0, \\
-1, \quad \omega<0 .
\end{array}\right.
$$

Sendo assim, para anular a porção negativa do espectro e manter a positiva (multiplicada por 2) podemos fazer

$$
X_{a}(\omega)=X(\omega)+\operatorname{sgn}(\omega) X(\omega) .
$$

A partir da TF inversa obtemos a expressão no tempo para o sinal analítico

$$
\begin{aligned}
z(t) & =\mathcal{F}^{-1}\left\{X_{a}(\omega)\right\} \\
& =\mathcal{F}^{-1}\{X(\omega)+\operatorname{sgn}(\omega) X(\omega)\} \\
& =\mathcal{F}^{-1}\{X(\omega)\}+\mathcal{F}^{-1}\{\operatorname{sgn}(\omega) X(\omega)\} \\
& =\mathcal{F}^{-1}\{X(\omega)\}+\mathcal{F}^{-1}\{\operatorname{sgn}(\omega)\} * \mathcal{F}^{-1}\{X(\omega)\} \\
& =x(t)+i \frac{1}{\pi t} * x(t),
\end{aligned}
$$

sendo * o símbolo da operação de convolução. Nesta expressão o kernel da TH fica em evidência, e temos a definição da mesma como [Hah96]

$$
\hat{x}(t)=x(t) * \frac{1}{\pi t}=\frac{1}{\pi} \int_{-\infty}^{+\infty} \frac{x(\tau)}{t-\tau} d \tau
$$

com $\tau$ representando também o domínio do tempo.

A expressão 2.68 mostra que, assim como a TF, a TH é uma transformada integral, sendo que o cálculo a partir da convolução do sinal de entrada com o kernel da transformada requer o conhecimento do sinal inteiro. No entanto, a implementação baseada em TF utiliza a Transformada de Fourier de Tempo Reduzido (Short Time Fourier Transform - STFT), caracterizada pelo janelamento do sinal em pequenos blocos e cálculo de sucessivas transformadas (utilizando o algoritmo Fast Fourier Transform - FFT [JWC65]). A obtenção do sinal analítico a partir de janelas do sinal de entrada associadas à Transformada de Fourier representa portanto uma abordagem quasilocal [VV77], que também possibilita a realização de implementações em tempo-real, contanto que uma latência referente ao tamanho do bloco seja tolerada. Existem ainda outras possibilidades para implementação da TH, consideradas em [OS75] [RD12] [Hah96] [Zöl11]. 


\section{As condições de Vakman para a decomposição}

Vimos que a partir das porções real e imaginária do sinal analítico podemos utilizar as expressões 2.55, 2.56 e 2.57 e calcular o envelope e a frequência instantânea. Utilizar a combinação Transformada de Hilbert e sinal analítico foi a saída proposta por Gabor [Gab46] para garantir unicidade na decomposição AM/FM [Pic97]. Picinbono se refere ao resultado deste esquema de decomposição utilizando o sinal analítico como par canônico [Pic97].

No entanto Loughlin observa [Lou98] que a Transformada de Hilbert não foi o único método proposto para a obtenção da parte imaginária que se associa com $x(t)$ para gerar um sinal complexo. Outros métodos como o de Shekel [She53] e Mandelstam [Vak96] geram diferentes sinais para $\hat{x}(t)$. Os sinais complexos assim obtidos não são o sinal analítico, e como consequência as estimativas de amplitude instantânea e frequência instantânea serão diferentes das obtidas com a metodologia apresentada nesta seção.

Vakman [VV77] [Vak98] propôs 3 condições para os sinais de amplitude instantânea $a(t)$, fase $\phi(t)$ e frequência instantânea $\dot{\phi}(t)$ em relação ao sinal real $x(t)$ que será analisado. Ele argumenta que tais condições são baseadas em considerações sobre o significado físico dos valores obtidos com a decomposição e deveriam ser respeitadas por qualquer esquema de decomposição AM/FM, representado por $\underset{F M}{\stackrel{A M}{\longrightarrow}}$ nas descrições a seguir:

- Condição A - Continuidade da amplitude: uma pequena variação adicionada ao sinal $x(t)$ deve ter como consequência uma pequena variação na amplitude instantânea:

$$
x(t)+\delta(t), \quad \delta(t) \rightarrow 0 \quad \stackrel{A M}{F M} \quad a(t)+\epsilon(t), \quad \epsilon(t) \rightarrow 0 ;
$$

- Condição B - Independência entre fase e ganho: a multiplicação do sinal $x(t)$ por uma constante $c>0$ não deve influenciar nas estimativas da fase (e da frequência):

$$
x(t) \quad \underset{F M}{\stackrel{A M}{\longrightarrow}} a(t), \phi(t) \quad \Rightarrow \quad c x(t) \quad \underset{F M}{\stackrel{A M}{\longrightarrow}} \quad c a(t), \phi(t)
$$

- Condição C - Correspondência harmônica: os valores constantes da amplitude e da frequência de uma senoide simples devem ser retidos pela decomposição:

$$
A \cos \left(\omega_{0} t+\phi\right) \quad \underset{F M}{\stackrel{A M}{\longrightarrow}} \quad a(t)=A, \quad \phi(t)=\omega_{0} t+\phi, \quad \dot{\phi}(t)=\omega_{0} .
$$

Vakman mostra [Vak98] que a decomposição utilizando a Transformada de Hilbert com o sinal analítico é o único método que satisfaz as 3 condições. Loughlin concorda que as condições propostas por Vakman são sensatas, mas lembra [Lou98] que, no entanto, tais condições não são as únicas de interesse em processamento de sinais. Ele sugere, por exemplo, outra condição que pode ser considerada essencial em alguns casos:

- Condição A* - Envelope limitado para sinal limitado: um sinal limitado em amplitude deve gerar uma estimativa de amplitude instantânea também limitada em amplitude:

$$
|x(t)|<\infty \quad \underset{F M}{\stackrel{A M}{\longrightarrow}}|a(t)|<\infty .
$$


Loughlin mostra que a TH de um sinal limitado em amplitude não apresenta necessariamente valores limitados, logo, se considerarmos as condições A*, B e C, um paradigma diferente do sinal analítico é necessário; utilizando a TH junto com o sinal analítico, instantes de descontinuidade num sinal $x(t)$, mesmo que limitadas em amplitude, podem produzir valores infinitos na estimativa do envelope [Lou98], violando a condição A*.

Outro exemplo de condição de extremo interesse é requerer que a estimativa da AM se inicie e termine junto com o sinal de entrada [Lou97]. Tal condição não é obedecida pelo sinal analítico obtido com a TH. O próprio Vakman descreve [Vak98] tal problema como o paradoxo do envelope retangular, ilustrado na Figura 2.13: podemos notar que antes da senoide analisada iniciar seu primeiro ciclo o envelope estimado já apresenta valores não-nulos.

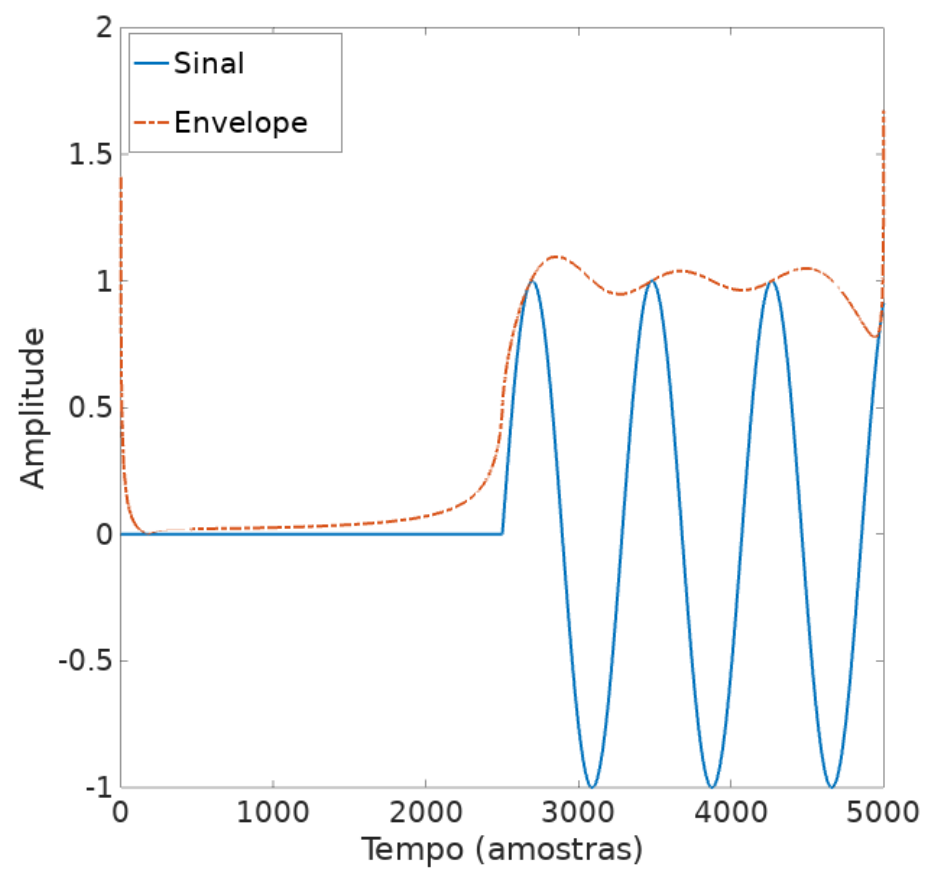

Figura 2.13: Paradoxo do envelope retangular: levando em consideração um sinal senoidal como entrada, a amplitude instantânea estimada (curva tracejada) a partir da Transformada de Hilbert apresenta valores não-nulos mesmo antes do início da senoide (curva continua).

Outro fato que fica evidente na Figura 2.13 é que a decomposição via sinal analítico pressupõe a porção AM como sendo não-negativa [LA08]. No sinal estimado para a AM, valores nulos podem ser instantes em que o AM cruzaria o zero e passaria a ter valores negativos, mas de acordo com a Equação 2.55, a raiz quadrada da soma dos quadrados de $x(t)$ e $\hat{x}(t)$ gera apenas valores nãonegativos, então a estimativa para a AM pode forçar quebras na continuidade da fase estimada. Sendo assim, a estimativa para a frequência instantânea, que é relacionada com a fase do sinal, pode apresentar distorções nos pontos onde $a(t)$ é nula (cruzamento de zero). Li e Atlas [LA04] sugerem filtragem passa-baixa e correção da fase em $\pi$ nestes pontos, como tentativa de amenizar este problema, mas lembram que nem sempre a distorção de fase apresentará esse valor, e outros métodos são necessários para soluções mais gerais. 


\subsubsection{Decomposição AM/FM via Separação de Energia}

Como comentado na seção anterior, a decomposição a partir da Transformada de Hilbert e sinal analítico apresenta um aspecto global, uma vez que requer o sinal inteiro sob análise para estimar suas porções AM e FM. Mesmo que utilizemos porções específicas do sinal, ou janelas, para realizar a análise, ainda assim o caráter será quasi-local [VV77].

A decomposição AM/FM pelo método de separação de energia, por sua vez, apresenta um caráter local. Com uma janela de poucas amostras do sinal, o operador de energia de TeagerKaiser (TEO) estima a energia envolvida na geração da oscilação sob análise [DM06]. Aplicando tal operador tanto ao sinal quanto à sua derivada, o método de separação de energia estima amostra a amostra o envelope (amplitude instantânea) e a frequência instantânea de um sinal utilizando uma janela de 4 ou 5 amostras, dependendo do tipo de algoritmo utilizado para estimar a derivada. No entanto, o preço a se pagar por uma técnica que necessita apenas de informação local do sinal para a decomposição é uma maior sensibilidade a ruídos, mas algumas possibilidades foram desenvolvidas para minimizar este problema.

Como uma motivação [Kve03] para a compreensão do TEO, podemos pensar num sistema massamola, representado pela equação diferencial

$$
\frac{d^{2}}{d t} x(t)+\frac{k}{m} x(t)=0
$$

sendo $m$ a massa do objeto e $k$ a constante da mola. Este é um modelo simplificado (pois não considera as características do meio) de um sistema acústico/mecânico, sendo que a oscilação do objeto representa variações de pressão no meio ao redor. A solução para esta equação diferencial é dada por

$$
x(t)=A \cos (\omega t+\phi),
$$

sendo $x(t)$ a posição do objeto no instante $t, A$ a amplitude da oscilação, $w=\sqrt{\frac{k}{m}}$ a frequência da oscilação e $\phi$ a fase inicial ( $\phi=0$ representa o caso em que o objeto estava inicialmente na posição de equilíbrio).

Sabemos que a energia total deste sistema é dada pela soma das energias potencial e cinética do objeto, de acordo com

$$
E=\frac{1}{2} k x^{2}(t)+\frac{1}{2} m v^{2}(t) .
$$

Substituindo $x(t)$ como em 2.70, temos $v=\dot{x}(t)=-A \omega \sin (\omega t+\phi)$ e $k=\omega^{2} m$, assim

$$
\begin{aligned}
E & =\frac{1}{2} k x^{2}+\frac{1}{2} m v^{2} \\
& =\frac{1}{2} \omega^{2} m x^{2}(t)+\frac{1}{2} m v^{2} \\
& =\frac{1}{2} m\left(\omega^{2} A^{2} \cos ^{2}(\omega t+\phi)+\omega^{2} A^{2} \sin ^{2}(\omega t+\phi)\right) \\
& =\frac{1}{2} m A^{2} \omega^{2}
\end{aligned}
$$

ou seja, a energia é proporcional a $A^{2} \omega^{2}$. 


\section{O operador no caso contínuo}

Para chegar na definição do operador de energia podemos considerar algumas manipulações em 2.71. Continuamos a trabalhar com $x(t)$ como em 2.70, de modo que $v=\dot{x}(t)=-A \omega \sin (\omega t+\phi)$ e $\ddot{x}(t)=-A \omega^{2} \cos (\omega t+\phi)=-\omega^{2} x(t)$, ficando com

$$
\begin{aligned}
E & =\frac{1}{2} k x^{2}(t)+\frac{1}{2} m v^{2}(t) \\
& =\frac{1}{2} m\left(\omega^{2} x^{2}(t)+v^{2}(t)\right) \\
& =\frac{1}{2} m\left(\omega^{2} x^{2}(t)+\dot{x}^{2}(t)\right) \\
& =\frac{1}{2} m\left(x(t) \omega^{2} x+\dot{x}^{2}(t)\right) \\
& =\frac{1}{2} m\left(x(t)(-\ddot{x}(t))+\dot{x}^{2}(t)\right) .
\end{aligned}
$$

Visualizamos assim justamente a definição do operador de energia no caso contínuo,

$$
\psi(x(t))=\dot{x}^{2}(t)-x(t) \ddot{x}(t)
$$

Aplicando o operador no caso $x(t)=A \cos (\omega t)$ obtemos

$$
\begin{aligned}
\psi(x(t)) & =(-A \omega \sin (\omega t))^{2}-(A \cos (\omega t))\left(-\omega^{2} A \cos (\omega t)\right) \\
& =A^{2} \omega^{2}\left(\sin (\omega t)^{2}+\cos (\omega t)^{2}\right) \\
& =A^{2} \omega^{2} .
\end{aligned}
$$

Podemos assim perceber que o valor estimado pelo TEO, a despeito de uma constante multiplicativa, é similar ao encontrado em 2.72, mostrando que para o caso de um sinal de entrada senoidal, a estimativa é perfeita.

\section{O algoritmo para separação de energia, caso contínuo}

Vimos que o operador de energia estima a energia necessária para que ocorra o fenômeno oscilatório sob análise, energia aquela dada pelo quadrado do produto do envelope pela frequência instantânea. O algoritmo de separação de energia (ESA) é capaz de separar $a(t)$ e $\omega(t)$ a partir da aplicação do TEO tanto no sinal quanto em sua derivada.

Observe que partindo de $\dot{x}(t)=-A \omega \sin (\omega t)$ temos

$$
\begin{aligned}
\psi(\dot{x}(t)) & =\ddot{x}^{2}(t)-\dot{x}(t) \dddot{x}(t) \\
& =\left(-A \omega \cos \left(\omega^{2} t\right)\right)^{2}-(-A \omega \sin (\omega t))\left(A \omega^{3} \sin (\omega t)\right) \\
& =A^{2} \omega^{4} \cos ^{2}(\omega t)+A^{2} \omega^{4} \sin ^{2}(\omega t) \\
& =A^{2} \omega^{4} .
\end{aligned}
$$

Sendo assim, a partir de 2.75 e 2.76 podemos perceber que a última etapa do ESA é calcular a FI e o envelope de acordo com 


$$
\omega(t)=\sqrt{\frac{\psi(\dot{x}(t))}{\psi(x(t))}}
$$

$$
|a(t)|=\frac{\psi(x(t))}{\sqrt{\psi(\dot{x}(t))}} .
$$

\section{O operador no caso discreto}

Uma vez que existem diversas maneiras para fazer a aproximação da derivada de um sinal no caso do sinal amostrado [MKQ93a], diversas são as possibilidades para a definição do operador de energia no caso discreto. Utilizando a diferença $x[n]-x[n-1]$ (derivada pra trás) como aproximação para a primeira derivada de $x[n]$, temos

$$
\begin{aligned}
\dot{x}[n] & =x[n]-x[n-1] ; \\
\ddot{x}[n] & =\dot{x}[n]-\dot{x}[n-1] \\
& =x[n]-x[n-1]-(x[n-1]-x[n-2]) \\
& =x[n]-2 x[n-1]+x[n-2] ; \\
\dot{x}^{2}[n] & =(x[n]-x[n-1])^{2} \\
& =x^{2}[n]-2 x[n] x[n-1]+x^{2}[n-1] ; \\
x[n] \ddot{x}[n] & =x^{2}[n]-2 x[n] x[n-1]+x[n] x[n-2] ; \\
\dot{x}^{2}[n]-x[n] \ddot{x}[n] & =x^{2}[n-1]-x[n] x[n-2] .
\end{aligned}
$$

Se por outro lado considerarmos a diferença $x[n+1]-x[n]$ (derivada pra frente) como aproximação para a primeira derivada de $x[n]$, podemos fazer um desenvolvimento similar e chegar em

$$
\dot{x}^{2}[n]-x[n] \ddot{x}[n]=x^{2}[n+1]-x[n+2] x[n] .
$$

Note que as duas últimas expressões diferem apenas por um atraso de duas amostras, a primeira combinando os valores das amostras $x[n-2], x[n-1]$ e $x[n]$ onde figuram as amostras $x[n], x[n+1]$ e $x[n+2]$ na segunda. Na literatura relativa ao algoritmo de separação de energia, a definição mais comum do TEO discreto se posiciona entre estes dois casos apresentados. O operador é dado de acordo com a expressão [MKQ93a]

$$
\psi(x[n])=x^{2}[n]-x[n-1] x[n+1] .
$$

Para deduzir essa expressão podemos considerar que $x[n]-x[n-1]$, assim como $x[n+1]-x[n]$, correspondem respectivamente a derivadas exatas em algum ponto dos intervalos $[n-1, n]$ e $[n, n+1]$ (teorema do valor médio [THW09]). Se as considerarmos como $\dot{x}\left[n-\frac{1}{2}\right]$ e $\dot{x}\left[n+\frac{1}{2}\right]$, respectivamente, podemos obter a expressão acima da seguinte forma: 


$$
\begin{aligned}
\dot{x}[n] & \approx \underbrace{x[n+1]-x[n]}_{\dot{x}\left[n+\frac{1}{2}\right]} \approx \underbrace{x[n]-x[n-1]}_{\dot{x}\left[n-\frac{1}{2}\right]} ; \\
\ddot{x}[n] & \approx \dot{x}\left[n+\frac{1}{2}\right]-\dot{x}\left[n-\frac{1}{2}\right] \\
& \approx x[n+1]-2 x[n]+x[n-1] ; \\
\psi(x[n]) & =\dot{x}^{2}[n]-x[n] \ddot{x}[n] \\
& \approx \dot{x}\left[n+\frac{1}{2}\right] \dot{x}\left[n-\frac{1}{2}\right]-x[n]\left(\dot{x}\left[n+\frac{1}{2}\right]-\dot{x}\left[n-\frac{1}{2}\right]\right) \\
& \approx(x[n+1]-x[n])(x[n]-x[n-1])-x[n](x[n+1]-2 x[n]+x[n-1]) \\
& \approx \bar{x}[n] x[n+1]-x^{2}[n]-x[n-1] x[n+1]+\underline{x}[n-1] x[n]-\dot{x}[n] x[n+1]+2 x^{2}[n]-\underline{x}[n-1] x[n] \\
& \approx x^{2}[n]-x[n-1] x[n+1] .
\end{aligned}
$$

Note que no desenvolvimento acima trocamos $\dot{x}^{2}[n]$ por $\dot{x}\left[n+\frac{1}{2}\right] \dot{x}\left[n-\frac{1}{2}\right]$. A Figura 2.14 traz uma motivação para tal manipulação: nesse cenário (em que a derivada é monotonicamente crescente entre $x[n-1]$ e $x[n+1])$, considerando como estimativa da derivada contínua $\alpha$ a diferença para trás $x[n]-x[n-1]$ teremos um valor menor do que o correto $\left(\alpha-\epsilon_{b}\right.$ com $\left.\epsilon_{b}>0\right)$, e considerando a aproximação pra frente $x[n+1]-x[n]$ o valor da derivada estimada será maior $\left(\alpha+\epsilon_{f} \operatorname{com} \epsilon_{f}>0\right)$. Assim, dentre as alternativas a seguir para estimar $\alpha^{2}$ :

$$
\begin{aligned}
& \left(\alpha+\epsilon_{f}\right)\left(\alpha-\epsilon_{b}\right)=\alpha^{2}+\alpha\left(\epsilon_{f}-\epsilon_{b}\right)-\epsilon_{f} \epsilon_{b}, \\
& \left(\alpha+\epsilon_{f}\right)\left(\alpha+\epsilon_{f}\right)=\alpha^{2}+2 \alpha \epsilon_{f}+\epsilon_{f}^{2}, \\
& \left(\alpha-\epsilon_{b}\right)\left(\alpha-\epsilon_{b}\right)=\alpha^{2}-2 \alpha \epsilon_{b}+\epsilon_{b}^{2},
\end{aligned}
$$

a primeira, que é a média geométrica das outras duas, representa a melhor dentre as três alternativas, supondo $\epsilon_{f}$ e $\epsilon_{b}$ próximos e suficientemente pequenos (de tal modo que os termos quadráticos sejam negligenciáveis). Isso ocorre nesse caso em particular pois a estimativa para a frente sempre erra para mais (termo $+2 \alpha \epsilon_{f}$ ) enquanto a outra sempre erra para menos (termo $-2 \alpha \epsilon_{b}$ ), ao passo que na média geométrica o termo $\alpha\left(\epsilon_{f}-\epsilon_{b}\right)$ "quase se anula". Raciocínio análogo vale para o caso em que a derivada é monotonicamente decrescente entre $x[n-1]$ e $x[n+1]$, invertendo o papel das estimativas para trás e para a frente. Contra-exemplos dessa propriedade podem ser produzidos quando o intervalo contém singularidades na segunda derivada, e por essa mesma razão tais contraexemplos podem ser considerados relativamente raros.

\section{Estimativa utilizando o operador de energia discreto}

Utilizando o TEO discreto (Eq. 2.81), e partindo de $x[n]=A \cos (\omega n+\phi)$ temos [Kve03]

$$
\begin{aligned}
x[n] & =A \cos (\omega n+\phi), \\
x[n-1] & =A \cos (\omega(n-1)+\phi), \\
x[n+1] & =A \cos (\omega(n+1)+\phi) .
\end{aligned}
$$




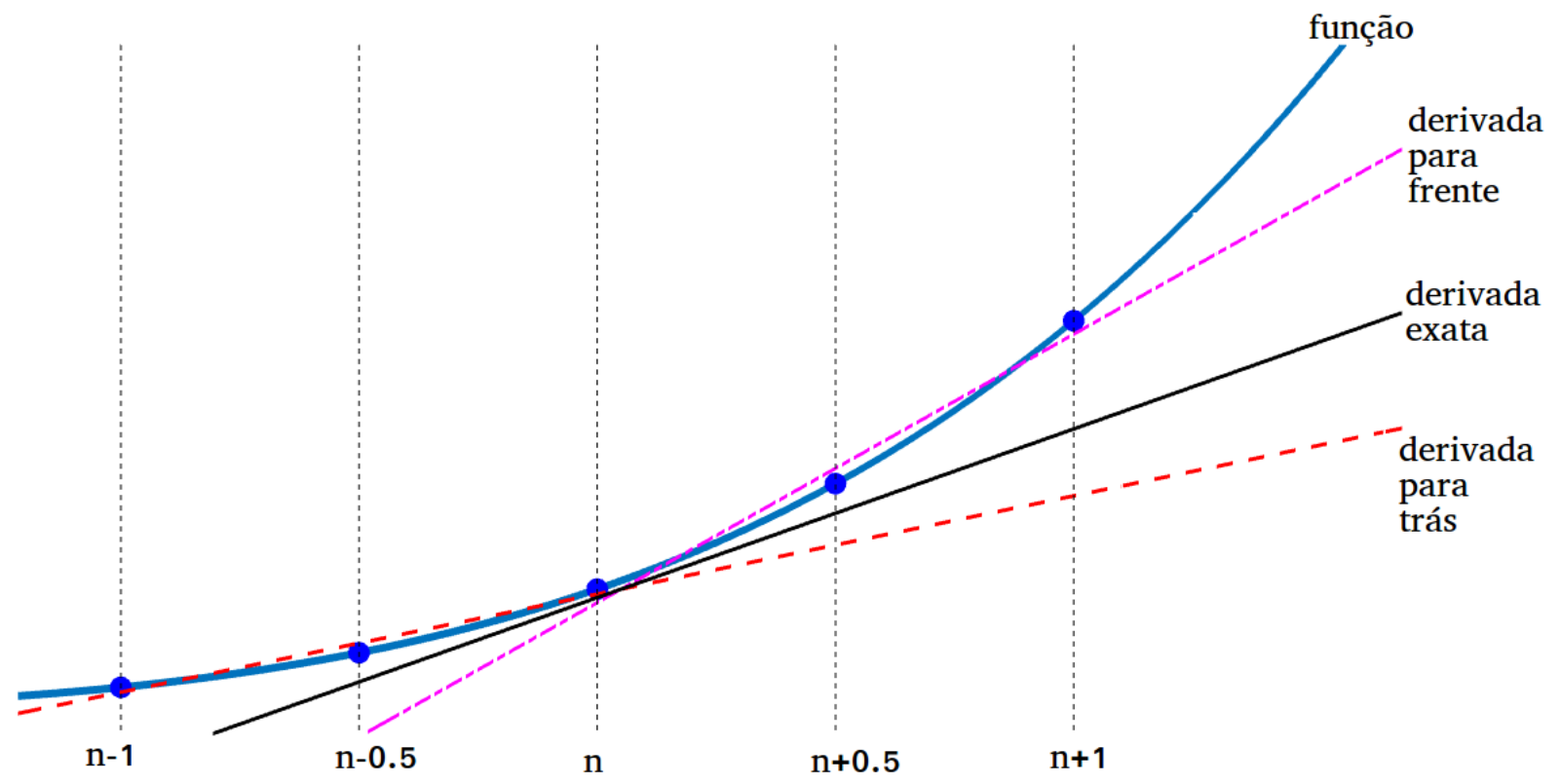

Figura 2.14: Cenários para aproximação da derivada de um sinal.

Lembrando das relações trigonométricas

$$
\cos (a+b) \cos (a-b)=\frac{1}{2}(\cos (2 a)+\cos (2 b))
$$

e

$$
\cos (2 a)=2 \cos ^{2}(a)-1=1-\sin ^{2}(a)
$$

temos

$$
\begin{aligned}
x[n-1] x[n+1] & =A \cos (\omega(n-1)+\phi) A \cos (\omega(n+1)+\phi) \\
& =A \cos (\omega n+\phi-\omega) A \cos (\omega n+\phi+\omega) \\
& =\frac{1}{2} A^{2}(\cos (2(\omega n+\phi))+\cos (2 \omega)) \\
& =\frac{1}{2} A^{2}\left(2 \cos ^{2}(\omega n+\phi)-1+1-\sin ^{2}(\omega)\right) \\
& =\frac{1}{2} A^{2}\left(2 \cos ^{2}(\omega n+\phi)-\sin ^{2}(\omega)\right) \\
& =A^{2} \cos ^{2}(\omega n+\phi)-\frac{1}{2} A^{2} \sin ^{2}(\omega) \\
& =x^{2}[n]-\frac{1}{2} A^{2} \sin ^{2}(\omega) .
\end{aligned}
$$

Logo,

$$
\psi(x[n])=x^{2}[n]-x[n-1] x[n+1]=\frac{1}{2} A^{2} \sin ^{2}(\omega) .
$$

A Figura 2.15 mostra a aplicação do TEO discreto a um sinal senoidal sem modulação. Note que a estimativa é constante, fato previsto na teoria (Eq. 2.82). 


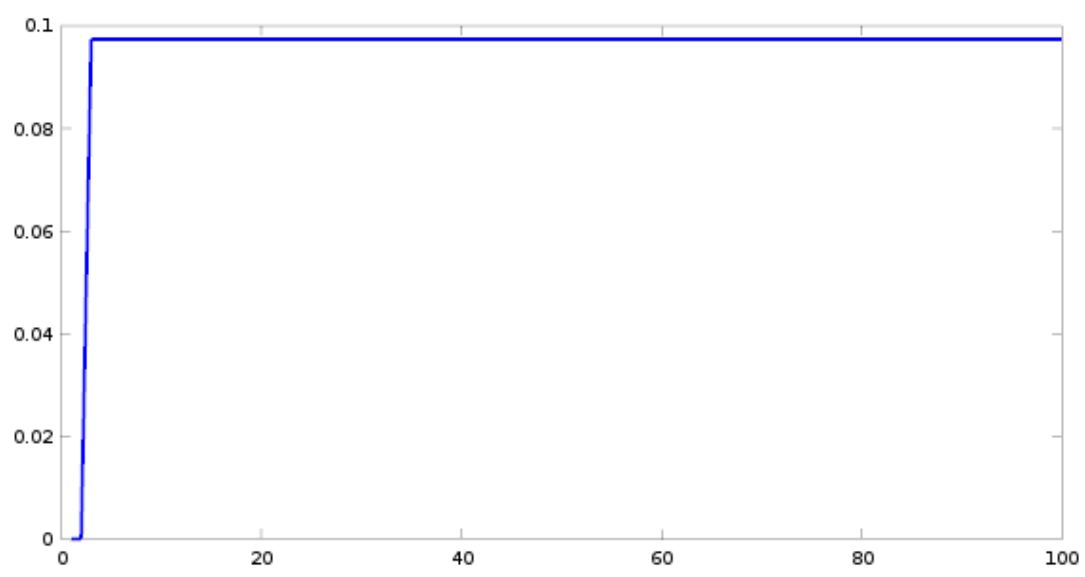

Figura 2.15: Valor constante do TEO discreto aplicado a uma entrada senoidal.

\section{O algoritmo para separação de energia, caso discreto}

Da mesma maneira que no caso contínuo, o algoritmo para separação de energia no caso discreto (DESA) é baseado na aplicação do operador de energia tanto no sinal quanto numa aproximação para a sua derivada. Para analisar a aplicação do TEO na derivada do sinal podemos fazer

$$
y[n]=x[n]-x[n-1]=A(\cos (\omega n+\phi)-\cos (\omega(n-1)+\phi)) .
$$

Lembrando que $\cos (a)-\cos (b)=2 \sin \left(\frac{a+b}{2}\right) \sin \left(\frac{b-a}{2}\right)$, temos

$$
y[n]=-2 A \sin \left(\frac{2 \omega n-\omega+2 \phi}{2}\right) \sin \left(\frac{\omega}{2}\right)=-2 A \sin \left(\frac{\omega}{2}\right) \sin \left(\omega n+\phi-\frac{\omega}{2}\right) .
$$

Aplicando o operador obtemos

$$
\begin{aligned}
\psi(y[n]) & =y^{2}[n]-y[n-1] y[n+1] \\
& =4 A^{2} \sin ^{2}\left(\frac{\omega}{2}\right)\left\{\sin ^{2}\left(\omega n+\phi-\frac{\omega}{2}\right)+\sin \left(\omega(n-1)+\phi-\frac{\omega}{2}\right) \sin \left(\omega(n+1)+\phi-\frac{\omega}{2}\right)\right\} \\
& =4 A^{2} \sin ^{2}\left(\frac{\omega}{2}\right)\left\{\sin ^{2}\left(\omega n+\phi-\frac{\omega}{2}\right)+\sin \left(\omega n+\phi-\frac{\omega}{2}-\omega\right) \sin \left(\omega n+\phi-\frac{\omega}{2}+\omega\right)\right\} .
\end{aligned}
$$

Fazendo $\theta=\omega n+\phi-\frac{\omega}{2}$ ficamos com

$$
\begin{aligned}
\psi(x[n]) & =4 A^{2} \sin ^{2}\left(\frac{\omega}{2}\right)\left\{\sin ^{2}(\theta)+\sin (w-\theta) \sin (\theta+\omega)\right\} \\
& =4 A^{2} \sin ^{2}\left(\frac{\omega}{2}\right)\left\{\sin ^{2}(\theta)+\cos (2 \theta)-\cos (2 \omega)\right\} \\
& =4 A^{2} \sin ^{2}\left(\frac{\omega}{2}\right)\left\{\sin ^{2}(\theta)+\left(1-\sin ^{2}(\theta)\right)-\left(1-\sin ^{2}(\omega)\right)\right\} \\
& =4 A^{2} \sin ^{2}\left(\frac{\omega}{2}\right)\left\{\sin ^{2}(\theta)+1-\sin ^{2}(\theta)-1+\sin ^{2}(\omega)\right\} .
\end{aligned}
$$

Logo,

$$
\psi(x[n]-x[n-1])=4 A^{2} \sin ^{2}\left(\frac{\omega}{2}\right) \sin ^{2}(\omega)
$$


De 2.82 e 2.83 temos que

$$
\frac{\psi(y[n])}{2 \psi(x[n])}=2 \sin ^{2}\left(\frac{\omega}{2}\right)=1-\cos (\omega) .
$$

Para calcular as estimativas de $a[n]$ e $w[n]$ no caso discreto fazemos

$$
\begin{gathered}
\omega[n]=\cos ^{-1}\left(1-\frac{\psi(x[n]-x[n-1])}{2 \psi(x[n])}\right) \\
|a[n]|=\sqrt{\frac{\psi(x[n])}{\sin ^{2}(\omega)}}=\sqrt{\frac{\psi(x[n])}{1-\cos ^{2}(\omega)}}=\sqrt{\frac{\psi(x[n])}{1-\left(1-\frac{\psi(x[n]-x[n-1])}{2 \psi(x[n])}\right)^{2}}} .
\end{gathered}
$$

A Figura 2.16 mostra o resultado da aplicação do algoritmo de separação de energia a uma entrada senoidal sem modulação AM nem FM. Note que neste cenário a estimativa é perfeita, ou seja, recuperamos perfeitamente o valor do envelope (neste exemplo, unitário) e da frequência instantânea (neste exemplo, constante).
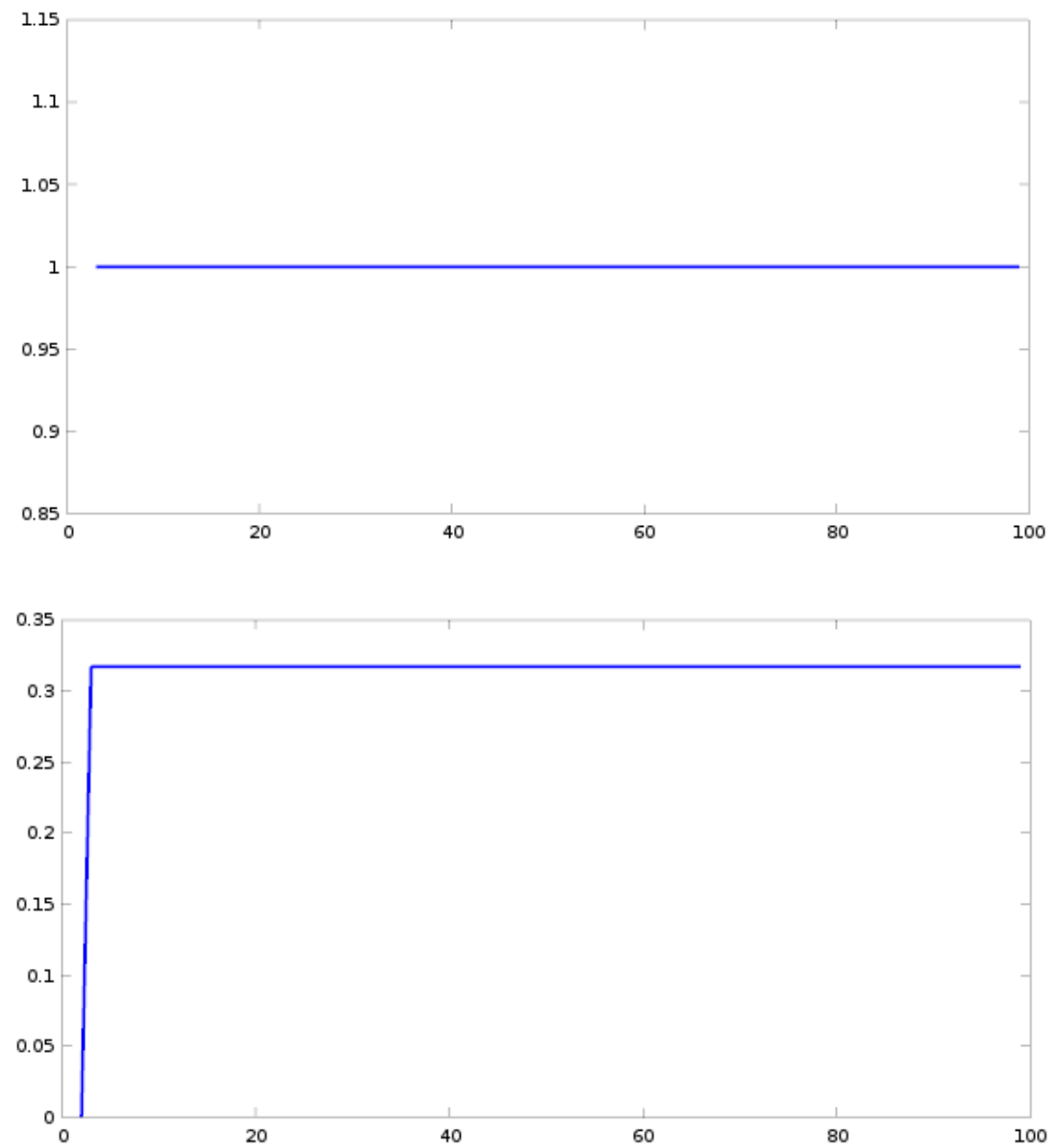

Figura 2.16: Estimativa via DESA de envelope (alto) e frequência instantânea (baixo) de senoide com frequência $2 \mathrm{~Hz}$ e amplitude de pico unitária. Exemplo criado com amostragem em $20 \mathrm{~Hz}\left(\frac{2 \pi}{20} \approx 0.32 \frac{\mathrm{rad}}{\mathrm{s}}\right)$.

A implementação em Csound do DESA é realizada a partir de atrasos (que possibilitam acesso às amostras da janela considerada pelo algoritmo) e aplicação direta das fórmulas apresentadas previamente. O Código 2.10 mostra nossa implementação de um opcode para calcular as estimativas 
de envelope e frequência instantânea.

Código 2.10: UDO para decomposição AM/FM baseada em Operador de Energia de Teager-Kaiser e Algoritmo de Separação de Energia.

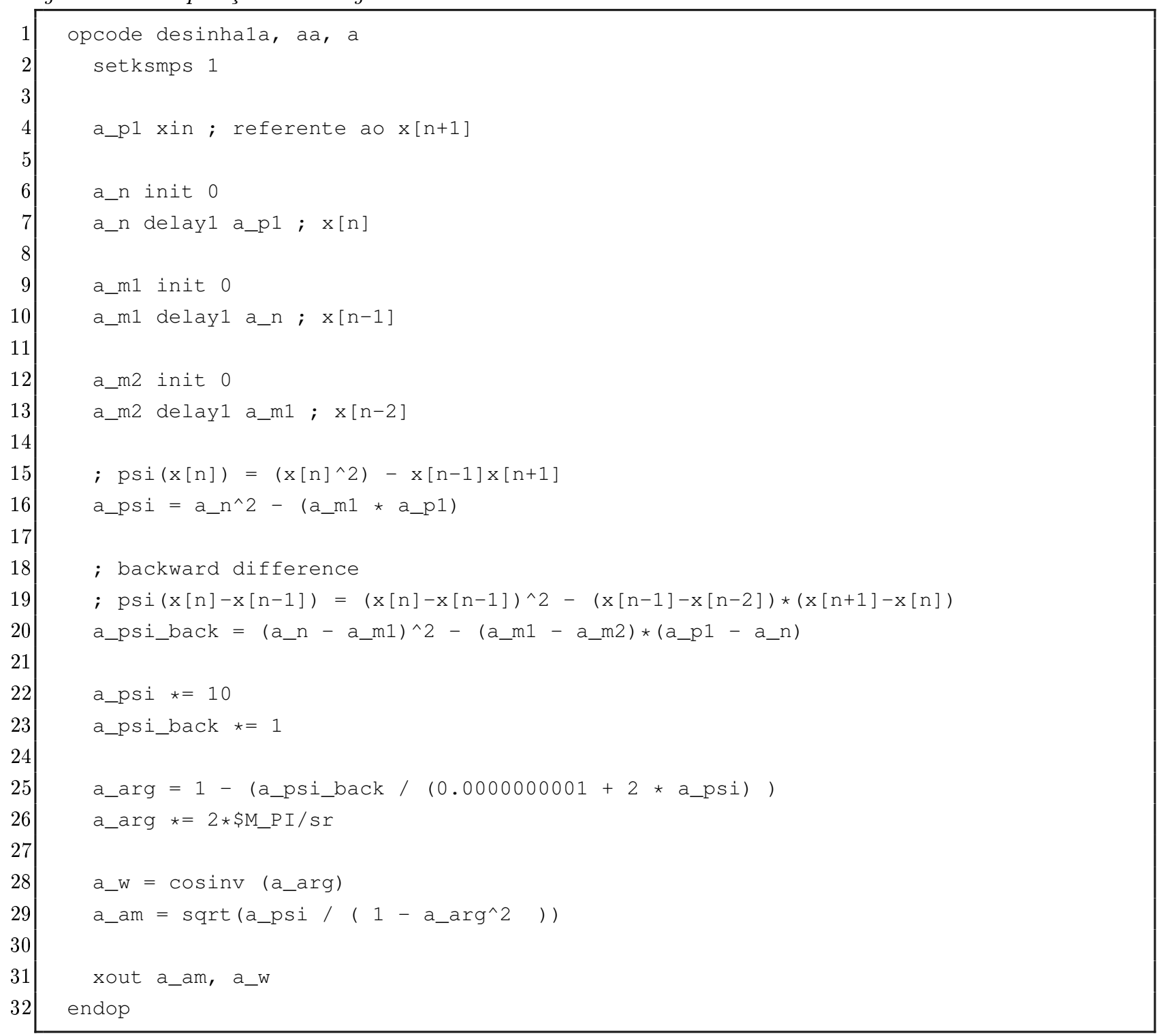

\section{Aplicação do operador de energia a sinais modulados}

Nas seções anteriores mostramos o funcionamento da estimativa de envelope e frequência instantânea de sinais senoidais sem modulação. Mostramos que a partir da aplicação do TEO no sinal e em sua derivada, combinamos os resultados para obter valores exatos para os parâmetros da senoide sob análise. No entanto, quando aplicado a sinais da forma

$$
y(t)=a(t) \cos \left(\int_{0}^{t} \omega(\tau) d \tau\right)
$$

com $a(t)$ e/ou $\omega(t)$ variantes, o operador de energia não apresenta os resultados como em 2.75 e 2.76, mas apresenta também uma parcela de erro somada a estes valores.

Para entender o comportamento deste erro podemos deduzir uma das propriedades do operador 
de energia referente à sua aplicação a um produto de sinais, de acordo com

$$
\begin{aligned}
\psi[x(t) y(t)] & =\left(\frac{d}{d t}(x y)\right)^{2}-x y\left(\frac{d^{2}}{d t^{2}}(x y)\right) \\
& =(x \dot{y}+y \dot{x})^{2}-x y(x \ddot{y}+\dot{y} \dot{x}+y \ddot{x}+\dot{x} \dot{y}) \\
& =\left(x^{2} \dot{y}^{2}+2 x \dot{x} y \dot{y}+y^{2} \dot{x}^{2}\right)-x y(x \ddot{y}+\dot{x} \dot{y}+y \ddot{x}) \\
& =x^{2}\left(\dot{y}^{2}-y \ddot{y}\right)+y^{2}\left(\dot{x}^{2}-x \ddot{x}\right) \\
& =x^{2}(t) \psi[y(t)]+y^{2}(t) \psi[x(t)] .
\end{aligned}
$$

A partir desta propriedade podemos analisar o comportamento do TEO aplicado a um oscilador modulado em AM e FM, fazendo

$$
\psi[a(t) \cos (\phi(t))]=a^{2}(t) \psi[\cos (\phi(t))]+\cos ^{2}(\phi(t)) \psi[a(t)]
$$

Utilizando 2.74 temos

$$
\psi[\cos \phi(t)]=\left(\frac{d \cos (\phi(t))}{d t}\right)^{2}-\cos (\phi(t)) \frac{d^{2} \cos (\phi(t))}{d t^{2}},
$$

sendo

$$
\frac{d \cos (\phi(t))}{d t}=-\sin (\phi(t)) \dot{\phi}(t)
$$

$\mathrm{e}$

$$
\frac{d^{2} \cos (\phi(t))}{d t^{2}}=\frac{d\{-\sin (\phi(t)) \dot{\phi}(t)\}}{d t}=-\sin (\phi(t)) \ddot{\phi}(t)-\dot{\phi}^{2}(t) \cos (\phi(t)) .
$$

Substituindo a última expressão em 2.89 temos

$$
\begin{aligned}
\psi[a(t) \cos (\phi(t))] & =a^{2}(t)\left\{\sin ^{2}(\phi(t)) \dot{\phi}^{2}(t)+\cos ^{2}(\phi(t)) \dot{\phi}^{2}(t)+\sin (\phi(t)) \cos (\phi(t)) \ddot{\phi}(t)\right\}+\cos ^{2}(\phi(t)) \psi[a(t)] \\
& =a^{2} \dot{\phi}^{2}(t)+\frac{1}{2} a^{2} \ddot{\phi}^{2}(t) \sin (2 \phi)+\cos ^{2}(\phi(t)) \psi[a(t)] \\
& =\underbrace{a^{2}(t) \dot{\phi}^{2}(t)}_{D}+\underbrace{\frac{\psi(a(t))}{2}}_{E_{L}}+\underbrace{a^{2}(t) \phi \ddot{(}(t) \sin (2 \phi(t))+\frac{\psi(a(t))}{2} \cos (2 \phi(t))}_{E_{H}} .
\end{aligned}
$$

Nesta expressão, o termo desejado é representado por $D$ (quadrado da multiplicação entre envelope e FI, como em 2.75). Os termos denotados por $E_{L}$ e $E_{H}$ representam parcelas de erro na estimativa [MKQ93a].

Nos trabalhos seminais sobre TEO, Maragos, Kaiser e Quatieri [MKQ93b] [MKQ93a] apresentam cálculos do erro considerando casos específicos com restrições para os valores de $a(t)$ e $\omega(t)$. Os autores mostram analiticamente e por meio de experimentos algumas condições em que os erros nas estimativas de energia são desprezíveis. Para isso eles partem de um sinal AM/FM mais específico do que aquele representado em 2.87 , dado por

$$
y(t)=a(t) \cos \left(\omega_{c} t+\omega_{m} \int_{0}^{t} q(\tau) d \tau+\phi(0)\right)
$$

sendo $q(t) \in[-1,1], \omega_{m} \in\left[0, \omega_{c}\right]$, e $a(t)$ senoidal com frequência $\omega_{a}<\omega_{c}$. Este é um modelo de sinal pouco comum em sinais de áudio, mas que faz sentido em telecomunicações, onde a frequência da 
portadora $\omega_{c} t$ é muito mais alta do que as frequências de interesse no sinal a ser codificado (basta lembrar que para a transmissão de sinais radiofônicos a portadora corresponde às estações de rádio, na faixa dos $\mathrm{MHz})$.

Aplicando o esquema de análise a um sinal gerado de acordo com 2.91, podemos fazer as seguintes considerações [PM94b] quanto aos termos apresentados na Equação 2.90:

- o termo desejado $D$ é limitado em banda, com frequência máxima bem abaixo de $2 \omega_{c}$;

- o termo $E_{L}$ representa a parcela do erro localizada nas frequências "baixas" (próximas a $\omega_{c}$ );

- o termo $E_{H}$ representa a parcela do erro localizada em frequências "altas" (próximas a $2 \omega_{c}$ ).

Sendo assim, de uma maneira geral, uma possibilidade [MKQ93b] [PM94b] para diminuir o erro nas estimativas de energia é realizar uma filtragem passa-baixa após a aplicação do TEO, escolhendo uma frequência de corte abaixo de $2 \omega_{c}$. Utilizando esta técnica de separação de energia com suavização (SESA) foram relatadas [PM94b] reduções de até 50\% no erro.

Em relação à aplicação do TEO na derivada do sinal de um oscilador modulado em amplitude e frequência teremos (de acordo com a regra da cadeia para derivada do produto [THW09])

$$
\begin{aligned}
x(t) & =a(t) \cos \phi(t) \\
\dot{x}(t) & =\dot{a}(t) \cos (\phi(t))-a(t) \dot{\phi}(t) \sin (\phi(t)) \\
\psi[\dot{x}(t)] & =\psi[\dot{a}(t) \cos (\phi(t))]-\psi[a(t) \dot{\phi}(t) \sin (\phi(t))] .
\end{aligned}
$$

Utilizando a propriedade já apresentada para o operador de energia do produto, além da propriedade do TEO aplicado a uma composição de funções [Kai93], pode-se chegar numa expressão similar a 2.90 para $\psi[\dot{x}(t)]$. A expressão apresentará o termo desejado $a^{2}(t) \dot{\phi}^{4}(t)$ acrescido de parcelas de erro [MKQ93a]. Aplicando a mesma filtragem mencionada para o caso de $\psi[x(t)]$, uma parte do erro, com componentes em "altas frequências", será cortada da estimativa.

É importante notar que, mesmo com a redução do erro em $\psi[x(t)]$ e $\psi[\dot{x}(t)]$, se o sinal sob análise não é puramente senoidal e sem modulação, esse erro não será nulo. Como já comentado, existem casos de sinais sintetizados com modulação AM e FM nos quais podemos, por meio de uma série de restrições nos parâmetros escolhidos para a síntese, diminuir o erro na estimativa de energia via TEO (e em alguns caso inclusive garantir que o erro pós-filtragem seja desprezível). Na Figura 2.17 mostramos a aplicação do algoritmo de separação de energia a um sinal de acordo com 2.91, com parâmetros obedecendo às condições para controlar o erro. A estimativa do envelope é perfeita, a menos de um transiente. A frequência instantânea cresce de acordo com a reta responsável pela modulação FM neste exemplo. No entanto podemos notar picos (spikes) nos valores da FI, relacionados com instantes em que o envelope apresenta valor nulo.

Sinais de áudio oriundos de instrumentos musicais, no entanto, geralmente não são resultado de uma síntese de acordo com a Equação 2.91. Outro fator que passa a ser complicado ao se trabalhar com sinais instrumentais é a adequação de argumentos de funções às fórmulas ao longo do algoritmo. Por exemplo, na Equação 2.84 temos um quociente $\frac{\psi(\dot{x}[n])}{2 \psi(x[n])}$. Independentemente do sinal de entrada $x[n]$, todos os itens nessa fórmula (derivada do sinal e aplicação do TEO) são gerados sem complicações (linhas 16, 20 e 25 no Código 2.10). No entanto, em 2.85, o quociente é utilizado como argumento para um cosseno inverso, com domínio $[-1,1]$ (linha 28 no Código 2.10). 

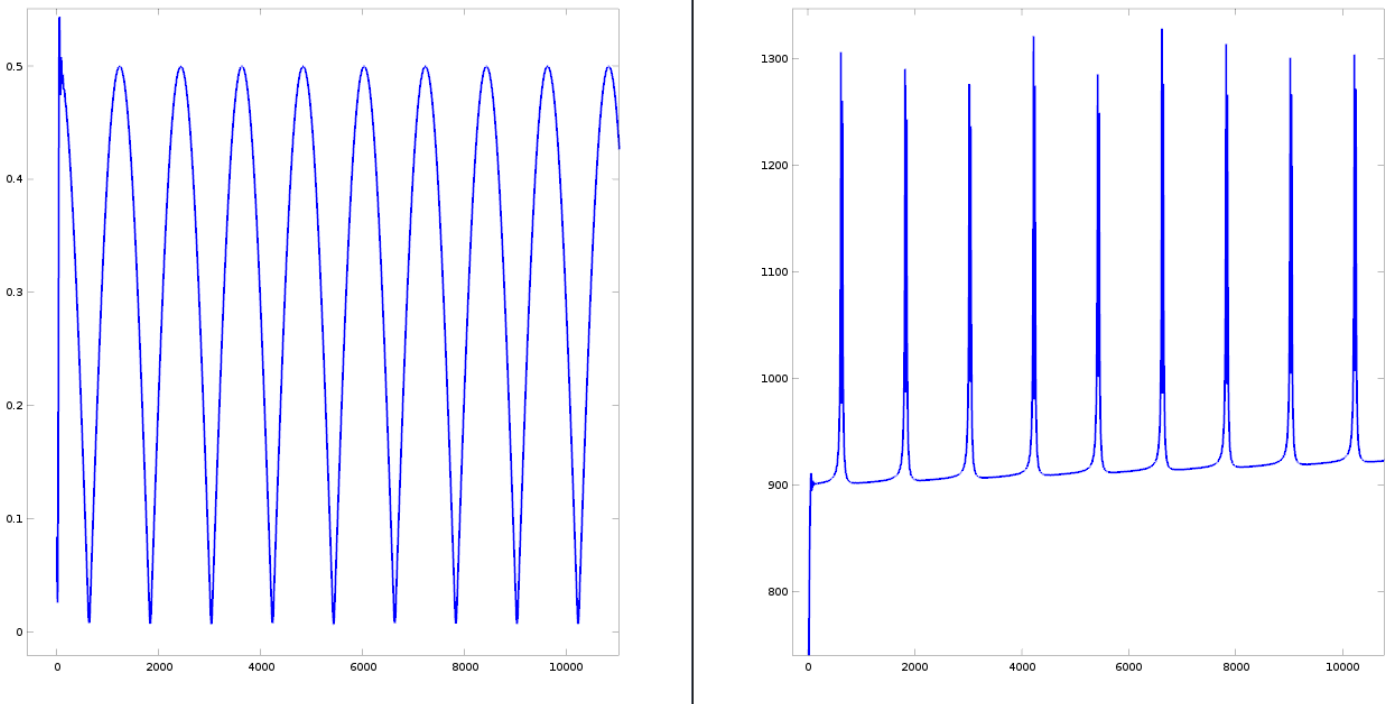

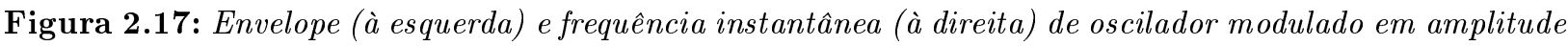
e frequência. Neste exemplo a AM foi gerada com um oscilador senoidal e a FM com uma rampa linear.

Não são raras situações em que ocorrem valores fora desta faixa ao utilizar sinais de instrumentos musicais, sendo assim importante investigar de antemão o comportamento do sinal de entrada e prever algum tipo de condicionamento antes da decomposição.

Diferentemente da decomposição via Transformada de Hilbert e sinal analítico, a decomposição de sinais de instrumentos acústicos utilizando ESA e suas variantes não é transparentes, ou seja, não conseguimos na maioria dos casos uma ressíntese perfeita do sinal analisado. No entanto, mesmo sem a transparência, por gerar na decomposição sinais de natureza diferente dos sinais gerados pela decomposição utilizando o sinal analítico, a decomposição via ESA pode ser uma escolha igualmente interessante para o projeto de efeitos de áudio.

\subsubsection{Decomposição multicomponente}

Nos esquemas de decomposição mostrados nas seções anteriores, o processo descrito leva em conta um sinal de áudio de entrada que será decomposto em dois sinais, correspondentes ao envelope e à frequência instantânea. Independentemente das características do sinal de entrada, a decomposição vai atribuir a um par envelope/FI características que consigam reproduzir ou aproximar o fenômeno oscilatório sendo analisado.

O espectro deste sinal de áudio de entrada pode apresentar diversos cenários, que variam desde uma única componente, no caso de um sinal senoidal sem modulação, até componentes presentes em toda a largura de banda disponível, de acordo com a taxa de amostragem considerada [DJ97]. Intuitivamente podemos pensar que quanto maior for a largura de banda de um sinal de áudio, mais difícil será para uma técnica de decomposição conseguir codificar a informação no par envelope/FI que pressupõe um único oscilador modulado em AM e FM. Em outras palavras, esperamos uma decomposição mais precisa se limitamos a banda do sinal. Além da largura de banda, outras características espectrais do sinal de entrada (e.g. harmonicidade, ruidosidade) também são determinantes para a precisão da decomposição.

Nesta seção consideramos um pré-processamento que consiste em dividir o sinal da entrada em bandas, e posteriormente realizar uma decomposição AM/FM individual para cada uma dessas 
bandas. Dessa maneira, ao invés de um único oscilador modulado em AM e FM, teremos um conjunto de osciladores para representar o sinal analisado. Em outras palavras, dividimos a tarefa de decomposição em diversas componentes, ou seja, cada par envelope/FI ficará responsável por codificar menos informação (apenas uma porção do espectro) do sinal original.

Diferentes aplicações da decomposição AM/FM utilizam diferentes estratégias para considerar a filtragem do sinal em bandas antes da etapa de decomposição. Os detalhes serão especificados nas seções seguintes, nas quais apresentaremos uma breve revisão das principais linhas de trabalhos de processamento de sinais de áudio com decomposição AM/FM.

No presente trabalho decidimos explorar uma decomposição do sinal de entrada utilizando filtros passa-banda centrados na frequência fundamental do sinal de entrada e em seus múltiplos inteiros, ou seja, uma decomposição harmônica. Tal decisão se apoia em dois pontos igualmente importantes:

- existência de um algoritmo [ZSM12] eficaz e preciso para estimativa de frequência fundamental de sinais de áudio, baseado em modificações na estrutura de um Phase-Lock Loop. Tal algoritmo é configurável para diferentes tipos de sinais de entrada, apresentando parâmetros que podem ser ajustados em função da natureza do sinal gerado pelo instrumento musical sob análise;

- instrumentos como guitarra e contrabaixo apresentarem espectros harmônicos, consequência do fato de que uma corda vibrante apresenta a tendência de se dividir em seções de igual comprimento (chamadas parciais), que também vibram produzindo componentes na série harmônica da nota tocada [Oka15].

Nas próximas seções vamos detalhar o funcionamento do algoritmo mencionado para estimativa da fundamental e levantar possibilidades a serem experimentadas em relação à filtragem prédecomposição AM/FM do sinal.

\section{Princípio de funcionamento do Phase-Lock Loop}

Phase-Lock Loop (PLL) é um sistema de controle que opera sincronizando a fase de seu oscilador local com a fase de um sinal de entrada, por meio de retroalimentação negativa. PLLs são utilizados em diversos tipos de aplicações, como por exemplo na demodulação de sinais AM e FM. No cenário de recepção de ondas de rádio moduladas, o receptor precisa dos valores de frequência e fase da portadora utilizada no transmissor. O processo de estimativa destes valores é denominado recuperação da portadora [JS03]. No caso de transmissões de rádio, mesmo que tenhamos de antemão o valor da frequência da portadora (é a frequência da estação que queremos sintonizar), a recuperação da portadora se faz necessária pois podem ocorrer flutuações (drift) em decorrência da transmissão [JS03].

Na Figura 2.18 apresentamos um diagrama do funcionamento do PLL. Os principais componentes do PLL se encontram na parte superior da figura: o detector de fase (PD) compara a fase dos sinais de entrada e do oscilador local (VCO), gerando um sinal de erro proporcional à diferença entre as mesmas; na sequência o sinal de erro é filtrado (LF) e usado para alimentar o oscilador local, adaptando sua frequência no sentido de diminuir o sinal de erro gerado no detector de fase [Gar05]. Estabelecida a sincronia, o oscilador local e o sinal de entrada apresentam aproximadamente a mesma frequência. 


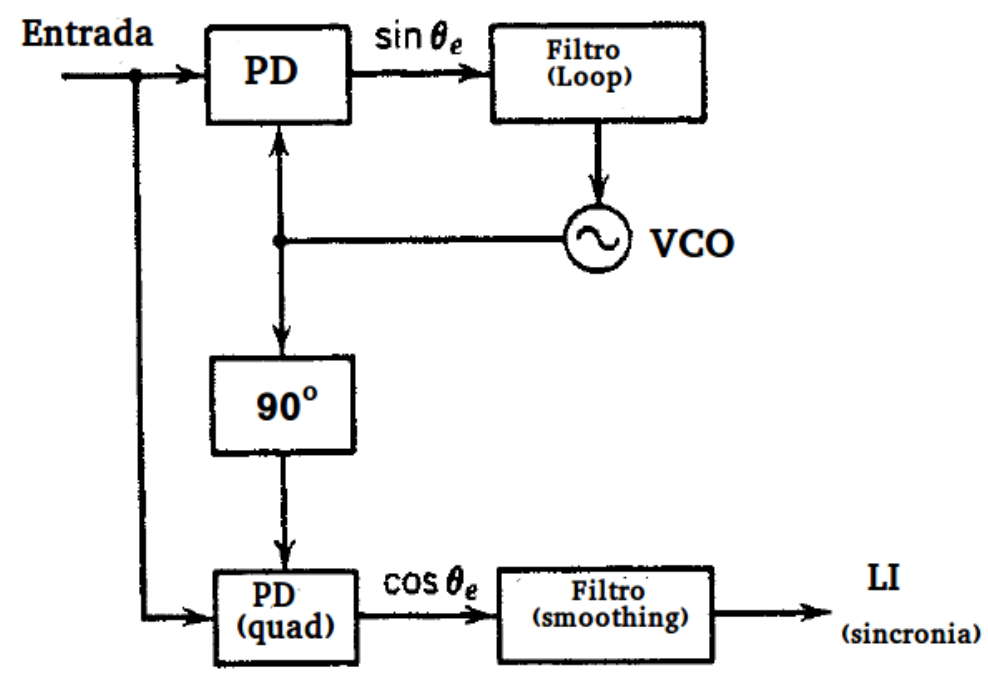

Figura 2.18: Diagrama de blocos do PLL. Na parte superior da figura temos os 3 elementos principais: detector de fase, filtro, e oscilador local. Na parte inferior da figura temos um esquema para obtenção de um indicativo de sincronia. Fonte: [Gar05] (adaptada).

Geralmente, o detector de fase é um simples multiplicador. Supondo um sinal de entrada senoidal $x(n)=\sin \left(\omega_{i}(n)+\phi_{i}(n)\right)$ e o sinal do VCO dado por $x_{v c o}(n)=\cos \left(\omega_{v c o}(n)+\phi_{v c o}(n)\right)$. Estes sinais são multiplicados e filtrados no bloco LF, de acordo com:

$$
x(n) x_{v c o}(n)=L P F\left\{\sin \left(\omega_{i}(n)+\phi_{i}(n)\right) \cos \left(\omega_{v c o}(n)+\phi_{v c o}(n)\right)\right\},
$$

sendo $L P F\{\}$ a representação da aplicação de um filtro passa-baixas. Lembrando que

$$
\sin (a) \cos (b)=\frac{1}{2}(\sin (a+b)+\sin (a-b))
$$

temos

$$
\begin{gathered}
x(n) x_{v c o}(n)=L P F\left\{\sin \left(\omega_{i}(n)+\phi_{i}(n)\right) \cos \left(\omega_{v c o}(n)+\phi_{v c o}(n)\right)\right\} \\
=\frac{1}{2} L P F\{\sin \left(\left(\omega_{i}-\omega_{v c o}\right)(n)+\phi_{i}(n)-\phi_{v c o}(n)\right)+\underbrace{\cos \left(\left(\omega_{i}+\omega_{v c o}\right)(n)+\phi_{i}(n)+\phi_{v c o}(n)\right)}_{L P F \text { elimina }}\} .
\end{gathered}
$$

Supondo que a filtragem passa-baixas elimine o segundo termo dentro de $L P F\{\}$, o sinal de erro filtrado é da forma

$$
v_{e}(n)=\frac{1}{2} \sin \left(\left(\omega_{i}-\omega_{v c o}\right)(n)+\phi_{i}(n)-\phi_{v c o}(n)\right) .
$$

Para valores pequenos do argumento do seno, vale a aproximação

$$
v_{e}(n) \approx \frac{1}{2}\left(\left(\omega_{i}-\omega_{v c o}\right)(n)+\phi_{i}(n)-\phi_{v c o}(n)\right)
$$

Como no estado de sincronia $\omega_{v c o}$ tende ao valor de $\omega_{i}$, o primeiro termo de $v_{e}(n)$ tende a desaparecer e ficamos com

$$
v_{e}(n) \approx \frac{1}{2}\left(\phi_{i}(n)-\phi_{v c o}(n)\right)
$$


Além destes componentes básicos de um sistema PLL, é comum encontrarmos também a produção de um sinal de saída relativo à qualidade da estimativa da frequência. A Figura 2.18 mostra um diagrama de blocos que considera tal funcionalidade. O bloco marcado com $90^{\circ}$ representa a operação de quadratura, que defasa um sinal em $90^{\circ}$. Para entender seu efeito, podemos alterar $x_{v c o}(n)$ na expressão 2.93 para $x_{v c o q}(n)=\sin \left(\omega_{v c o q}(n)+\phi_{v c o q}(n)\right)$ e ficar com

$$
x(n) x_{v c o q}(n)=\operatorname{LPF}\left\{\sin \left(\omega_{i}(n)+\phi_{i}(n)\right) \sin \left(\omega_{v c o q}(n)+\phi_{v c o q}(n)\right)\right\} .
$$

Lembrando então que

$$
\sin (a) \sin (b)=\frac{1}{2}(\cos (a-b)-\cos (a+b))
$$

ficamos com

$$
\begin{aligned}
x_{L I} & =x(n) x_{v c o q}(n)=L P F\left\{\sin \left(\omega_{i}(n)+\phi_{i}(n)\right) \sin \left(\omega_{v c o q}(n)+\phi_{v c o q}(n)\right)\right\} \\
& =\frac{1}{2} \operatorname{LPF}\{\cos \left(\left(\omega_{i}-\omega_{v c o q}\right)(n)+\phi_{i}(n)-\phi_{v c o q}(n)\right)-\underbrace{\cos \left(\left(\omega_{i}+\omega_{v c o q}\right)(n)+\phi_{i}(n)+\phi_{v c o q}(n)\right)}_{L P F \text { elimina }}\} \\
& \approx \frac{1}{2} \cos \left(\phi_{i}(n)-\phi_{v c o q}(n)\right) .
\end{aligned}
$$

Sendo assim, para sinais com erros $\phi_{i}(n)-\phi_{v c o q}(n)$ pequenos, temos $x_{L I} \rightarrow \frac{1}{2}$. Finalmente, aplica-se uma filtragem passa-baixas em $x_{L I}$ para diminuir as flutuações no indicativo de sincronia.

Nas aplicações usuais do PLL este indicador de sincronia pode ser utilizado como medida de confiabilidade do sistema; no nosso contexto de aplicação de efeitos de áudio, podemos pensar num esquema de gate, que só libera o sinal processado a partir de um determinado limiar para o valor de $x_{L I}$, e no caso desse sinal estar abaixo do limiar o efeito não atua, desviando diretamente para a saída o sinal de entrada.

\section{Audio PLL - Sistema para estimativa de fundamental baseado em PLLs}

Zölzer et al propuseram um sistema [ZSM12] baseado no funcionamento do PLL para estimativa de frequência fundamental de sinais de áudio, cujo diagrama de blocos é apresentado na Figura 2.19, e que abordaremos na sequência.

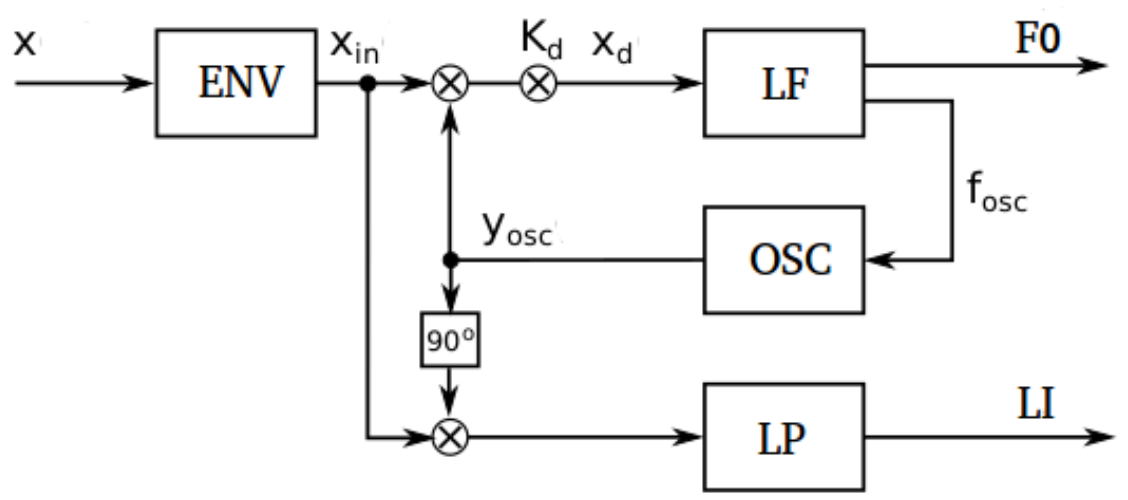

Figura 2.19: PLL adaptado para estimava de frequência fundamental. Fonte: [ZSM12] (adaptada).

A largura de banda que o sistema deverá considerar é um parâmetro importante no projeto. Zölzer propõe que consideremos a faixa que vai de $20 \mathrm{~Hz}$ a $1.5 \mathrm{KHz}$ para trabalhar com sinais de 
áudio, e além desta filtragem, propõe um pré-processamento para deixar constante o envelope do sinal (bloco ENV na Figura 2.19), facilitando o trabalho do PLL. Sendo assim temos

$$
x_{i n}(n)=\underbrace{x(n) * h_{L}(n) * h_{H}(n)}_{20 \mathrm{~Hz} \text { a } 1.5 \mathrm{kHz}} \cdot \underbrace{g_{\text {env }}(n)}_{\text {envelope constante }}
$$

com $g_{\text {env }}(n)=\frac{1}{x_{e n v}(n)}$, sendo $x_{e n v}(n)$ o envelope de $x(n) ; h_{L}$ e $h_{H}$ são os filtros responsáveis pela adequação inicial do sinal à banda mencionada.

A comparação da fase do sinal de entrada com a fase do oscilador local ocorre a partir da multiplicação $x_{i n}(n) . y_{o s c}(n)$. Na sequência do fluxo do sinal na malha, $K_{d}$ representa o ganho da malha, sendo

$$
x_{d}(n)=x_{i n}(n) \cdot y_{o s c}(n) \cdot K_{d}
$$

o sinal de erro que entra no bloco LF. Neste bloco, diferentemente dos PLLs tradicionais, temos além do filtro passa-baixas um curto circuito (trecho com ganho unitário), que somados dão origem a um filtro shelving [Zöl11], ou seja,

$$
F_{L F}(z)=1+H_{L P}(z)
$$

Note que como $H_{L P}$ é um passa-baixas seu ganho DC ( $\left.z=1\right)$ vale 1 , ou seja, o ganho DC de $F_{L F}$ vale 2 .

Sendo $f_{L F}(n)$ a representação no domínio do tempo para o filtro $F_{L F}(z)$, a filtragem de $x_{d}(n)$ por este filtro gera

$$
f_{\text {osc }}(n)=x_{d}(n) * f_{L F}(n),
$$

que é utilizada na geração do sinal do oscilador local, dado por

$$
y_{\text {osc }}(n)=\cos \left(2 \pi f_{\text {osc }}(n) n\right) .
$$

A estimativa de $F 0$ é feita também no bloco LF a partir do filtro passa-baixas, sendo

$$
F 0(n)=2 . x_{d}(n) * h_{L P}(n) .
$$

A multiplicação por 2 é para compensar o ganho DC em 2.101. A parte inferior da Figura 2.19 mostra um esquema para a obtenção de um sinal indicativo da qualidade da sincronia (LI), como comentado previamente.

Na literatura de sistemas de controle [FPEN14] e PLLs [Gar05], o comportamento de um sistema é geralmente analisado a partir das funções de transferência de malha aberta (sem retroalimentação) e malha fechada (com retroalimentação). No caso do sistema apresentado na Figura 2.19, considerando a malha superior temos as funções de transferência de malha aberta $G(z)$ e malha fechada $H(z)$ dadas por

$$
\begin{gathered}
G(z)=K_{d} F_{L F}(z) \frac{z^{-1}}{1-z^{-1}}=K_{d} F_{L F}(z) \frac{1}{z-1} \\
H(z)=\frac{G(z)}{1+G(z)}=\frac{K_{d} F_{L F}(z)}{(z-1)+K_{d} F_{L F}(z)} .
\end{gathered}
$$


Assim como no caso de um PLL comum, o comportamento do sistema depende de ajustes de desempenho que escolhemos no projeto, de acordo com as necessidades específicas de cada contexto. Por exemplo, quanto menor a largura de banda da faixa na qual a operação do PLL vai se concentrar, maior será a quantidade de ruído rejeitada [Gar05]; como outro exemplo, um sistema que acompanha mais rapidamente as alterações no valor de F0 também será mais ruidoso do que um sistema mais vagaroso, ou seja, apresentará mais flutuações na saída.

O projeto do PLL de Zölzer et al é dado basicamente por três parâmetros:

- ganho de malha / ganho de loop, $K_{d}$ : controla a faixa de frequência na qual o PLL vai operar, ajustando numa relação diretamente proporcional à frequência de corte de $H(z)$ em 2.106 $(H(z)$ apresenta um comportamento de filtro passa-baixas);

- frequência de corte $f_{c}$ do filtro shelving $F_{L F}(z)$ : controla o tempo de ataque do PLL, ou seja, a velocidade com a qual o sistema acompanha as variações de frequência no sinal de entrada. Valores maiores para $f_{c}$ permitem que frequências mais altas atuem no sistema, aumentando sua velocidade, porém aumentam também as flutuações (ripples). Reduzindo $f_{c}$ obtemos uma estimativa mais limpa, porém mais lenta, para a fundamental;

- fator de mérito / fator de qualidade $Q$ do filtro shelving $F_{L F}(z)$ : o fator $Q$ de um filtro está relacionado com a inclinação de sua banda de transição. No caso de $F_{L F}(z)$, valores maiores de $Q$ tornam mais íngreme a banda de transição, mas aumentam também a ressonância em torno de $f_{c}$. Sendo assim, o ajuste de $Q$ influencia na capacidade do sistema de acompanhar as variações da fundamental do sinal sob análise.

A partir destes valores os coeficientes do filtro

$$
H_{L P}(z)=\frac{b_{0}+b_{1} z^{-1}+b_{2} z^{-2}}{1+a_{1} z^{-1}+a_{2} z^{-2}}
$$

presente no bloco LF (Equação 2.101) são dados por [ZSM12]

$$
a_{1}=2 .\left(k^{2}-1\right) \cdot k_{1}, \quad a_{2}=\left(1-\frac{k}{Q}+k^{2}\right) \cdot k_{1}, \quad b_{0}=k^{2} \cdot k_{1}, \quad b_{1}=2 . k \cdot k_{1}, \quad b_{2}=k^{2} \cdot k_{1},
$$

sendo

$$
k=\tan \left(\pi \frac{f_{c}}{f_{S}}\right) \quad \text { e } \quad k_{1}=\frac{1}{1+\frac{k}{Q}+k^{2}} .
$$

Em Csound temos disponível o opcode plltrack, com a implementação do sistema descrito nesta seção. Nos trabalhos em que este sistema baseado em PLL para detecção de fundamental foi proposto [ZSM12] ótimos resultados foram relatados aplicando o sistema tanto em sinais sintetizados quanto em sinais de instrumentos musicais acústicos.

Neste trabalho o sistema foi utilizado para detecção de fundamental em sinais de guitarra elétrica, flauta, e saxofone, apresentando resultados satisfatórios. O Código 2.11 apresenta uma das aplicações sugeridas pelos autores do Audio PLL, batizada de oscilador multi-senoidal [Zöl12]: o efeito consiste em detectar a fundamental tocada numa guitarra elétrica e sintetizar um sinal com o mesmo pitch, porém timbre sintetizado de acordo com a intenção artística, a partir da soma de senoides com frequências relacionadas com a fundamental detectada. Neste exemplo geramos um simples sinal senoidal. 
Código 2.11: Efeito de áudio baseado na detecção de fundamental e transformação do sinal de instrumento acústico para senoide mantendo o pitch original.

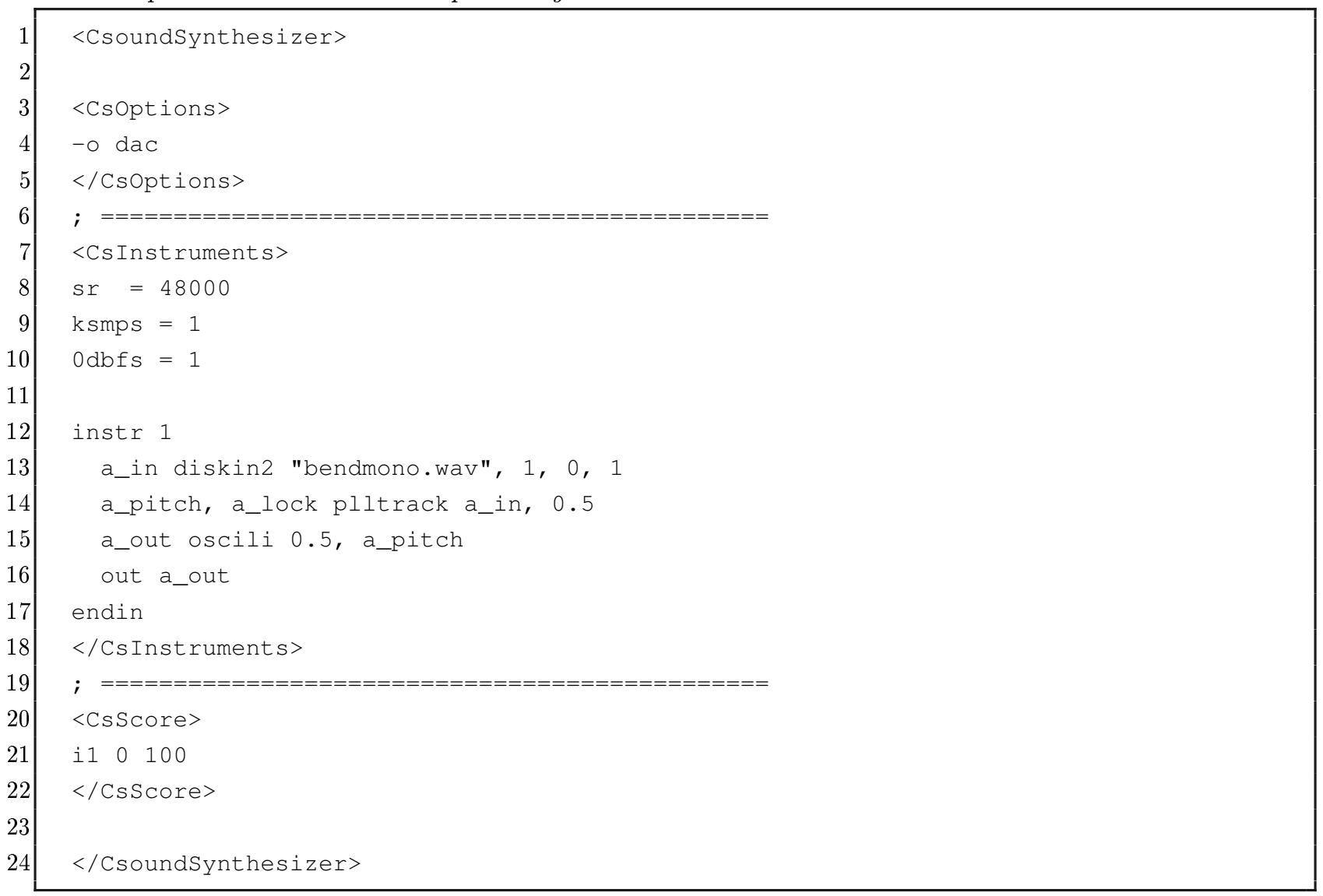

No capítulo seguinte mais detalhes sobre a afinação do PLL serão apresentados. É importante lembrar que existem diversos outros métodos disponíveis para estimativa de frequência fundamental em sinais de áudio. Uma revisão voltada para estimativa em sinais de guitarra com possibilidade de aplicação em tempo real foi apresentada em [vdKZ10]. No entanto, o baixo custo computacional do Audio PLL de Zölzer e sua adequação à estimativa de fundamental em nossos testes preliminares fizeram deste o método escolhido para o presente trabalho. Além disso, a possibilidade de alterar em tempo real os parâmetros do PLL, e assim alterar as características do sinal da estimativa de F0, apresenta diversas possibilidades musicais, por exemplo, a criação de efeitos que exploram artefatos na detecção; por outro lado, essa mesma possibilidade permite afinar o sistema ao longo de toda uma performance, de acordo com as necessidades e variações de timbre exploradas em diferentes contextos.

\section{Cenários para separação pré-decomposição do sinal em bandas}

Nesta pesquisa estamos interessados principalmente na aplicação de efeitos de áudio a sinais de instrumentos acústicos, especialmente guitarra e contrabaixo. Tais instrumentos são bastante versáteis, podendo ser explorados de diversas maneiras e em diferentes contextos musicais. A guitarra e o contrabaixo possibilitam a execução tanto de melodias quanto de harmonias, alteração rápida da tensão das cordas (alterando assim as frequências produzidas), além da execução de sons percussivos, sendo assim considerados instrumentos coringa, capazes de assumir diversas funções musicais.

Considerando o cenário de processamento de sinais para aplicação de efeitos, uma das facilida- 
des apresentadas por estes instrumentos é o fato de possuírem captadores que convertem o sinal proveniente da vibração das cordas do instrumento para um sinal elétrico, que pode facilmente ser levado ao computador com um cabo e uma interface de áudio ${ }^{3}$. No entanto, qualquer instrumento acústico pode ser utilizado, com a ressalva de que a qualidade do microfone e o controle da acústica do ambiente onde ocorrerá a performance serão decisivos para a obtenção de um bom sinal que possibilite um processamento posterior adequado.

Num primeiro momento, nossa exploração de efeitos AM/FM está circunscrita ao contexto de linhas melódicas, ou seja, notas individuais tocadas no instrumento. A guitarra e o contrabaixo, assim como outros instrumentos, apresentam um espectro harmônico, ou seja, composto por componentes com frequências dadas por múltiplos inteiros de uma frequência fundamental. Sendo assim, alguns exemplos de cenários que podem ser explorados na separação do sinal previamente à decomposição $\mathrm{AM} / \mathrm{FM}$ são:

- considerar uma única banda centrada na fundamental do sinal: uma vez que os efeitos que serão aplicados após a decomposição apresentam a possibilidade de enriquecer o espectro do sinal, começar com um espectro estreito pode ser uma abordagem que libera a maior parte do espectro disponível para componentes que serão criadas. Esta estratégia de evitar competição pelo espectro é adotada no contexto de mixagem de sinais de áudio;

- considerar uma banda centrada na fundamental e outras bandas centradas em múltiplos inteiros da fundamental: nesta abordagem também temos a opção de deliberadamente empobrecer o espectro inicial do instrumento como no caso anterior, ou então considerar o espectro como um todo, numa abordagem parecida com um banco de filtros. O controle de quanto do espectro será retido é feito a partir do número de bandas e da largura destas;

- considerar uma banda estreita centrada em cada harmônico do instrumento: nesta abordagem a decomposição apresenta menos ruído/erro e mais sinais ficam disponíveis para aplicação de efeitos, porém o custo computacional também aumenta.

É interessante notar que a separação do sinal em bandas torna possível o projeto efeitos multifacetados, em que um tipo diferente de efeito é aplicado em cada banda (ou subconjunto específico de bandas). Outra possibilidade é controlar o nível wet do sinal ${ }^{4}$ não por meio de um controle $d r y /$ wet convencional, mas aplicando o efeito em poucas ou muitas bandas do sinal original, dependendo de quão perceptível se deseja o efeito após a ressíntese. Exemplos considerando estas artimanhas são apresentados no capítulo seguinte.

Também é natural pensar em efeitos stereo, em que subconjuntos diferentes das bandas processadas são roteados para diferentes saídas de áudio. Em Csound os filtros passa-banda nativos são representados pelos opcodes butterbp e reson. No Código 2.12 mostramos a decomposição do sinal em 3 bandas, centradas em $F 0,2 F 0$ e $3 F 0$, sendo que a fundamental $F 0$ é estimada pelo Audio PLL já apresentado. O efeito implementado neste exemplo é um exemplo simples de efeito stereo [ pll-stereo.wav]: enquanto a banda centrada em $F 0$ é copiada nos dois canais de saída, a banda centrada em $2 F 0$ vai apenas pro canal esquerdo e a banda centrada em $3 F 0$ apenas para o canal direito.

\footnotetext{
${ }^{3}$ Para mais informações veja o Apêndice A.

${ }^{4} \mathrm{O}$ controle $d r y /$ wet é um parâmetro comum em efeitos de áudio, tanto em pedaleiras quanto em plugins. Tipicamente pode apresentar valores $k \in[0,1]$. Chamando o sinal original de $d(d r y)$ e o processado de $w$ (wet), temos na saída do sistema o sinal $k w+(1-k) d$.
} 
Código 2.12: Separação do sinal em bandas centradas na fundamental e dois primeiros múltiplos inteiros.

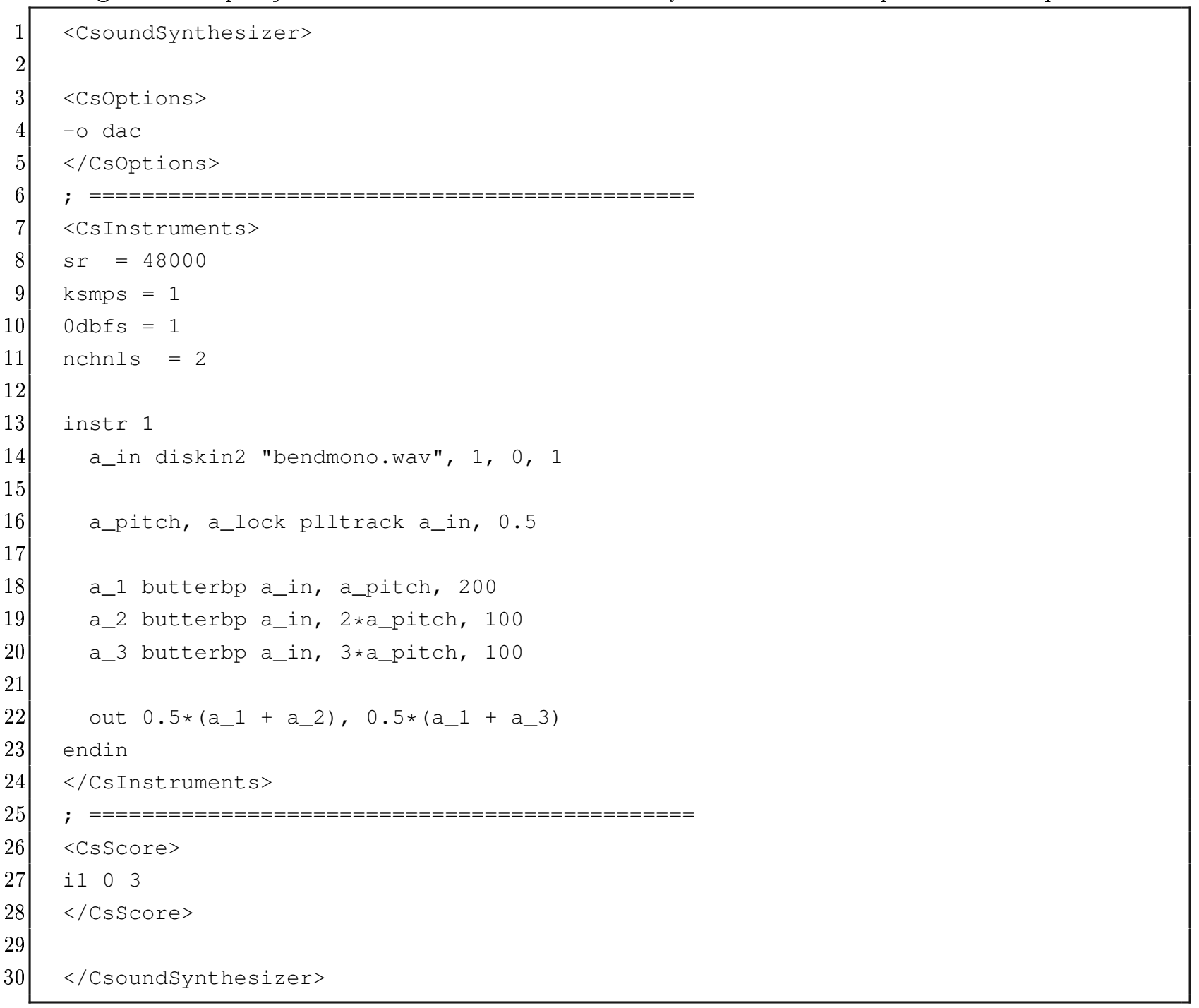

\subsection{Processamento de áudio no domínio AM/FM}

\subsubsection{Modulation Vocoder}

O Modulation Vocoder (MOD-VOC) é uma das linhas de trabalhos relacionados mais próximas da nossa pesquisa. Numa série de artigos de Sascha Disch e Bernd Edler, apresentados principalmente nas conferências Digital Audio Effects (DAFx) [DE08] [DE09a] [DE10] e International Conference on Acoustics, Speech and Signal Processing (ICASSP) [DE09b] [DE11].

Nos trabalhos com o MOD-VOC uma pré-análise do sinal de entrada é realizada para dividí-lo em bandas com frequências centrais dadas adaptativamente de acordo com os valores dos centros de gravidade espectral (COGs) do sinal analisado. Cada um dos COGs equivale à frequência representativa em sua banda, sendo que as bandas não apresentam largura uniforme, mas são determinadas a partir de escalas perceptuais específicas.

O esquema de decomposição utilizado no MOD-VOC é parecido com aquele utilizado em nosso trabalho e sua aplicação em cada banda está ilustrada na Figura 2.20. Em cada uma das bandas nas quais o sinal foi separado, o sinal analítico é obtido e utilizado para a estimativa do envelope e frequência instantânea. A diferença se dá pelo fato de que antes de estimar a fase do sinal analítico 
(de acordo com a expressão 2.56) este é multiplicado por um oscilador senoidal com frequência dada pelo valor da COG da banda em questão (no jargão de telecomunicações, este é um processo de heterodyning). Sendo assim, a decomposição utilizada no MOD-VOC produz 3 saídas para cada sinal utilizado: AM, FM, e frequência central (FC).

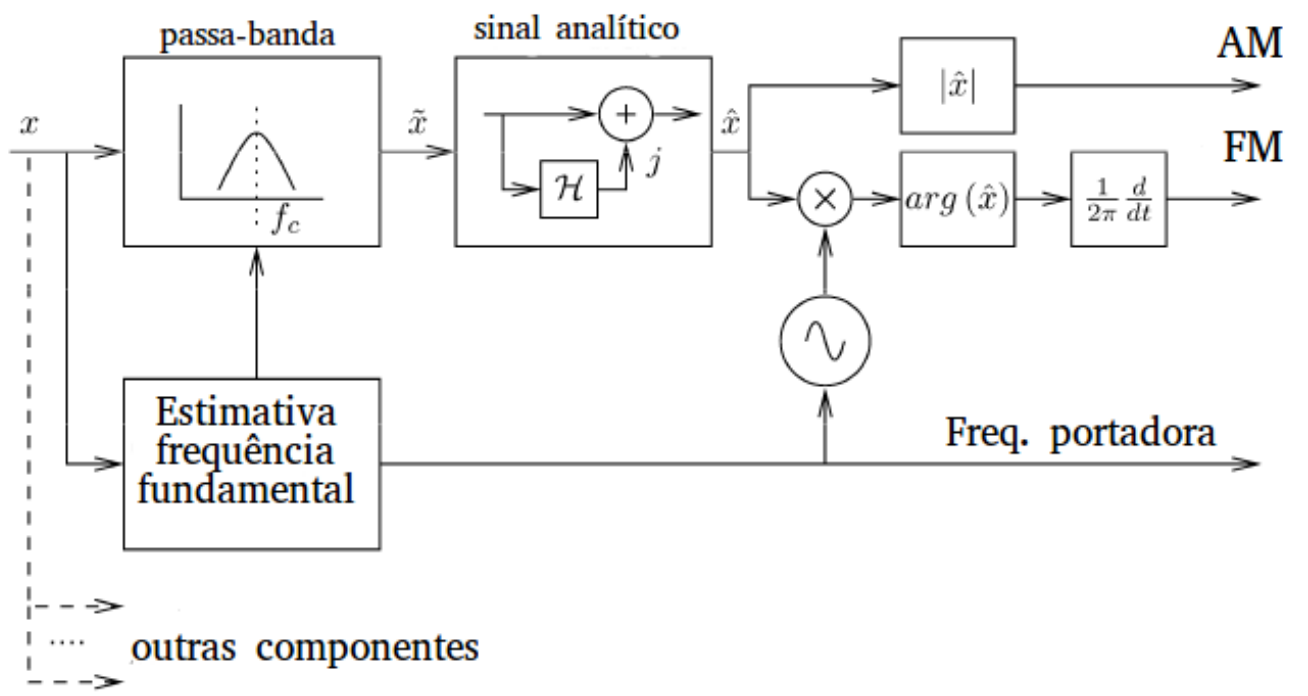

Figura 2.20: Esquema de análise do modulation vocoder. Fonte: adaptado de [DE08] (adaptada).

A partir do esquema apresentado os autores relatam interesse em explorar 3 possibilidades:

- utilização da análise AM/FM para determinar parâmetros significativos no modelo em termos de cognição, possibilitando assim o desenvolvimento de novos algoritmos para codificação de áudio para fins de compressão. Os autores apontam para estudos [McE92] sobre deteç̧ão de modulações por parte do nosso sistema auditivo;

- processamento da porção AM da decomposição para fins de alteração de timbre e controle de aspereza (roughness) do sinal;

- processamento das porções FC e FM da decomposição para fins de transposição tanto do sinal como um todo, quanto apenas de notas específicas.

Os resultados enfatizados nos artigos são aqueles com relação a este último tópico. Um exemplo simples de efeito citado é a multiplicação de todas as FCs por um mesmo valor, obtendo assim a transposição do sinal como um todo, como por exemplo no efeito de áudio conhecido como oitavador [Zöl11].

No entanto, a decomposição oferece potencial para transpor apenas algumas FCs, possibilitando assim uma transposição seletiva [DE11]. Os autores apresentam exemplos de alteração de modo de peças musicais, por exemplo alterando uma peça de modo menor para modo maior. Eles não entram em discussões profundas sobre teoria musical, mas indicam que a implementação do procedimento se dá por meio da transposição das FCs relacionadas com as notas de uma determinada escala que, quando alteradas, resultarão em outra escala, alterando assim o campo harmônico e modo da peça. Eles lembram também que, multiplicando as FMs pelo mesmo valor multiplicado pelas FCs, preserva-se o índice de modulação na aplicação do efeito. 


\subsubsection{Modulation Filtering}

Esta linha de trabalho é dedicada principalmente ao processamento de sinais de voz, visando diferentes aplicações como aumento de inteligibilidade, realce de sinal, separação de sinais [SA05] e filtragem comum do sinal de modulação [LA08]. Em [CA09] são investigadas restrições no processamento pós-decomposição com o intuito de diminuir ruídos em decorrência do esquema de análise; são também discutidas adaptações para o sistema que acabaram não apresentando melhorias no nível de ruído dos sinais considerados.

A ideia principal nos trabalhos de modulation filtering (MF) é a de que sinais de áudio são processos em que moduladores de "baixa" frequência modulam portadoras de "alta" frequência [CA09]. A decomposição utilizada em MF é denominada coerente, uma vez que considera, previamente à decomposição, as frequências presentes no sinal sob análise. Diferentemente do esquema de análise baseado no sinal analítico (expressões 2.55, 2.56 e 2.57), que gera um envelope real e não-negativo, a decomposição utilizada em MF gera um sinal complexo para o envelope, apresentando diferentes possibilidades para o processamento.

Primeiramente o sinal $s(t)$ a ser analisado é separado em bandas $x(t)$, de maneira que cada um de seus harmônicos sejam separados em sinais distintos, sendo então gerado um sinal analítico $z(t)=x(t)+i \hat{x}(t)$ para cada banda. Na sequência, a frequência de cada harmônico é dada de acordo com a frequência instantânea do sinal naquela banda. Os procedimentos para estimar a FI variam e são baseados em técnicas como cálculo da frequência média condicional [LA08] (momento condicional na frequência, tal como apresentado em 2.45), cálculo da frequência a partir de sinal de fase com média nula [SA05], e centros de gravidade espectral [CA09]. Para cada harmônico obtém-se uma portadora com frequência dada pela FI e amplitude constante unitária, e sendo assim toda a informação relativa à dinâmica do sinal é codificada num envelope $m(t)$ que modula cada portadora em amplitude.

Para cada uma destas bandas $x(t)$, a portadora é representada por um fasor

$$
c(t)=e^{i \phi(t)}
$$

de tal modo que $\frac{d \phi(t)}{d t}$ equivale ao valor da frequência instantânea do harmônico da banda considerada. Sendo assim, temos como aproximação para $x(t)$ o produto

$$
x(t) \approx m(t) c(t)
$$

Logo, para separar uma estimativa do sinal modulador $m(t)$, ou envelope, desta banda, basta fazer a operação de demodulação (condições para a demodulação, visando manter baixo o nível de distorção introduzido com o procedimento, foram estudadas em [CA09]) de acordo com

$$
m(t)=x(t) c^{*}(t)=x(t) e^{-i \phi(t)} .
$$

Finalmente, numa abordagem semelhante àquela explorada em nosso trabalho, pode-se então processar $m(t)$ em cada banda e seguir para a etapa de ressíntese para obter o sinal com o efeito desejado. 


\subsubsection{Análise e classificação de sinais}

A maioria dos trabalhos nesta linha aplicam a decomposição AM/FM para posteriormente analisar e classificar principalmente sinais de voz, embora trabalhos com análise de sinais musicais também tenham sido realizados. Como discutido brevemente no capítulo de introdução, nosso sistema de produção de fala apresenta não-linearidades que induzem modulações em amplitude e frequência nos jatos de ar que servem de fonte para a produção da voz. Diferentemente dos modelos lineares de produção de voz, que não levam em conta tais fenômenos, o modelo AM/FM para sinais de voz considera cada formante como um oscilador modelado em AM e FM, sendo o sinal total a soma dos osciladores que representam cada formante. As características dos sinais gerados pelo aparelho fonador dos humanos serviram como motivação para as pesquisas iniciais de Teager com o operador de energia [Tea80] [TT90]. Posteriormente Kaiser continuou o desenvolvimento e propôs os algoritmos de separação de energia [Kai90a] [Kai90b] cuja revisão já apresentamos.

Algumas aplicações que utilizam o modelo AM/FM de sinais são rastreamento de formantes (formant tracking) [PM94a] [HMP93] [MQK91], reconhecimento de voz [DMP05], classificação de fonemas [DM06], análise de sinais musicais [SS04] [TS10] e reconhecimento de instrumentos [ZM12] [SK96].

Da mesma maneira que o processamento de sinais AM/FM apresenta diferentes possibilidades para aplicações de efeitos de áudio, de uma maneira geral, a tentativa de obtenção de parâmetros alternativos [ZM12] para as tarefas de análise e classificação de sinais pode revelar informações que não apareceriam claramente com as abordagens mais comuns, como técnicas baseadas em parâmetros obtidos no domínio do tempo ou no espectro.

Nos trabalhos citados sobre análise de sinais de voz, previamente à etapa de decomposição o sinal de entrada é separado em bandas, de maneira que cada formante fique contida em uma destas bandas. Na sequência a decomposição AM/FM é aplicada; o esquema de decomposição baseado no sinal analítico e também a decomposição via separação de energia foram utilizados, além de outras técnicas como decomposição baseada em taxa de cruzamento por zeros [SS04]. Em aplicações como deteç̧ão de transição de fonemas, onde a variação dos parâmetros vocais é muito rápida, a decomposição via separação de energia (caráter local) mostrou ser uma alternativa melhor em relação a métodos anteriores, baseados em interpolação de dados provenientes de janelas vizinhas [PM94b] (caráter quasi-local).

Uma contribuição [DM06] interessante foi a proposta de um mecanismo que agrupa num único passo duas etapas importantes da decomposição AM/FM em sinais de voz: a separação inicial do sinal em bandas e a diferenciação do sinal, restando assim apenas o último passo de aplicar o operador de energia e calcular envelope e frequência instantânea com o algoritmo de separação de energia. A técnica é baseada no princípio de que a operação de convolução comuta com a operação de diferenciação, ou seja

$$
\frac{d^{m}}{d t^{m}}(s(t) * g(t))=s(t) * \frac{d^{m}}{d t^{m}} g(t), \quad m=1,2,3, \ldots
$$

Sendo assim, ao invés de filtrar o sinal de entrada $s(t)$ antes da etapa de análise para dividi-lo em bandas $x(t)$ às quais são aplicadas derivações, uma alternativa é aplicar a derivação na expressão de cada filtro passa-banda, utilizando estes resultados numa convolução com $s(t)$. O modelo de passa-banda utilizado no trabalho é o filtro de Gabor [Pap62]. Este modelo de filtro apresenta 
fórmulas fechadas para as suas derivadas. Logo, neste cenário tendemos a trabalhar com sinais mais limpos, pois evitamos aplicar derivadas diretamente a sinais de áudio. Os autores reportaram [DM06] melhoria da decomposição utilizando a técnica.

Como podemos perceber nesta revisão sobre trabalhos relacionados ao processamento de áudio no domínio AM/FM, na maioria dos casos a decomposição é aplicada a sinais pré-processados. Na linha de Modulation Filtering cada harmônico do sinal original é separado e então a decomposição é realizada. Nos trabalhos de análise de sinais de voz, o pré-processamento separa o sinal de voz em formantes, restringindo os tipos de sinal e evitando que a decomposição se encarregue de representar todo o espectro em um único oscilador AM/FM. 


\title{
Capítulo 3
}

\section{AM/FM DAFx: Efeitos de áudio no domínio AM/FM}

\author{
It's not about the equipment, \\ but about what you do with it. \\ We all use the same tools. \\ Instead your job is to find an \\ emotional connection with the \\ song, and trust your own \\ feelings. When you do, other \\ people will get it too. ${ }^{1}$
}

Manny Marroquin

Os sinais produzidos a partir das técnicas de decomposição AM/FM oferecem diversas possibilidades para a implementação de efeitos de áudio. O envelope, ou amplitude instantânea, juntamente com a estimativa de frequência instantânea representam uma visão alternativa sobre o sinal analisado.

Para o projeto de efeitos AM/FM, além de uma boa intuição sobre o significado dos sinais gerados com a decomposição, o conhecimento sobre as faixas de valores nas quais o sistema vai operar é de fundamental importância. Nas seções a seguir serão apresentados efeitos que dependem, por exemplo, da escolha de frequências de corte para filtragens, limiares para mapeamentos, parâmetros para modulações, entre outros parâmetros importantes para realizar as intenções artísticas e técnicas do usuário.

Sendo assim, um estudo prévio sobre o comportamento de um instrumento musical cujo sinal queremos processar é fundamental. Munidos do conhecimento sobre características gerais como faixas de amplitude, componentes espectrais presentes, entre outros fatores, podemos projetar efeitos que consideram cenários específicos de utilização. Podemos também considerar efeitos adaptativos, cujo comportamento varia em função de alguma informação de interesse no sinal instrumental.

\footnotetext{
${ }^{1}$ Tradução do autor: Não é o equipamento, mas o que você faz com o mesmo. Todos nós utilizamos as mesmas ferramentas. Na verdade, seu trabalho é encontrar uma conexão emocional com a música, e confiar nos seus sentimentos. Quando você o faz, outras pessoas sentirão o mesmo.
} 


\subsection{Decisões de projeto}

Para nossas investigações neste trabalho utilizamos um sinal composto de uma frase curta tocada com uma guitarra ${ }^{2}$. O sinal [ bendmono. wav] consiste de um bend seguido do retorno à nota inicial, seguido da conclusão da frase com um leve vibrato e um slide que produz um glissando. Na Figura 3.1 apresentamos sua forma de onda e espectrograma. Um sinal com tais características era de interesse pois bend, vibrato e slide representam variações na frequência que idealmente devem aparecer na decomposição AM/FM, além de serem artifícios amplamente utilizados em diversos instrumentos musicais.
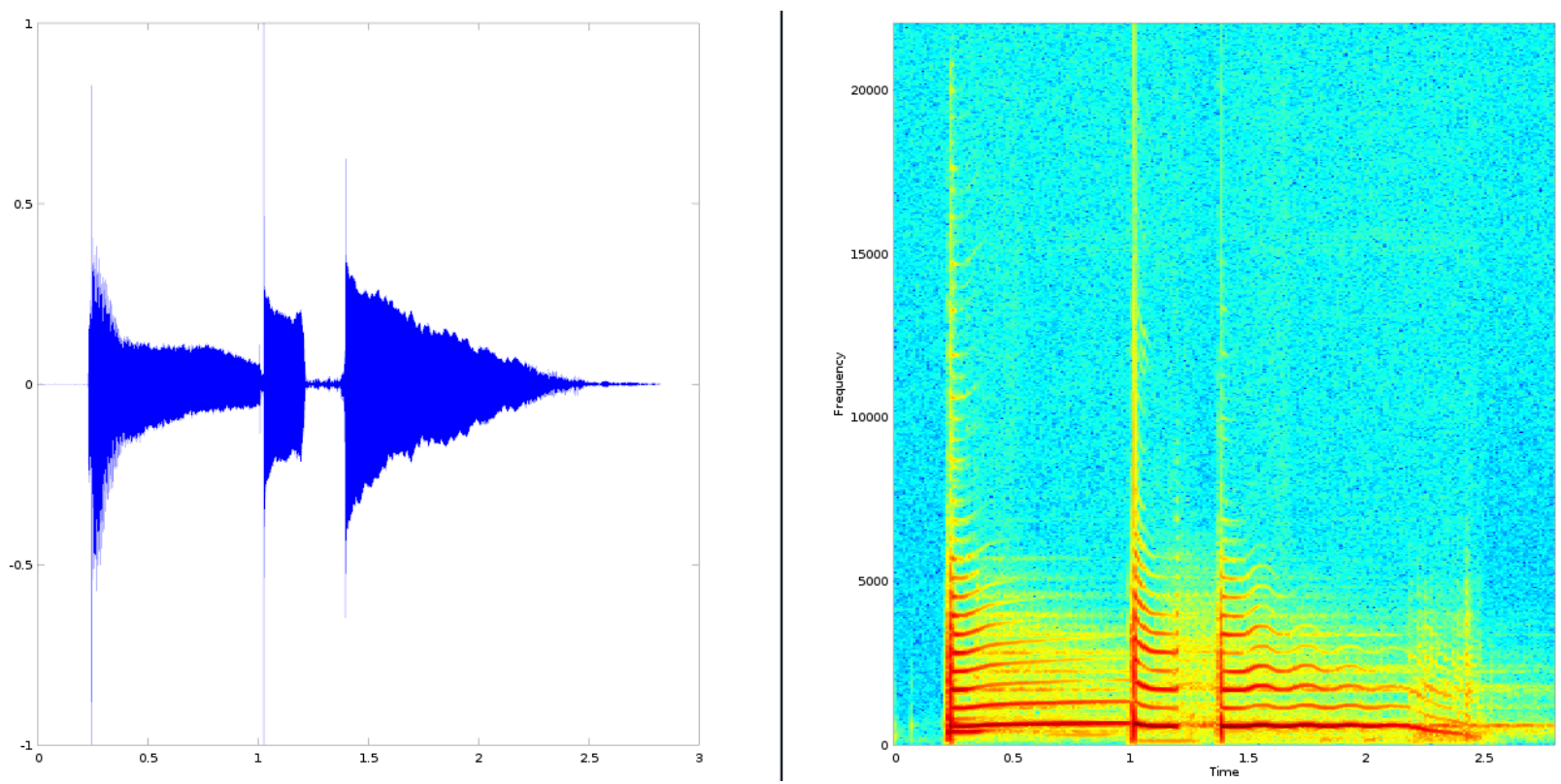

Figura 3.1: Sinal de guitarra utilizado nos experimentos; forma de onda à esquerda e espectrograma à direita.

\subsubsection{Método de decomposição}

Neste trabalho apresentamos duas possibilidades para a decomposição AM/FM. O clássico método baseado na TH em conjunto com o sinal analítico é amplamente utilizado com sucesso em diversos contextos científicos apesar das ressalvas quanto à natureza dos sinais gerados. O método baseado no operador de energia em conjunto com o algoritmo de separação de energia (DESA) foi proposto para enriquecer a modelagem de sinas de voz e também apresenta resultados satisfatórios apesar da elevada sensibilidade a ruído. Nas Figuras 3.2 e 3.3 apresentamos a decomposição $\mathrm{AM} / \mathrm{FM}$ do mesmo sinal de áudio utilizando, respectivamente, TH e DESA.

Os sinais gerados na decomposição AM/FM são diferentes para cada técnica utilizada. Podemos notar pelas Figuras 3.2 e 3.3 que os envelopes estimados apresentam semelhanças e valores próximos, porém o mesmo não ocorre com os sinais estimados para frequência instantânea. Na Figura 3.4 podemos observar as estimativas de frequência instantânea das duas técnicas de decomposição, apresentadas com foco na faixa de valores relevantes: enquanto TH gera valores em torno de 600 $\mathrm{Hz}$, DESA gera valores acima de $1000 \mathrm{~Hz}$.

\footnotetext{
${ }^{2} \mathrm{O}$ arquivo de áudio foi disponibilizado no FreeSound pelo usuário guitarguy1985. Para mais informações: http://freesound.org/people/guitarguy1985/sounds/52080/
} 

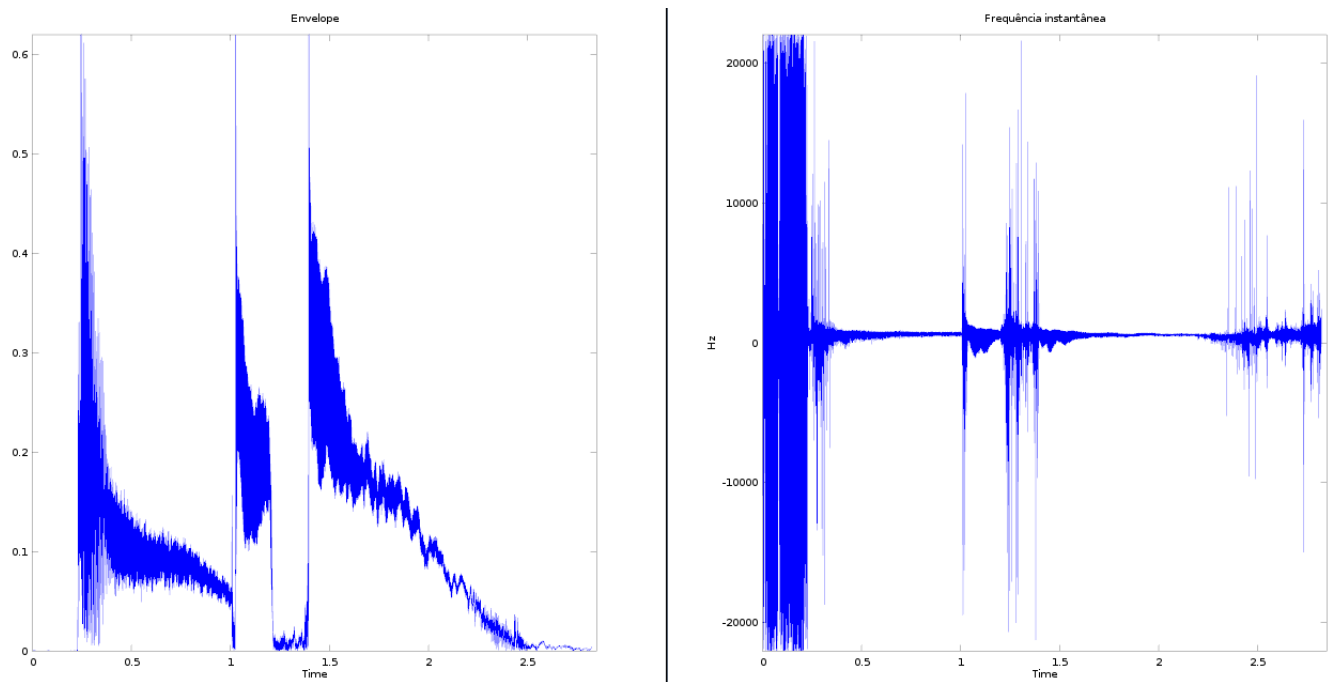

Figura 3.2: Sinais estimados para envelope (esquerda) e frequência instantânea (direita) de sinal de guitarra, utilizando decomposição baseada em Transformada de Hilbert em conjunto com o sinal analítico.
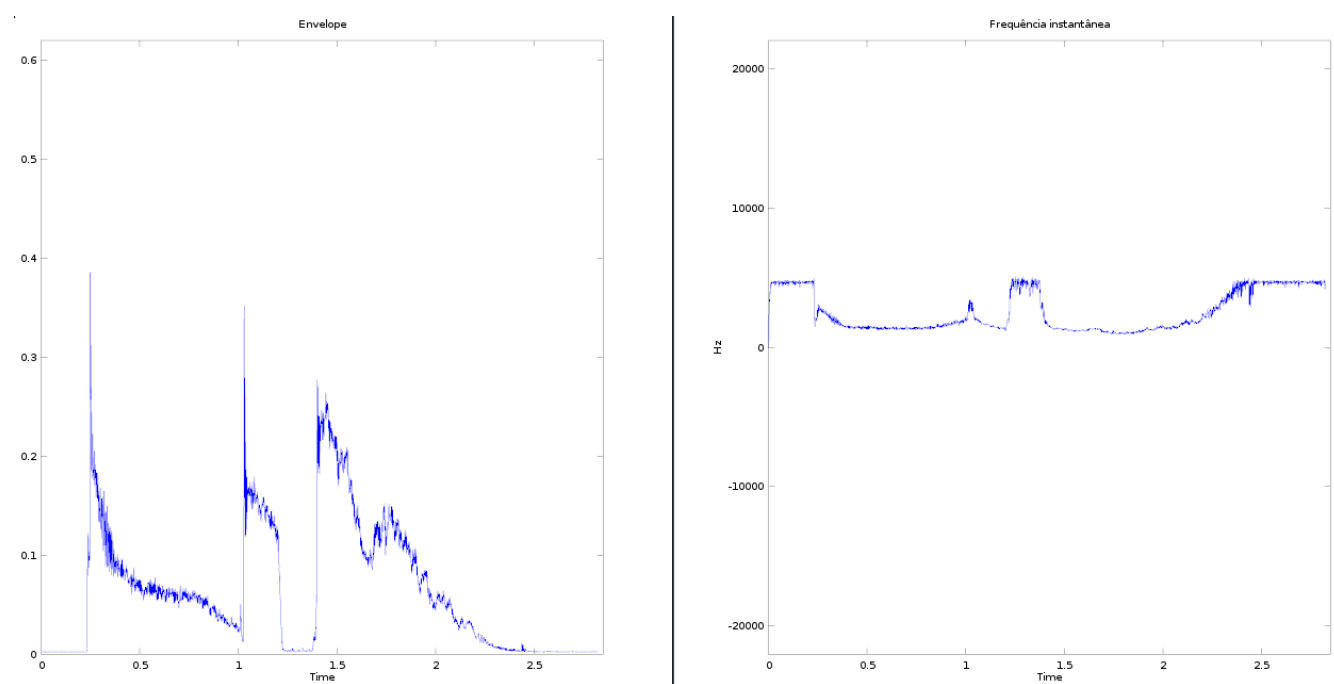

Figura 3.3: Sinais estimados para envelope (esquerda) e frequência instantânea (direita) de sinal de guitarra, utilizando decomposição baseada em operador de energia e algoritmo de separação de energia.
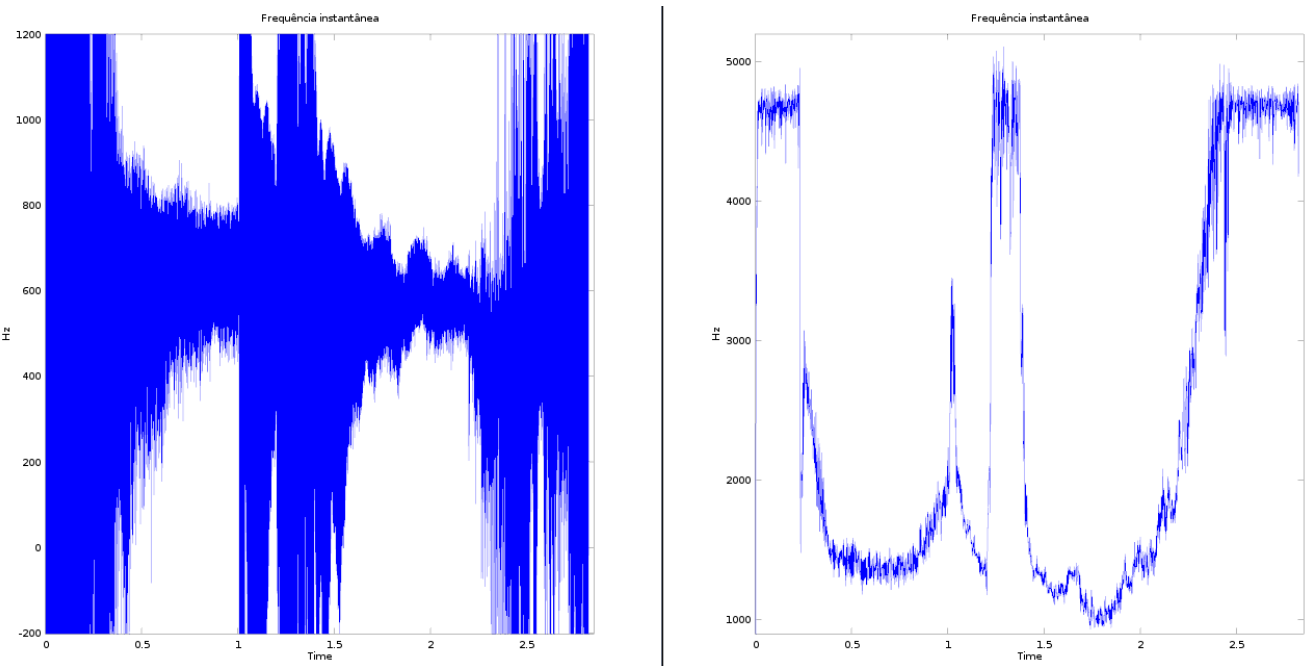

Figura 3.4: Comparação das estimativas de FI utilizando TH (esquerda) e DESA (direita). 
Embora bastante diferentes, ambos os pares de sinais apresentam a capacidade de ressintetizar o mesmo sinal analisado. É interessante notar que embora a estimativa obtida com TH pareça mais ruidosa e com spikes muito mais proeminentes, a ressíntese [ resynth-hilb.wav] com este método é perfeita, enquanto a ressíntese [resynth-desa.wav] utilizando sinais obtidos via ESA apresenta ruído.

Além da questão da qualidade da ressíntese, como podemos perceber pela audição dos exemplos supracitados, a principal diferença entre as decomposições mencionadas reside no fato de que a ressíntese via DESA tem embutida uma modulação em anel do sinal original com uma senoide. Para ressintetizar um sinal mais próximo do sinal original, podemos atenuar o sinal de FI com um ganho de 0.5, mas ainda assim teremos a modulação em anel [resynth-desa-halfi.wav] bastante perceptível.

Sendo assim optamos por concentrar as implementações para esta pesquisa utilizando a decomposição baseada em Transformada de Hilbert em conjunto com o sinal analítico. Lembramos no entanto que a utilização de decomposição por separação de energia não deve ser descartada. Suas peculiaridades podem ser de interesse em diversos contextos específicos, como por exemplo no processamento de sinais de voz, motivação inicial para seu desenvolvimento e área principal de aplicação da técnica.

Já foram apresentados nas Figuras 3.2 e 3.4 os sinais (domínio do tempo) de envelope e frequência instantânea utilizando Transformada de Hilbert. O conhecimento prévio destes sinais será importante para o projeto de efeitos baseados em mapeamento não-linear (Seção 3.3).

Outro tipo de conhecimento necessário é quanto às componentes presentes nas estimativas do envelope e FI. Para o projeto de efeitos baseados em filtragem (Seção 3.2) nos utilizaremos de tal informação. Na Figura 3.5 são apresentados o espectrograma do envelope e da FI. Na Figura 3.6 são apresentadas ampliações dos espectrogramas na faixa de 0 até aproximadamente $2500 \mathrm{~Hz}$, para melhor visualização dos valores em questão.
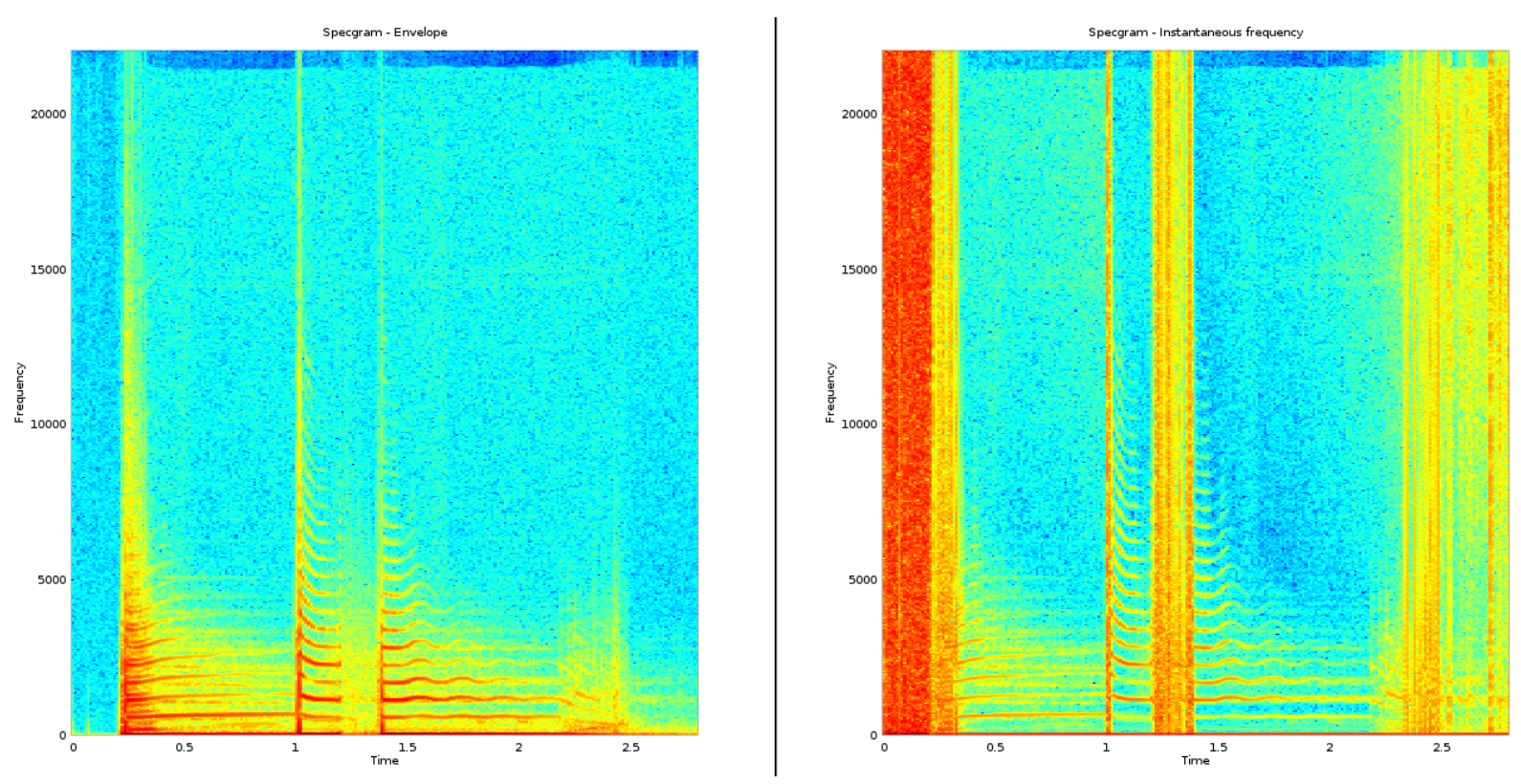

Figura 3.5: Espectrograma do sinais estimados para envelope (esquerda) e frequência instantânea (direita) utilizando Transformada de Hilbert. 

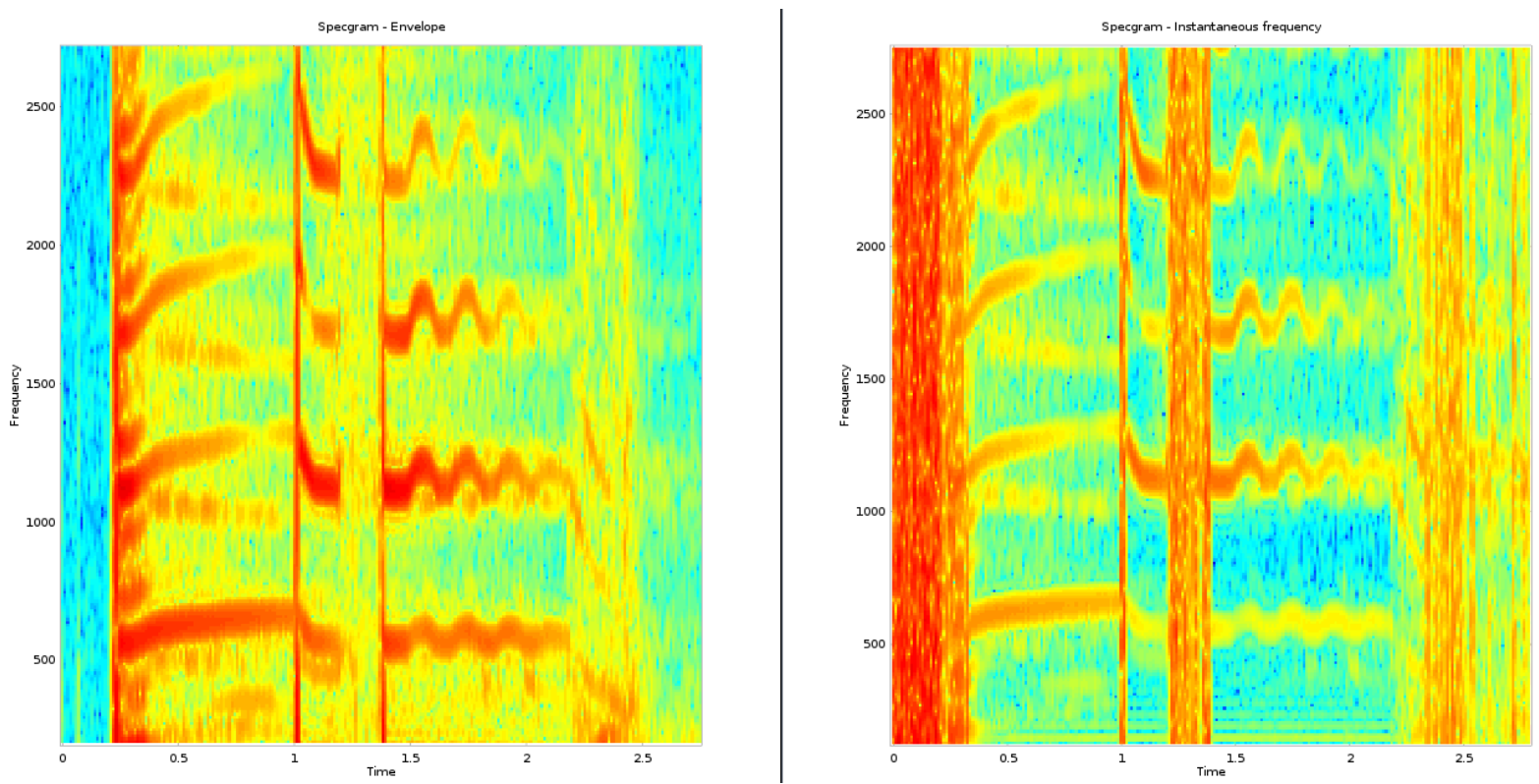

Figura 3.6: Espectrograma do sinais estimados para envelope (esquerda) e frequência instantânea (direita) utilizando TH. Ampliação da faixa de 0 até $2500 \mathrm{~Hz}$. Notar a presença de harmônicos regularmente espaçados.

Finalmente, lembramos que embora na ressíntese AM/FM o envelope (porção AM) e a frequência instantânea (porção FM) atuem em conjunto para a reconstrução do sinal original, também podemos considerar apenas uma das porções para a ressíntese do sinal, senão pelo seu interesse enquanto efeitos, ao menos pelo interesse matemático e perceptual sobre quanto do sinal original é preservado em cada uma das componentes. O arquivo [resynth-am-only -wav] foi gerado considerando apenas o envelope da decomposição e fazendo a FI nula em toda sua duração. O arquivo [resynth-fm-only -wav] foi gerado considerando apenas a frequência instantânea e fazendo o envelope da decomposição unitário em toda sua duração.

O caso supracitado não deve ser confundido com os casos extremos de decomposição comentados na Seção "Ambiguidade da decomposição" (Capítulo 2). Naquele contexto nosso interesse era codificar o sinal analisado utilizando apenas a porção AM ou apenas a porção FM, sem perder informação com a decomposição. Aqui o interesse é realizar normalmente a decomposição AM/FM, obtendo as duas porções e na sequência deliberadamente descartar uma delas e proceder para a ressíntese.

\subsubsection{Separação prévia em bandas}

Na Seção 2.2.4 foram apresentados cenários de interesse de separação do sinal em bandas previamente à realização da decomposição AM/FM. Nestas primeiras explorações de efeitos AM/FM estamos interessados especialmente no caso de considerar a pré-filtragem do sinal em várias bandas centradas na frequência fundamental do sinal instrumental e múltiplos inteiros desta.

Na Figura 3.7 apresentamos versões ampliadas do [ bendmono.wav] considerando apenas as faixa de 0 até aproximadamente $4 \mathrm{kHz}$ (Fig. 3.7(a)) e 0 até $2 \mathrm{kHz}$ (Fig. 3.7(b)). Podemos notar a presença de harmônicos espaçados e bem definidos, os quais desejamos separar em sinais individuais. No caso de utilizar hardware com capacidade limitada de processamento pode-se também considerar um menor número de bandas contendo grupos de harmônicos. 


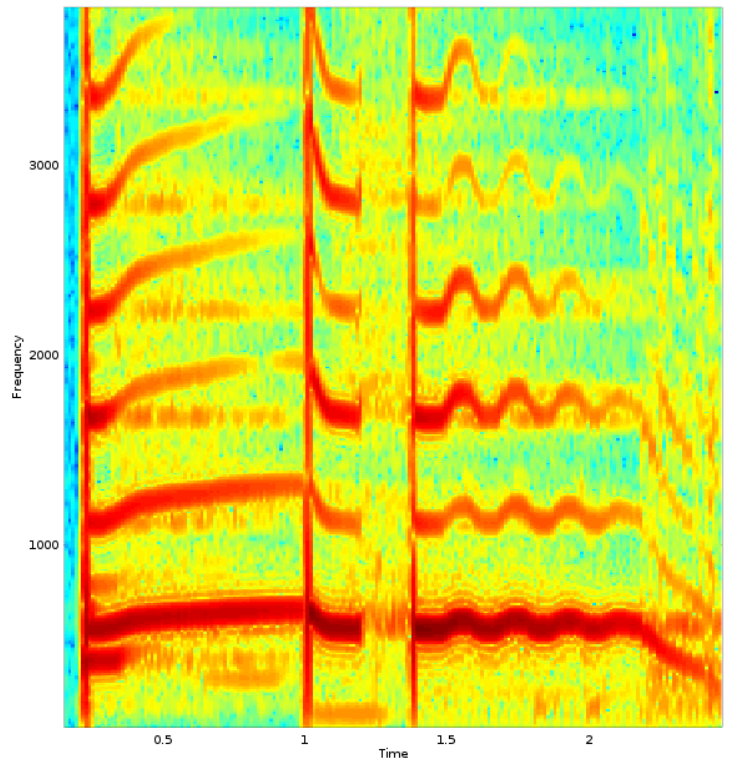

(a) 0 até $4 \mathrm{kHz}$

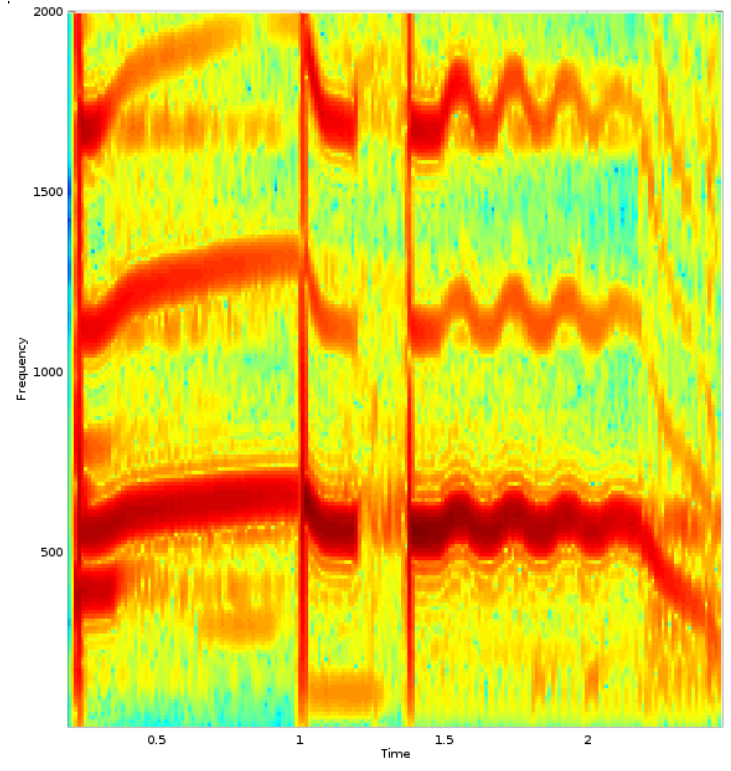

(b) 0 até $2 \mathrm{kHz}$

Figura 3.7: Espectro do sinal de guitarra. Versões ampliadas em regiões específicas.

A detecção da frequência fundamental do sinal instrumental a ser processado é realizada por meio do Audio PLL apresentado no capítulo anterior. Como já comentado, quanto mais sabemos sobre o sinal de entrada, melhor podemos configurar o PLL para que a detecção seja o mais ágil possível porém sem apresentar um comportamento demasiadamente oscilatório.

Os parâmetros do Audio PLL (Figura 2.19) são: ganho de malha, frequência de corte e fator de mérito do filtro passa-baixa externo ao loop, além da frequência de corte de um passa-baixa externo ao sistema. A influência de cada um destes parâmetros na detecção da fundamental está detalhada no Capítulo 2. O PLL foi calibrado a partir de experimentos com o sinal de áudio [ - bendmono.wav] comparando a detecção com o espectrograma (Figura 3.8), e também a partir da audição de um sinal sintetizado [ $\bullet$ bend-Fzero.wav] utilizando um oscilador com frequência dada pela estimativa da fundamental a cada amostra. Os valores de 0.15 para ganho de malha, 80 $\mathrm{Hz}$ para frequência de corte do passa-baixa interno, $\frac{1}{9}$ para fator de mérito e $400 \mathrm{~Hz}$ para frequência de corte do passa-baixa externo foram obtidos. Notamos que nas transições de silêncio para notas o sistema pode apresentar um comportamento vagaroso. Tal comportamento pode ser melhorado aumentando o valor do parâmetro de realimentação, mas tal medida pode, em contrapartida, trazer instabilidade na detecção de notas sustentadas [cso15].

\section{Esqueleto para apresentação dos códigos}

Nas próximas seções apresentamos efeitos AM/FM juntamente com implementações em Csound. O Código 3.1 será utilizado como um esqueleto, comum à maioria dos efeitos. Na apresentação de cada efeito mostraremos apenas as linhas que devem substituir o bloco marcado entre as linhas 15 e 17 no esqueleto. Em alguns casos faremos a ressalva e apresentaremos códigos completos.

Juntamente com as apresentações dos efeitos AM/FM comentamos nossas impressões subjetivas em relação à percepção das sonoridades. No entanto no capítulo seguinte apresentaremos uma avaliação objetiva dos efeitos, juntamente com análises dos resultados. 


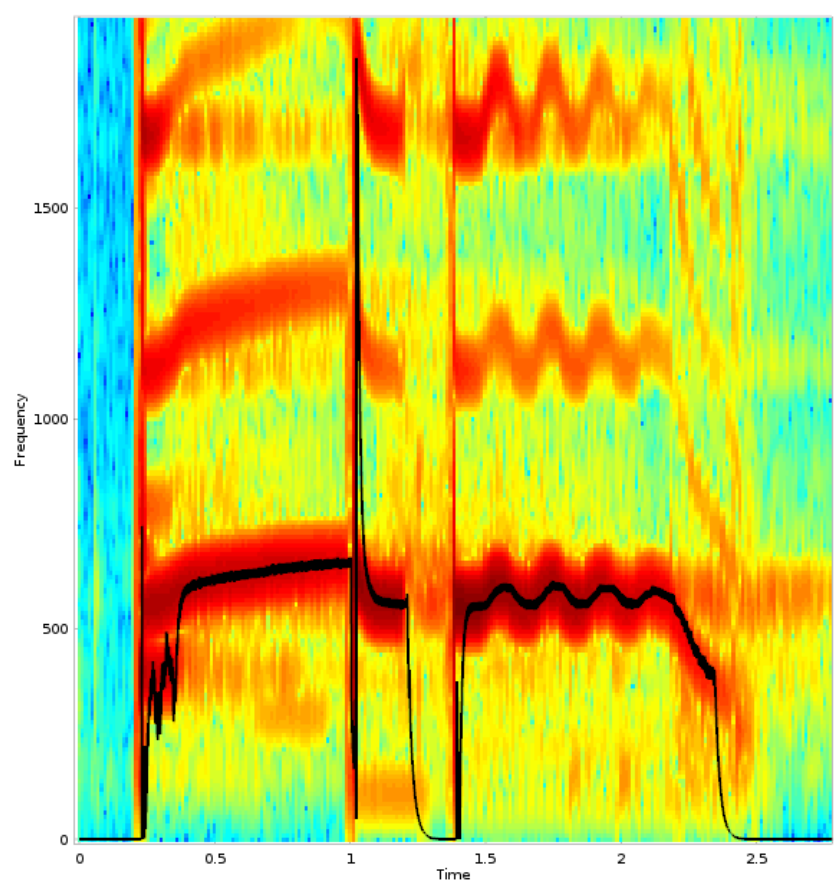

Figura 3.8: Detecção de frequência fundamental utilizando o Audio PLL.

Código 3.1: Esqueleto para implementação dos efeitos $A M / F M$.

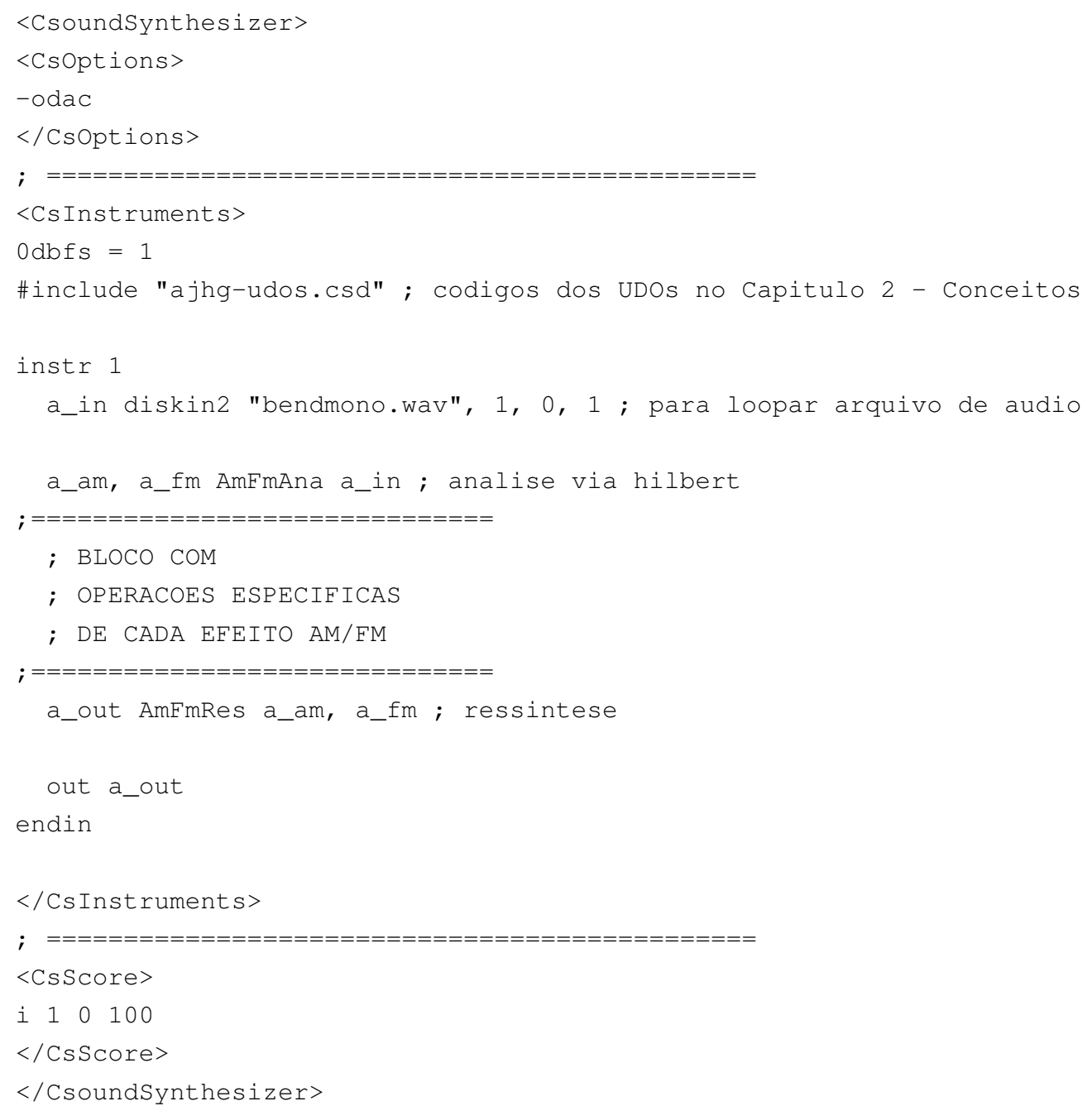




\subsection{Efeitos baseados em filtragem}

Nesta seção abordamos efeitos em que os sinais de amplitude instantânea e frequência instantânea são submetidos a processos de filtragem. Utilizamos as formas mais comuns de filtros lineares, ou seja, filtros passa-baixa, passa-banda e passa-alta.

Na Figura 3.9 estão representadas respostas em frequência de dois tipos de filtros passa-baixas amplamente utilizados. O filtro de Butterworth é caracterizado por uma resposta plana tanto na banda de passagem quanto na banda de rejeição, mas sua banda de transição é mais larga se comparada com a de outros tipos de filtros. Os filtros de Chebyshev, por outro lado, apresentam banda de transição mais curta, porém resposta em frequência oscilante na banda de rejeição (Tipo I) ou na banda de passagem (Tipo II) [Ham97].

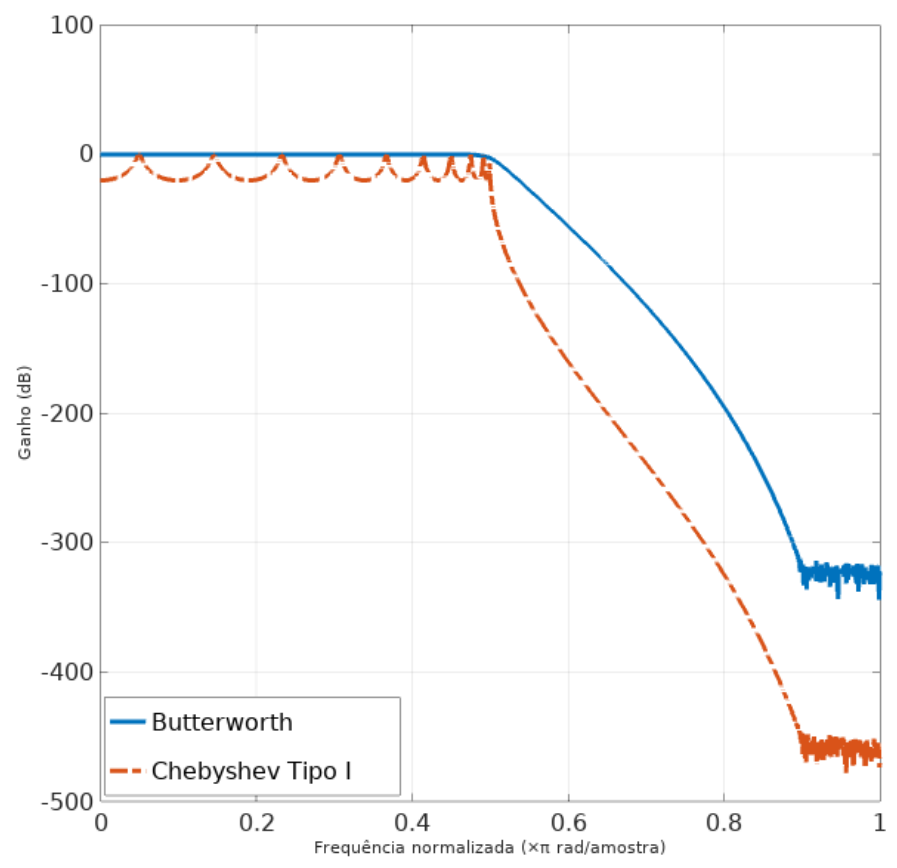

Figura 3.9: Exemplos de projetos de filtros passa-baixa. O filtro de Butterworth não apresenta ripples na banda de passagem e banda de rejeição, mas sua banda de transição é maior que a dos filtros de Chebyshev.

Neste trabalho utilizamos filtros de Butterworth, uma vez que o requisito de banda de transição estreita não é tão importante quanto o de resposta plana nas bandas de passagem e rejeição. Para o projeto de efeitos AM/FM não precisamos de um corte preciso que determina quais frequências passarão ou não pelo filtro, mas uma resposta oscilatória pode acarretar em mudanças na FI que resultam em artefatos facilmente perceptíveis após a ressíntese. Os opcodes butterlp, butterbp e butterhp estão disponíveis em Csound como versões dos filtros passa-baixa, passa-banda e passa alta, respectivamente.

Quando filtramos um sinal de áudio o que fazemos é selecionar quais componentes do espectro do sinal permanecerão presentes. Em outras palavras, se cortamos, por exemplo, as altas frequências, impediremos o sinal de variar rapidamente, mas as variações lentas continuam inalteradas. Neste caso o sinal de áudio soará abafado, menos brilhante, uma vez que o brilho é característico de oscilações de alta frequência. Diferentemente da filtragem direta de um sinal ao qual queremos aplicar um efeito, os sinais filtrados de envelope e frequência instantânea não necessariamente 
representam as frequências que estarão presentes no sinal de áudio com efeito aplicado.

\subsubsection{Passa-baixa da AM/FM: env-lowpf, lowp-if}

Entendendo a operação de filtragem como uma seleção de componentes que permanecerão no sinal filtrado, aplicar filtragem no envelope e FI da decomposição AM/FM significa limitar os padrões com que se alteram tais sinais ao longo do tempo. Sabemos que a FI pode ser compreendida como a frequência da senoide que se ajusta localmente ao sinal analisado. Sendo assim, se aplicamos um passa-baixas ao sinal de FI estamos impedindo a FI de variar bruscamente. A implementação em Csound deste efeito se dá complementando o Código 3.1 com as linhas no Código 3.2.

Código 3.2: lowpif: filtragem passa baixa da frequência instantânea.

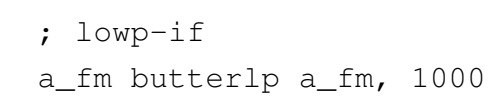

Neste exemplo utilizamos um passa-baixa com frequência de corte em $1000 \mathrm{~Hz}$. Como resultado da aplicação desta técnica [lowpif-1000 wav] [ lowpif-500.wav] podemos notar uma sonoridade opaca (sem brilho) e com menos articulação (variação dinâmica) se comparada com o sinal sem efeito. No entanto é importante observar que com a filtragem não limitamos a excursão de valores, mas apenas quão rápido pode ser o sinal. A estimativa de frequência instantânea corresponde, a cada instante, à velocidade com a qual o oscilador na ressíntese irá girar. Sendo assim, se levamos a técnica ao extremo e escolhemos uma frequência de corte, por exemplo, em $1 \mathrm{~Hz}$, notamos um interessante efeito. Variações grandes nos valores da FI continuarão a existir, mas após a filtragem passa-baixa a varredura nestas faixas que apresentam altos contrastes vai acontecer lentamente, de tal maneira que conseguiremos perceber um chirp [-lowpif-1.wav].

O estudo de efeitos como esse, além de seu uso enquanto efeitos propriamente ditos, pode nos auxiliar a compreender melhor a maneira como um sinal de áudio espectralmente complexo é representado através da decomposição AM/FM. Podemos ver nesse caso que parte do que relacionamos perceptualmente ao brilho do sinal está de algum modo vinculado à possibilidade de variar rapidamente o sinal FI no oscilador AM/FM, no sentido de que impor um limite à velocidade de atualização da FI produz uma sensação de opacidade. Como vimos, esse vínculo não seria evidente a priori já que a frequência instantânea continua podendo percorrer todo o âmbito das frequências audíveis, ou seja, não é matematicamente evidente que a filtragem passa-baixa no sinal FI seja comparável a uma filtragem passa-baixa do sinal original.

A aplicação de filtragem passa-baixa no envelope resultará em outro tipo de efeito de áudio. Se removemos as altas frequências de um sinal que representa aspectos da amplitude do áudio de entrada, mantemos apenas as variações lentas relativas à dinâmica do sinal. Sendo assim, momentos de ataque (onset), caracterizados por transientes (altas frequências) no sinal de áudio ficarão menos proeminentes. Tomando a guitarra como exemplo, palhetadas ou dedilhados terão menos ênfase, fazendo com que a porção inicial do som se pareça mais com o ataque do som de um violino tocado com arco. A implementação deste efeito utilizando $10 \mathrm{~Hz}$ como frequência de corte para o passa-baixas [ envlowpf-10. wav] pode ser realizada com o Código 3.3.

Código 3.3: env-lowpf: filtragem passa-baixa do envelope.

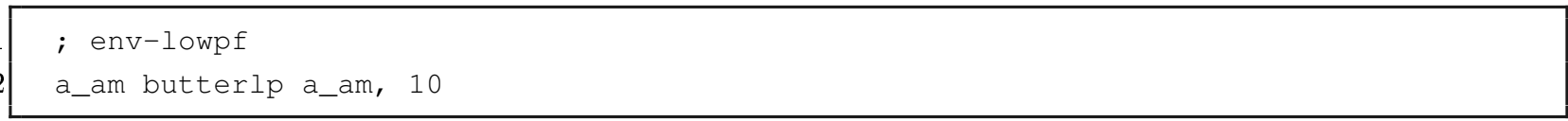




\subsubsection{Passa-alta da AM/FM: hip-env, hip-if}

Nos efeitos de áudio baseados em filtragem do sinal de FI, quanto mais filtramos deste sinal mais deixamos o sinal resultante dependente apenas da amplitude instantânea estimada na decomposição. Diversos estilos de música popular possuem forte dependência do baixo e da bateria, responsáveis pela "levada" (ou groove) da música. Sendo assim, no processo de mixagem geralmente tentamos prevenir competições pelo espectro, que tiram a clareza e equilíbrio dos sinais conflitantes.

Normalmente utiliza-se equalização dos sinais que competem por uma faixa de frequências, posicionando-os complementarmente no espectro. No entanto, filtrar o envelope ou a FI utilizando um passa-altas também se mostra como uma alternativa. O resultado observado da aplicação deste efeito é uma diminuição na presença (corpo) do som, mas com timbre resultante [ hipenv-1000.wav] diferente do obtido utilizando equalização [-eq-comp-hipenv •wav]. A implementação de uma filtragem do envelope com frequência de corte em $1 \mathrm{KHz}$ pode ser realizada complementando o Código 3.1 com o Código 3.4 .

Código 3.4: hip-env: filtragem passa-alta do envelope.

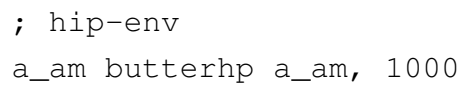

Com relação à filtragem passa-alta da FI, podemos pensar o processo como uma forma de proibição da mesma variar suavemente. Sendo assim, nos momentos em que a FI apresenta valores constantes ou com variação lenta, o processo de ressíntese dependerá somente do envelope estimado na decomposição. A implementação com o Código 3.5, com corte do passa-alta em $100 \mathrm{~Hz}$, resulta [-hipif-1000.wav] num efeito que enfatiza os transientes iniciais, mas que ao longo do sinal apresenta sonoridade similar ao caso em que anulamos a FI e consideramos apenas o envelope para a ressíntese [ resynth-am-only •wav].

Código 3.5: hip-if: filtragem passa-alta da frequência instantânea.

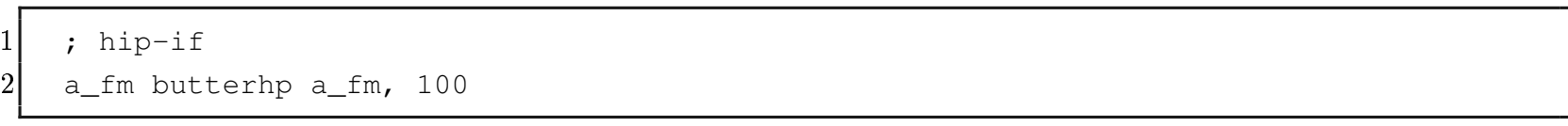

\subsubsection{Passa-banda da AM: env-wah-lope}

O wah-wah é outro efeito clássico utilizado em diversos estilos musicais. Sua inconfundível sonoridade foi projetada para imitar o som do trompete quando tocado com uma surdina sendo movimentada para tampar e destampar a campana do instrumento (efeito muito utilizado também na gaita, abrindo e fechando a mão). O posicionamento da surdina à frente do instrumento funciona como um filtro acústico/mecânico, atenuando algumas frequências. A movimentação da surdina varia dinamicamente quais frequências estarão presentes, dando assim origem ao efeito.

As implementações analógicas e computacionais do wah-wah podem obtidas por meio da utilização de um filtro passa-banda com frequência central (ou largura de banda) variante. O deslizamento do filtro ao longo de alguma faixa de interesse no espectro tem como consequência um efeito similar à filtragem mecânica mencionada.

Para implementação do env-wah-lope em Csound podemos fornecer parâmetros para o deslizamento do filtro passa-banda a partir de um controlador $\mathrm{MIDI}^{3}$ ou utilizar sinais gerados no próprio

\footnotetext{
${ }^{3}$ Para mais informações consultar o Apêndice A.
} 
código. No Código 3.6 utilizamos uma onda triangular para variar a frequência central de um filtro passa-banda de Butterworth, numa tentativa de imitar a informação que seria gerada pisando no pedal (Figura 1.5 - pedal VOX). A sonoridade obtida com a técnica [ env-wah-lope.wav] revela um efeito mais suave se comparado com o original [ wah-comp.wav] utilizando parâmetros similares.

Código 3.6: env-wah-lope: filtragem passa-banda variante do envelope.

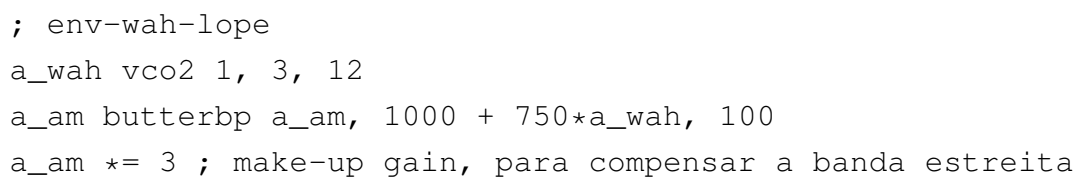

\subsection{Efeitos baseados em mapeamento não-linear}

As técnicas de mapeamento não-linear consistem na alteração da forma de um sinal por meio da aplicação de funções de transferência específicas. Nesta seção abordaremos a aplicação de métodos de distorção, compressão e expansão de faixa dinâmica de formas de onda.

Nos efeitos apresentados na seção anterior, baseados em filtragem, atuamos selecionando faixas de frequências que queremos presentes nos sinais de FI e envelope que são utilizados na ressíntese. Por outro lado, nos efeitos baseados em processamento de dinâmica atuamos selecionando faixas de amplitude que queremos presente nos sinais gerados com a decomposição AM/FM do sinal instrumental ao qual queremos aplicar um efeito. Sendo assim, podemos condicionar a excursão da frequência instantânea a uma faixa desejada, assim como adequar a dinâmica do sinal resultante por meio da manipulação do envelope.

\subsubsection{Distorção da AM/FM: env-ortion, if-ortion}

É difícil pensar alguns estilos musicais, especialmente o rock, sem o efeito de distorção. Este é um efeito muito popular, explorado em diversos tipos (overdrive, fuzz, etc.) principalmente por guitarristas. Tipicamente o efeito de distorção é implementado por meio do ceifamento de uma forma de onda, adicionando assim harmônicos altos ao espectro do sinal. Um exemplo de curva de distorção comumente utilizada é a tangente hiperbólica, apresentada na Figura 3.10. Podemos notar que para valores baixos do sinal de entrada a função se comporta aproximadamente como uma reta, ou seja, não ocorre distorção. No entanto conforme aumentam os valores do sinal de entrada, a função entra suavemente na região não-linear e depois na região de saturação. Notamos ainda que a função é anti-simétrica, podendo ser diretamente aplicada a sinais de áudio com valores no intervalo $[-1,1]$.

A implementação da distorção do envelope utilizando tangente hiperbólica pode ser realizada com o opcode clip, como mostrado no Código 3.7. A sonoridade resultante [env-ortion.wav] é uma leve distorção que pode ser útil nos cenários musicais em que a distorção tipo overdrive é explorada.

Código 3.7: env-ortion: distorção do envelope.

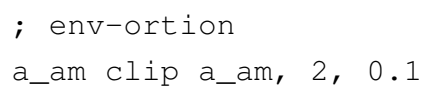




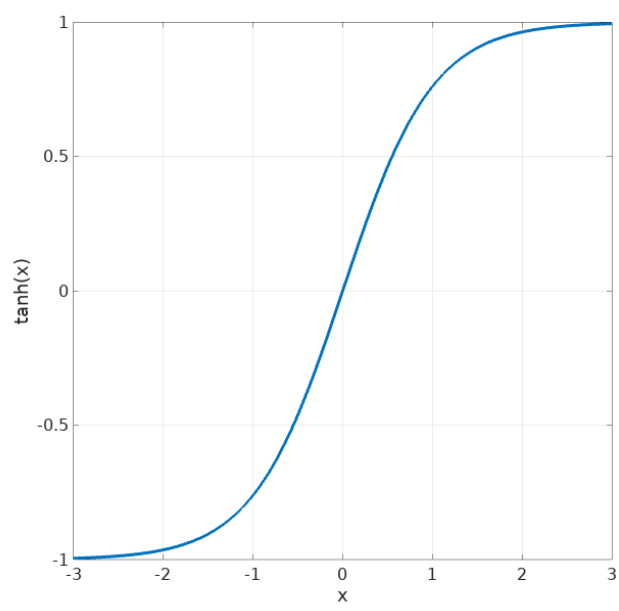

Figura 3.10: Tangente hiperbólica.

Ao invés de distorcer o envelope temos também a opção de distorcer o sinal de frequência instantânea. Como já comentado, a operação de distorção consiste em submeter uma forma de onda a uma função de transferência que geralmente ceifa valores acima de um limiar (por exemplo, região de saturação da tangente hiperbólica na Figura 3.10). Se submetemos a FI a um processo de ceifamento, momentos em que a FI apresentar valores abaixo da região de saturação não irão apresentar alteração em relação ao sinal original, mas caso contrário a FI apresentará um valor máximo dado de acordo com a função de transferência. No Código 3.8 apresentamos um exemplo em que valores da FI são ceifados a partir do momento que ultrapassam $400 \mathrm{~Hz}$. É possível notar [—if-ortion-400.wav] que ficamos com a sensação de uma nota musical predominante (referente a $400 \mathrm{~Hz}$ ), enquanto mantém-se a dinâmica do sinal original.

Código 3.8: if-ortion: ceifamento da frequência instantânea.

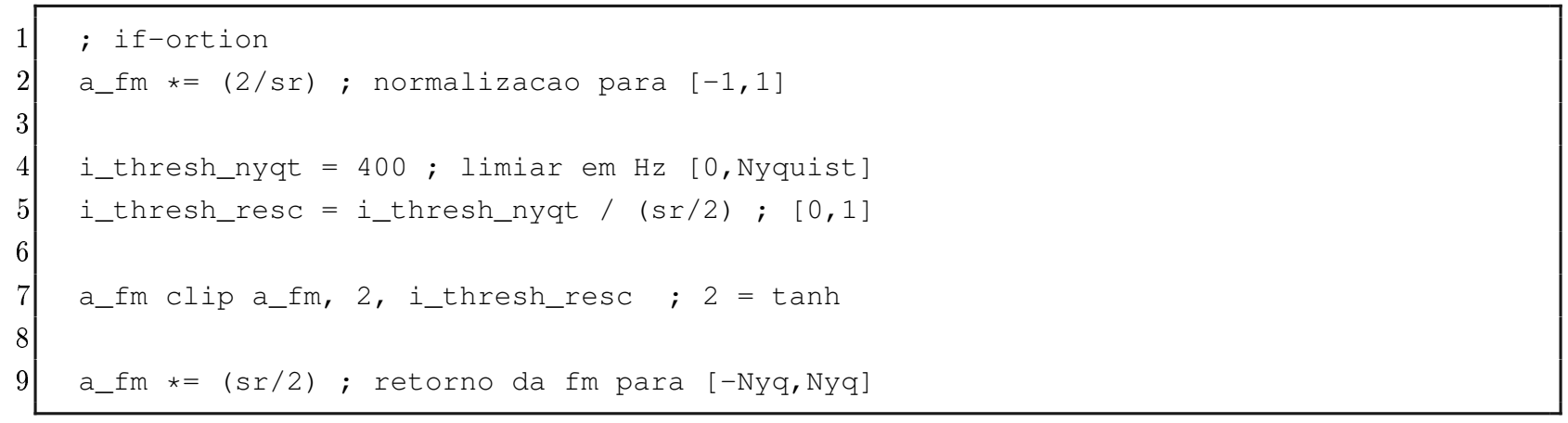

\subsubsection{Compressão da AM/FM: compr-env, compr-if}

Compressores de áudio são ferramentas extremamente úteis tanto no contexto de possibilidades artísticas quanto no de resolução de problemas. O nome desta ferramenta deriva do fato de sua utilização para diminuir, ou comprimir, a faixa dinâmica de um sinal de áudio. Sendo assim, são duas as possibilidades de compressão: atenuação de valores que estejam acima de um limiar (compressão descendente) ou aplicação de ganho em valores que estejam abaixo de um limiar (compressão ascendente). Tais possibilidades são mostradas na Figura 3.11.

Além do limiar, outro parâmetro fundamental para o funcionamento do sistema é a taxa de compressão. Este valor determina quão severa será a alteração de valores acima (compressão des- 


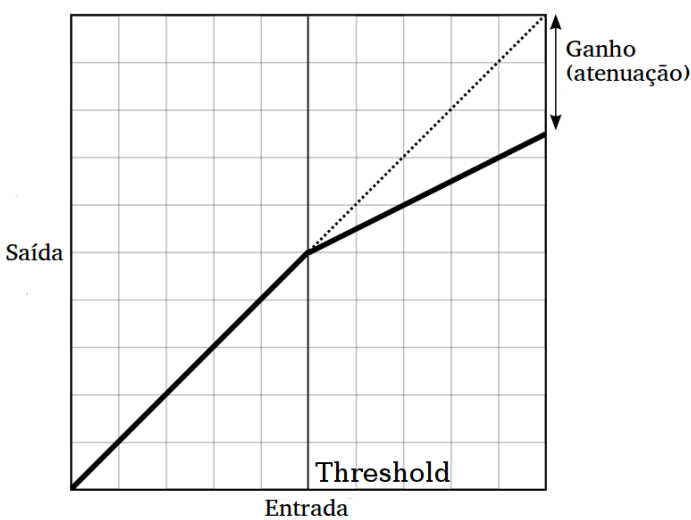

(a) Compressão descendente

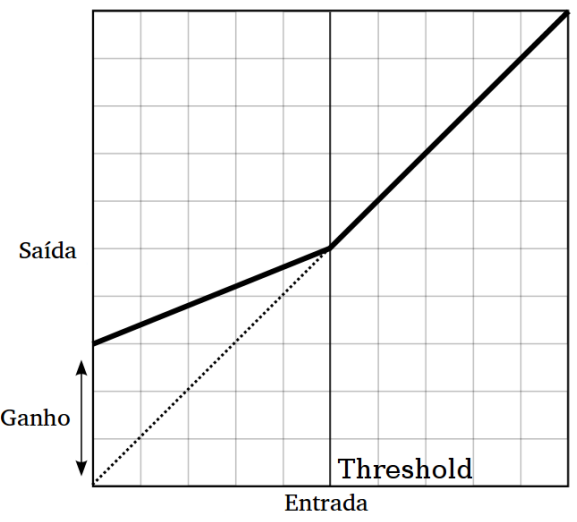

(b) Compressão ascendente

Figura 3.11: Tipos de compressão de dinâmica. Fonte: Wikimedia Commons (adaptada).

cendente)/abaixo (compressão ascendente) do limiar. Na Figura 3.12 mostramos diversos valores de taxas de compressão para o caso de compressão descendente. Uma taxa de compressão de 2:1 significa que para cada unidade acima do limiar no sinal de entrada, o compressor só permite em sua saída metade deste valor. No caso $\infty: 1$ temos o caso do limitador, que literalmente ceifa qualquer valor acima deste limiar.

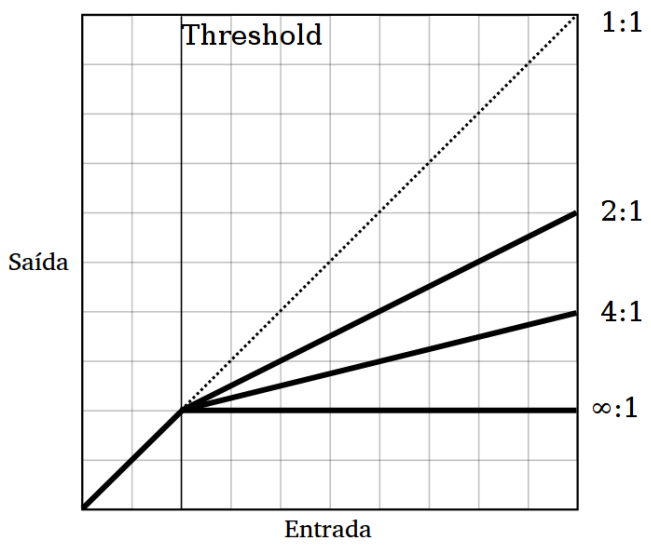

Figura 3.12: Comportamento do compressor de acordo com diferentes taxas de compressão. Fonte: Wikimedia Commons (adaptada).

Finalmente temos os parâmetros de attack e release. O valor do primeiro determina quanto tempo leva até que a amplitude do sinal de entrada seja readequada após ter ultrapassado o limiar. De maneira análoga, o valor de release determina quanto tempo o compressor leva para deixar de atuar a partir do momento em que a amplitude do sinal em sua entrada volta a apresentar um valor abaixo do limiar. A Figura 3.13 mostra o comportamento dinâmico de um compressor descendente com taxa 2:1. O princípio de funcionamento do attack e do release para o compressor ascendente é análogo.

A compressão aplicada ao envelope [ compr-env . wav] resulta num efeito similar à compressão do sinal de áudio [compression-original.wav], porém aparentemente mais sutil. Uma possibilidade para implementação da compressão em Csound se dá por meio do opcode dam, como apresentado no Código 3.9. 


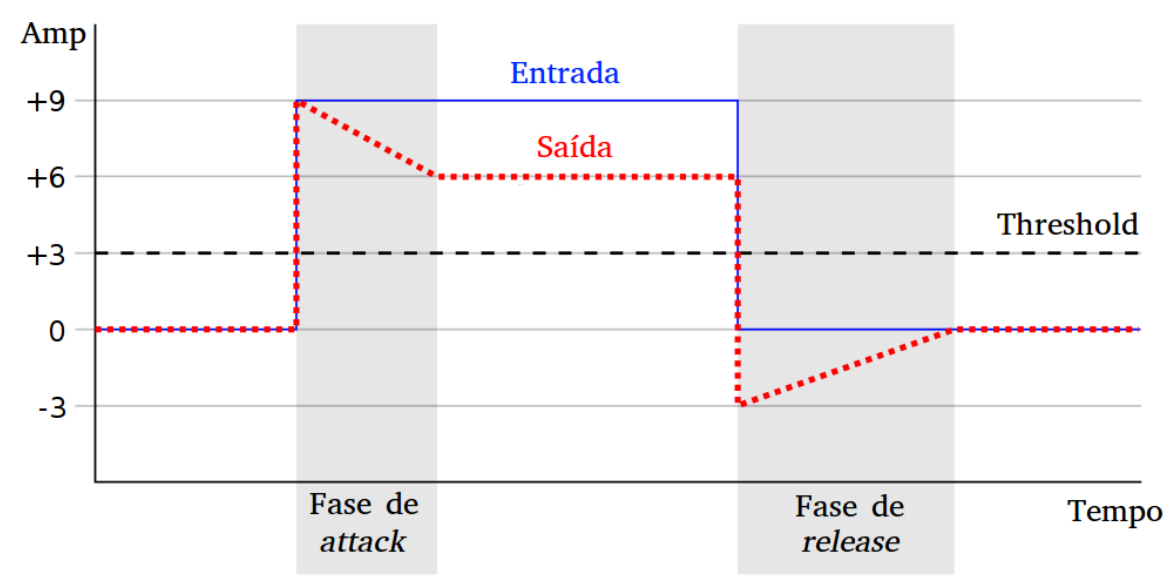

Figura 3.13: Influência dos parâmetros de attack e release no comportamento do compressor descendente. Fonte: Wikimedia Commons (adaptada).

Código 3.9: compr-env: compressão (descendente neste exemplo) do envelope.

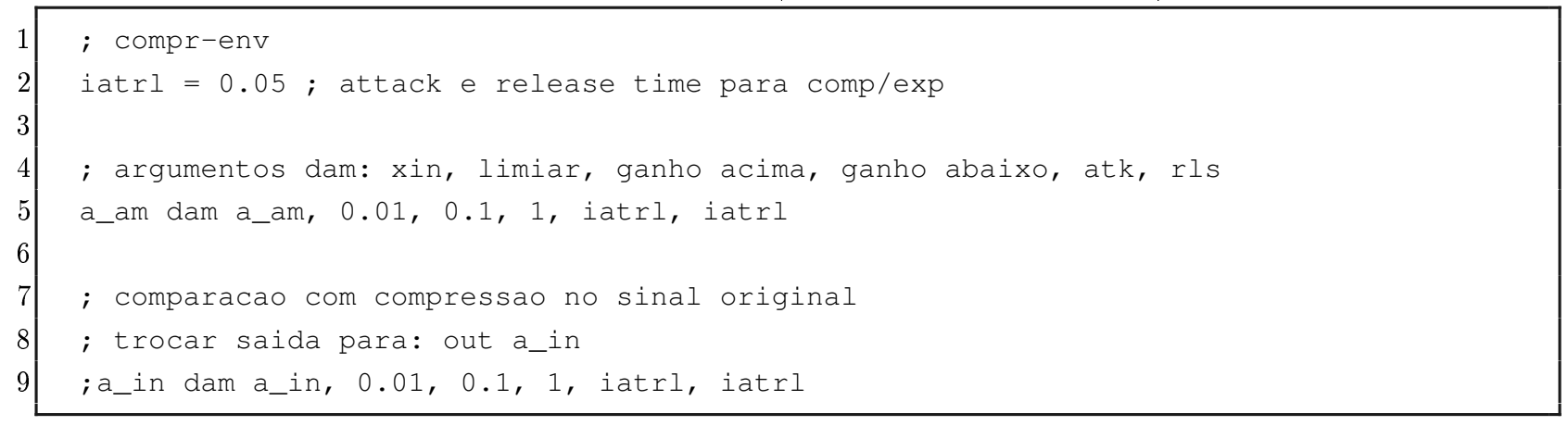

A compressão aplicada à FI apresenta diferentes possibilidades. Como podemos notar nas Figura 3.2 e 3.4, a despeito de picos (spikes) na curva da FI e o momento da palhetada inicial, a informação relevante da FI se encontra abaixo de $1000 \mathrm{~Hz}$. Escolhendo este valor como limiar e aplicando compressão na FI podemos notar que o sinal resultante [ compr-if-1000 • wav] é perceptualmente indiferente do sinal original. Da mesma maneira, escolhendo um limiar ainda mais alto a percepção continua inalterada [ compr-if-2000 . wav]. Podemos interpretar os picos na FI como instantes nos quais ocorreram uma mudança brusca no sinal analisado, geralmente resultado de ruído ou transientes, necessitando de um alto valor na FI para ser representada. A alteração da FI nestes momentos de ruído parece não fazer tanta diferença para nossa percepção.

No entanto, manipular o sinal de FI na faixa em que de fato há informação importante resultará em diversos efeitos musicais. De uma maneira geral, a compressão da FI resultará em alterações do pitch do sinal, diminuindo a altura musical da nota original. Quanto menor o limiar escolhido para o compressor atuar, maior será a diminuição. Quanto maior for a taxa de compressão, também mais baixa será a altura resultante. A implementação está representada no Código 3.10. Neste exemplo foi escolhido o limiar em $500 \mathrm{~Hz}$ pois a faixa de interesse da estimativa da frequência instantânea apresenta valores (Figura 3.4) ao redor deste limiar. Sendo assim, é importante conhecer de antemão as faixas de operação dos sinais no contexto musical no qual o efeito será utilizado (tipo de instrumento, região que será explorada, entre outras informações). Podemos pensar também na possibilidade de acoplamento de algum outro mecanismo de análise do sinal (por exemplo o Audio PLL) para o projeto de efeitos adaptativos (por exemplo, um limiar para a compressão dado de acordo com o pitch detectado no sinal instrumental). 
Código 3.10: compr-if: compressão (descendente neste exemplo) da frequência instantânea.

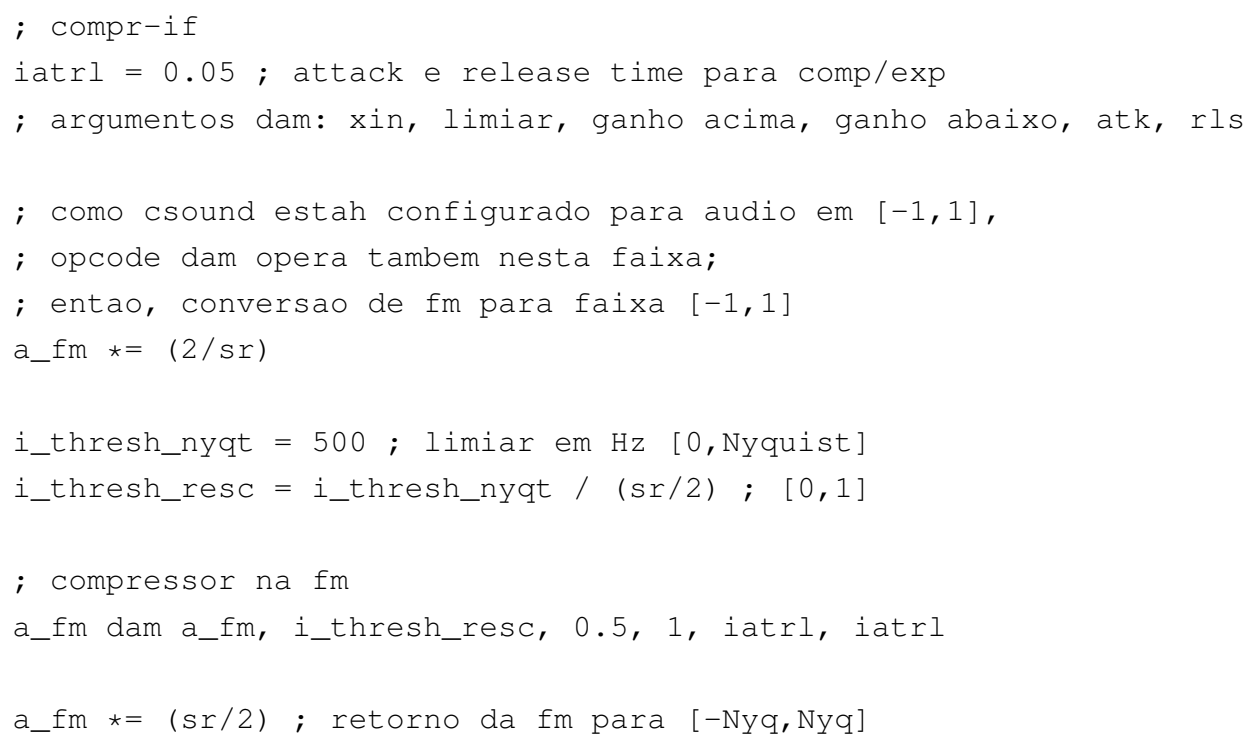

Tendo estudado a distorção e a compressão de sinais, podemos agora refletir sobre a diferença entre os dois mecanismos. Compressão, na verdade, é um tipo de distorção, e isto fica evidente observando a semelhança entre as Figuras 3.10, 3.11(a) e 3.12. No entanto, quando falamos em efeito de distorção, esperamos de certa forma um ceifamento do sinal, ceifamento este relacionado com a região de saturação de válvulas/transistores (caso analógico). No efeito de compressão, ceifamento de fato apenas ocorre quando a taxa de compressão é elevada. Nesse caso temos o limiter, que é um caso específico do uso de um compressor (mas geralmente a configuração de um compressor é bem sutil, longe do ceifamento).

Outra diferença fundamental é a questão do tempo, representada pelos parâmetros de attack e release. O efeito de distorção é um mapeamento instantâneo, que gera uma amostra na saída em função do valor da amostra na entrada. No caso da compressão, existe um tempo de ataque entre o momento que o sinal de entrada ultrapassa o limiar escolhido e o momento em que de fato, a compressão atinge a taxa determinada. O mesmo vale para o release. É importante ressaltar que, para um mesmo conjunto de parâmetros, uma pequena diferença no tempo de attack e/ou no tempo de release podem ser responsáveis por tremendas diferenças na percepção do sinal resultante.

\subsubsection{Expansão da AM/FM: exp-env, exp-if, gat-if}

O caso oposto da compressão é a expansão da faixa dinâmica. Neste contexto também são duas as situações: aplicação de ganho nos valores de um sinal que ultrapassem um determinado limiar (expansão ascendente) ou atenuação de valores abaixo de um limiar (expansão descendente).

A taxa de expansão tem um significado inverso ao caso da compressão. No caso ascendente com taxa 2:1, por exemplo, para cada unidade acima do limiar o expander dobra o valor em sua saída. No caso da expansão descendente, para cada unidade abaixo do limiar, o expander diminui ainda mais a mesma.

Em seu extremo (taxa de expansão $\infty: 1$ ), a expansão descendente é conhecida como gate. Esta ferramenta é muito útil, especialmente para guitarristas. Podemos escolher um limiar abaixo do qual o sinal será expandido para baixo (fecha-se o gate, utilizando uma alta redução de ganho na taxa de expansão). Assim conseguimos cortar o ruído do captador da guitarra (humming) nos 
momentos em que o instrumento não é tocado (amplitude de entrada abaixo do limiar).

Pensando na expansão do sinal de FI na decomposição AM/FM temos duas possibilidades para explorar: aumentar ainda mais a excursão da FI em instantes em que esta apresenta valores altos, ou atenuar/eliminar o sinal da mesma caso a FI não apresente um valor mínimo de interesse. O primeiro caso resultará num sinal com altura musical mais alta em relação ao sinal original. A diferença para a implementação em relação a compressão consiste em trocar o ganho para valores acima do limiar (terceiro argumento do opcode dam). Ao invés de um valor menor que 1 , que resultaria em compressão, podemos trocar as linhas 13 e 14 do Código 3.10 pelas linhas apresentadas no Código 3.11. Assim aplicamos expansão ascendente e obtemos como resultado um novo sinal com outra altura musical [ exp-if-asc.wav].

Código 3.11: exp-if: expansão (ascendente neste exemplo) da frequência instantânea.

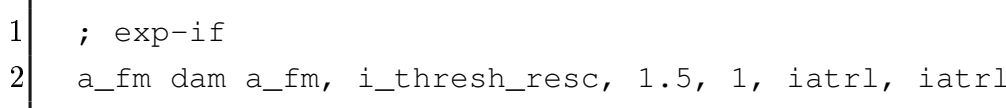

A aplicação de compressão descendente também pode ser de extremo interesse para um efeito de áudio. Podemos pensar na ideia de um gate para a FI, ou seja, permitimos que a FI seja considerada na ressíntese apenas nos momentos em que apresentar valores a partir de um determinado limiar de nosso interesse. Nos momentos em que o gate corta o sinal de FI, a ressíntese será dada apenas pelo envelope do sinal [ envelope-only-resynth.wav]. A implementação do efeito pode ser realizada com o Código 3.12 .

Como já comentado, é importante ter ideia da faixa de valores em que o sinal a ser processado opera. No caso do nosso sinal de guitarra, sabemos que os valores da FI oscilam em torno de $500 \mathrm{~Hz}$ (exceto nas palhetadas, quando crescem valores de FI). Sendo assim, escolhendo um limiar em $400 \mathrm{~Hz}$ [ gatif-400.wav] o efeito apresenta momentos em que o gate oscila (abre e fecha rapidamente), podendo tal comportamento ser um problema ou uma possibilidade artística; escolhendo $600 \mathrm{~Hz}$ [-gatif-600.wav] como limiar ressalta momentos de ataque (palhetadas), cortando a FI na sequência destes ataques.

Código 3.12: gat-if: gate (expansão descendente extrema) da frequência instantânea.

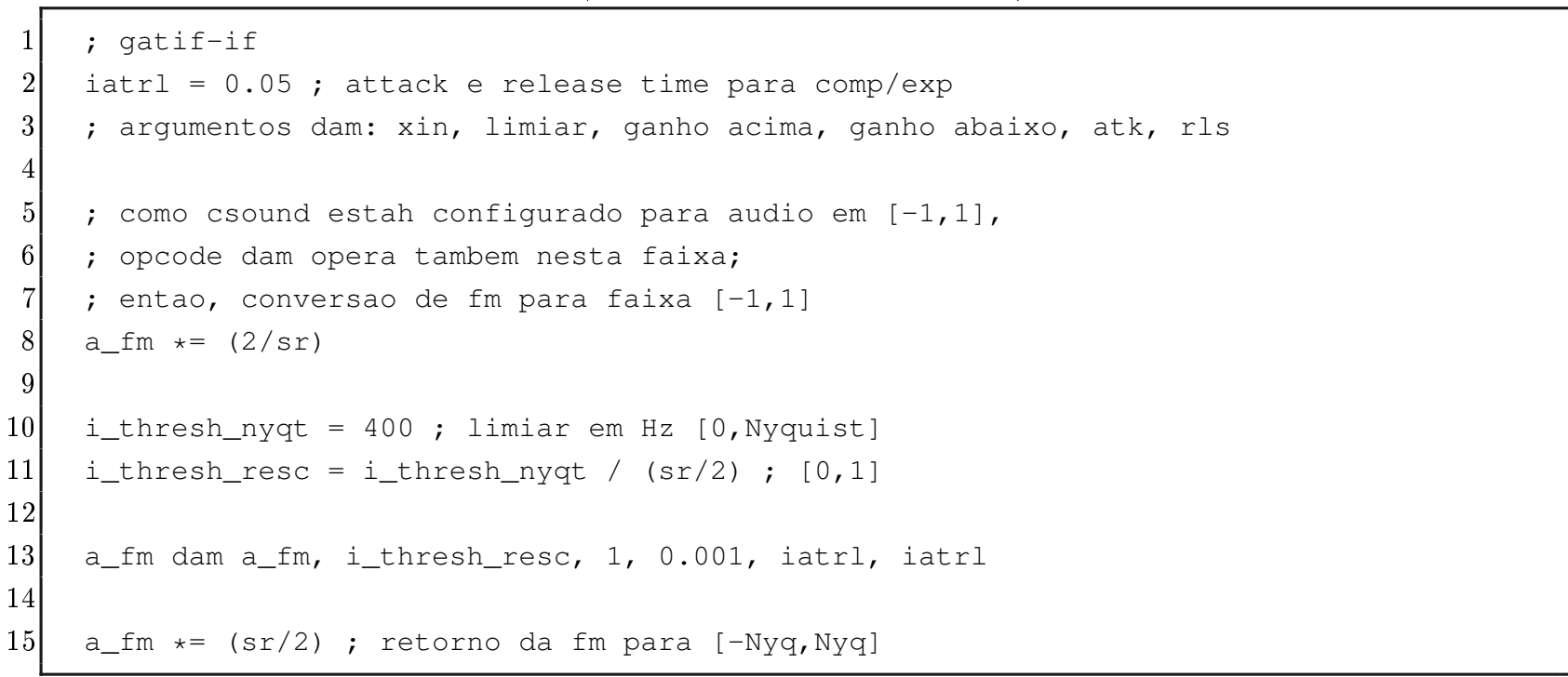




\subsection{Miscelânea de efeitos}

\subsubsection{Modulação da FM: gliss-if, wheel-if, d-if-tune, v-if-brato}

A técnica de tremolo utilizada em instrumentos de corda consiste em rápidos movimentos com o $\mathrm{arco}^{4}$ ou rápidas palhetadas alternadas. Para emular esta técnica com um efeito de áudio podemos utilizar modulação em anel do sinal com um oscilador ${ }^{5}$, escolhendo uma frequência apropriada. Quando aplicamos o tremolo (modulação em anel) ao envelope da decomposição AM/FM temos um efeito similar ao efeito clássico aplicado diretamente ao sinal de áudio.

A aplicação do tremolo na frequência instantânea apresenta outras possibilidades musicais. glissif é um efeito baseado na modulação "lenta" (em torno de $0.1 \mathrm{~Hz}$ ) do sinal da FI. Para um efeito bastante proeminente podemos utilizar um sinal modulador com valores, por exemplo, na faixa $[0,1]$. Fazemos a modulação em anel deste oscilador com a FI, impondo assim a esta uma variação: a FI passa a apresentar oscilações entre 0 e seus próprios valores. Como resultado desta operação teremos glissandos periódicos forçados no sinal original; a frequência do oscilador é um parâmetro muito importante neste efeito: quanto mais baixa, mais evidente fica o glissando [ gliss-if.wav]. A implementação da técnica em Csound pode ser realizada complementando o esqueleto de código com o Código 3.13.

Código 3.13: gliss-if: modulação em anel "lenta" da frequência instantânea.

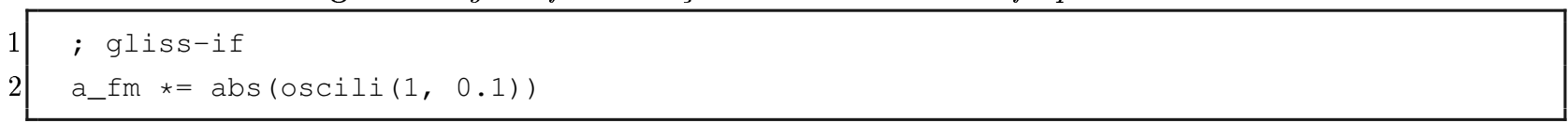

É interessante notar que em diversas situações, para um mesmo ferramental/técnica, comportamentos diferentes são obtidos dependendo da calibração dos parâmetros do sistema. Utilizando o mesmo algoritmo do gliss-if, porém com modulação ligeiramente mais rápida, em torno de $4 \mathrm{~Hz}$, como apresentado no Código 3.14. Essa variação mais rápida dá origem a um efeito bastante agressivo [wheel-if.wav], que pode apresentar interesse musical. Ao invés de utilizar um oscilador para modular a FI pode-se também utilizar um pedal de expressão para ter assim uma versão alternativa do whammy pedal ${ }^{6}$.

Código 3.14: wheel-if: modulação em anel da frequência instantânea.

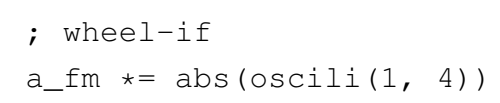

Ao invés de considerar a modulação em anel da FI, como nos efeitos gliss-if e wheel-if, podemos considerar a modulação em amplitude clássica (somando um nível DC à moduladora e então multiplicando a portadora por essa soma). Uma vez que alterações da FI resultam num desafinamento, como já mencionado, podemos nos valer de leves desafinamentos dinâmicos para obter um interessante efeito. Para isso somamos ao sinal da FI um oscilador, cuja amplitude e frequência devem ser configurados com extrema cautela de acordo com o contexto musical. Consideramos que no nosso exemplo, uma excursão extra de até $15 \mathrm{~Hz}$ para a FI resulta num efeito sutil [ d-if-tune.wav]. A implementação do efeito pode ser realizada de acordo com o Código 3.15.

\footnotetext{
${ }^{4}$ https://www.youtube.com/watch?v=gaRpaJW-YSI

${ }^{5}$ Nancy Sinatra, "Bang bang": https://www.youtube.com/watch?v=U2LAdyE81EU

Portishead, "Roads": https://www.youtube.com/watch?v=BmxXHF9C3Yg

${ }^{6}$ https: //www.youtube.com/watch? $\mathrm{v}=\mathrm{Ti} 27 \mathrm{CmWD0kg}$
} 
Código 3.15: d-if-tune: modulação em amplitude "lenta" da frequência instantânea.

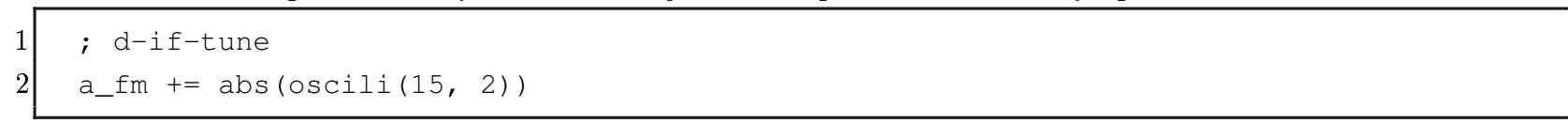

Da mesma maneira que a frequência influenciou fortemente no tipo de efeito obtido aplicando modulação em anel na FI, a frequência escolhida na modulação AM clássica do sinal estimado para a FI também influencia no efeito. Enquanto que uma modulação lenta $(2 \mathrm{~Hz})$ gerou um leve desafinamento, aumentando a frequência do modulador $(14 \mathrm{~Hz})$ obtemos um efeito [ $\vee$-if-brato.wav] semelhante ao vibrato ${ }^{7}$. A implementação pode ser realizada como no Código 3.16.

Código 3.16: v-if-brato: modulação em amplitude da frequência instantânea.

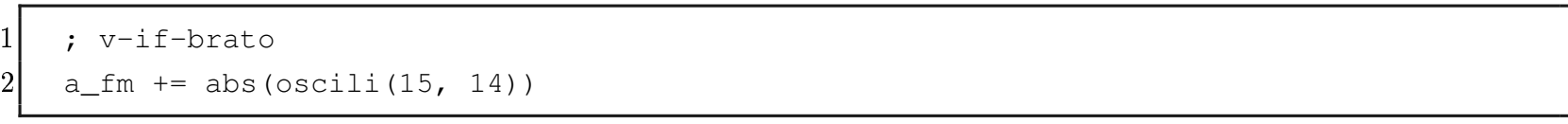

\subsubsection{FM fixada em nota específica: fix-if}

Já foi comentado que o envelope por si só guarda informações gerais sobre o sinal analisado. De fato, a ressíntese considerando apenas o envelope [ฉenv-only $\cdot$ wav] se apresenta como uma possibilidade viável. Mas ao invés de desconsiderar a frequência instantânea, podemos torná-la fixa em algum valor de interesse, por exemplo numa frequência relacionada com alguma nota musical específica $^{8}$.

O efeito resultante com a ressíntese irá impor ao sinal instrumental o timbre de uma senoide com frequência dada por um valor constante, o próprio valor no qual foi fixado o sinal de FI. Assim a sonoridade resultante apresenta semelhança com o sinal original nos aspectos de dinâmica, mas com diferentes possibilidades de pitch (e timbre). A implementação do efeito é realizada completando o esqueleto com as linhas do Código 3.17. Neste exemplo, a FI foi fixada em $400 \mathrm{~Hz}$ [ fix-if-400.wav].

Código 3.17: fix-if: fixação da frequência instantânea em nota específica.

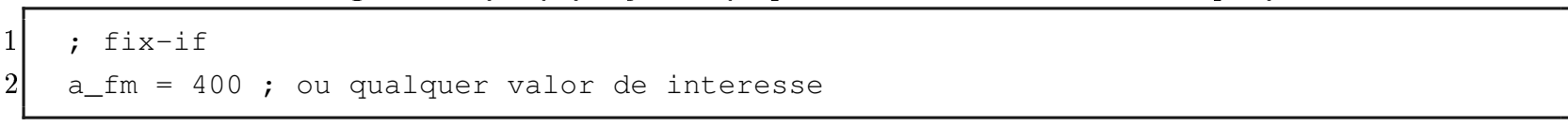

É importante notar que a fixação da FI é diferente do ceifamento (distorção) da FI, discutido na apresentação do efeito if-ortion. No efeito baseado em ceifamento, se ocorrem momentos de longa duração em que valores da FI se encontram acima de um determinado limiar, então nestes momentos a percepção será semelhante ao efeito de fixação da FM. No caso do nosso sinal utilizado para os testes, sabemos (Figura 3.4) que os valores de FI se encontram em torno de 500/600 Hz. Sendo assim, escolhendo um limiar de $400 \mathrm{~Hz}$ para o efeito if-ortion [-if-ortion-400.wav], esperamos uma sonoridade parecida com aquela obtida utilizando o efeito fix-if em $400 \mathrm{~Hz}$, o que de fato se confirma.

O valor no qual a FM será fixada, e as condições de atualização deste valor, podem variar de acordo com diversos cenários. Como aplicações de interesse citamos destemperamento de escala da guitarra/contrabaixo, aumento da extensão de instrumentos, entre outras. Podemos também pensar em aplicações educativas ou jogos musicais que abordem aspectos melódicos e harmônicos.

\footnotetext{
${ }^{7}$ https://www.youtube.com/watch?v=vg7ugDja1fA

${ }^{8}$ https://en.wikipedia.org/wiki/Piano_key_frequencies
} 


\subsubsection{Hibridização de instrumentos: hybr-if}

A mistura de diferentes sonoridades possibilita diversas aplicações de interesse musical, como a busca por novos timbres que se encontram entre dois outros. Podemos pensar em misturas de instrumentos similares em algum aspecto (sauta/flaux), instrumentos dissimilares (guitoz/votarra), entre outras possibilidades. A possibilidade da mistura entre voz e guitarra pode ser de especial interesse para guitarristas de jazz (geralmente preferem a sonoridade limpa, mas cantar acompanhando linhas melódicas na guitarra ${ }^{9}$ é um artifício comumente explorado no gênero). No contexto da engenharia de produção musical, a obtenção de sonoridades baseadas numa mistura de outros sinais pode ser um interessante paradigma para abordar mixagens em produções mais experimentais.

No hybr-if obtemos hibridização de sinais instrumentais a partir da combinação de seus sinais de frequência instantânea. A atribuição de pesos para cada FI é uma possibilidade de parâmetro para o efeito. Embora seja possível combinar também os envelopes, nossos experimentos mostraram que geralmente escolher apenas um dos envelopes envolvidos apresenta melhores resultados.

O Código 3.18 apresenta a implementação em Csound do efeito, com algumas possibilidades de combinação entre flauta e sax (linhas 18 a 20). A sonoridade resultante [ sauta-flaux.wav] lembra os dois instrumentos utilizados como matéria-prima. A interação do envelope da flauta resultou numa sonoridade que se assemelha à da gaita de fole.

Código 3.18: Hibridização de instrumentos com o efeito hybr-if.

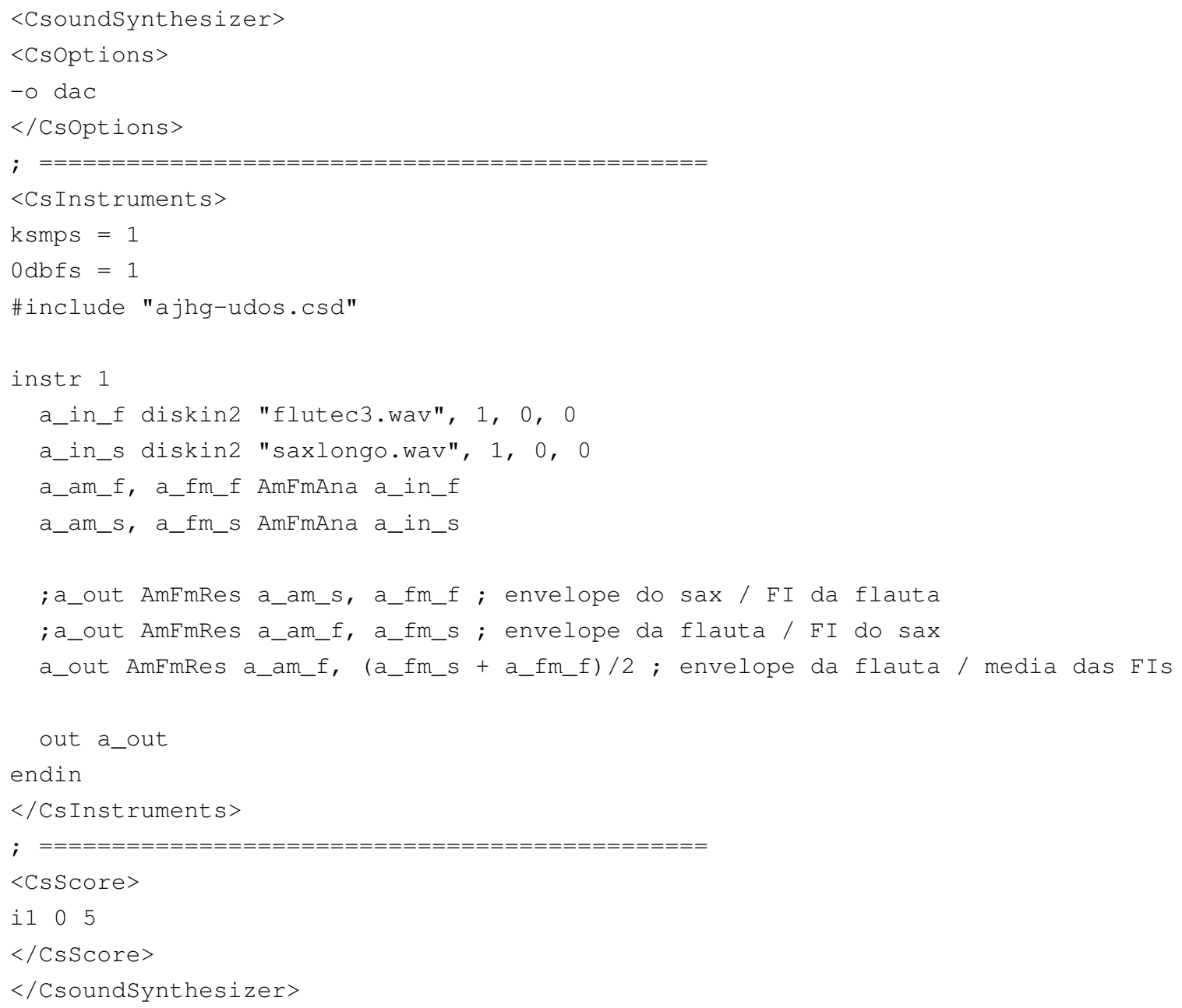

${ }^{9}$ https://www.youtube.com/watch?v=ARqktykO0Ts 


\subsection{Implementações alternativas de efeitos clássicos}

\subsubsection{Chorus alternativo: chor-if}

O efeito de chorus ou chorusing acontece quando fontes sonoras com timbres parecidos e alturas próximas são somadas. A rica sonoridade de um coral (daí o nome do efeito) de pessoas cantando, por exemplo, é decorrente do fato que os timbres das vozes são parecidos, e pequenas variações de nota e tempo inevitavelmente acontecem quando o grupo canta.

A implementação deste efeito é realizada por meio da soma de cópias ligeiramente atrasadas e desafinadas do sinal a ser processado. Uma artimanha já apresentada em outros efeitos que exploram o desafinamento do sinal instrumental consiste em alterar o sinal de estimativa da frequência instantânea por meio de soma ou multiplicação. Sendo assim podemos nos valer de leves desafinamentos a partir da manipulação da FI e ressintetizar um conjunto de sinais que servirão de matéria-prima para o chorus. Cada um destes sinais pode ainda ser levemente atrasado, preferencialmente com valores diferentes de atraso, para trazer mais realismo ao efeito. Em Csound podemos implementar o chor-if [ chor-if.wav] com o Código 3.19.

Código 3.19: chor-if: releitura do efeito chorus.

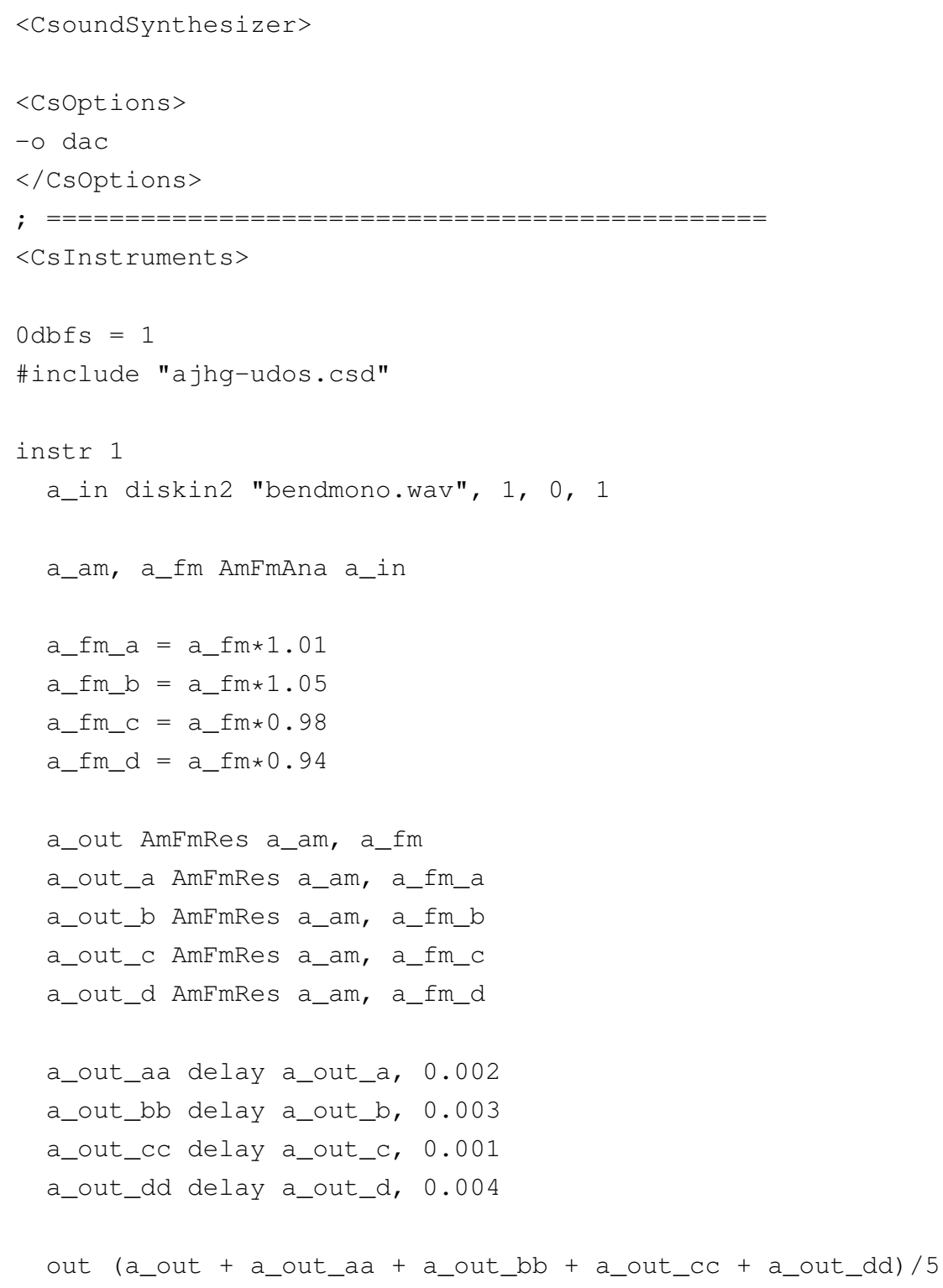




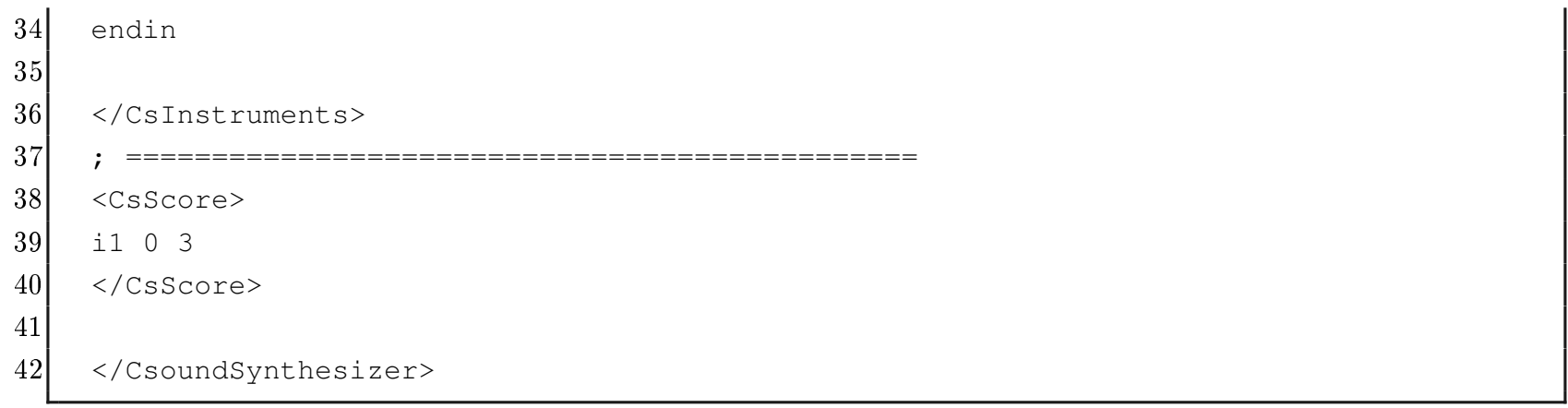

\subsubsection{Octaver alternativo: oct-if}

O efeito oitavador é baseado na soma de um sinal a ser processado com uma versão cuja fundamental se encontra uma oitava acima ou uma oitava abaixo da original. O octaver clássico, muito utilizado no passado por Jimi Hendrix, e atualmente por Jack White ${ }^{10}$ na guitarra e Tim Lefebvre ${ }^{11}$ no contrabaixo (entre tantos outros músicos) explora a oitava para baixo. Variações baseadas em outras transposições, por exemplo, na soma do sinal original com uma versão transposta para sua quinta justa acima, também são populares.

Como já comentado no caso do efeito gliss-if, a multiplicação do sinal da frequência instantânea por valores que oscilam entre 0 e 1 causou glissandos no sinal, ou seja, variações da altura foram impostas ao sinal de entrada. O oct-if é baseado na multiplicação da FI por $\frac{1}{2}$ ou por 2 , dependendo do efeito desejado. O efeito resultante não é exatamente o som oitavado, mas uma equalização que enfatiza a parte baixa do espectro no caso da multiplicação da FI por $\frac{1}{2}$, ou os agudos, caso utilizemos o dobro do valor da FI na ressíntese. Este último caso [ oct-if-up.wav] é implementado com o Código 3.20.

Código 3.20: oct-if up: dobro da frequência instantânea.

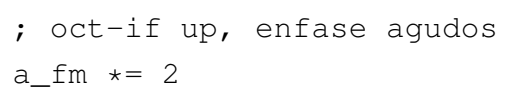

Dependendo da tessitura utilizada em determinado contexto musical, pode-se também explorar outras potências de $\frac{1}{2}$ e 2 para a obtenção de um efeito mais proeminente. Em particular, a multiplicação do sinal de FI por 0.25 gera uma linda releitura [ oct-if-down.wav] do octaver clássico, se somarmos o sinal processado com o sinal original. A implementação é realizada com o Código 3.21.

Código 3.21: oct-if down: metade da frequência instantânea.

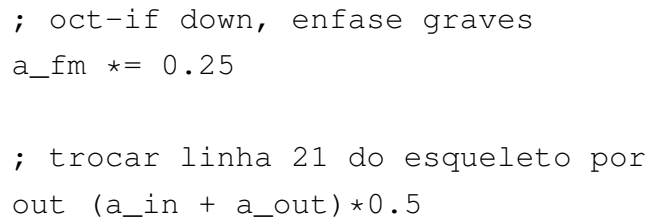

\footnotetext{
${ }^{10}$ https://www.youtube.com/watch?v=jW8UlrtcEac

${ }^{11}$ https://www.youtube.com/watch?v=QB0czM9eXzU
} 


\subsubsection{Reverb alternativo: $s q-e n v$}

No contexto de processamento do envelope gerado com a decomposição AM/FM podemos pensar em utilizar funções com domínio em valores não-negativos. Por exemplo, mapear o envelope para sua raiz quadrada mostrou ser um interessante tipo de efeito. Para entender o comportamento do efeito podemos notar que a função raiz quadrada (Figura 3.14) com argumentos no intervalo $(0,1)$ retorna valores maiores que o argumento. Notamos que

$$
\frac{\sqrt{x}}{x}=\frac{1}{\sqrt{x}}
$$

ou seja, quanto mais próximo de 0 for o argumento, maior será o ganho relativo.

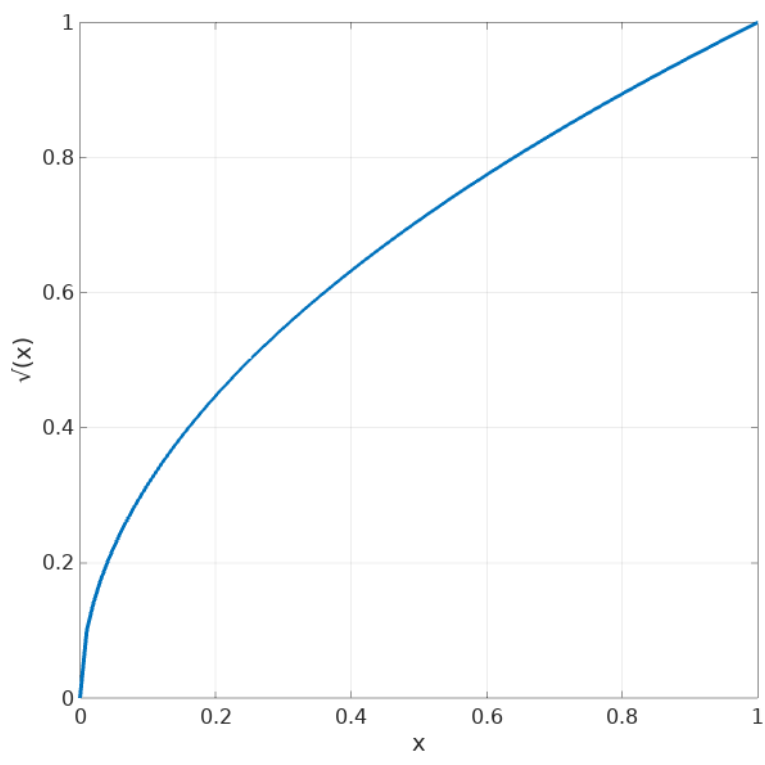

Figura 3.14: Raiz quadrada de valores no intervalo [0,1].

A implementação [ฉ sq-env •wav] em Csound desta simples técnica se dá com o Código 3.22.

Código 3.22: sq-env: raiz quadrada do envelope.

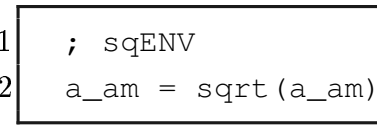

Podemos notar que a distorção do envelope utilizando a raiz quadrada resulta num efeito similar ao reverb. Para entender o porquê podemos pensar nas características da reverberação de um sinal de áudio. Um sinal sonoro que ouvimos (ou captamos com um microfone) é composto tanto da própria emissão que nos atinge diretamente, assim como das reflexões na sala. Tais reflexões também nos atingem e continuam se multiplicando nas paredes da sala (de acordo com as característica geométricas da sala), decaindo em amplitude, uma vez que energia é absorvida de acordo com o coeficiente de absorção dos materiais presentes. As numerosas reflexões tardias (late reflections), também conhecidas como cauda da reverberação, apresentam baixa amplitude, mas contribuem para a percepção do efeito, pois são justamente nesses momentos de menor intensidade do sinal original que a reverberação é mais notada.

Ao aplicar a raiz quadrada no envelope da decomposição AM/FM de um sinal de áudio temos 
como resultado um ganho seletivo no envelope. Valores próximos de 0 receberão um ganho relativo maior que valores próximos de 1 . Sendo assim, momentos de baixa dinâmica de um sinal de áudio serão realçados, tendo como consequência uma sensação de reverberação.

Nossa percepção quanto à duração de um som está relacionada com o decaimento do fenômeno, ou seja, as relações de amplitude ao longo do tempo de duração do som. Diferentemente de um simples ganho que multiplica todo o sinal por um mesmo valor, não alterando portanto as relações de amplitude do sinal ao longo do tempo, a raiz quadrada o faz, prolongando a sensação da duração ${ }^{12}$. Podemos, de fato, calcular a influência da técnica no tempo de reverberação de uma determinada sala ${ }^{13}$.

\subsection{Efeitos multi-bandas}

\subsubsection{Aplicação dos efeitos}

Nesta seção e nas próximas consideramos possibilidades que aparecem com a separação do sinal instrumental em bandas previamente à decomposição AM/FM.

Por efeito AM/FM multi-bandas nos referimos a efeitos baseados na aplicação de diferentes técnicas em diferentes harmônicos do sinal analisado. São inúmeras as possibilidades que podem despertar interesse musical. Alguns exemplos são listados a seguir:

- compressão gradativa: neste efeito podemos aplicar compressão individualmente em cada harmônico, escolhendo diferentes parâmetros para cada um. Podemos por exemplo abaixar o limiar e aumentar a taxa de compressão em função da faixa de frequência do harmônico, obtendo assim uma compressão mais agressiva para componentes mais altas;

- filtragem seletiva: consiste da aplicação de diferentes filtros (ou diferentes configurações de um mesmo filtro) em cada harmônico do sinal. Desse modo podemos preservar diversos tipos de padrões do sinal original, mas em faixas diferentes;

- hibridização aumentada: podemos levar o hybr-if ao extremo hibridizando cada um dos harmônicos com um instrumento diferente;

- pedal-if: como foi visto que com a técnica fix-if podemos impor a percepção de uma nota específica na ressíntese, podemos aplicar a técnica em alguns harmônicos enquanto outros ficam livres para representar o pitch original. Assim obtemos uma (ou mais) nota(s) sempre presente(s), sempre que houver uma nota qualquer sendo executada.

Apresentamos o pedal-if no Código 3.23. Neste exemplo a FM da segunda e da terceira banda foram fixadas em $250 \mathrm{~Hz}$ e $500 \mathrm{~Hz}$, respectivamente, enquanto a primeira banda fica com sua FI inalterada, permitindo que a nota original apareça na ressíntese [-pedal-if-250-500 .wav]. Em outro exemplo fixamos a frequência instantânea da terceira banda em $400 \mathrm{~Hz}$, enquanto a primeira permanece inalterada e a segunda é fixada $250 \mathrm{~Hz}$ [-pedal-if-250-400.wav]. Ouvindo os dois

\footnotetext{
${ }^{12}$ Podemos pensar em efeitos que apresentam uma compreensão local do sinal (como a operação de ganho, que altera o sinal localmente mas não altera a percepção global do mesmo) ou uma compreensão global, que afeta a percepção do sinal ao longo de toda sua duração.

${ }^{13} \mathrm{O}$ tempo de reverberação, ou $R T_{60}$, é o tempo que leva para a intensidade de uma emissão sonora decair em 60 dB [RM15].
} 
exemplos em sequência temos a sensação de uma melodia que se repete sobre uma harmonia que varia.

Código 3.23: Obtenção de acordes com o efeito pedal-if.

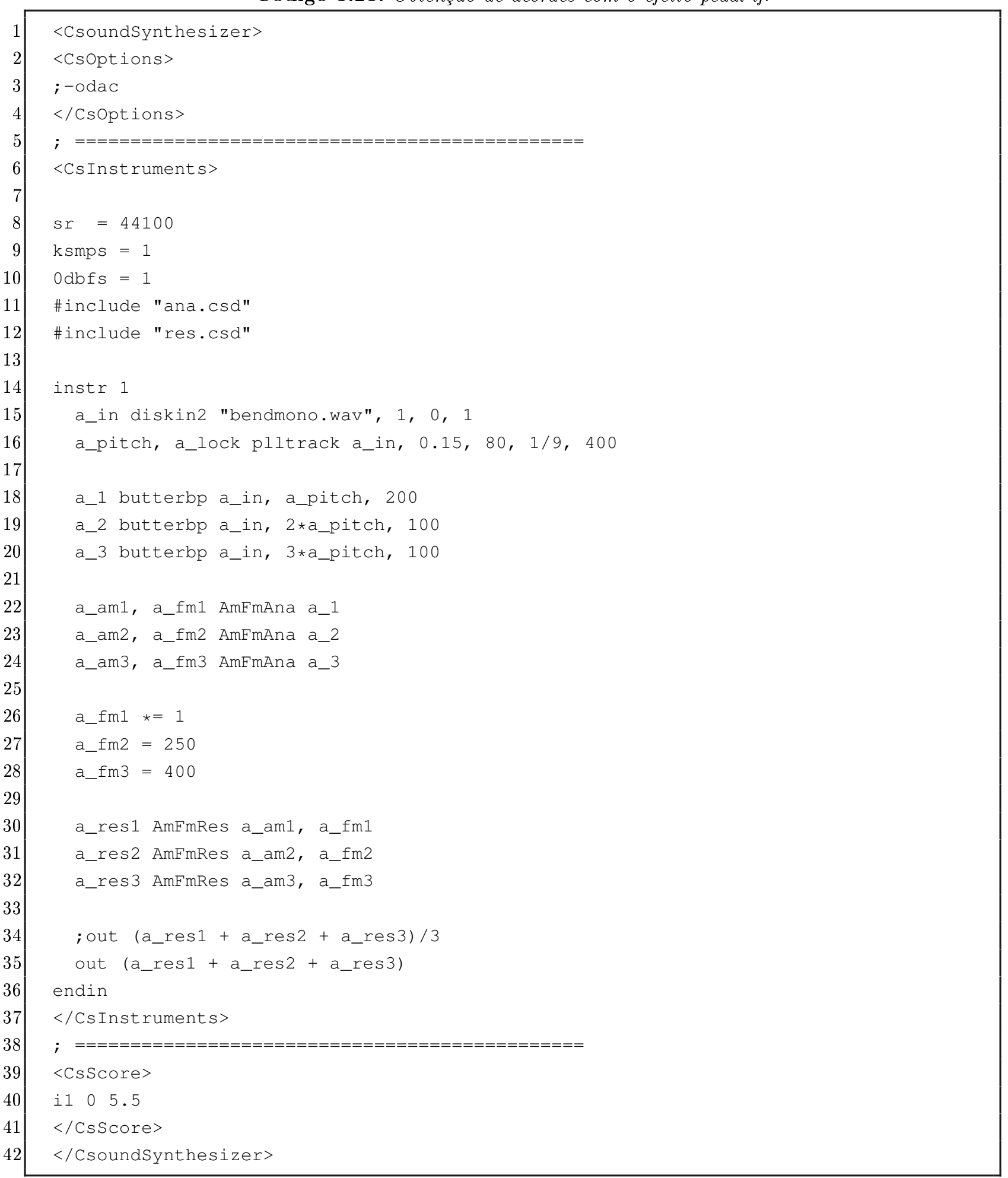

\subsubsection{Controle $d r y / w e t$ alternativo}

Com vários harmônicos de um sinal separados em sinais uma possibilidade que surge é aplicar um mesmo efeito apenas num subconjunto de harmônicos. Quanto menos harmônicos forem processados, mais sutil será o efeito obtido. Assim temos um controle dry/wet alternativo, que no lugar 
de uma mistura ponderada do sinal limpo com o sinal processado, é baseado na decomposição do sinal em bandas seguida de aplicação efetiva de efeito apenas num subconjunto destas bandas.

Para conferir a sonoridade do dry/wet alternativo implementamos o multi-oct-if, baseado no oct-if. O código é baseado na alteração das linhas 25 a 28 do Código 3.23 pelo Código 3.24.

Código 3.24: Geração de acordes baseado no efeito multi-oct-if.

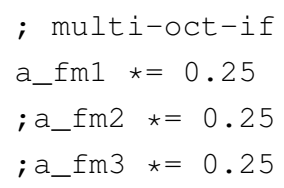

O efeito decompões o sinal em 3 bandas, aplica o efeito oct-if e ressintetiza o sinal. Podemos notar que quanto mais bandas são processadas, mais profundo fica o efeito:

- banda 1 processada (código como apresentado): [-multi-octif-1.wav];

- bandas 1 e 2 processadas ("descomentar" linha 3): [-multi-octif-12.wav];

- bandas 1, 2 e 3 processadas ("descomentar" linha 4): [-multi-octif-123.wav]).

\subsubsection{Alargamento stereo alternativo}

No capítulo anterior apresentamos um efeito stereo na demonstração do código em Csound para separação do sinal instrumental em bandas (Código 2.12). Naquele exemplo foram obtidas bandas centradas em $F 0,2 F 0$ e $3 F 0$, sendo $F 0$ a frequência fundamental estimada com o Audio PLL. O simples efeito ali apresentado consistia em direcionar a primeira banda tanto para o canal esquerdo quanto para o direito, porém direcionar a segunda banda apenas para o esquerdo e a terceira apenas para o direito.

É justamente essa a essência da nossa técnica alternativa para alargamento stereo. As técnicas clássicas [Tho10] para a implementação de alargamento stereo são baseadas em copiar um sinal para mais de um canal, separar os canais por meio de paneamento [Zöl11], e processar cada canal com um mesmo efeito, porém com configurações distintas. Se a escolha de parâmetros não for bem feita, o alargamento obtido pode não ser tão impactante, ou no outro extremo, se a distinção entre a configuração dos canais for demasiada, as sonoridades serão muito dissimilares e ficarão isoladas entre si, perdendo assim o efeito de alargamento.

O próprio ferramental da decomposição AM/FM multicomponente torna possível a realização de outro tipo de alargamento stereo, baseado na distribuição dos sinais ressintetizados de cada banda em canais diferentes. Assim como nas técnicas convencionais, a configuração dos processamentos em cada banda é importante para o sucesso do efeito. 


\section{Capítulo 4}

\section{Avaliação experimental dos efeitos $\mathrm{AM} / \mathrm{FM}$}

It is at this point that we learn how immensely complex the real world really is and how adept the ear is in discerning every little aspect of its complexity. ${ }^{1}$

James Justice

Juntamente com a intuição proporcionada pela teoria e pela audição dos efeitos AM/FM, a análise objetiva dos sinais de áudio é de fundamental importância para o projeto e refinamento dos efeitos. Neste capítulo apresentamos avaliações de efeitos AM/FM baseadas no comportamento de descritores de áudio e no aferimento da intensidade computacional ao executar os algoritmos. Juntamente com os gráficos dos descritores fazemos análises baseadas na interpretação das quantias e comparação com os resultados esperados, relacionando assim a intuição baseada na descrição matemática e na percepção auditiva das sonoridades com as medidas objetivas derivadas dos dados brutos dos sinais de áudio.

\subsection{Metodologia experimental}

Os efeitos AM/FM atuam diretamente nos sinais de envelope e frequência instantânea de um sinal de áudio ao qual queremos aplicar um efeito. Sendo assim, temos interesse em analisar o comportamento de descritores referentes à dinâmica e ao espectro de sinais.

Descritores de áudio são quantias extraídas diretamente de sinais de áudio, podendo estar relacionadas com algum tipo de modelo (por exemplo, modelos psicoacústicos) ou serem manipulações matemáticas com o intuito de revelar algum tipo de informação [Col10]. Neste trabalho a avaliação de cada efeito é baseada na comparação dos descritores extraídos de um sinal limpo (sem aplicação de efeitos) com os mesmos descritores extraídos do sinal após a aplicação do efeito. Em alguns casos também realizamos a comparação entre os descritores extraídos de dois sinais de áudio em que o mesmo efeito foi aplicado, porém com configurações distintas.

\footnotetext{
${ }^{1}$ Tradução do autor: É nesse ponto que aprendemos o quão complexo realmente é o mundo real e o quão hábil é o ouvido em discernir cada pequeno aspecto da sua complexidade.
} 
O sinal de áudio limpo escolhido para os experimentos é um arquivo no formato $\mathrm{WAV}^{2}$, com 16 bits de quantização e amostrado à $44100 \mathrm{~Hz}$. O arquivo [ bendmono . wav] contém uma breve melodia tocada na guitarra, cuja forma de onda e espectrograma foram apresentados na Figura 3.1. A melodia é baseada em variações de dinâmica e frequência fundamental, exploradas por meio das técnicas de palhetada, bend, vibrato e slide, comumente utilizadas por guitarristas em vários gêneros musicais.

Os sinais de áudio processados foram gerados utilizando Csound, por meio dos códigos apresentados ao longo do Capítulo 3. Arquivos de áudio ${ }^{3}$ (também em formato WAV) com a mesma duração foram gerados para os diversos efeitos e diferentes configurações de parâmetros de um mesmo efeito.

A biblioteca Essentia [BWG $\left.{ }^{+} 13\right]$ foi utilizada para extração dos descritores. Um script ${ }^{4} \mathrm{em}$ Python foi desenvolvido para acessar a biblioteca, colher os dados e criar os gráficos. O programa recebe como argumentos dois sinais de áudio, procede para a extração dos descritores especificados, e gera um gráfico para cada descritor, apresentando os valores daquele descritor para os dois sinais passados como argumento, ao longo de toda a duração dos sinais de áudio.

$\mathrm{O}$ aferimento da intensidade computacional foi realizado por meio do software time ${ }^{5}$. Este software apresenta relatórios com informações sobre o consumo de recursos da unidade central de processamento (CPU), consumo de memória, assim como ocorrências ao longo da execução de programas específicos.

Para os experimentos, Csound foi programado para executar em loop o arquivo de áudio limpo, utilizando este sinal para alimentar os algoritmos de efeitos AM/FM. Para cada efeito, o consumo de recursos pelo Csound foi monitorado por 10 segundos pelo time. Os testes foram realizados utilizando um RaspberryPi 2B e um laptop ThinkPad (especificações apresentadas na Seção 4.3).

\subsection{Avaliação baseada em descritores perceptuais}

Dentre tantos descritores disponíveis na Essentia escolhemos trabalhar com aqueles que evidenciam o impacto das manipulações de envelope e frequência instantânea em diversos aspectos de dinâmica e espectro do sinal processado resultante da aplicação de um efeito AM/FM.

Apresentamos uma breve revisão dos descritores selecionados, baseada na própria documentação ${ }^{6}$ da biblioteca Essentia:

- Centroide espectral: indica a posição do "centro de massa" do espectro de um sinal, ou seja, o ponto que divide o espectro em duas porções balanceadas [Bea82]. O centroide é fortemente relacionado com o brilho (brightness) do sinal: quanto maior o valor do centroide, a percepção é de um som mais brilhante;

- Fluxo espectral: calculado a partir da norma (distância euclidiana) da diferença do espectro entre duas janelas consecutivas de um sinal [TC99]. Sendo assim, o fluxo espectral mede quão rapidamente o espectro do sinal varia, podendo ser utilizado para caracterização de timbre, deteç̧ão de onsets [GMR13], entre outras possibilidades;

\footnotetext{
${ }^{2}$ Waveform Audio File Format; é um formato de codificação de áudio sem qualquer tipo de compressão dos dados.

${ }^{3}$ Todos disponíveis para download em https://www.ime.usp.br/ ag/balde/code-audio.zip

${ }^{4}$ Disponível para download (mesmo endereço da nota anterior).

${ }^{5}$ http://manpages.ubuntu.com/manpages/xenial/man1/time.1.html

${ }^{6} \mathrm{http}: / /$ essentia.upf.edu/documentation/algorithms_reference.html
} 
- Proeminência de pitch (Pitch salience): mede a sensação de pitch num sinal, a partir de determinadas relações da função de autocorrelação. Sons sem pitch bem definido, assim como sinais puros (que possuem apenas uma componente) apresentam baixos valores de proeminência de pitch, enquanto sons com harmônicos apresentam valores altos para o descritor;

- Dissonância: mede a aspereza [Hel85] de um som, baseada em curvas de dissonância compartilhadas entre pares de componentes senoidais no sinal. A interação entre componentes espectrais de um sinal pode causar variações de intensidade que, caso lentas, serão percebidas como batimentos, ou, a partir do ponto em que a intensidade é percebida como constante, flutuações que serão percebidas como aspereza [NV05];

- RMS (root mean square - média quadrática): é um indicador da potência do sinal, estando assim relacionado com a percepção de volume do mesmo. O RMS é calculado a partir da média aritmética dos quadrados dos valores do sinal [Col10].

\subsubsection{Experimentos}

Como apresentado no Capítulo 3, são inúmeras as possibilidades de manipulações na etapa de processamento dos sinais de envelope e frequência instantânea, assim como diferentes formas para combinar os sinais na etapa de ressíntese.

Embora tenhamos realizado experimentos abordando todos os efeitos apresentados, apresentamos nesta seção uma seleção dos experimentos. Foram escolhidos representantes de todas as "famílias" de efeitos AM/FM apresentadas. A seguir listamos os experimentos, ressaltando a quais famílias de efeito pertencem as manipulações. Os resultados obtidos serão apresentados e discutidos na sequência.

\section{filtragem}

1. Filtragem passa-baixa na frequência instantânea;

\section{mapeamento não-linear}

2. Compressão da frequência instantânea;

3. Expansão da frequência instantânea;

\section{miscelânea (modulação/fixação)}

4. Fixação da frequência instantânea;

5. Modulação em amplitude da frequência instantânea;

6. Modulação em anel da frequência instantânea;

\section{implementações alternativas de efeitos clássicos}

7. Ganho constante na frequência instantânea;

8. Distorção do envelope por aplicação de raiz quadrada. 


\subsubsection{Resultados e discussão}

\section{Filtragem passa-baixa na frequência instantânea}

As Figuras 4.1 e 4.2 mostram a influência de filtragem passa-baixa da FI no centroide espectral do sinal. Podemos perceber que a filtragem com frequência de corte em $1000 \mathrm{~Hz}$ (Figura 4.1) abaixou ligeiramente o centroide.

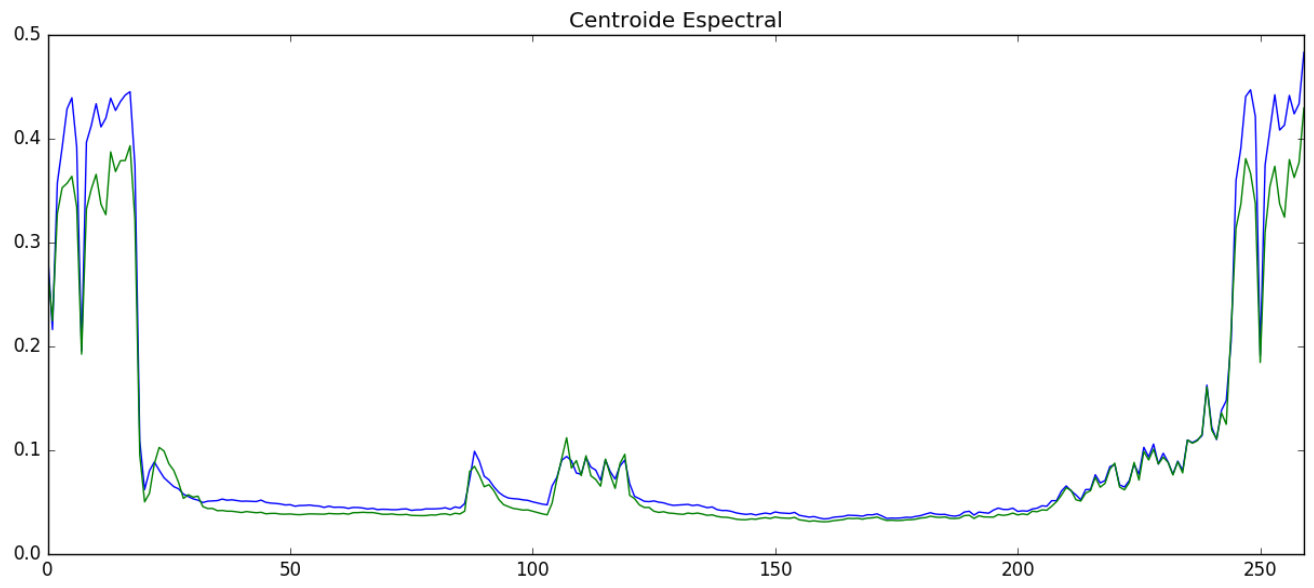

Figura 4.1: Influência de filtragem passa-baixa no centroide espectral. Frequência de corte em $1000 \mathrm{~Hz}$. Sinal limpo em azul e processado em verde.

No entanto nota-se também que parece não haver diferença no centroide espectral resultante de filtragens com frequência de corte em $10 \mathrm{~Hz}$ e em $1000 \mathrm{~Hz}$ (Figura 4.2).

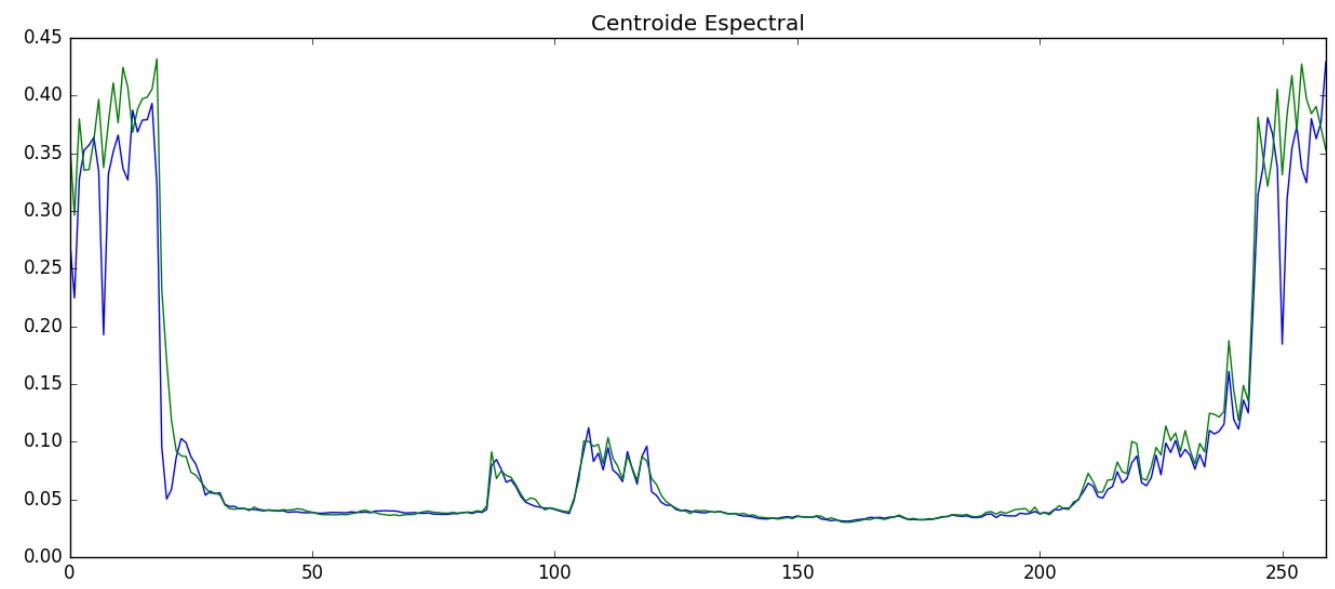

Figura 4.2: Influência de filtragem passa-baixa no centroide espectral. Frequência de corte em $1000 \mathrm{~Hz}$ (azul) e $10 \mathrm{~Hz}$ (verde).

Na Figura 4.3 mostramos as consequências no centroide espectral quando a frequência de corte do passa-baixa é $1 \mathrm{~Hz}$. É interessante notar que justamente quando abaixamos a frequência de corte ao extremo o resultado é uma elevação do centroide em relação ao sinal limpo. Nota-se também que a curva no início do sinal acompanha justamente o chirp que podemos ouvir no início do arquivo lowpif-1.wav]. 


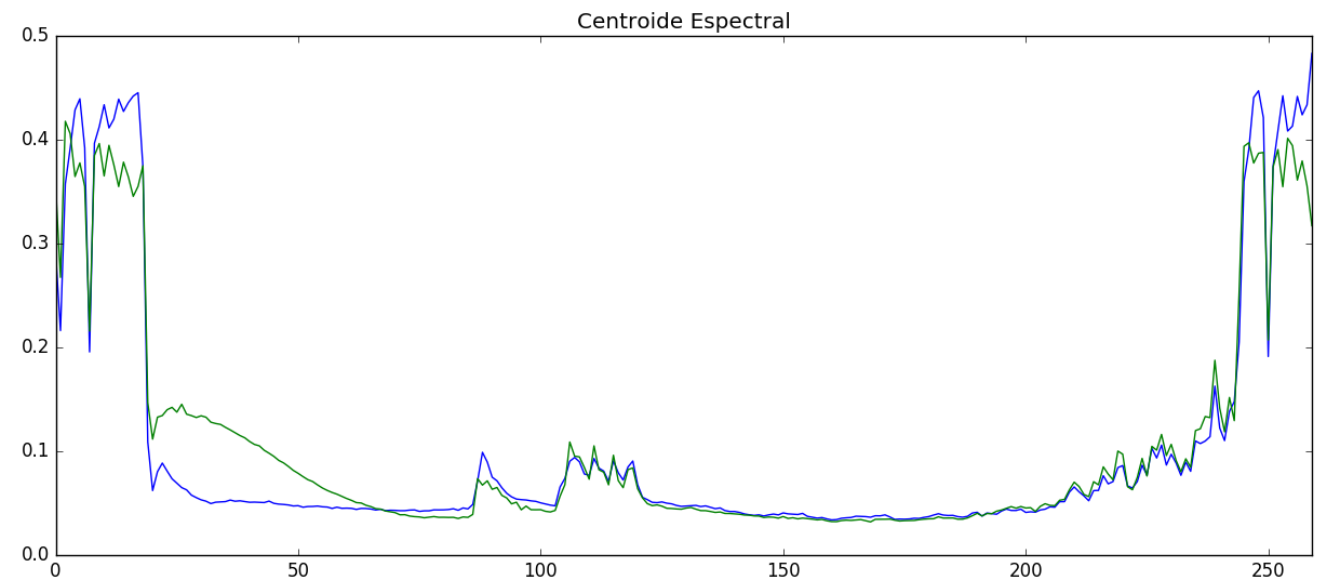

Figura 4.3: Influência de filtragem passa-baixa no centroide espectral. Frequência de corte em $1 \mathrm{~Hz}$. Sinal limpo em azul e processado em verde.

Em relação à influência no fluxo espectral, a Figura 4.4 mostra que a frequência de corte em 10 $\mathrm{Hz}$ aumentou o valor do fluxo nos momentos em que ocorre uma palhetada (percussivo/ruído), em comparação com a filtragem com corte em $100 \mathrm{~Hz}$. Lembramos que o fluxo é utilizado, entre outras aplicações, justamente para detecção de onsets. Notamos também que tal resultado confirma a audição dos sinais [ lowpif-1000.wav] e [ lowpif-500 wav]. Quanto mais baixa a frequência de corte do passa-baixa na FI, mais evidentes ficam os momentos percussivos do sinal.

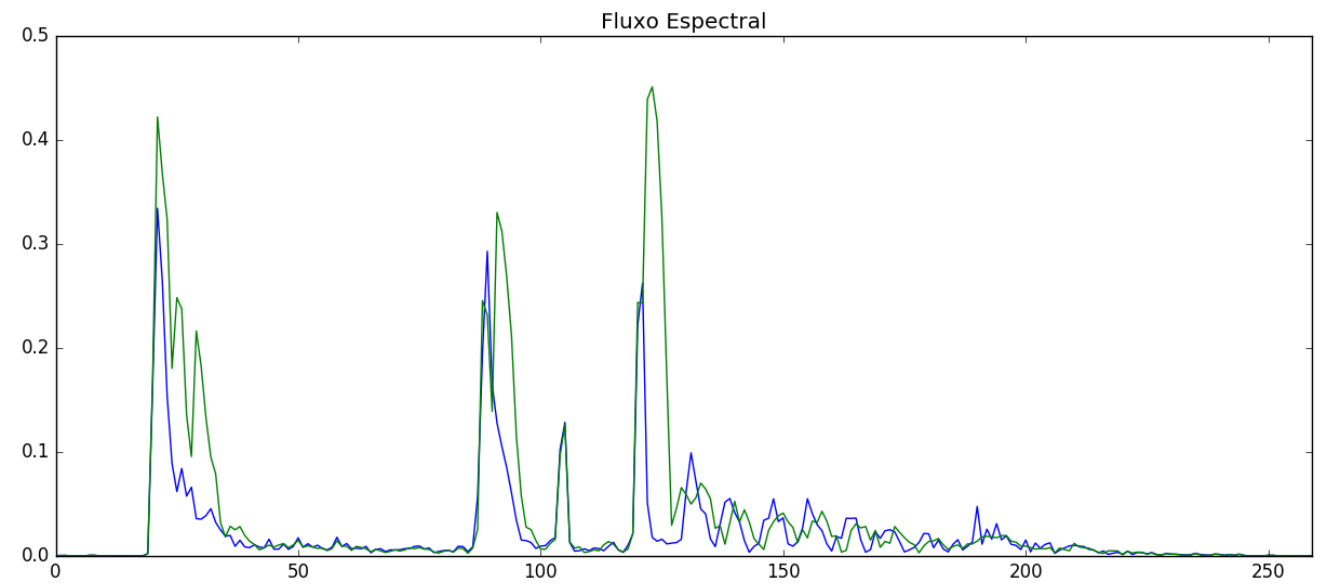

Figura 4.4: Influência de filtragem passa-baixa no fluxo espectral. Frequência de corte em $1000 \mathrm{~Hz}$ (azul) e $10 \mathrm{~Hz}$ (verde). 
O RMS, como era de se esperar, não foi influenciado pela filtragem passa-baixa da FI, como mostrado na Figura 4.5. Este descritor parece ser principalmente afetado por manipulações no envelope, como ficará evidente adiante.

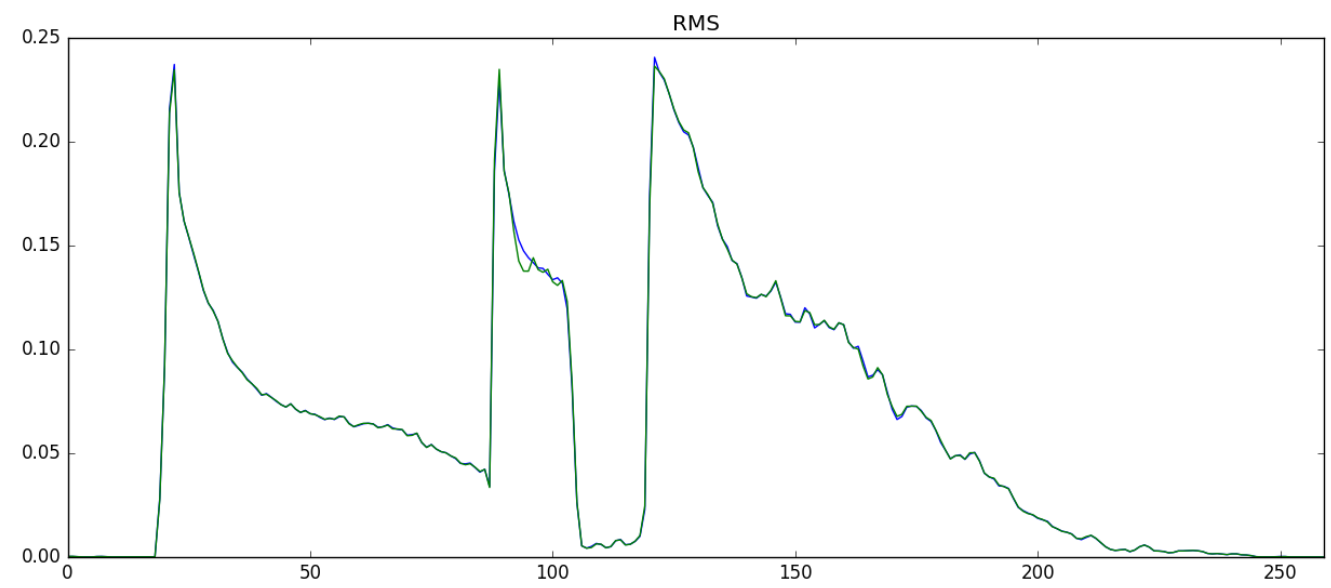

Figura 4.5: Influência de filtragem passa-baixa no RMS. Frequência de corte em $1 \mathrm{~Hz}$. Sinal limpo em azul e processado em verde.

\section{Compressão da frequência instantânea}

Como comentamos no capítulo anterior, atuar na amplitude do sinal de FI, na verdade está relacionado com atuar em frequências que serão consideradas na ressíntese do sinal. Aplicando compressão da faixa dinâmica da FI esperamos como resultado uma diminuição do centroide espectral do sinal processado, o que é confirmado na Figura 4.6.

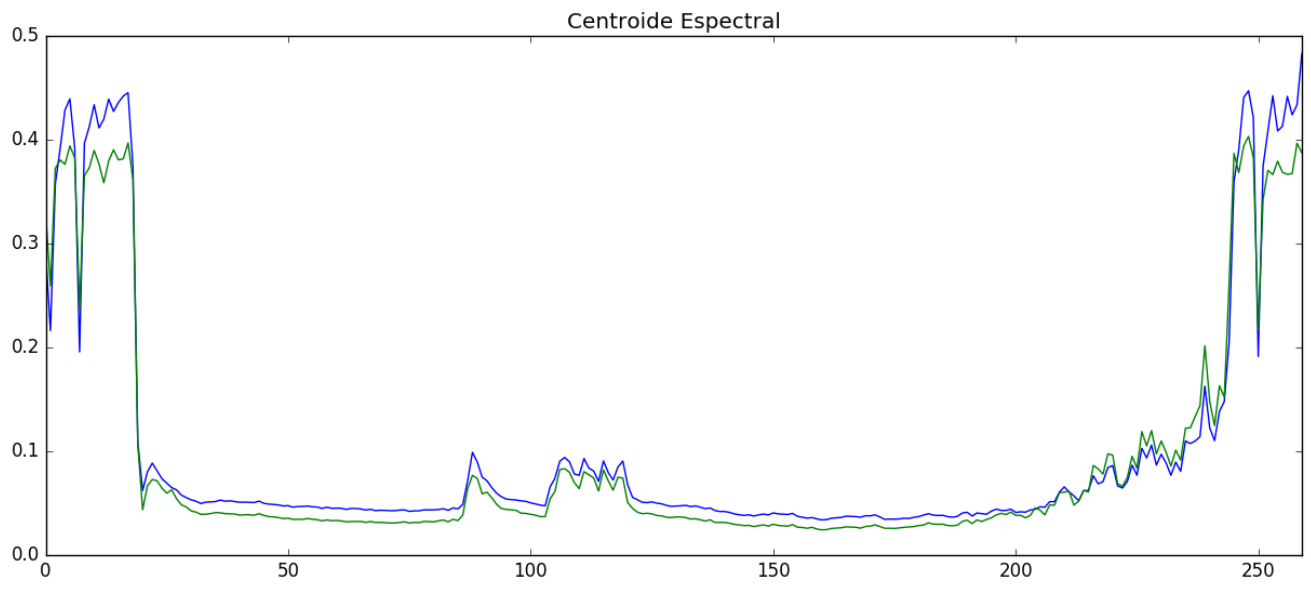

Figura 4.6: Influência de compressão de FI no centroide. Limiar em 100 Hz e taxa 2:1. Sinal limpo em azul e processado em verde. 
Pela Figura 4.7 notamos ainda que, quanto maior é a taxa de compressão, mais decai o centroide espectral, corroborando a intuição matemática e também a audição dos sinais com compressão da FI de $2: 1$ [ compr-if-100-0_5.wav] e $4: 1$ [ compr-if-100-0_25.wav].

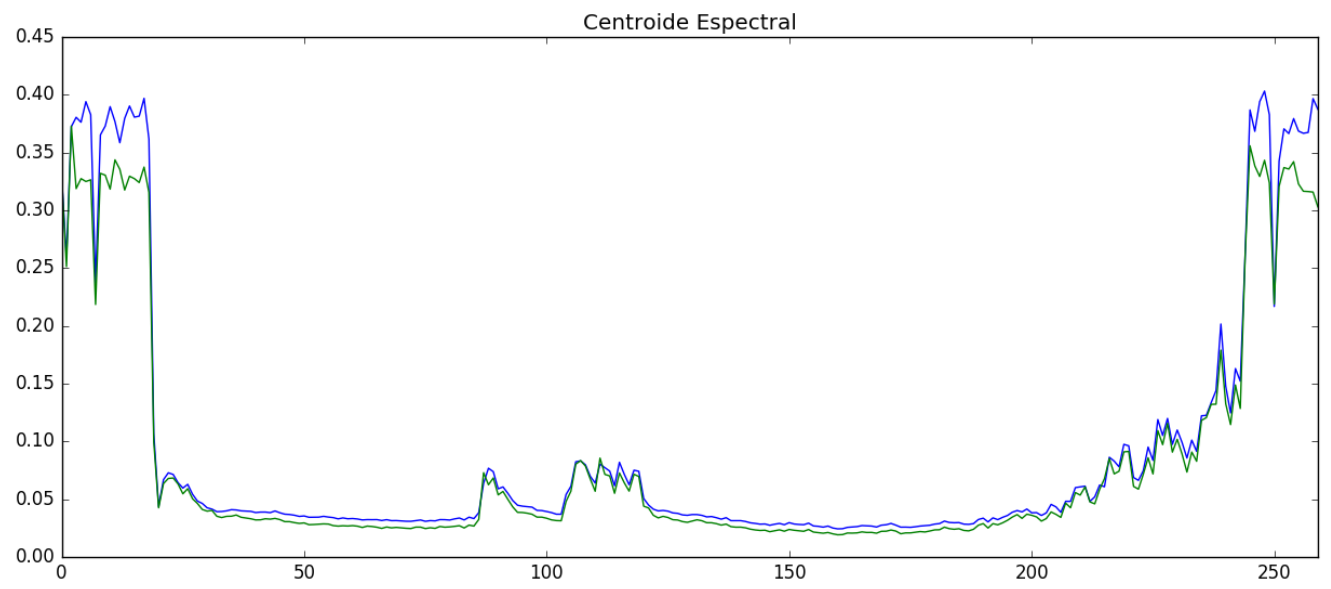

Figura 4.7: Influência de compressão de FI no centroide. Em azul, taxa de compressão 2:1. Em verde, taxa 4:1. Limiares em $100 \mathrm{~Hz}$.

\section{Expansão da frequência instantânea}

Um efeito contrário ao obtido com a compressão da FI é esperado ao expandir a FI. A Figura 4.8 confirma tal intuição; ao longo de todo o sinal o centroide do sinal com FI expandida se encontra acima do centroide do sinal original.

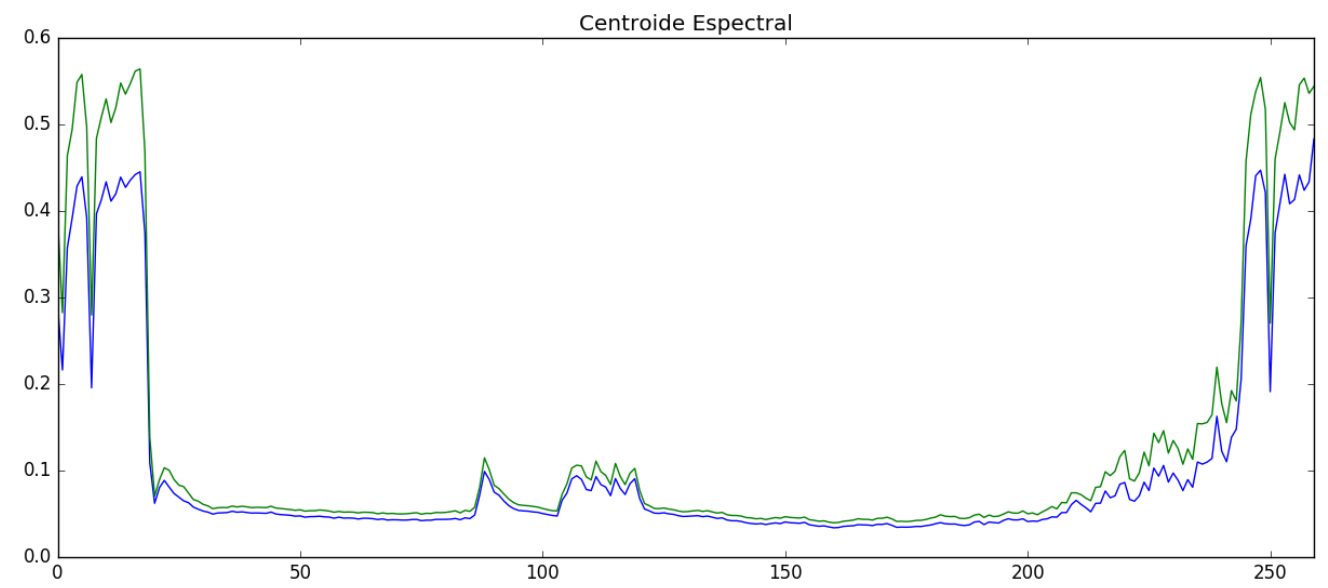

Figura 4.8: Influência de expansão de FI no centroide. Limiar em $100 \mathrm{~Hz}$ e taxa de expansão 1.2:1. Sinal limpo em azul e processado em verde. 
Analogamente ao caso da compressão, esperamos que a subida do centroide aumente de acordo com o aumento da taxa de expansão, confirmação que obtemos pela Figura 4.9.

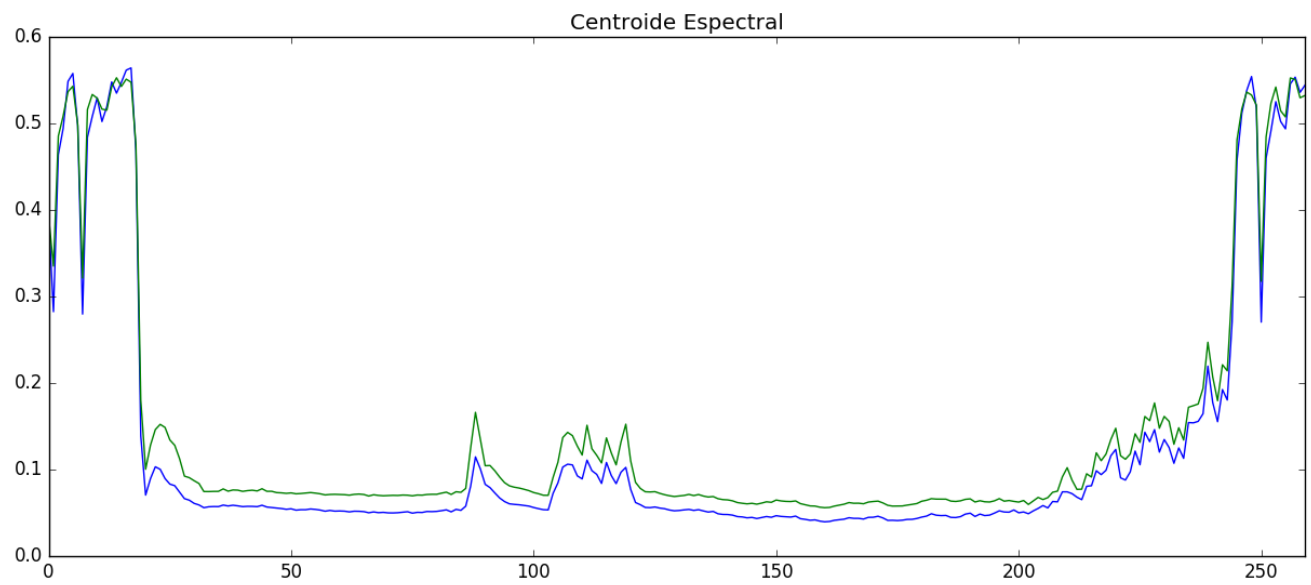

Figura 4.9: Influência de expansão de FI no centroide. Em azul, taxa 1.2:1. Em verde, taxa 2:1. Ambos os limiares em $100 \mathrm{~Hz}$.

Na Figura 4.10 podemos notar a influência da escolha do limiar. Para um limiar mais baixo, teremos mais valores da FI expandidos, elevando assim o centroide.

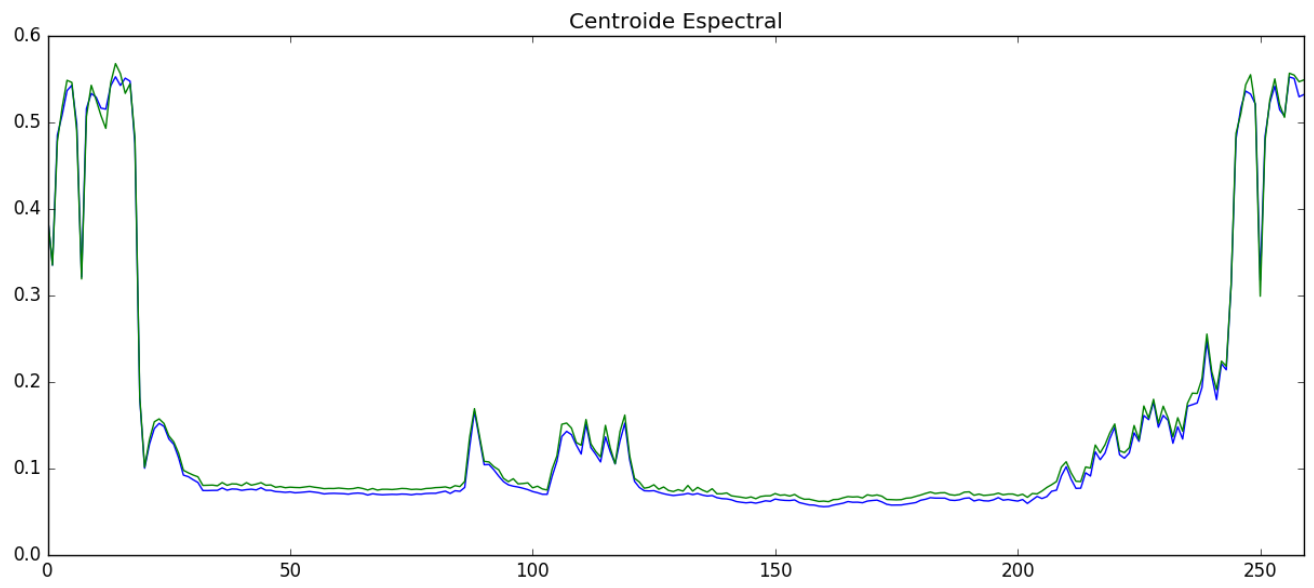

Figura 4.10: Influência de expansão de FI no centroide. Em azul, limiar em $100 \mathrm{~Hz}$. Em verde, limiar em $10 \mathrm{~Hz}$. Ambas as taxas em 2:1. 


\section{Fixação da frequência instantânea}

Uma vez que no efeito fix-if o resultado sonoro é uma senoide com frequência dada pelo novo valor (fixo) da FM, é de se esperar que a escolha de um valor baixo para a fixação (em comparação com os valores estimados para a FI do sinal limpo) diminua o centroide espectral (Figura 4.11) e um valor alto aumente o descritor (Figura 4.12).

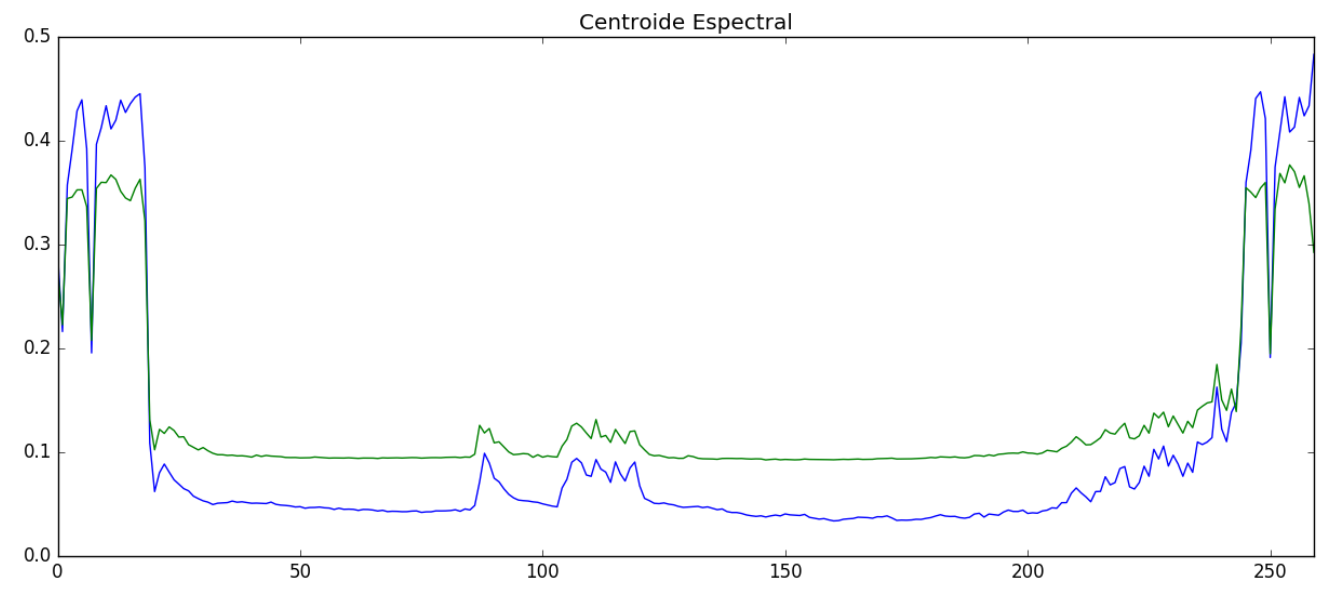

Figura 4.11: Influência de fixação de FI no centroide. FI=2000 Hz. Sinal limpo em azul e processado em verde.

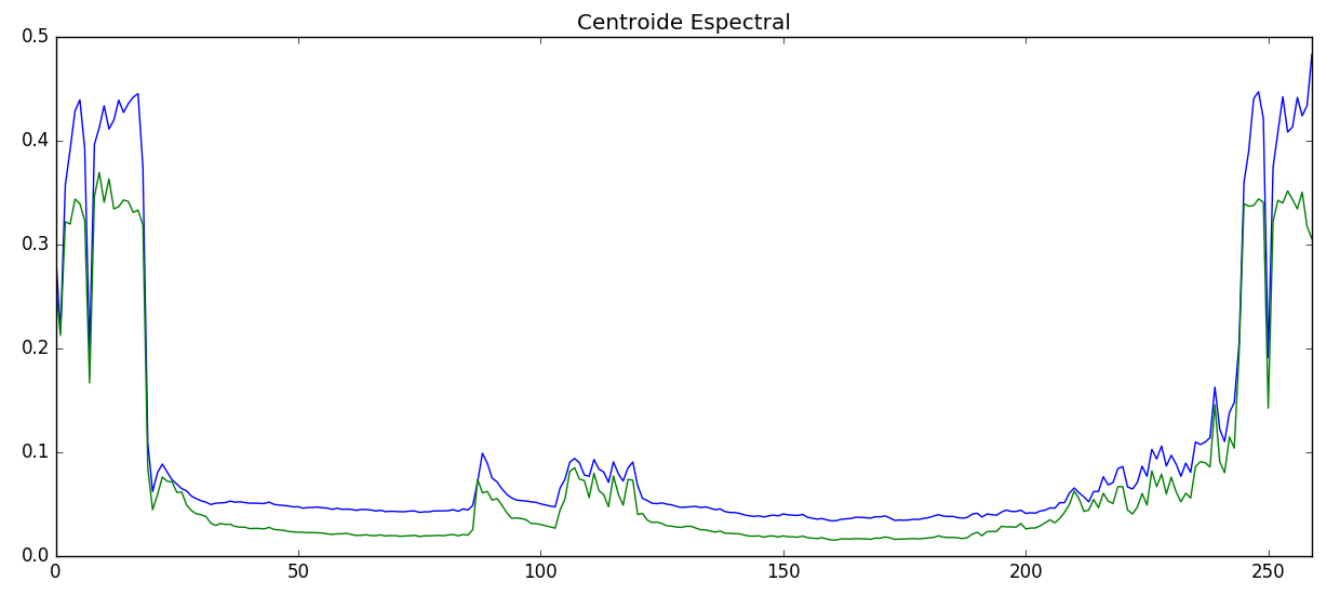

Figura 4.12: Influência de fixação de FI no centroide. FI = $200 \mathrm{~Hz}$. Sinal limpo em azul e processado em verde. 
O RMS, que a princípio está mais atrelado à dinâmica do sinal, permanece inalterado, como evidenciado pela Figura 4.13.

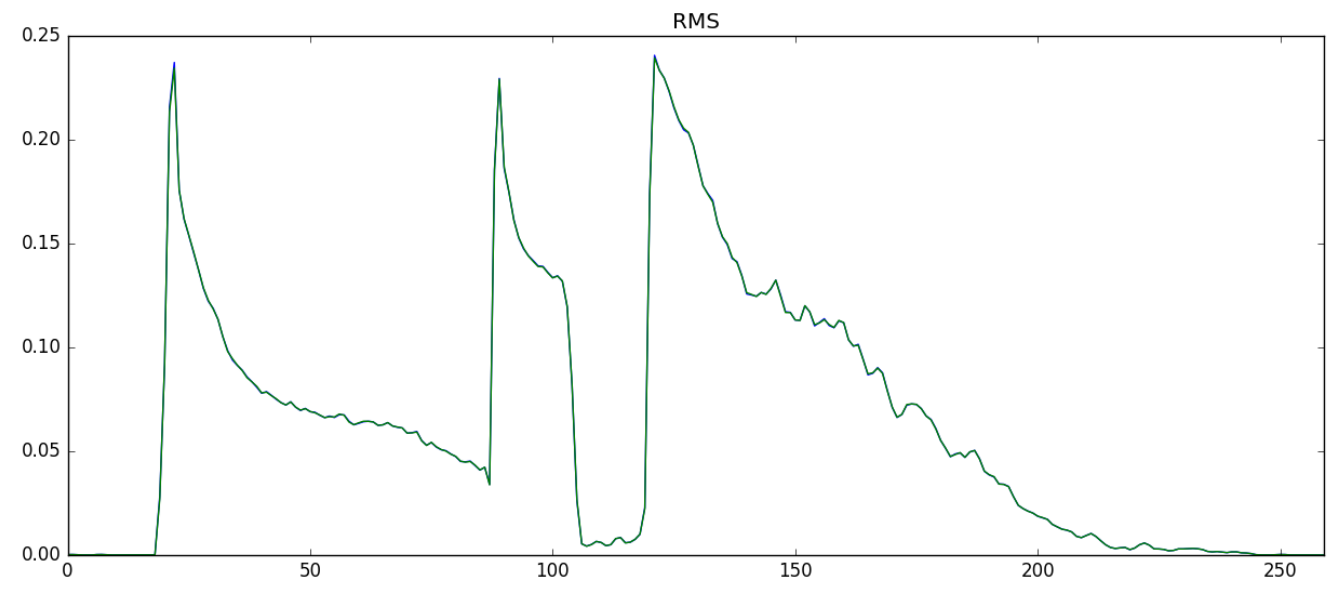

Figura 4.13: Influência no RMS de fixação de FI em $2 \mathrm{kHz}$. Sinal limpo em azul e processado em verde.

\section{Modulação em amplitude da frequência instantânea}

A Figura 4.14 mostra o centroide espectral no caso do efeito $v$-if-brato. Uma vez que a modulação em amplitude clássica (com o offset) preserva o sinal e adiciona um modulador que aplica um vibrato de profundidade sutil, a diferença no centroide é imperceptível.

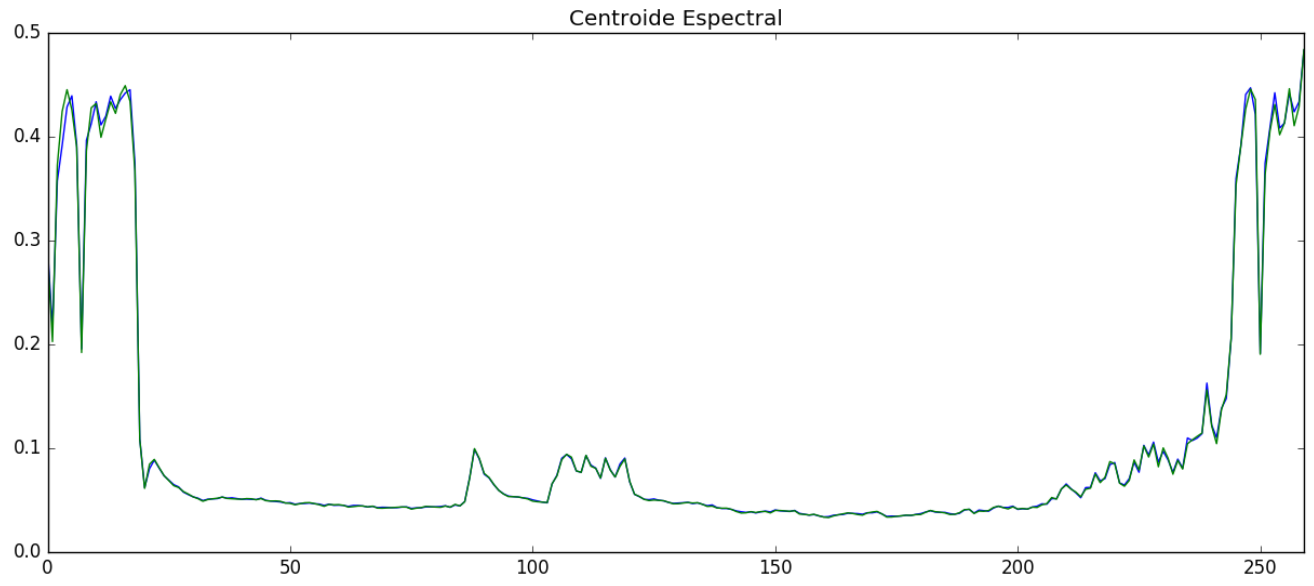

Figura 4.14: Influência de modulação em amplitude da FI no centroide. Sinal limpo em azul e processado em verde. Efeito $A M / F M$ v-if-brato. 


\section{Modulação em anel da frequência instantânea}

Nesta seção os efeitos são baseados na modulação em anel da FI, ou seja, não existe o offset como na modulação clássica, em que se preserva a portadora (no caso, o sinal da FI). Assim temos efeitos que causam variações bruscas no sinal de FI, como fica evidenciado na Figura 4.15. Podemos notar que a modulação em anel na FI impacta fortemente o centroide, que oscila junto com o modulador do efeito [ wheel-if.wav]. Como o modulador apresenta valores no intervalo [0,1], o centroide do sinal processado é limitado pelo centroide do sinal limpo, mas nos momentos em que o modulador atinge 0 o centroide do sinal com efeito apresenta valor mínimo.

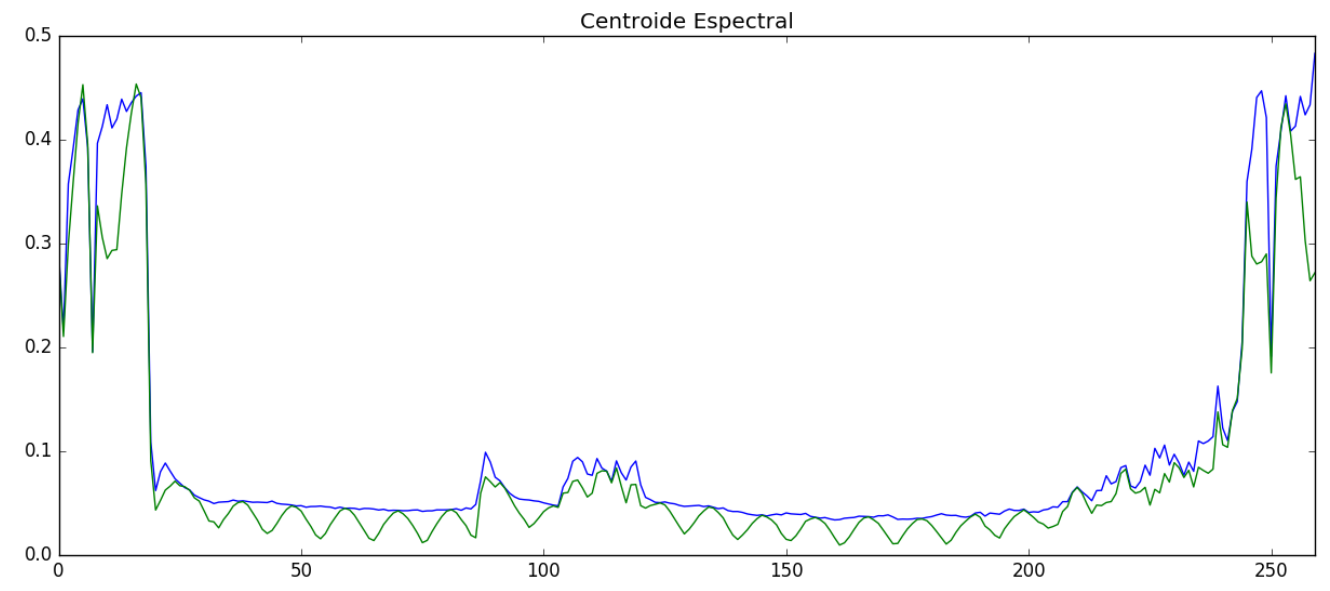

Figura 4.15: Influência de modulação em anel da FI no centroide. Sinal limpo em azul e processado em verde. Efeito $A M / F M$ whee-if.

O fluxo espectral, que mede variações no espectro ao longo do sinal, se eleva em relação ao sinal limpo, como era esperado. O fluxo para este caso é apresentado na Figura 4.16.

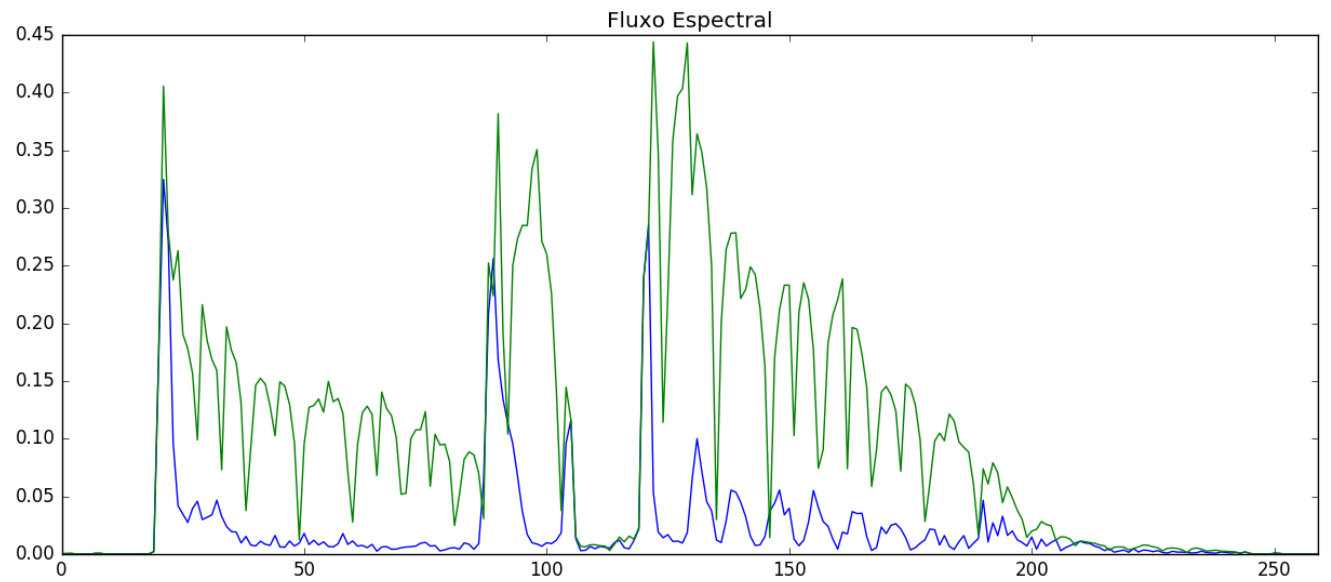

Figura 4.16: Influência de modulação em anel da FI no fluxo espectral. Sinal limpo em azul e processado em verde. 
A proeminência de pitch também passa a apresentar comportamento oscilatório de acordo com o sinal modulador, apresentando valores sempre acima do descritor no caso do sinal limpo.

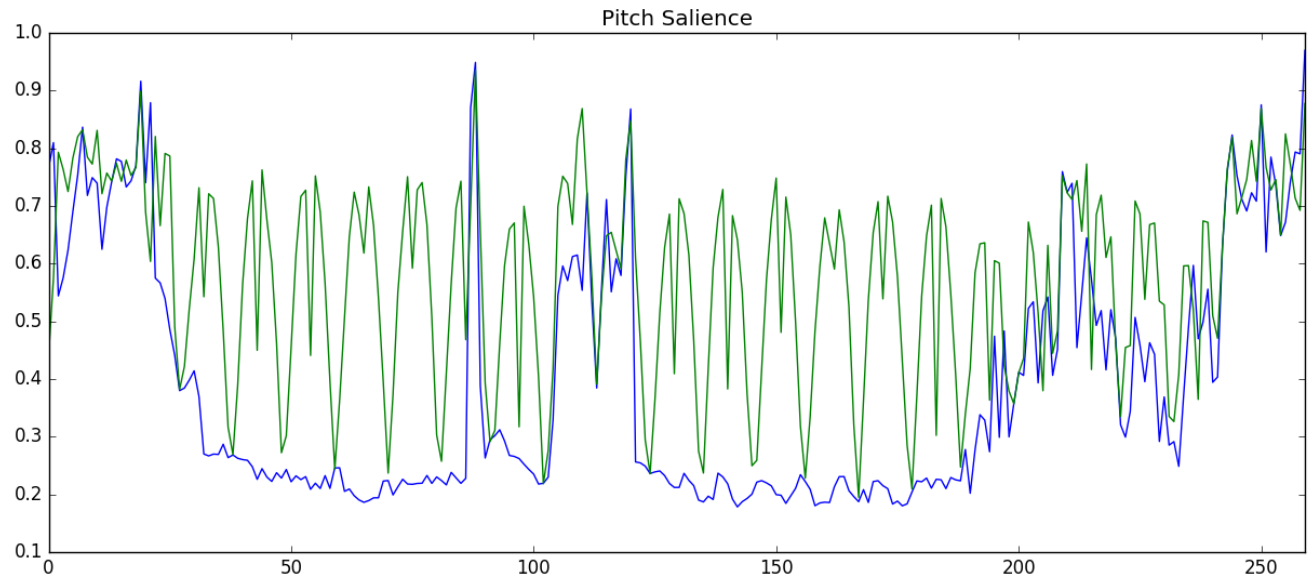

Figura 4.17: Influência de modulação em anel da FI na proeminência de pitch. Sinal limpo em azul e processado em verde.

Um comportamento completamente diferente para o centroide espectral é observado na Figura 4.18, que representa o caso do efeito gliss-if, no qual a modulação em anel da FI é extremamente lenta (também com valores no intervalo $[0,1]$ ). Como resultado temos um centroide que começa bem abaixo do centroide do sinal limpo, justamente quando o modulador apresenta valores baixos. Conforme os valores do oscilador vão aumentando o centroide vai alcançando o centroide do caso do sinal limpo, até que ao final do trecho de áudio [ gliss-if.wav] o modulador apresenta valores próximos de 1 e o centroide do sinal processado equivale ao do sinal limpo.

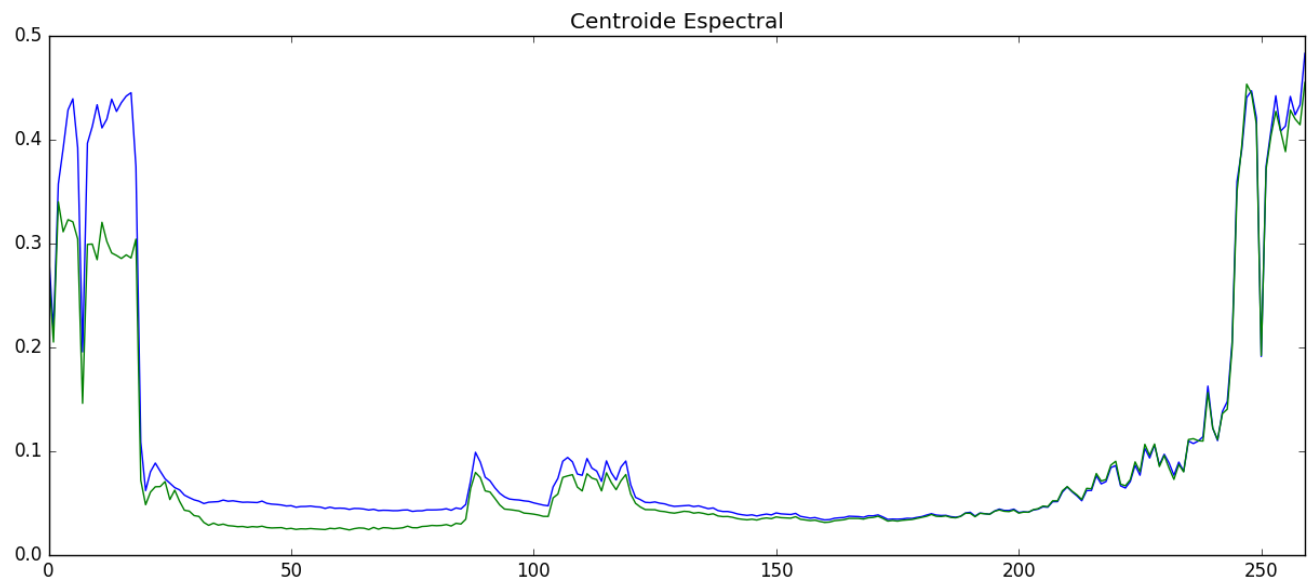

Figura 4.18: Influência de modulação em anel da FI no centroide. Sinal limpo em azul e processado em verde. Efeito $A M / F M$ gliss-if. 


\section{Ganho constante na frequência instantânea}

Agora vamos considerar o efeito oct-if, tanto na versão oitava acima quanto oitava abaixo. Como era esperado, o efeito oitavador considerando a oitava para baixo diminui o valor do centroide espectral, como é evidenciado na Figura 4.19.

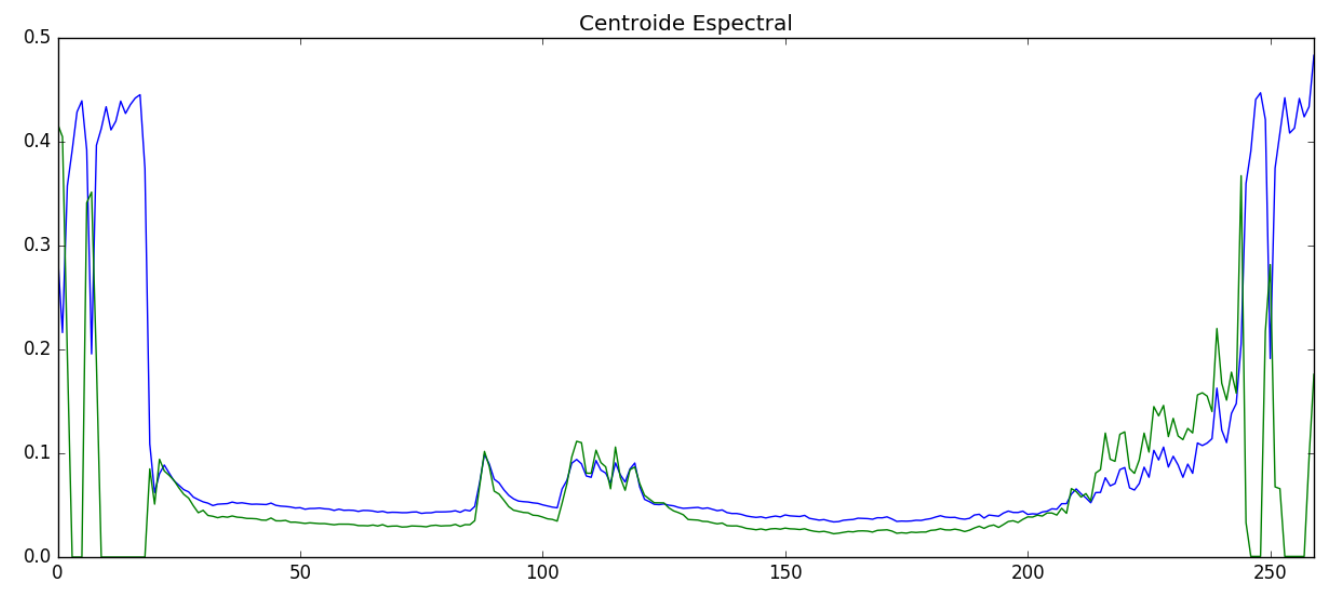

Figura 4.19: Influência de ganho (multiplicação por 0.25) na FI no centroide. Sinal limpo em azul e processado em verde.

O fluxo espectral aumenta por todo o sinal, especialmente nas palhetadas, como mostra a Figura 4.20. Este pode ser um sinal de que o efeito tem o efeito colateral de adicionar uma leve camada de ruído ao sinal.

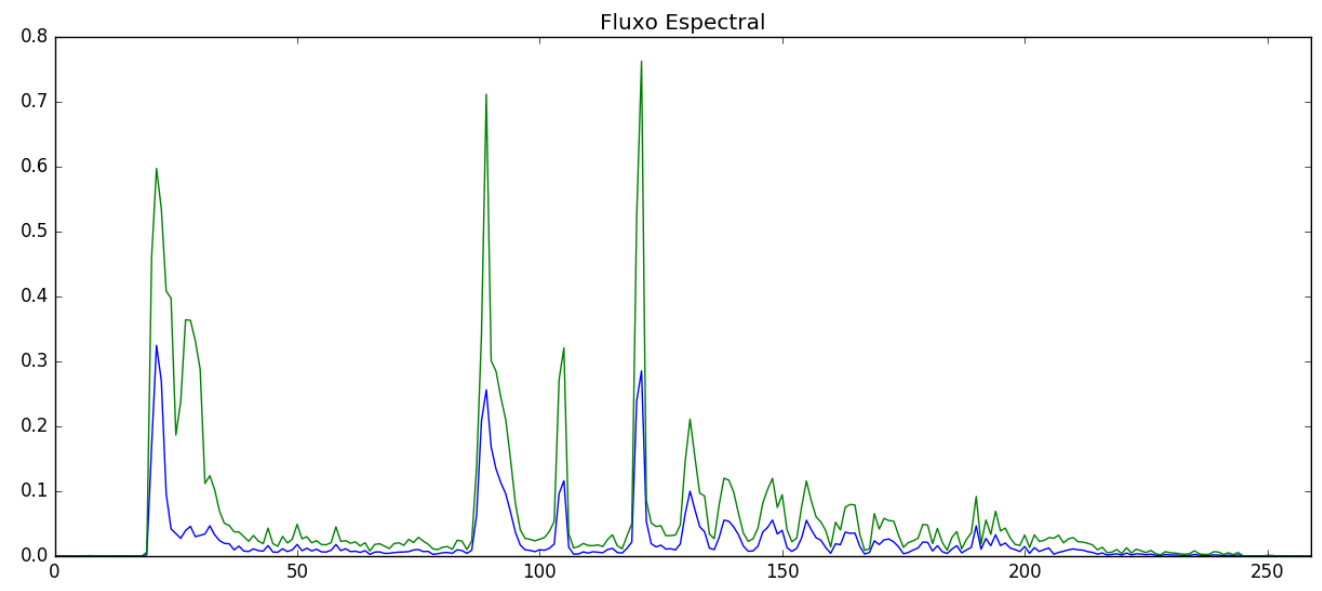

Figura 4.20: Influência de ganho (multiplicação por 0.25) na FI no fluxo espectral. Sinal limpo em azul e processado em verde. 
A proeminência de pitch, mostrada na Figura 4.21 aumenta ao longo de todo o sinal. Uma vez que este descritor apresenta valores elevados para sinais com harmônicos, o aumento do mesmo era esperado, pois o oitavador aumenta a largura de banda do sinal com mais harmônicos ainda.

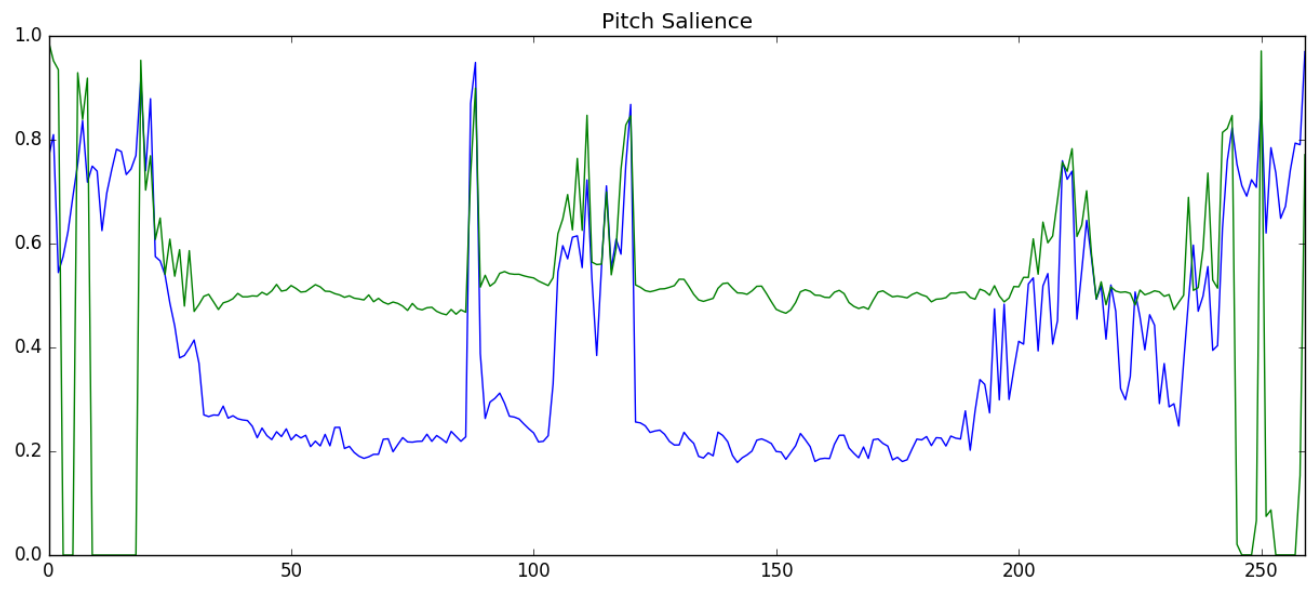

Figura 4.21: Influência de ganho (multiplicação por 0.25) na FI na proeminência de pitch. Sinal limpo em azul e processado em verde.

Finalmente, como também era esperado, a versão oitava acima do efeito eleva o centroide espectral em relação ao centroide do sinal limpo, como mostrado na Figura 4.22.

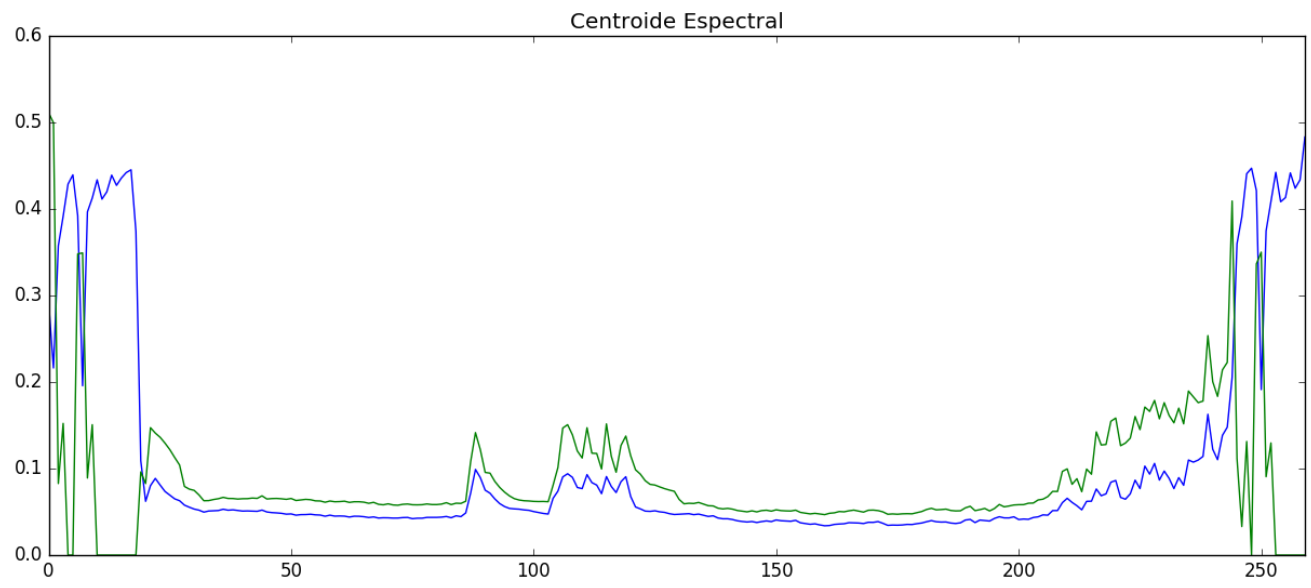

Figura 4.22: Influência de ganho (multiplicação por 2) na FI no centroide. Sinal limpo em azul e processado em verde. 


\section{Distorção do envelope por aplicação de raiz quadrada}

Neste efeito processamos apenas o envelope da decomposição AM/FM. Como podemos notar pela Figura 4.23 o processamento não apresenta alteração significativa nos valores do centroide.

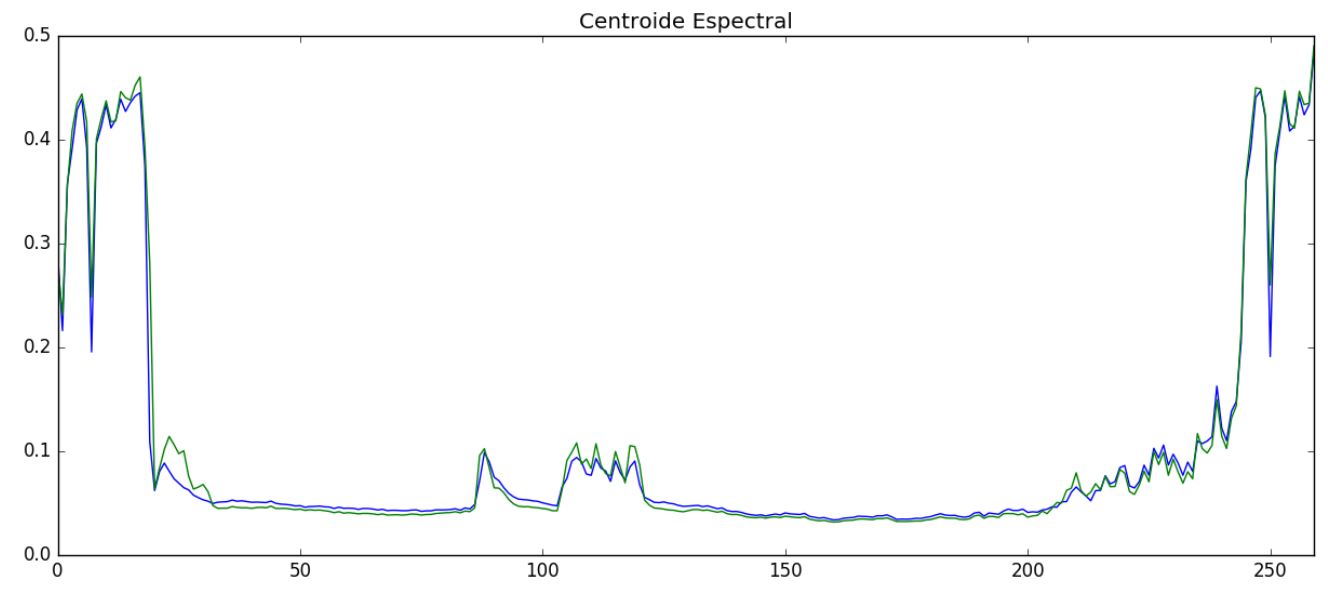

Figura 4.23: Influência de aplicação de raiz quadrada do envelope no centroide. Sinal limpo em azul e processado em verde.

Como comentado no capítulo anterior, a aplicação da raiz quadrada em valores na faixa $[0,1]$ resulta, na verdade, numa operação de ganho. Sendo assim, esperamos um aumento dos valores de RMS, como podemos confirmar pela Figura 4.24.

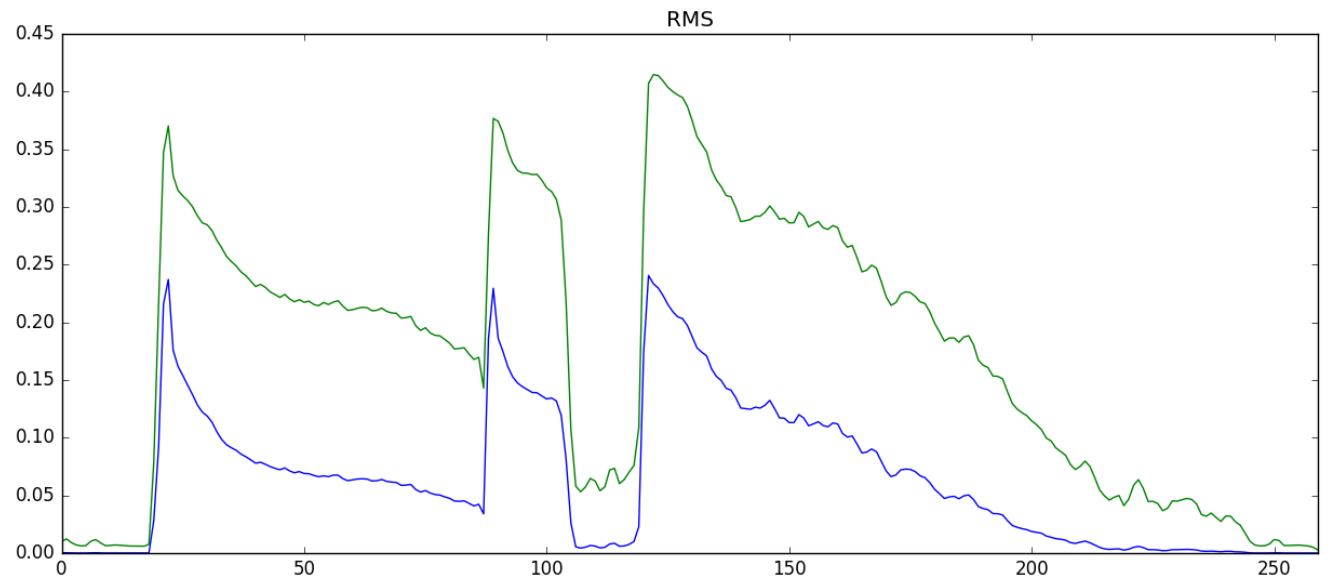

Figura 4.24: Influência de aplicação de raiz quadrada do envelope no RMS. Sinal limpo em azul e processado em verde. 
Em relação à dissonância, não percebemos pela Figura 4.25 alteração significativa entre o sinal com efeito e o limpo. Quando pensamos em distorção rapidamente associamos o nome ao fato de que novos harmônicos aparecem no sinal como resultado de um ceifamento. Mas é importante lembrar que neste efeito não ocorre de fato um ceifamento do envelope, apenas um mapeamento em que trechos menos intensos recebem uma amplificação maior do que trechos mais intensos, resultando numa sonoridade [ sq-env . wav] similar ao reverb.

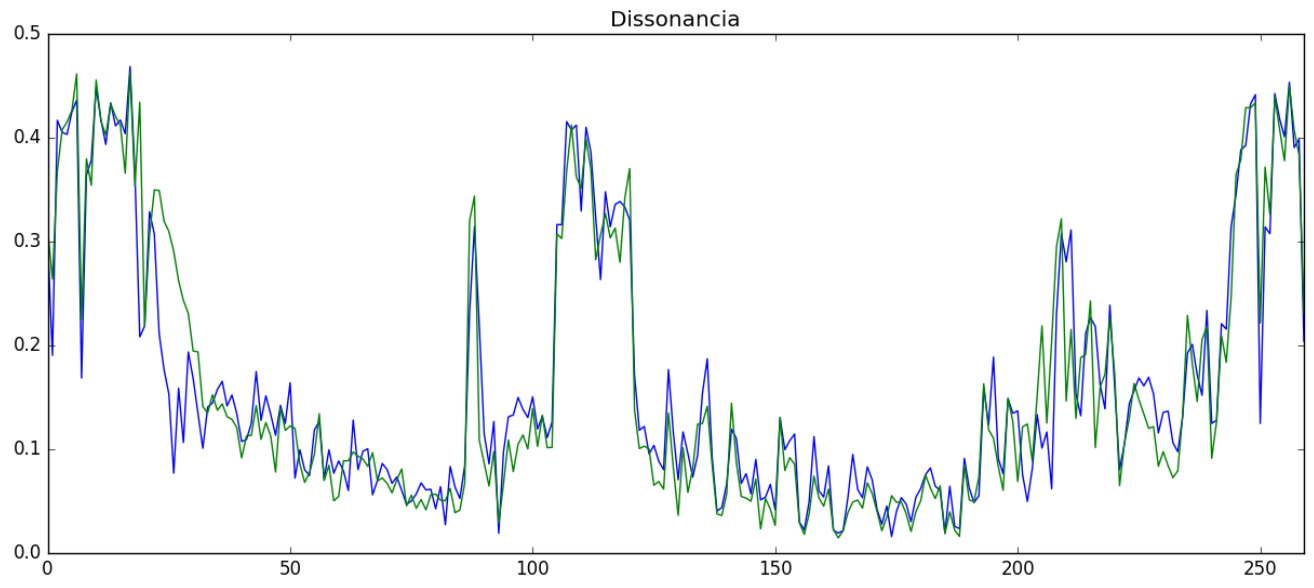

Figura 4.25: Influência de aplicação de raiz quadrada do envelope na dissonância. Sinal limpo em azul e processado em verde.

\subsection{Avaliação de desempenho computacional}

Um aspecto importante a se considerar no projeto de efeitos de áudio é a intensidade computacional necessária para executá-los em tempo real, sendo este resultado importante tanto para considerações artísticas (e.g. latências máximas toleradas) quanto técnicas (e.g. dimensionamento de hardware necessário).

Apresentamos a intensidade computacional em termos da porcentagem de CPU consumida ao executar os efeitos em dois dispositivos:

- RaspberryPi 2 modelo B (Figura 1.7), com processador quad-core ARM Cortex-A7 @ $900 \mathrm{MHz}$ 32 bits e 1 GB de memória SD-RAM @ 400 MHz, sistema operacional Raspbian ${ }^{7}$ (baseado em Debian/Linux), e Csound 6.08. Este sistema é utilizado pelo autor como sua única pedaleira de efeitos ${ }^{8}$ (laptops com capacidade de processamento modesta e netbooks também podem ser utilizados para tal);

- laptop ThinkPad x220 (Figura 1.3), com processador dual-core i5-2520M @ $2.5 \mathrm{GHz} 64$ bits e 8 GB de memória RAM DDR3 @ 1333 MHz, sistema operacional Debian/Linux, e Csound 6.09.1.

\footnotetext{
${ }^{7}$ https://www.raspberrypi.org/downloads/raspbian/

${ }^{8}$ Para mais informações consultar o Apêndice A.
} 


\subsubsection{Experimentos}

A intenção com os experimentos desta seção é comparar a intensidade necessária para a execução de diversos efeitos AM/FM com a intensidade necessária para a execução de outros efeitos já estabelecidos na literatura de efeitos digitais de áudio, além de uma comparação com tarefas comumente utilizadas em sistemas para computação musical.

Assim como nos experimentos dos descritores, foram escolhidos representantes de todas as famílias de efeitos AM/FM apresentadas. A seguir listamos os experimentos realizados para aferimento de desempenho computacional.

\section{operações em computação musical}

1. Reprodução de sample de áudio

2. Distorção convencional (ceifamento)

3. FFT seguida de FFT inversa

\section{efeitos convencionais}

4. Oitavador baseado em FFT

5. Reverb baseado em convolução

\section{ferramental AM/FM}

6. Decomposição AM/FM seguida de ressíntese AM/FM

\section{efeitos AM/FM}

7. Filtragem passa-baixa da FI

8. Compressão descendente da FI

9. Modulação em anel da FI

releituras AM/FM

10. Oitavador $\mathrm{AM} / \mathrm{FM}$ oct-if

11. Reverb AM/FM sq-env 
O time é executado pelo shell. O comando

time csound programa.csd

especifica o modo padrão de operação do time para aferir a intensidade computacional requisitada pelo Csound ao executar o arquivo programa. csd. Para os experimentos, um arquivo de Csound foi preparado ${ }^{9}$ para executar cada efeito por 10 segundos, em tempo real.

A operação padrão do time retorna três valores:

- real, a duração total do processo sob análise;

- user, o tempo gasto pela CPU trabalhando diretamente no processo;

- sys, tempo gasto pela CPU em tarefas do sistema relacionadas com o processo.

Para cada programa analisado, a intensidade computacional é dada em termos de $\frac{\text { user }+ \text { sys }}{\text { real }}$.

\subsubsection{Resultados e discussão}

A Tabela 4.1 sumariza o consumo de recursos do RaspberryPi 2B e do ThinkPad x220 ao executar os diversos algoritmos testados.

\begin{tabular}{|c|c|c|c|c|c|c|c|c|}
\cline { 3 - 10 } \multicolumn{1}{c|}{} & \multicolumn{7}{c|}{ RaspberryPi 2 B } & \multicolumn{3}{c|}{ ThinkPad x220 } \\
\hline efeito de áudio & real & user & sys & \% CPU & real & user & sys & \% CPU \\
\hline \hline áudio em loop & 10.221 & 0.62 & 0.35 & 9.49 & 10.032 & 0.308 & 0.162 & 4.69 \\
distorção (clip) & 10.211 & 0.83 & 0.27 & 10.77 & 10.036 & 0.36 & 0.148 & 5.06 \\
\hline FFT/FFT inv. (1024/512) & 10.245 & 2.3 & 0.4 & 26.35 & 10.043 & 0.644 & 0.212 & 8.52 \\
FFT/FFT inv. (1024/256) & 10.22 & 3.53 & 0.29 & 37.38 & 10.069 & 0.852 & 0.192 & 10.37 \\
FFT/FFT inv. (1024/128) & 10.206 & 4.44 & 0.23 & 45.76 & 10.044 & 1.08 & 0.156 & 12.31 \\
FFT/FFT inv. (512/256) & 10.21 & 2.35 & 0.31 & 26.05 & 10.047 & 0.72 & 0.152 & 8.68 \\
FFT/FFT inv. (512/128) & 10.213 & 3.27 & 0.17 & 33.68 & 10.046 & 0.888 & 0.164 & 10.47 \\
\hline \hline oitavador FFT (1024/128) & 10.187 & 4.67 & 0.22 & 48.00 & 10.028 & 1.116 & 0.128 & 12.41 \\
reverb convolução & 10.227 & 9.0 & 0.1 & $88.98 *$ & 10.03 & 2.184 & 0.12 & $22.97^{*}$ \\
\hline \hline dec./res. AM/FM & 10.225 & 2.18 & 0.4 & 25.23 & 10.035 & 0.6 & 0.156 & 7.53 \\
\hline \hline filtragem FI & 10.23 & 2.78 & 0.26 & 29.72 & 10.042 & 0.64 & 0.136 & 7.73 \\
compressão FI & 10.209 & 3.08 & 0.31 & 33.21 & 10.021 & 0.644 & 0.136 & 7.78 \\
modulação FI & 10.229 & 2.66 & 0.33 & 29.23 & 10.046 & 0.648 & 0.148 & 7.92 \\
\hline \hline oitavador AM/FM & 10.21 & 2.63 & 0.42 & 29.87 & 10.039 & 0.636 & 0.148 & 7.81 \\
reverb AM/FM & 10.243 & 2.66 & 0.26 & 28.51 & 10.04 & 0.608 & 0.172 & 7.77 \\
\hline
\end{tabular}

Tabela 4.1: Intensidade computacional para execução de efeitos de áudio. ${ }^{*}$ Os experimentos de aplicação de reverb por convolução foram realizados com uma resposta ao impulso de 5000 amostras no ThinkPad e com 2000 amostras no RaspberryPi.

\footnotetext{
${ }^{9}$ Arquivos Csound para os experimentos estão inclusos no pacote para download.
} 
As primeiras linhas da tabela ilustram, para fins de comparação com os efeitos AM/FM, a intensidade computacional necessária para a realização de duas tarefas leves, comuns no contexto de computação musical: a reprodução de um sample de áudio, e a aplicação de distorção por ceifamento. As linhas seguintes revelam o consumo de recursos para calcular a FFT de um sinal de áudio, seguida da FFT inversa, em diferentes tamanhos de janelas de análise e sobreposição. Este paradigma de processamento de sinais baseado no ferramental FFT é amplamente difundido na literatura e utilizado em aplicações práticas, constituindo-se assim como outro importante ponto de comparação.

De uma maneira geral, os resultados mostram que as técnicas baseadas em decomposição e ressíntese $\mathrm{AM} / \mathrm{FM}$ são acessíveis do ponto de vista da intensidade computacional necessária para executá-las. A computação da decomposição seguida da ressíntese apresenta, por exemplo, um custo inferior ao custo para utilização do ferramental da FFT, em todas as configurações testadas.

Tanto no caso AM/FM quanto FFT a aplicação de algum efeito (no qual o processamento ocorre no domínio alternativo, ou seja, entre a decomposição e a ressíntese) pouco acrescenta no cálculo geral da intensidade computacional, em comparação com o custo das transformadas apenas. Sendo assim, a implementação de oitavador baseada em AM/FM se mostrou vantajosa, em termos de esforço computacional, em relação à tradicional técnica baseada em FFT. É importante lembrar que para aplicações de pitch shifting baseadas em FFT, quando mais profunda for a mudança de pitch maior é a necessidade de sobreposição entre as janelas da FFT (para manter a qualidade do áudio), onerando assim o custo geral do efeito. Outro fator importante na utilização do ferramental da FFT é a latência inevitavelmente introduzida no sistema, uma vez que a transformada ocorre em janelas sucessivas do sinal.

A reverberação AM/FM também mostrou economia de intensidade computacional, se comparada a custosa reverberação por convolução. Ressaltamos aqui que no caso do RaspberryPi a implementação da convolução com 5000 pontos não foi possível devido à limitada capacidade de processamento do dispositivo. Utilizando uma resposta ao impulso com apenas 2000 amostras foi possível executar o efeito, porém a qualidade da sonoridade passa a ser questionável [ converb2000 . wav], além do fato de que mesmo com a redução no número de amostras o processamento consumiu quase toda a capacidade do RaspberryPi. A reverberação baseada em AM/FM, no entanto, pôde ser executada sem complicações no dispositivo, deixando ainda capacidade de sobra para a execução de outros efeitos. A execução da técnica com 5000 pontos [ converb5000 . wav] no ThinkPad apresentou um custo elevado, chegando quase ao dobro da intensidade necessária para executar a FFT mais pesada que foi testada. Lembramos que como a convolução no domínio do tempo é equivalente a uma multiplicação no domínio da frequência, uma alternativa para a implementação do reverb por convolução pode ser utilizar a Fast Convolution (operação baseada na FFT), pagando, porém, o preço atrelado ao uso do ferramental FFT. 


\section{Capítulo 5}

\section{Conclusão}

I feel that the processing in only there to emphasize things that are already there ... I'm never very interested in the kind of sound processing that leads me way too far away from the original sound, unless it really makes connections. ${ }^{1}$

Hildegard Westerkamp

Neste trabalho foram explorados efeitos de áudio baseados na decomposição AM/FM. Assim como em outras técnicas de análise, a decomposição AM/FM fornece uma abordagem alternativa em relação ao sinal o qual queremos manipular para obter um efeito. Manipulações, mesmo que simples, neste domínio alternativo, podem resultar em profundas transformações. Os sinais AM e FM processados alimentam um processo de ressíntese, de tal maneira que novidades na AM e/ou FM apresentam o potencial de serem convertidas em efeitos de áudio.

A apreciação e principalmente o controle efetivo dos efeitos AM/FM dependem da compreensão do significado físico das estimativas de envelope e frequência instantânea (FI). O envelope da decomposição AM/FM não é diferente do conceito de envelope de um sinal, ou seja, captura as características gerais do sinal analisado, como por exemplo informação referente a dinâmica. Já a FI representa a frequência do oscilador que melhor se ajusta localmente (a cada amostra do sinal).

Notamos que tanto o sinal de envelope quanto o de frequência instantânea podem ser considerados individualmente. A ressíntese baseada apenas em envelope revelou um sinal com características semelhantes às do sinal original em termos de pitch e dinâmica, mostrando assim que o envelope é também influenciado por informações relativas à frequência. A ressíntese baseada apenas em frequência instantânea revelou um sinal que mantém as características de pitch, embora sem variação dinâmica.

As técnicas amplamente utilizadas em diversos contextos de processamento de sinais podem ser trazidas para a representação AM/FM. Neste trabalho exploramos filtragem, processamento de dinâmica, ganho, modulações, entre outras técnicas, aplicadas aos sinais de envelope e FI.

\footnotetext{
${ }^{1}$ Tradução do autor: Eu sinto que o processamento está lá apenas para enfatizar coisas que já estão lá ... Eu nunca estou muito interessada no tipo de processamento sonoro que me leva para muito longe do som original, a não ser que isso realmente estabeleça conexões.
} 
Ao aplicar uma determinada filtragem à FI, estamos na prática limitando a velocidade com a qual ela pode variar, mas não a faixa de valores da estimativa; momentos de variações bruscas continuam a acontecer, mas as componentes da FI estarão limitadas a frequências baixas. Como consequência a ressíntese do sinal não será suficientemente rápida para acompanhar as variações, produzidos glissandos como artefatos.

Podemos também aplicar um mapeamento não-linear à FI. A faixa dinâmica do sinal de FI apresenta unidade em $\mathrm{Hz}$, ou seja, ao aplicar, por exemplo, um ceifamento nos valores acima de um determinado limiar, impedimos a FI de alcançar tais valores, impedindo então que o oscilador na ressíntese possa atingir certas frequências. Sendo assim, informações musicais guardadas nos momentos de valores grandes da FI não mais serão consideradas na ressíntese.

As definições de envelope e FI dependem da técnica utilizada, uma vez que a decomposição AM/FM é ambígua. O esquema de Gabor, baseado na Transforma de Hilbert e geração do sinal analítico foi uma forma encontrada para garantir unicidade da decomposição. Embora este esquema de análise respeite todas as condições de Vakman para a decomposição, não há garantia de que posteriores processamentos no envelope e na frequência resultarão em ressínteses livres de artefatos. Mesmo que a decomposição seja transparente (obtém-se na ressíntese um sinal idêntico ao analisado) é importante conhecer os tipos de sinal que essa decomposição produz para evitar manipulações das porções AM e FM que possam comprometer a ressíntese.

O operador de energia de Teager-Kaiser, que rastreia a energia de um sinal utilizando relações entre suas derivadas foi uma importante contribuição para a área de processamento de sinais de voz. Apesar da existência de diversos modelos lineares de produção da fala humana, as não linearidades do fenômeno não encaixavam bem na maioria dos modelos utilizados. O novo método de análise foi proposto e ótimos resultados obtidos, especialmente em aplicações mais voltadas para a análise de sinais. No entanto seu aspecto local resulta numa alta sensibilidade a ruído que pode ser um desafio para a etapa de ressíntese nos projetos de efeitos AM/FM.

Apesar das imperfeições dos métodos de decomposição utilizados neste trabalho, diferentemente de alguns cenários de aplicação de processamento de voz onde a inteligibilidade da linguagem é um quesito fundamental, num cenário de aplicação de efeitos musicais tal quesito pode ser menos forte. Efeitos musicais, muitas vezes, alteram significativamente o sinal original, sendo possível aceitar eventuais imperfeições na ressíntese.

Uma alternativa interessante para aumentar a fidelidade da decomposição pode ser a préfiltragem do sinal de entrada em bandas e prosseguir com uma decomposição AM/FM para cada banda. Podemos controlar a quantidade e a largura das bandas nessa pré-filtragem, fazendo-as tão estreitas quanto necessário para uma decomposição mais fiel. Nesse caso, quanto mais bandas maior será a intensidade de processamento necessária. Evidentemente, além de melhorar a decomposição, a separação do sinal em bandas possibilita o projeto de efeitos multi-bandas, controle da profundidade do efeito, efeitos stereo, entre outros.

De uma maneira geral, o ferramental AM/FM, especialmente a decomposição baseada em Transformada de Hilbert e sinal analítico, se mostrou adequado para a aplicação de efeitos de áudio em sinais instrumentais. Neste trabalho mostramos a possibilidade de obtenção de diversas sonoridades de interesse musical. Diversas são as possíveis facetas dos efeitos AM/FM. Alguns exemplos são comentados a seguir:

- sutileza: diversos foram os exemplos em que a aplicação de um efeito com o ferramental 
AM/FM geravam versões suavizadas de seus correlatos;

- releitura de clássicos: as sonoridades obtidas com chor-if, oct-if e sq-env;

- experimentalismo: como na sonoridade obtida com hybr-if, lowp-if com frequência de corte baixa, entre outros;

- acompanhamento musical: contraponto ou harmonia com pedal-if.

Notamos que a manipulação da FI parece oferecer mais possibilidades para o desenvolvimento de novos efeitos do que a manipulação do envelope, cujas possibilidades são similares à manipulação direta do sinal original. No entanto, efeitos de manipulação da FI resultam em alterações no pitch facilmente perceptíveis. É importante ter a consciência de que, mesmo que timbres bonitos (voltando à fala de Mathews apresentada no primeiro capítulo) sejam encontrados, as notas musicais escolhidas apresentam um enorme potencial de arruinar uma performance. Sendo assim, cautela e conhecimento do contexto musical no qual os efeitos serão utilizados são fundamentais.

Além das sonoridades obtidas com um efeito digital de áudio, outro aspecto importante é o de intensidade computacional necessária para a realização dos efeitos em algum sistema computacional. Os experimentos de desempenho dos efeitos AM/FM mostraram, de maneira geral, custos computacionais atrativos, especialmente quando comparados a outras técnicas utilizadas no contexto de processamento de sinais de áudio. Os valores de intensidade computacional para reprodução de arquivo de áudio e distorção convencional, assim como para as operações de FFT, possibilitam uma comparação direta destes resultados com os resultados referentes à utilização das técnicas AM/FM.

A intensidade computacional necessária para execução da decomposição AM/FM seguida de ressíntese se mostrou ligeiramente menor em comparação à utilização de uma FFT seguida da FFT inversa, quando considerada uma janela de análise de 512 pontos com sobreposição de apenas $50 \%$; considerando uma FFT mais precisa, o custo fica tão alto que chega quase ao dobro do custo para utilização do ferramental AM/FM (cálculo da FFT em cada janela de análise, operações de overlap-add, entre outras operações, oneram o custo geral). Lembramos ainda que o ferramental da FFT, assim como outras técnicas baseadas em janelamento, inevitavelmente aumentam a latência do sistema.

O conjunto decomposição $\mathrm{AM} / \mathrm{FM}$, processamento $\mathrm{AM} / \mathrm{FM}$ (filtragem/mapeamento/modulação/ganho/etc.), ressíntese AM/FM mostrou intensidade computacional bastante acessível, possível de ser executada no RaspberryPi com sobra para execução de outros efeitos. Estes resultados são importantes pois o RaspberryPi representa a categoria de dispositivos com poder computacional modesto, como é o caso de laptops antigos e netbooks. Uma vez que laptops são sempre substituídos por modelos novos mais potentes, e netbooks foram descartados após a chegada dos tablets e smartphones, é de se supor a existência de enorme quantidade de dispositivos, hoje engavetados, que poderiam ser utilizados como pedaleira de efeitos (eliminando a necessidade da compra de pedais, funcionando como resistência à questões de obsolescência programada, estimulando o aprendizado de programação por parte de músicos, entrou outros aspectos). Lembramos, também, que os próprios tablets, smartphones e plataformas de programação similares ao RaspberryPi também apresentam poder computacional baixo.

A comparação entre as implementações alternativas de oitavador e reverb com as suas implementações tradicionais eram de especial interesse, uma vez que a qualidade das sonoridades obtidas 
com estes efeitos mostra que (pelo lado musical/artístico) os mesmos apresentam potencial para serem utilizados no lugar das técnicas convencionais.

\subsection{Contribuições}

Neste trabalho apresentamos uma extensa revisão sobre as técnicas de modulação AM, FM, e variações, utilizadas em processos de síntese e efeitos de áudio. Apresentamos implementações de toda a revisão e também das novas técnicas em Csound, linguagem de código aberto projetada para a programação de processamento de áudio. Espera-se que as implementações aqui apresentadas sirvam para que músicos interessados em utilização das possibilidades do computador em suas obras possam utilizar os efeitos AM/FM com facilidade. Todos as implementações são disponibilizadas, juntamente com um tutorial sobre a linguagem e configuração de hardware (Apêndice A).

A configuração (ajuste) dos efeitos de áudio AM/FM depende do conhecimento sobre as características dos sinais que irão entrar no sistema. Neste trabalho apresentamos um estudo passo a passo sobre o contexto no qual iríamos trabalhar (guitarra/bend/vibrato/slide, presentes no sinal utilizado para os testes e experimentos), tal como apresentado na seção sobre decisões de projeto. A mesma rotina pode ser aplicada para um estudo prévio de qualquer instrumento, para calibrar a separação em bandas, a decomposição, e os efeitos em si da melhor maneira possível. Se flexibilidade é um requisito, pode-se pensar num sistema que se configura adaptativamente, de acordo com um conjunto de circunstâncias. Outra abordagem seria projetar um sistema a ser "pilotado" pelo músico, por exemplo, por meio de um pedal de expressão, em que a posição do pedal prepara o sistema para um cenário específico.

$\mathrm{Na}$ sequência foram apresentados diversos efeitos AM/FM, separados em famílias, e contextualizados. Apresentamos códigos para implementação dos efeitos e variações. Embora estabelecer cenários de utilização apropriados para cada efeito proposto não seja uma tarefa sequer viável, de uma maneira geral foram apresentados efeitos que podem despertar interesse tanto para aplicações musicais (design de instrumentos, timbre, etc.) quanto de engenharia (técnicas de mixagem, correção de problemas). Em meio às novidades propostas, enfatizamos que as sonoridades obtida com a releitura de dois clássicos (octaver/oct-if e reverb/sq-env) apresentam o potencial de despertar profundo interesse naqueles mais voltados ao uso destes efeitos consagrados.

Artigos foram publicados e apresentados em importantes conferências da área de computação musical: Digital Audio Effects Conference (DAFx) [GTL15], Sound and Music Computing Conference (SMC) [GTLQ15], Linux Audio Conference [Gou14] [GQTL15], International Conference on Live Coding [GA15], Simpósio Brasileiro de Computação Musical [dESdSG15] e Seminário de Música, Ciência e Tecnologia [SGQ12]. Destacamos ainda a realização de estágio sanduíche na Maynooth University ${ }^{2}$ (Irlanda) sob supervisão de Victor Lazzarini e Joseph Timoney.

Além das contribuições técnicas e científicas, outras atividades realizadas durante o doutorado completam a formação do candidato. Foram diversas participações em projetos musicais junto com os alunos da Escola de Comunicações e Artes, dentre os quais se destacam a participação na Orquestra Errante e a organização do evento ${ }^{3}$ ¿Música\#10?.

\footnotetext{
${ }^{2}$ https://www.maynoothuniversity.ie/

${ }^{3}$ http://www2.eca.usp.br/nusom/musica10
} 


\subsection{Trabalhos futuros}

Embora tenhamos utilizado neste trabalho a decomposição AM/FM baseada em Transformada de Hilbert em conjunto com o sinal analítico, grande parte da comunidade, principalmente da área de processamento de sinais de voz, advoga contra o método. Os sinais obtidos com a decomposição, de fato, não apresentam garantia de que posteriores processamentos seguidos de ressíntese não apresentarão distorção, mas isso não significa que não apresentam total possibilidade para o projeto de efeitos de áudio livres de distorção, ou em alguns casos, com alguma distorção tolerável. No entanto é de extrema importância a continuidade na busca por melhorias nos métodos de decomposição vigentes, assim como a tentativa de propor algoritmos com novas soluções para o problema.

Como foi apresentado na seção sobre a decomposição pelo método de separação de energia, melhorias foram incorporadas ao algoritmo básico, numa tentativa de melhorar a estimativa. A ideia da filtragem para eliminar a porção do erro localizada em frequências altas se mostrou útil, ao menos nas investigações utilizando sinais sintetizados sobre os quais tínhamos total controle. Uma pesquisa de extremo interesse tanto para a pesquisa em sinais de voz quanto para a aplicação de efeitos AM/FM seria a busca pela caracterização do tipo de erro gerado ao aplicar o operador de energia em instrumentos específicos. Assim, contornos específicos para cada problema possam ser desenvolvidos para melhorar as estimativas de energia. Um tema relacionado é a tentativa de propor condições suficientes e condições necessárias para que valores ao longo do algoritmo de separação de energia estejam sempre adequados, produzindo valores dentro das faixas esperadas pelas fórmulas.

Mais experimentos objetivos são necessários. Todos os efeitos aqui propostos precisam ser analisados, e outros descritores da própria biblioteca Essentia podem ser utilizados. Uma vez que a maioria dos efeitos apresentados resultam em alterações no pitch do sinal instrumental, mais atenção pode ser dada aos descritores tonais.

Pesquisas no âmbito da percepção dos efeitos AM/FM também são importantes para revelar mais aspectos sobre a decomposição AM/FM, e sobre a apreciação propriamente dita dos efeitos. Com o conhecimento fornecido pelas avaliações objetivas apresentadas no capítulo anterior experimentos subjetivos podem também ser projetados para gerar informações complementares.

A decomposição AM/FM leva um sinal de áudio para um novo tipo de informação, codificada num novo par de sinais. Esta informação alternativa pode ser utilizada em recuperação de informação musical para diversos aplicações. Novas pesquisas poderão revelar vantagens e desvantagens desta representação em relação aos paradigmas já consolidados.

Sistemas modulados estão relacionados com a família de sistemas variantes, cujo comportamento varia em função do tempo de acordo com um conjunto de leis. O ferramental AM/FM pode ser entendido como modulações acopladas, sendo que uma das porções funciona para a outra como lei de variação de um sistema global. A ideia de estudar sistemas AM/FM pela ótica de sistemas variantes, em conjunto com a literatura de síntese e feitos de áudio baseados em sistemas periodicamente variantes podem representar um fértil terreno para a elaboração de um novo paradigma AM/FM.

Finalmente, observamos que na ressíntese AM/FM, a porção FM consiste de um processo de modulação de frequência comum, e a porção AM consiste de um sinal a ser modulado em anel com a porção FM. Diversas extensões e variações das técnicas de modulação em amplitude e modulação em frequência foram apresentadas no capítulo sobre revisão de conceitos, e podem ser exploradas no contexto de efeitos AM/FM. 
CONCLUSÃO 


\section{Apêndice A}

\section{Csound, linguagem para programação de processamento de áudio}

All mail clients suck.

This one just sucks less. ${ }^{1}$

Michael Elkins

Esta breve introdução à linguagem Csound foi compilada a partir dos manuais FLOSS ${ }^{2}$ e get started da documentação ${ }^{3}$ disponível no repositório principal.

Serão apresentados neste apêndice apenas os conceitos essenciais para a compreensão das implementações das técnicas de síntese e efeitos de áudio apresentadas nesta pesquisa, além de um guia sobre utilização do computador como pedaleira operando em tempo real.

Todos os exemplos de códigos apresentados neste trabalho (disponíveis também na página pessoal $^{4}$ do autor) foram testados em Debian/Linux, utilizando a versão 6.09.1 do Csound.

Primeiramente algumas justificativas sobre a escolha de trabalhar com esta linguagem:

1. Csound é software livre, com uma vasta comunidade ativa, aumentando a qualidade da linguagem e facilitando questões de distribuição de programas criados a partir da mesma;

2. Csound é tão liberal em relação a sistemas operacionais que não obriga ninguém a usar o sistema que não quer. Além de rodar em Linux, a compatibilidade com outros sistemas garante que todos possam experimentar as técnicas aqui apresentadas em seus ambientes favoritos;

3. Csound foi projetada para síntese de áudio em tempo real, apresentando opcodes específicos para tarefas neste contexto, que aumentam a eficiência do software e facilitam a programação; os códigos em Csound para as técnicas discutidas neste trabalho são curtos e elegantes;

4. existência de frameworks para geração de plugins e aplicativos para dispositivos móveis a partir de código em Csound.

\footnotetext{
${ }^{1}$ Tradução do autor: Todos os clientes de email falham. Esse aqui apenas falha um pouco menos.

${ }^{2}$ http://write.flossmanuals.net/csound/preface/

${ }^{3}$ https://csound.github.io/documentation.html

${ }^{4}$ http://www.ime.usp.br/ ag/balde/code-audio.zip
} 


\section{Csound na linha de comando}

Embora existam diversas IDEs disponíveis, a forma mais simples e versátil de rodar programas em Csound é a partir da linha de comando. Para rodar um código em Csound nomeado programa.csd, digite no shell:

csound programa.csd

\section{A.1 Sintaxe}

As linhas de código em Csound são separadas em blocos específicos, de acordo com o exemplo mostrado a seguir. Linhas que começam com ";" são comentários no código. Neste exemplo, comentários mostram o tipo de código que vai em cada bloco:

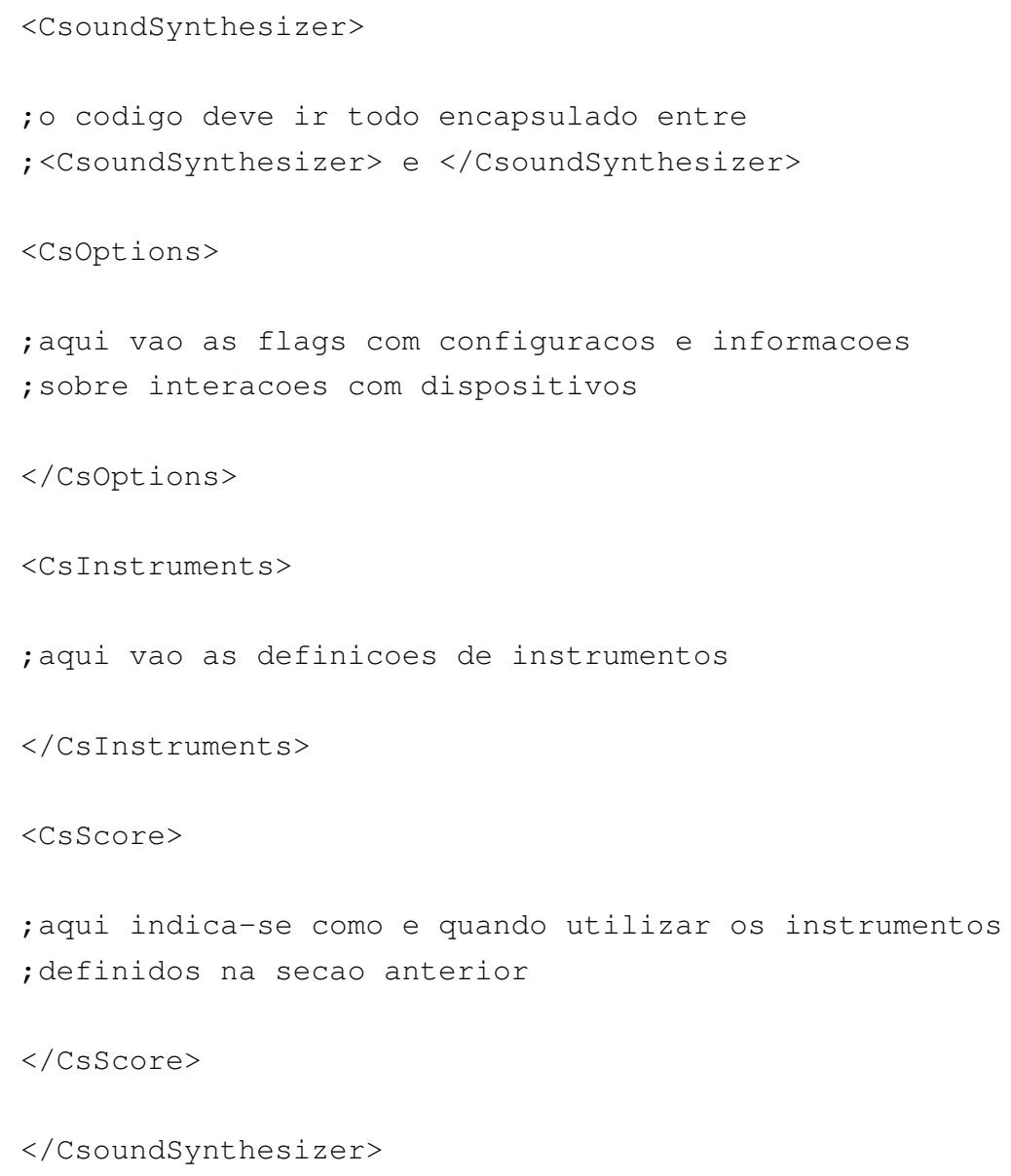

Csound apresenta diversos opcodes, ou UGENs (unidades geradoras). Estas podem realizar diversos tipos de processamento e tarefas. Além dos mais de 1700 opcodes disponíveis nativamente na linguagem, é possível criar novos a partir da API do Csound $^{5}$. Opcodes recebem entradas à direita de seus nomes, e guardam a saída em variáveis à sua esquerda, como mostrado a seguir:

saida1, saida2 opcode entrada1, entrada2, entrada3

Existem 3 tipos básicos de variáveis em Csound, tipo-A, tipo-K, e tipo-I. Variáveis A são atualizadas amostra a amostra, e variáveis K são atualizadas uma vez para cada período de controle

\footnotetext{
${ }^{5}$ https://csound.github.io/docs/api/group__OPCODES.html
} 
(definido com ksmps em exemplo que será mostrado mais adiante). Variáveis do tipo-I são inicializadas quando o código é compilado. O nome de uma variável A obrigatoriamente se inicia com "a", e o mesmo vale para os outros tipos.

Instrumentos em Csound são as unidades responsáveis pelas rotinas de geração ou processamento de áudio. A definição de um instrumento é feita num bloco de código entre as palavras reservadas instr e endin. O exemplo de código a seguir mostra um sintetizador que gera uma onda dente-deserra com o opcode vco2, cuja saída é filtrada por um passa-baixas que emula o filtro do $\mathrm{Moog}^{6}$, utilizando o opcode moogladder. O opcode madsr gera um envelope ADSR, que é multiplicado pelo sinal de saída do filtro do Moog. Note que a frequência de corte está variando, obtendo-se assim um interessante efeito muito explorado na música eletrônica dançante.

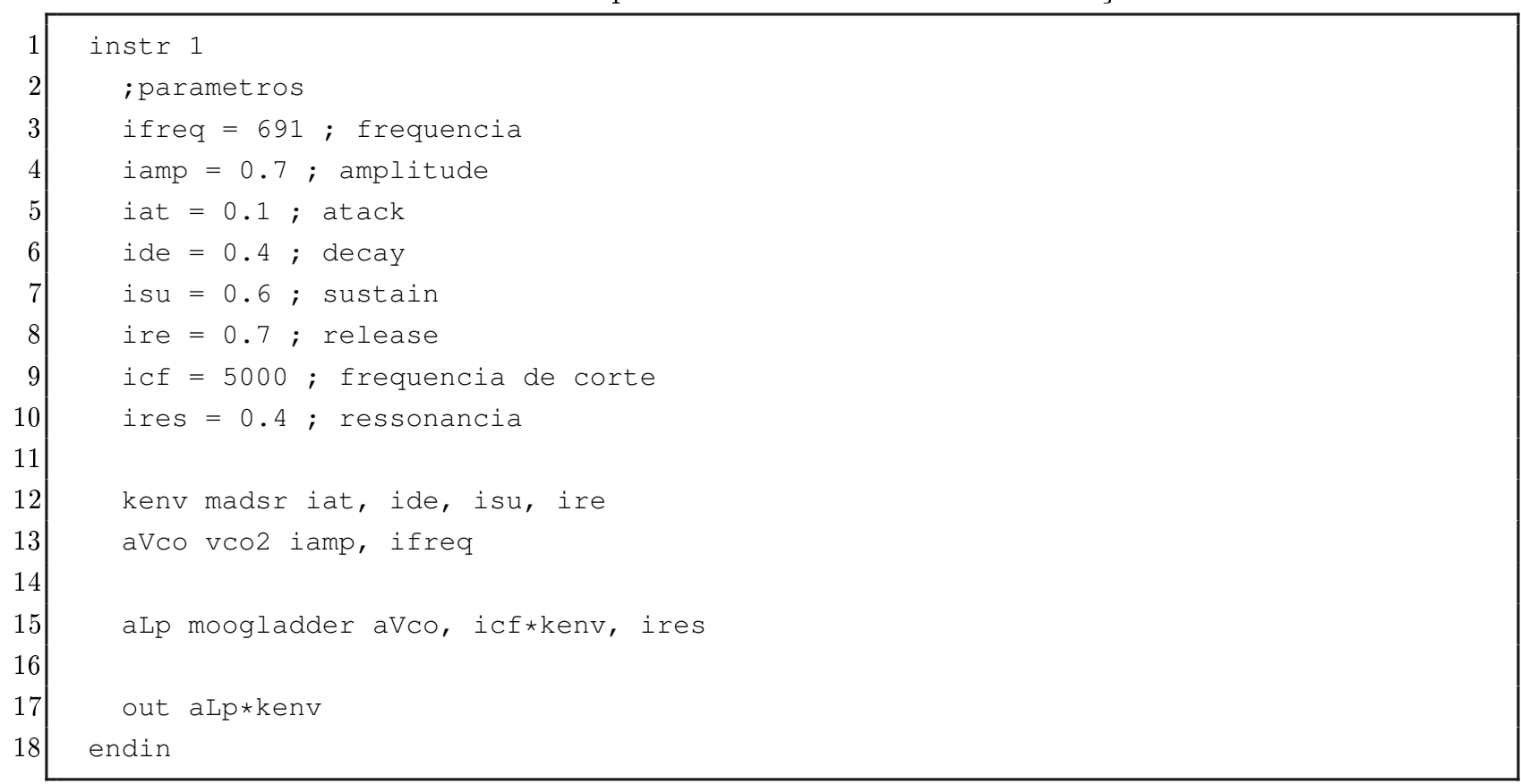

A seção CsScore de um código em Csound recebe instruções para ativação dos instrumentos. A linha a seguir ativa o instrumento 1 (chamado assim na primeira linha do exemplo anterior) logo no início da performance (instante 0), deixando-o soar por 5 segundos.

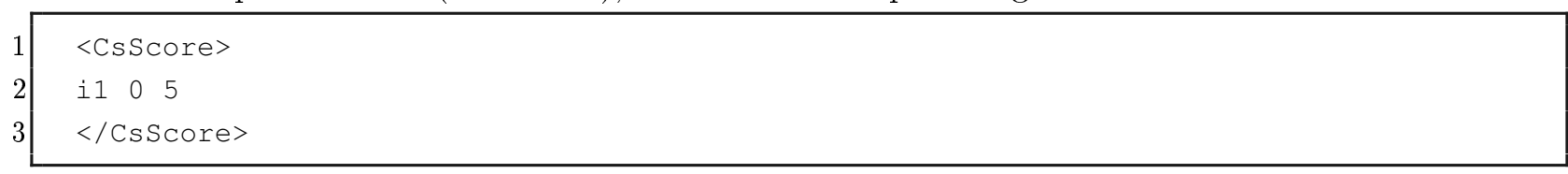

Ao invés de definir a frequência e amplitude podemos deixar tais parâmetros em aberto, para que possam ser determinados ao invocar os instrumentos, proporcionando assim controle do mesmo, ou, em outras palavras, a possibilidade de "tocá-lo". O exemplo a seguir apresenta um código completo, sendo que as atribuições $p 4$ e $p 5$ para os argumentos de vco2 buscam no quarto e quinto parâmetros da invocação do instrumento, respectivamente, os valores para frequência e amplitude. A linha no bloco CsOptions pede que o Csound encaminhe as amostras de áudio geradas diretamente para a saída de áudio do computador, ao invés de gerar um arquivo com extensão wav, como seria o comportamento padrão. A linha com sr determina a taxa de amostragem de 44100 amostras por segundo, ksmps determina o tamanho do bloco de controle, nchnls determina o número de canais, e Odbfs indica o valor referente à $0 \mathrm{~dB}$ (full scale), ou seja, a excursão máxima do sinal de áudio (cuidado! perigo!).

\footnotetext{
${ }^{6}$ https://www.moogmusic.com/
} 


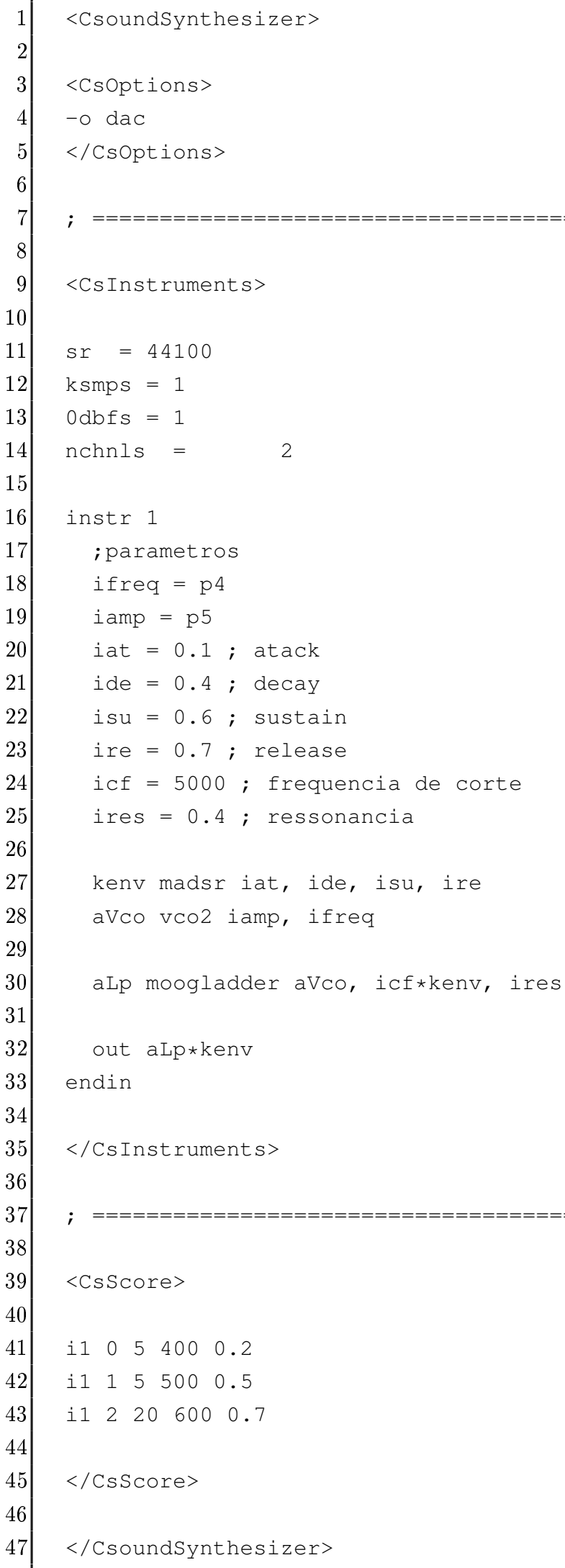




\section{A.2 Definição de opcodes pelo usuário}

Para exemplificar a criação de um opcode vamos utizar o seguinte código:

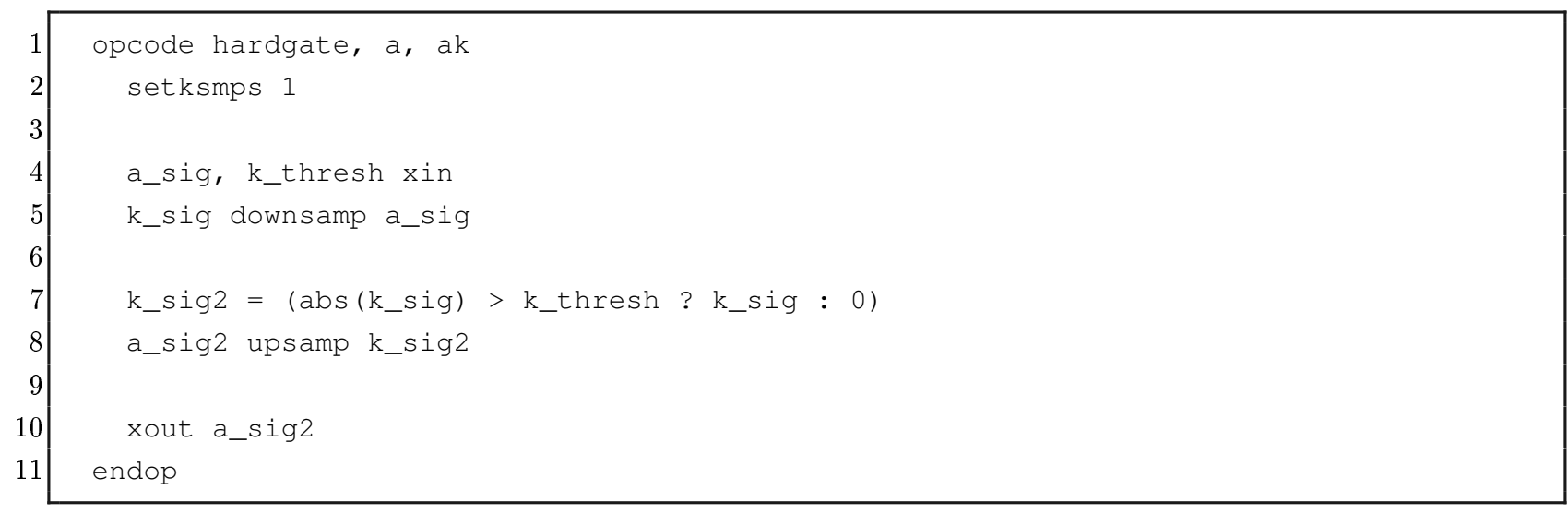

As palavras reservadas opcode e endop iniciam e finalizam a definição do opcode, respectivamente. Logo à direita da palavra opcode aparece o nome dado pelo usuário, no nosso caso, hardgate. Após o nome que escolhemos para o opcode, o primeiro argumento representa a(s) saída(s) do opcode, e o segundo argumento representa a(s) entrada(s). Como já comentado, em Csound variáveis de áudio possuem nome que se inicia com a letra "a", enquanto variáveis de controle possuem nome que se inicia com "k". Podemos então concluir que no caso do nosso hardgate o opcode recebe um sinal de áudio e um sinal de controle, e produz em sua saída um sinal de áudio.

O comando xin, na linha 4, define como os argumentos serão referenciados no bloco de código do opcode. Repare que a ordem de declaração importa. O primeiro argumento de entrada é um sinal de áudio que será chamado internamente de a_sig, enquanto o segundo argumento de entrada é um sinal de controle que será chamado internamente de k_thresh.

Na linha 2 do código notamos o comando setksmps, que é utilizado para determinar o tamanho do bloco de controle (neste caso, uma amostra) apenas para o opcode em questão. Na linha 5 um sinal de áudio é convertido para sinal de controle com o opcode downsamp. Na linha 7 ocorre uma operação de condicional que retorna o valor da amostra caso este seja maior que o limiar k_thresh, ou zero caso contrário. Na linha 8 um sinal de controle é convertido para sinal de áudio com o opcode upsamp. Finalmente, a linha 10 mostra o comando xout, relacionado com o que será direcionado para a saída do opcode.

\section{A.3 Resumo dos opcodes utilizados no trabalho}

A seguir são apresentados os nomes, descrições gerais, e listas de argumentos, dos opcodes utilizados neste trabalho:

- butterbp - filtro passa-banda tipo Butterworth saída BUTTERBP entrada, frequência central, largura de banda

- butterhp - filtro passa-alta tipo Butterworth 
- butterlp - filtro passa-baixa tipo Butterworth saída BUTTERLP entrada, frequência de corte

- clip - distorção de forma de onda saída CLIP entrada, metodo de distorção (2 = tanh), limiar

- dam - ferramenta para processamento de dinâmica de sinal saída DAM entrada, limiar, ganho acima do limiar, ganho abaixo do limiar, attack, release

- dconv - convolução direta entre sinal de entrada e resposta ao impulso saída DCONV entrada, número de amostras a se considerar para... ... a convolução, número da tabela com a resposta ao impulso

- delay1 - atrasa sinal em 1 amostra saída DELAY1 entrada

- diff - diferenciação de uma sequência de números saída DIFF entrada

- diskin2 - leitura de arquivo de áudio sample DISKIN2 "bendmono.wav", 1, 0, 1

- downsamp - conversão de sinais de áudio para sinais de controle k_saída DOWNSAMP a_entrada

- hilbert - transformador de Hilbert baseado em implementação IIR saída_real, saída_imaginaria HILBERT sinal_entrada

- integ - integração de uma sequência de números saída INTEG entrada

- linseg - segmentos de reta concatenados saída LINSEG valor1, duração-1-2, valor2, [duração-2-3, valor3, ...] 
- oscili - oscilador simples com interpolação linear saída OSCILI amplitude, frequência

- phasor - rampa de fase normalizada entre 0 e 1 saída PHASOR freq, [fase]

- plltrack - rastreamento de fundamental baseado em PLL

pitch, lock_indicator PLLTRACK sinal, ganho de malha, frequência de corte do passa-baixa interno, fator de mérito, frequência de corte do passa-baixa externo

- poscil - oscilador de alta precisão saída POSCIL amplitude, frequência

- pvsanal - análise FFT espectro (domínio da frequência) PVSANAL entrada, tamanho de bloco... ... para a FFT, sobreposição, tamanho da janela, tipo de janela

- pvsynth - síntese FFT sinal (domínio do tempo) PVSYNTH espectro

- table - leitura de tabelas saída TABLE índice, número da tabela

- tablei - leitura interpolada de tabelas saída TABLEI índice, número da tabela

- upsamp - conversão de sinais de controle para sinais de áudio a_saída UPSAMP k_entrada

- vco2 - oscilador de banda limitada (modo 12 é onda triangular) saída VCO2 amplitude, frequência, modo 


\section{A.4 Csound, Linux, controladores, interface de áudio, tempo-real (ou, Configurando seu computador como pedaleira de efeitos)}

Para utilizar um computador como pedaleira precisamos nos preocupar com

- entrada de sinal de áudio no computador;

- o software que vai aplicar os efeitos de áudio;

- controle dos parâmetros dos efeitos;

- saída de sinal de áudio do computador.

Entrada e saída de áudio em sistemas computacionais são realizadas tipicamente por meio de uma interface de áudio. A interface converte sinais analógicos para digitais, entrega para o sistema, e posteriormente recebe do sistema amostras de sinais de áudio e converte as mesmas para sinais de saída analógicos.

A maioria das interfaces de áudio funciona nativamente em Linux, mas é importante conferir nos fóruns antes de adquirir algum modelo específico. Munido de uma interface conectada via USB ao computador, para descobrir o número de dispositivo da mesma utilizamos o comando:

aplay -1

Com este número podemos inicializar o Csound especificando entrada e saída de áudio, além dos tamanhos de bloco considerados nos buffers de áudio. De uma maneira geral, o tamanho dos blocos é diretamente proporcional à latência que será introduzida ao sistema, mas blocos menores exigem maior intensidade computacional. O comando seguinte inicializa Csound especificando entrada e saída de áudio por meio da interface listada como número 1 e especifica tamanhos de bloco que estabelecem um bom compromisso entre desempenho e latência:

$<$ CsOptions $>$

-iadc:plughw:1,0 -odac:plughw:1,0 -B 512 -b 128 -Ma

$</$ CsOptions $>$

A opção -Ma estabelece a comunicação do Csound com todos os controladores MIDI conectados ao sistema via USB. O acesso via código Csound dos valores provenientes de knobs do controlador pode ser feito com o opcode ctrl7. Como exemplo, a linha

k_knob_5 ctrl7 4, 5, -12, 12

estabelece que o knob número 5 do controlador utilizando o canal número 4, produzirá valores entre -12 e 12, sendo que o acesso via código Csound a tais valores será feito pela variável k_knob_5.

Se o seu instrumento musical, ou um microfone, estiver conectado à interface de áudio pela entrada número 1, o acesso ao sinal via código Csound pode ser realizada no código com a linha

a_in inch 1

Manipulamos o sinal a_in para a implementação de efeitos de áudio. 


\section{Referências Bibliográficas}

[Bea82] James Beauchamp. Synthesis by spectral amplitude and 'brightness' matching of analyzed musical instrument tones. J. Audio Eng. Soc, 30(6), 1982. 96

[Bia14] André Jucovsky Bianchi. Processamento de áudio em tempo real em dispositivos computacionais de alta disponibilidade e baixo custo. Tese de Doutorado, Instituto de Matemática e Estatística da Universidade de São Paulo, Janeiro 2014. 9

[Boa92] B. Boashash. Estimating and interpreting the instantaneous frequency of a signal-part 1: Fundamentals. Proceedings of the IEEE, 80(4), Apr 1992. 36

[Bod84] Harald Bode. History of electronic sound modification. J. Audio Eng. Soc, 32(10):730730, 1984. 8

[Bru77] Marc Le Brun. A derivation of the spectrum of fm with a complex modulating wave. Computer Music Journal, 1(4):51-52, 1977. 24

[BWG $\left.{ }^{+} 13\right]$ Dmitry Bogdanov, Nicolas Wack, E. Gómez, Sankalp Gulati, Perfecto Herrera, O. Mayor, Gerard Roma, Justin Salamon, J. R. Zapata e Xavier Serra. Essentia: an audio analysis library for music information retrieval. Em International Society for Music Information Retrieval Conference (ISMIR), páginas 493-498, Curitiba, Brazil, 04/11/2013 2013. 12, 96

[CA09] P. Clark e L. Atlas. Time-frequency coherent modulation filtering of nonstationary signals. IEEE Transactions on Signal Processing, 57(11):4323-4332, Nov 2009. 66

[Cas11] Alexander U. Case. Mix Smart. ELsevier Inc., 2011. 36

[Che03] Mickhail Cherniakov. An introduction to parametric digital filters and oscillators. John Wiley \& Sons Ltd, England, 2003. 18

[Cho73] John Chowning. The synthesis of complex audio spectra by means of frequency modulation. Journal of the Audio Engineering Society, 21(7):526-534, 1973. xvii, 20, 21, 22

[Coh92] L. Cohen. What is a multicomponent signal? Em Acoustics, Speech, and Signal Processing, 1992. ICASSP-92., 1992 IEEE International Conference on, volume 5, páginas 113-116 vol.5, Mar 1992. 36

[Coh93] L. Cohen. Instantaneous 'anything'. Em Acoustics, Speech, and Signal Processing, 1993. ICASSP-93., 1993 IEEE International Conference on, volume 4, páginas 105108 vol.4, April 1993. 36 
[Coh95] Leon Cohen. Time-Frequency Analysis. Prentice Hall, Englewood Cliffs, NJ, 1995. 36

[Col10] Nick Collins. Introduction to Computer Music. Wiley and Sons, 2010. 6, 8, 24, 95, 97

[CR] Bob Childlaw e Jesse Remignanti. What is the "envelope" in envelope filter a reference to? Source Audio Tech Talk, acessado em 27/10/2016. Disponível em:

http://www.sourceaudio.net/techtalk/question/brad-what-is-an-envelope/. 35

[cso15] Csound floss manual - version 6, March/2015. 74

[DE08] Sascha Disch e Bernd Edler. An amplitude and frequency-modulation vocoder for audio signal processing. Em Proceedings of the International Conference on Digital Audio Effects (DAFX-08), Espoo, Finland, September 2008. xviii, 64, 65

[DE09a] Sascha Disch e Bernd Edler. An iterative segmentation algorithm for audio signal spectra depending on estimated local centers of gravity. Em Proceedings of the International Conference on Digital Audio Effects (DAFX-09), Como, Italy, September 2009. 64

[DE09b] Sascha Disch e Bernd Edler. Multiband perceptual modulation analysis, processing and synthesis of audio signals. Em International Conference on Acoustics, Speech, and Signal Processing, páginas 2305-2308, 2009. 64

[DE10] Sascha Disch e Bernd Edler. An enhanced modulation vocoder for selective transposition of pitch. Em Proceedings of the International Conference on Digital Audio Effects (DAFX-10), Graz, Austria, September 2010. 64

[DE11] Sascha Disch e Bernd Edler. Frequency selective pitch transposition of audio signals. Em International Conference on Acoustics, Speech, and Signal Processing, páginas 29-32, 2011. 64, 65

[dESdSG15] Guilherme Feulo do EspÃrito Santo, Micael Antunes da Silva e Antonio José Homsi Goulart. A study design about the influence of spectrum content in the perception of consonant and dissonant chords. Em Proceedings of the 15th Brazilian Symposium on Computer Music, Campinas, Brazil, November 2015. 118

[DJ97] Charles Dodge e Thomas Jerse. Computer Music: Synthesis, composition and performance. Schirmer Books, New York, NY, USA, segunda edição, 1997. 6, 7, 14, 15, 20, $23,24,25,30,37,56$

[DM06] Dimitrios Dimitriadis e Petros Maragos. Continuos energy demodulation methods and application to speech analysis. Speech Communication, 48(7):819-837, July 2006. 46, 67,68

[DMP05] D. Dimitriadis, P. Maragos e A. Potamianos. Robust am-fm features for speech recognition. IEEE Signal Processing Letters, 12(9):621-624, Sept 2005. 67

[DV13] S. D'Angelo e V. Valimaki. An improved virtual analog model of the moog ladder filter. Em 2013 IEEE International Conference on Acoustics, Speech and Signal Processing, páginas 729-733, May 2013. 5 
[Fin66] L. Fink. Relations between the spectrum and instantaneous frequency of a signal (english translation). Problemy Peredachi Informatsii, 2(4):26-38, 1966. 36, 37

[FPEN14] Gene F. Franklin, J. David Powell e Abbas Emami-Naeini. Feedback control of dynamic systems. Pearson, 2014. 60

[GA15] Antonio José Homsi Goulart e Miguel Diaz Antar. Live-coding-djing with the computer as part of a free-improvisation orchestra of acoustic instruments. Em Proceedings of the International Conference on Live Coding, páginas 27-34, Leeds, UK, 2015. 118

[Gab46] D. Gabor. Theory of communication. Journal of the IEE, 93:429-457, 1946. 44

[Gar05] Floyd M. Gardner. Phaselock techniques. Jonh Wiley \& Sons, 3rd edição, 2005. xviii, $57,58,60,61$

[GMR13] Dimitrios Giannoulis, Michael Massberg e Joshua D. Reiss. Parameter automation in a dynamic range compressor. J. Audio Eng. Soc, 61(10):716-726, 2013. 96

[Gou14] Antonio José Homsi Goulart. Live-coding djing with mixxx and supercollider. Em Proceedings of the Linux Audio Conference, Karlsruhe, Germany, 2014. 118

[GQTL15] Antonio José Homsi Goulart, Marcelo Queiroz, Joseph Timoney e Victor Lazzarini. Sound synthesis with periodically linear time-varying filters. Em Proceedings of the Linux Audio Conference, Mainz, Germany, 2015. 118

[GTL15] Antonio José Homsi Goulart, Joseph Timoney e Victor Lazzarini. Am/fm dafx. Em Proceedings of International Conference on Digital Audio Effects (DAFx), Trondheim, Norway, December 2015. 5, 35, 118

[GTLQ15] Antonio José Homsi Goulart, Joseph Timoney, Victor Lazzarini e Marcelo Queiroz. Psychoacoustic impact assessment of smoothed am/fm resonance signals. Em Proceedings of the Sound and Musical Computing Conference, Maynooth, Ireland, July 2015. 6,118

[GW15] Chet Gnegy e Kurt James Werner. Digitizing the ibanez weeping demon wah pedal. Em Proceedings of International Conference on Digital Audio Effects (DAFx), Trondheim, Norway, December 2015. 5

[Hah96] Stefan Hahn. Hilbert Transforms in Signal Processing. Artech House, Norwood, MA, 1996. 42,43

[Ham97] Richard W. Hamming. Digital Filters. Dover Publications, 3rd edição, 1997. 76

[Hel85] Hermann L. F. Von Helmholtz. On the sensations of tone. 1885. 3, 97

[HMP93] Helen M. Hanson, Petros Maragos e Alexandros Potamianos. Finding speech formants and modulations via energy separation: With application to a vocoder. Em Proceedings of the 1993 IEEE International Conference on Acoustics, Speech, and Signal Processing: Speech Processing - Volume II, ICASSP'93, páginas 716-719, Washington, DC, USA, 1993. IEEE Computer Society. 67 
[Huo04] Antti Huovilainen. Non-linear digital implementation of the moog ladder filter. Em Proceedings of International Conference on Digital Audio Effects (DAFx), Naples, Italy, October 2004. 5

[JS03] C. Richard Johnson Jr. e William A. Sethares. Telecommunication Breakdown. Prentice Hall, 2003. 36, 57

[JSK11] C. Richard Johnson, William Sethares e Andrew Klein. Software Receiver Design: Build your own digital communication system in five easy steps. Cambridge University Press, 2011. 35

[Jus79] James Justice. Analytic signal processing in music computation. IEEE Transactions on acoustics, speech and signal processing, ASSP-27(6):670-684, 1979. 27

[JWC65] John W. Tukey James W. Cooley. An algorithm for the machine calculation of complex fourier series. Mathematics of Computation, 19(90):297-301, 1965. 43

[Kai90a] J. F. Kaiser. On a simple algorithm to calculate the 'energy' of a signal. Em Acoustics, Speech, and Signal Processing, 1990. ICASSP-90., 1990 International Conference on, páginas 381-384 vol.1, Apr 1990. 67

[Kai90b] J. F. Kaiser. On teager's energy algorithm and its generalizations to continuous signals. Em Proceedings of the DSP Workshop, New Paltz, NY, September 1990. 67

[Kai93] J. F. Kaiser. Some useful properties of teager's energy operators. Em Acoustics, Speech, and Signal Processing, 1993. ICASSP-93., 1993 IEEE International Conference on, volume 3, páginas 149-152 vol.3, April 1993. 55

[KLP14] Damian Keller, Victor Lazzarini e Marcelo S. Pimenta, editors. Ubiquitous Music. Springer International Publishing AG, 2014. 9

[KLVT11] Jari Kleimola, Victor Lazzarini, Vesa Valimaki e Joseph Timoney. Feedback amplitude modulation synthesis. EURASIP Journal on Advances in Signal Processing, 2011(434378), 2011. xvii, 16, 17, 18

[Kve03] Eivind Kvedalen. Signal processing using the teager energy operator and other nonlinear operators, May/2003. Candidatus Scientiarum Thesis, University of Oslo Norway, Department of Informatics. 46, 49

[LA04] Qin Li e Les Atlas. Over-modulated am-fm decomposition. Em Proceedings of the SPIE - Advanced Signal Processing Algorithms, Architectures, and Implementations, páginas 172-183, Bellingham, WA, 2004. 45

[LA08] Qin Li e Les Atlas. Coherent modulation filtering for speech. Em 2008 IEEE International Conference on Acoustics, Speech and Signal Processing, páginas 4481-4484, March 2008. 45, 66

[Lay71] A. Layzer. Some idiosyncratic aspects of computer synthesized sound. Em Proceedings of the Annual Conference American Society of University Composers, páginas 27-39, 1971. 16 
[Laz09] Victor Lazzarini. A distortion synthesis tutorial. Em Proceedings of the Linux Audio Conference, páginas 12-20, 2009. 13, 25

[Let85] Tomasz Letowski. Development of technical listening skills: Timbre solfeggio. J. Audio Eng. Soc, 33(4):240-244, 1985. 8

[LKTV11] Victor Lazzarini, Jari Kleimola, Joseph Timoney e Vesa Valimaki. Aspects of secondorder feedback am synthesis. Em Proceedings of the International Computer Music Conference, University of Huddersfield, UK, 2011. 16, 18

[Lou97] P. J. Loughlin. Time-varying frequencies of a signal. SPIE Advanced Signal Processing Algorithms, Architectures and Implementations, II:109-122, 1997. 36, 37, 45

[Lou98] Patrick J. Loughlin. Do bounded signals have bounded amplitudes? Multidimensional Systems and Signal Processing, 9:419-424, 1998. 36, 37, 38, 44, 45

[LT97a] P. J. Loughlin e B. Tacer. Comments on the interpretation of instantaneous frequency. IEEE Signal Processing Letters, 4(5):123-125, May 1997. 36

[LT97b] P.J. Loughlin e B. Tacer. Instantaneous frequency and the conditional mean frequency of a signal. Signal Processing, 60(2):153 - 162, 1997. 36

[LT10a] Victor Lazzarini e Joseph Timoney. New perspectives on distortion synthesis for virtual analog oscillators. Computer Music Journal, 34(1):28-40, 2010. 32, 34

[LT10b] Victor Lazzarini e Joseph Timoney. Theory and practice of modified frequency modulation synthesis. Journal of the Audio Engineering Society, 58(6):459-471, 2010. xvii, 32,33

[LTKV09] Victor Lazzarini, Joseph Timoney, Jari Kleimola e Vesa Valimaki. Five variations on a feedback theme. Em Proceedings of the International Conference on Digital Audio Effects (DAFx-09), Como, Italy, 2009. 16, 17

[LTL08a] Victor Lazzarini, Joseph Timoney e Thomas Lysaght. Nonlinear distortion synthesis using the split-sideband method, with applications to adaptive signal processing. Journal of the Audio Engineering Society, 56(9):684-695, 2008. 27

[LTL08b] Victor Lazzarini, Joseph Timoney e Thomas Lysaght. Split-sideband synthesis. Em Proceedings of the International Computer Music Conference, 2008. 27

[Man97] L. Mandel. Interpretation of instantaneous frequencies. American Journal of Physics, 42:840-846, October 1997. 36, 37

[Mar97] S. Lawrence Marple Jr. Computing the discrete-time analytic signal via fft. Em Conference record of the Thirty-First Asilomar Conference on Signals, Systems and Computers, páginas 1322-1325, Pacific Grove, CA, USA, 1997. 27

[Mar15] André Lopes Martins. A guitarra elétrica na música experimental: composição, improvisação e novas tecnologias, 2015. Dissertação de Mestrado no Programa de PósGraduação em Música, Escola de Comunicações e Artes, Universidade de São Paulo. 5 
[McE92] R. McEachern. How the ear really works. Em Time-Frequency and Time-Scale Analysis, 1992., Proceedings of the IEEE-SP International Symposium, páginas 437-440, Oct 1992. 65

[MKQ93a] P. Maragos, J. F. Kaiser e T. F. Quatieri. Energy separation in signal modulations with application to speech analysis. IEEE Transactions on Signal Processing, 41(10):30243051, Oct 1993. 48, 54, 55

[MKQ93b] P. Maragos, J. F. Kaiser e T. F. Quatieri. On amplitude and frequency demodulation using energy operators. IEEE Transactions on Signal Processing, 41(4):1532-1550, Apr 1993. 54, 55

[Moo85] James Moorer. Signal processing aspects of computer music: A survey. Em John Strawn, editor, Digital audio signal processing. An anthology, páginas 149-220. Willian Kaufmann, Inc., Los Altos, California, 1985. 3

[Moo90] F. Richard Moore. Elements of computer music. Prentice Hall, Englewood Cliffs, New Jersey, USA, 1990. 15, 20, 21, 22, 24, 25

[Mor77] Dexter Morril. Trumpet algorithms for computer composition. Computer Music Journal, 1(1):46-52, 1977. 24

[MQK91] P. Maragos, T. F. Quatieri e J. F. Kaiser. Speech nonlinearities, modulations, and energy operators. Em Acoustics, Speech, and Signal Processing, 1991. ICASSP-91., 1991 International Conference on, páginas 421-424 vol.1, Apr 1991. 67

[NV05] Pantelis N. Vassilakis. Auditory roughness as a means of musical expression. 7 (Perspectives in Musicology):119-, 01 2005. 97

[OB98] P. M. Oliveira e V. Barroso. Instantaneous frequency of mono and multicomponent signals. Em Time-Frequency and Time-Scale Analysis, 1998. Proceedings of the IEEESP International Symposium on, páginas 105-108, Oct 1998. 36

[Oka15] Miles Okazaki. Fundamentals of guitar. Mel Bay, 2015. 57

[OS75] A.V. Oppenheim e R.W. Schafer. Digital signal processing. Prentice Hall, New Jersey, USA, 1975. 38, 39, 40, 43

[Pap62] A. Papoulis. The Fourier Integral and its Applications. McGraw-Hill, New York, NY, 1962. 67

[Pek08] J. Pekonen. Coefficient modulated first-order allpass filter as a distortion effect. Em Proceedings of the International Conference on Digital Audio Effects (DAFx-08), páginas 83-87, Espoo, Finland, 2008. 17

[Pic97] B. Picinbono. On instantaneous amplitude and phase of signals. IEEE Transactions on Signal Processing, 45(3):552-560, Mar 1997. 43, 44

[PM94a] Alexandros Potamianos e Petros Maragos. Applications of speech processing using an am-fm modulation model and energy operators, 1994. 67 
[PM94b] Alexandros Potamianos e Petros Maragos. A comparison of the energy operator and the hilbert transform approach to signal and speech demodulation. Signal Processing, $37(1): 95-120,1994.55,67$

[Pot95] Alexandros Potamianos. Speech processing applications using an AM/FM modulation model. Tese de Doutorado, Harvard University, Division of Applied Sciences, August 1995. 7

[PPR88] Jean-Pierre Palamin, Philippe Palamin e André Ronveaux. A method of generating and controlling musical asymmetrical spectra. Journal of the Audio Engineering Society, 36(9):671-685, 1988. 25

[RD12] David Ernesto Troncoso Romero e Gordana Jovanovic Dolecek. Digital FIR Hilbert Transformers: Fundamentals and Efficient Design Methods, páginas 445-482. InTech - Open Science, Open Minds, 2012. 42, 43

[Ris69] Jean Claude Risset. An introductory catalogue of computer synthesized sounds. Bell Laboratories, Murray Hill, New Jersey, 1969. xvii, 9, 16

[Ris96] Jean Claude Risset. My 1969 sound catalogue: looking back from 1992. Em Historical CD of digital sound synthesis. Computer Music Currents 13, Wergo, Germany, 1996. 8,20

[RM15] Joshua D. Reiss e Andrew P. McPherson. Introduction to Computer Music. CRC Press, 2015. 91

[Roa79] Curtis Roads. A tutorial on non-linear distortion or waveshaping synthesis. Computer Music Journal, 3(2):29-34, 1979. 6

[SA05] S. Schimmel e L. Atlas. Coherent envelope detection for modulation filtering of speech. Em Proceedings. (ICASSP '05). IEEE International Conference on Acoustics, Speech, and Signal Processing, 2005., volume 1, páginas 221-224, March 2005. 66

[Sch77] Bill Schottstaedt. A derivation of the spectrum of fm with a complex modulating wave. Computer Music Journal, 1(4):46-50, 1977. 24

[SGQ12] Flávio Schiavoni, Antonio José Homsi Goulart e Marcelo Queiroz. Apis para o desenvolvimento de aplicações de áudio. Em IV Seminário de Música, Ciência e Tecnologia, São Paulo, Brazil, 2012. 118

[She53] J. Shekel. Instantaneous frequency. Em Proceedings of the IRE, página 548, 1953. 44

[SK96] R. B. Sussman e M. Kahrs. Analysis and resynthesis of musical instrument sounds using energy separation. Em Acoustics, Speech, and Signal Processing, 1996. ICASSP96. Conference Proceedings., 1996 IEEE International Conference on, volume 2, páginas 997-1000 vol. 2, May 1996. 67

[Smi91] J. O. Smith. Viewpoints on the history of digital synthesis. Em Proceedings of the International Computer Music Conference, páginas 01-10, 1991. 8 
[Smi07] Julius Smith. Mathematics of the Discrete Fourier Transform, with Audio Applications. W3K Publishing, 2nd edição, 2007. 38

[SS96] T. Stilson e J. O. Smith. Analyzing the moog vcf with considerations for digital implementation. Em Proceedings of the International Computer Music Conference, páginas 398-401, Hong Kong, 1996. 5

[SS04] S. C. Sekhar e T. V. Sreenivas. Novel approach to am-fm decomposition with applications to speech and music analysis. Em Acoustics, Speech, and Signal Processing, 2004. Proceedings. (ICASSP '04). IEEE International Conference on, volume 2, páginas ii-753-6 vol.2, May 2004. 67

[TC99] George Tzanetakis e Perry Cook. Multifeature audio segmentation for browsing and annotation. Em IN PROC.1999 IEEE WORKSHOP ON APPLICATIONS OF SIGNAL PROCESSING TO AUDIO AND ACOUSTICS, WASPAA99, 1999. 96

[Tea80] H. M. Teager. Some observations on oral air flow during phonation. IEEE Transactions on Acoustics, Speech, and Signal Processing, 28(5):599-601, Oct 1980. 7, 67

[Tho10] Mike Thornton. Classic stereo-widening, 10/2010. Sound-on-Sound blog, acessado em 06/12/2017. Disponível em:

https://www.soundonsound.com/techniques/classic-stereo-widening. 93

[THW09] George B. Thomas, Joel R. Hass e Maurice D. Weir. Thomas' Calculus. Pearson, 12th edição, 2009. 48, 55

[TLPV09] J. Timoney, V. Lazzarini, J. Pekonen e V. Valimaki. Spectrally rich phase distortion sound synthesis using an allpass filter. Em Proceedings of the IEEE International Conference on Acoustics, Speech and Signal Processing (ICCASP-09), páginas 293296, Taipei, Taiwan, 2009. 17

[Tom81] Norio Tomisawa. Tone production method for an electronic musical instrument (patent us 4249447), February 1981. xvii, 29, 30, 32

[TS10] M. Triki e D. T. M. Slock. First-order global am-fm decomposition and application to music analysis and transformation. Em 2010 IEEE International Conference on Acoustics, Speech and Signal Processing, páginas 33-36, March 2010. 67

[TT90] H. M. Teager e S. M. Teager. Evidence for Nonlinear Sound Production Mechanisms in the Vocal Tract, páginas 241-261. Springer Netherlands, Dordrecht, 1990. 7, 67

[Vak96] D. Vakman. On the analytic signal, the teager-kaiser energy algorithm, and other methods for defining amplitude and frequency. IEEE Transactions on Signal Processing, 44(4):791-797, Apr 1996. 44

[Vak98] David Vakman. Signals, oscillations, and waves. Artech House, Norwood, MA, 1998. $36,37,38,43,44,45$ 
[vdKZ10] Adrian von dem Knesebeck e Udo Zölzer. Comparison of pitch trackers for real-time guitar effects. Em Proceedings of the International Conference on Digital Audio Effects (DAFX-10), Graz, Austria, September 2010. 62

[Vil48] J. Ville. Theorie et applications de la notion de signal analytique. Cables et Transmissions 2A, 1, 1948. 36, 37

[VM05] Nikolas Valsamakis e Eduardo Reck Miranda. Iterative sound synthesis by means of cross-coupled digital oscillators. Digital Creativity, 16(2):79-92, 2005. 16, 31

[VV77] D.E. Vakman e L.A. Vainshtein. Amplitude, phase, frequency - fundamental concepts of oscillation theory. Sov. Phys. Usp., 20(12):1002-1016, December 1977. 37, 43, 44, 46

[War99] S. Wardle. A hilbert transform frequency shifter for audio. Em Proceedings of the International Conference of Digital Audio Effects, páginas 25-29, 1999. 27

[Wat44] G. N. Watosn. A treatise on the theory of Bessel functions. Cambridge University Press, Cambridge, USA, segunda edição, 1944. 32

[WB98] D. Wei e A. C. Bovik. On the instantaneous frequencies of multicomponent am-fm signals. IEEE Signal Processing Letters, 5(4):84-86, April 1998. 36

[YAS07] David T. Yeh, Jonathan Abel e Julius O. Smith. Simulation of the diode limiter in guitar distortion circuits by numerical solution of ordinary differential equations. Em Proceedings of International Conference on Digital Audio Effects (DAFx), Bordeaux, France, September 2007. 5

[Zav12] Vadim Zavalishin. The art of VA filter design. 2012. 5

[ZM12] Athanasia Zlatintsi e Petros Maragos. Am-fm modulation features for music instrument signal analysis and recognition. Em Proceedings of the 20th European Signal Processing Conference (EUSIPCO-2012), páginas 2035-2039, Bucharest, Romania, August 2012. 67

[Zöl11] Udo Zölzer, editor. DAFx: Digital Audio Effects. Wiley \& Sons, 2011. 3, 5, 6, 43, 60, 65,93

[Zöl12] Udo Zölzer. Pitch-based digital audio effects. Em Communications, Control, and Signal Processing, 2012. ISCCSP, 1992 IEEE International Symposium on, Rome, Italy, May 2012. 61

[ZSM12] Udo Zölzer, Sujaritha Vettukadu Sankarababu e Stephan Moller. Pll-based pitch detection and tracking for audio signals. Em Proceedings of the Eighth International Conference on Intelligent Information Hiding and Multimedia Signal Processing (IIHMSP), 2012. xviii, 57, 59, 61 